\title{
A Study of the Heat Release Rate of Tunnel Fires and the Interaction between Suppression and Longitudinal Air Flows in Tunnels
}

\author{
A thesis submitted to \\ the Faculty of Graduate and Postdoctoral Affairs \\ in Partial Fulfillment of the requirements for the degree \\ Doctor of Philosophy
}

by

Yoon J. Ko

Department of Civil and Environmental Engineering
Carleton University

Ottawa-Carleton Institute of Civil and Environmental Engineering

April 2011

(C)2011 Yoon J. Ko 
Library and Archives
Canada

Published Heritage

Branch

395 Wellington Street Ottawa ON K1A ON4

Canada
Bibliothèque et

Archives Canada

Direction du

Patrimoine de l'édition

395 , rue Wellington

Ottawa ON K1A ON4

Canada
Your file Votre référence

ISBN: 978-0-494-81565-6

Our file Notre référence

ISBN: 978-0-494-81565-6
NOTICE:

The author has granted a nonexclusive license allowing Library and Archives Canada to reproduce, publish, archive, preserve, conserve, communicate to the public by telecommunication or on the Internet, loan, distribute and sell theses worldwide, for commercial or noncommercial purposes, in microform, paper, electronic and/or any other formats.

The author retains copyright ownership and moral rights in this thesis. Neither the thesis nor substantial extracts from it may be printed or otherwise reproduced without the author's permission.
AVIS:

L'auteur a accordé une licence non exclusive permettant à la Bibliothèque et Archives Canada de reproduire, publier, archiver, sauvegarder, conserver, transmettre au public par télécommunication ou par l'Internet, prêter, distribuer et vendre des thèses partout dans le monde, à des fins commerciales ou autres, sur support microforme, papier, électronique et/ou autres formats.

L'auteur conserve la propriété du droit d'auteur et des droits moraux qui protège cette thèse. Ni la thèse ni des extraits substantiels de celle-ci ne doivent être imprimés ou autrement reproduits sans son autorisation.
In compliance with the Canadian Privacy Act some supporting forms may have been removed from this thesis.

While these forms may be included in the document page count, their removal does not represent any loss of content from the thesis.
Conformément à la loi canadienne sur la protection de la vie privée, quelques formulaires secondaires ont été enlevés de cette thèse.

Bien que ces formulaires aient inclus dans la pagination, il n'y aura aucun contenu manquant. 


\section{ABSTRACT}

An experimental study addressing important tunnel fire safety issues has been conducted in a full-scale laboratory tunnel at Carleton University. The study developed a Heat Release Rate (HRR) measurement system that will be used for tunnel fire research. Also, the study investigated the effectiveness of Water-based Fixed Fire Fighting Systems (WFFFS) together with longitudinal ventilation systems in mitigating the effects of fires in tunnels.

First, a HRR measurement system was developed in the full scale laboratory tunnel. The system uses oxygen consumption calorimetry for reliable measurements under various ventilation conditions, as well as with a suppression system operating. The HRR measurement system measures mass flow rates and $\mathrm{CO}_{2}, \mathrm{CO}$ and $\mathrm{O}_{2}$ concentrations of the exhaust gas in a large-scale exhaust chamber that is designed to collect all combustion products from the tunnel. The instrumentation design for the HRR measurement system required an extensive analysis of the flow patterns in the exhaust fan chamber due to its large scale. This study identified the optimum amount of instrumentation and its optimum location to ensure reasonable accuracy. A series of calibration tests was conducted to evaluate the accuracy of the system for various fire sizes under different ventilation conditions. Based on the calibration test data, it was found that for unsuppressed fires the relative combined uncertainty of the system is about $10-15 \%$. The impact of water vapour introduced by the suppression system on the system accuracy was also investigated. A simple method was proposed to correct the HRR measured during suppression. 
Secondly, this study examined the strategy of using both a longitudinal ventilation system and WFFFS. Test results showed that this strategy effectively controls smoke and successfully resists backlayering with a reduced longitudinal air velocity. The present study established a method to estimate the degree of backlayering that considers the fire size, longitudinal air velocity and water spray density. Ceiling temperature profiles along the length of the tunnel were also examined, and a method to estimate the maximum ceiling temperature is proposed. The method can estimate the cooling effect of the WFFFS along with the longitudinal ventilation system on the maximum temperature that the tunnel ceiling experiences. The study also examined the radiation attenuation by the WFFFS. Results showed that the radiation attenuation was significant particularly in the area downstream of the fire. 


\section{ACKNOWLEDGEMENT}

I would like to thank Dr. George Hadjisophocleous for his supervision of this research and for his continued support, generous advice and patience throughout this research work. I would also like to express my gratitude to Dr. Ahmed Kashef, my co-supervisor, for his valuable advice and guidance.

I would like to sincerely acknowledge Mr. Ba Lamthien for his help in making these experiments possible. The NRC staff at the National Fire Laboratory is acknowledged for its kind help during the experiments. Special thanks to a good friend, Richard Michels, for his valuable contribution to the development of the HRR measurement system.

The faculty in the Civil Engineering and Fire Safety Engineering Program, Dr. Ehab Zalok, Dr. Juan Salinas, and Dr. Jim Mehaffey, have been an invaluable resource for me. Thank you to my fellow students Lindsay, Qingfei, Gian-Luca, Devin, Lei, Osama, Hao and Ling for making my time here memorable.

In addition, the financial support of the Natural Sciences and Engineering Research Council of Canada (NSERC) is gratefully acknowledged.

Lastly, a warm appreciation is given to my whole family including my husband, Sunki, for their love and encouragement throughout this endeavour. I would like to thank my son, Aaron, who was born during my Ph.D. program, for being so patient and understanding when I missed Thomas the Tank Engine readings in the evening to write this thesis. 


\section{TABLE OF CONTENTS}

Abstract ii

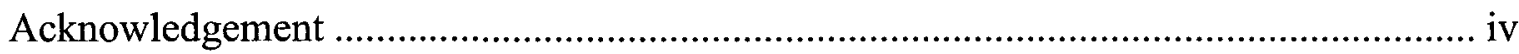

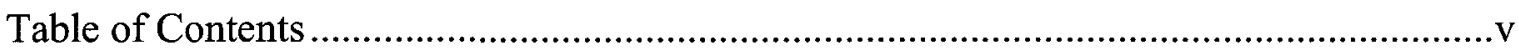

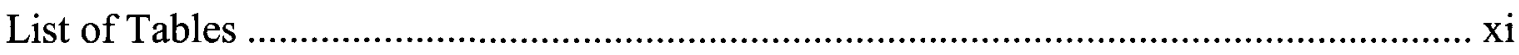

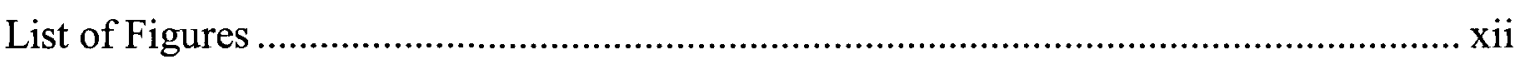

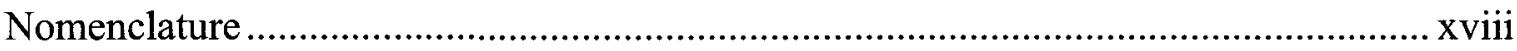

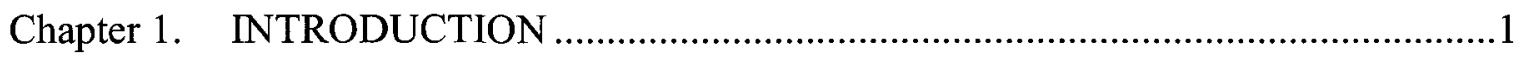

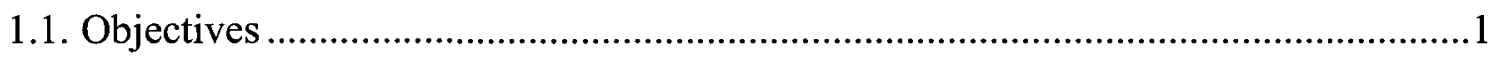

1.1.1. Development of a HRR measurement system to estimate HRR of tunnel

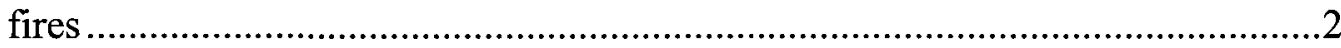

1.1.2. Investigation of the effect of the use of WFFFS under longitudinal air

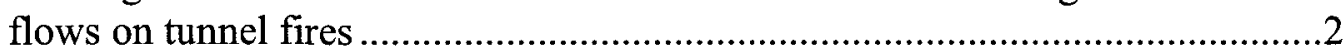

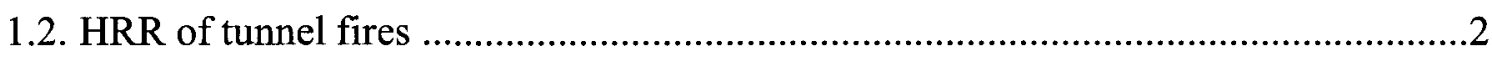

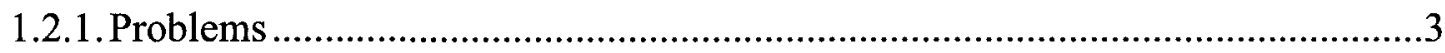

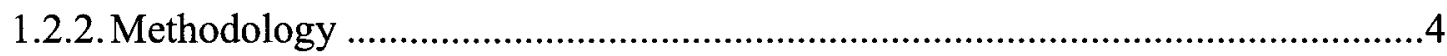

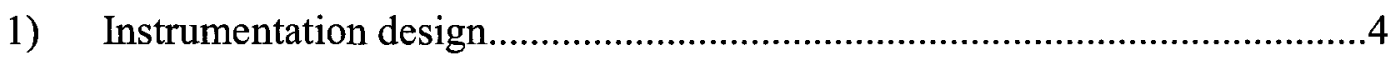

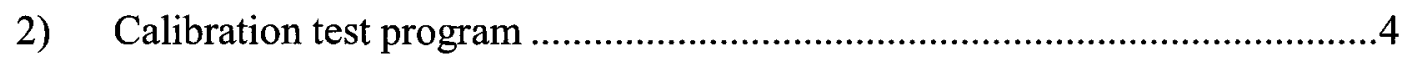

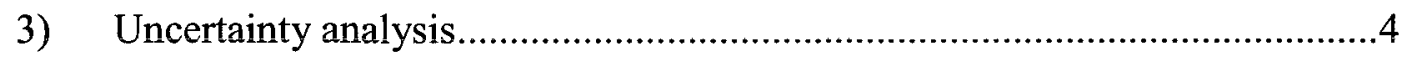

4) Analysis of HRR measurements during suppression and development of a simple method to correct the HRR measurements during suppression .......4

1.3. The effect of the use of WFFFS and longitudinal ventilation systems ......................

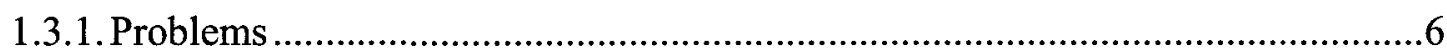

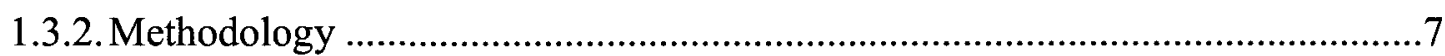

1) Full-scale suppression test program........................................................

2) Investigation of interaction of WFFFS and longitudinal air flows................7

3) CFD simulations of suppression tests......................................................

4) Analysis of cooling effect of WFFFS along with longitudinal air flows .......8

5) Analysis of backlayering during suppression along with longitudinal air

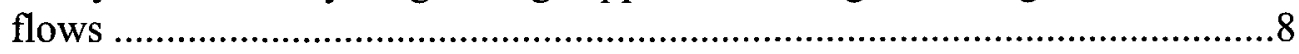

6) Analysis of radiation attenuation by WFFFS .............................................

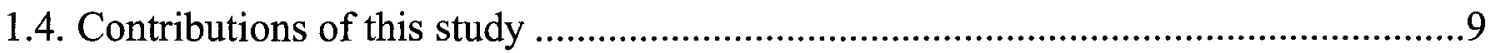


Chapter 2. LITERATURE REVIEW ……………............................................11

2.1. Introduction to Tunnel Fires ..............................................................................11

2.1.1. Tunnel fire accidents ............................................................................11

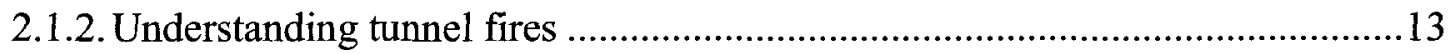

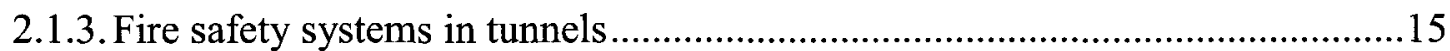

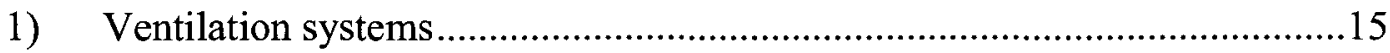

2) Longitudinal ventilation system and critical velocity..................................16

3) Water-based Fixed Fire Fighting Systems (WFFFS) ...................................18

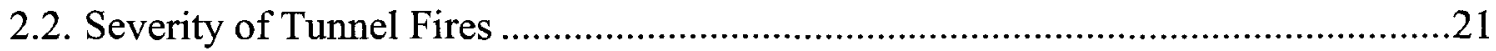

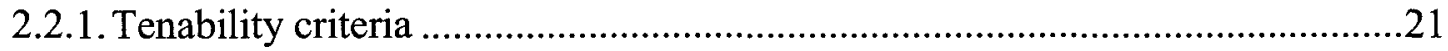

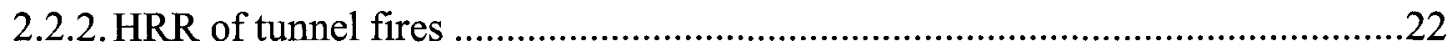

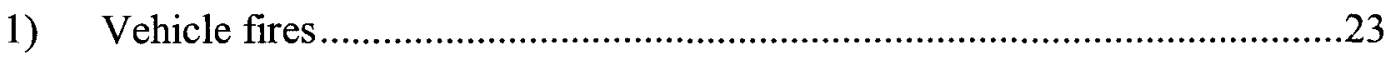

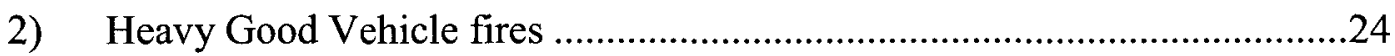

3) Effect of longitudinal airflows on tunnel fire development..........................26

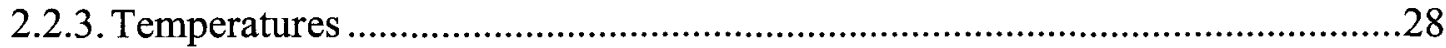

1) The maximum ceiling temperature in tunnels ..........................................28

2) Characteristics of smoke spread under natural ventilation ............................30

3) Smoke spread with a ventilation system.........................................................31

2.2.4. Measurement of HRR of tunnel fires ...............................................................34

1) Estimations based on burning rates .........................................................34

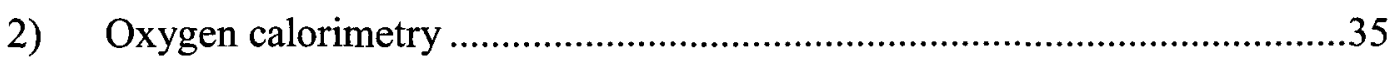

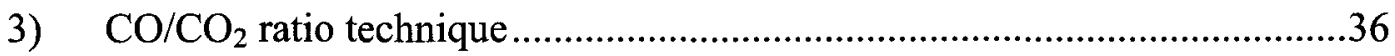

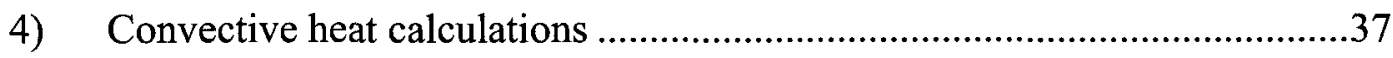

5) HRR measurement during suppression ...........................................................38

2.3. Water-based fixed fire fighting systems in tunnels .................................................39

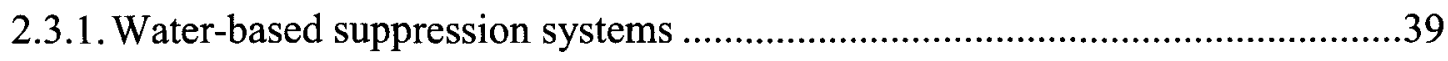

1) Suppression mechanisms ........................................................................41

2) Fire suppression in tunnels .....................................................................43

2.3.2. Suppression tests in tunnels.......................................................................

1) Ofenegg tunnel in 1965 [71] ..................................................................46

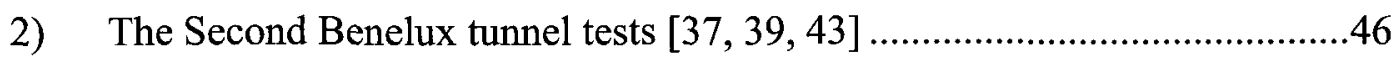

3) UPTUN DMT laboratory tunnel tests [72] .................................................47 


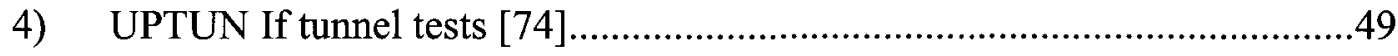

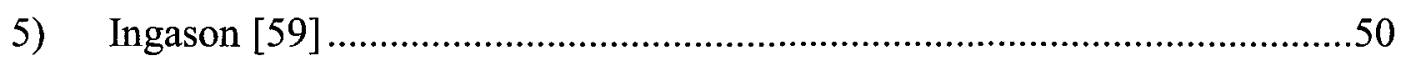

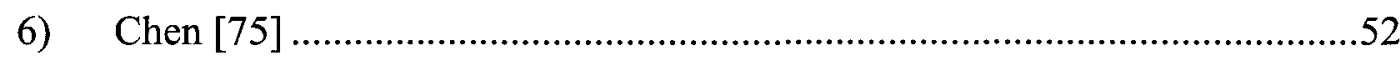

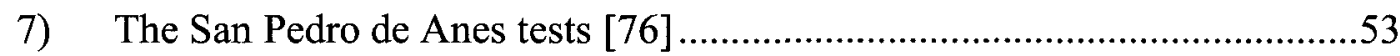

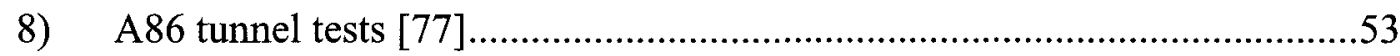

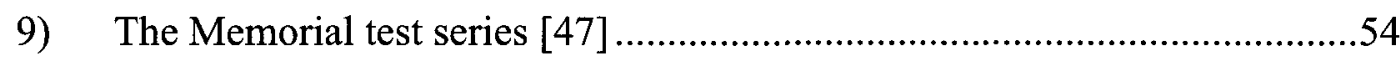

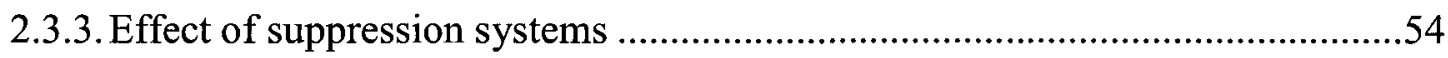

1) Suppression effect on heat release rate ...................................................54

2) Effect of suppression system on cooling smoke........................................57

3) Suppression effect on preventing fire spread and attenuating radiation........58

4) Effect of suppression system on smoke /scrubbing effect.............................59

5) Suppression effect on stratification under natural ventilation ......................60

6) Interaction with ventilation systems .............................................................61

7) Effect of the water curtain system ............................................................62

8) Comparison of different systems .............................................................63

9) Time of activation.....................................................................................64

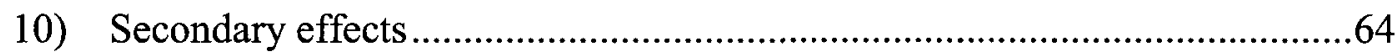

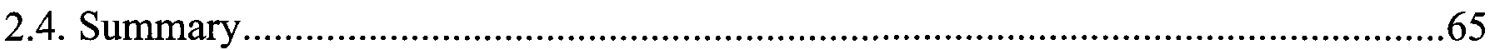

Chapter 3. DESIGN OF HRR MEASUREMET SYSTEM FOR THE TUNNEL

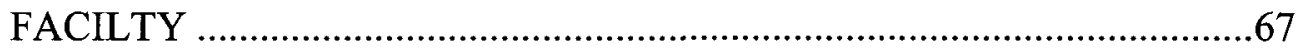

3.1. The tunnel facility and the design of HRR measurement system...........................67

3.2. Methodology of oxygen consumption calorimetry ...................................................70

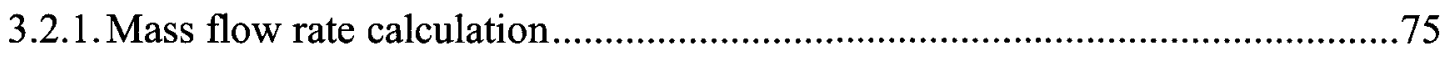

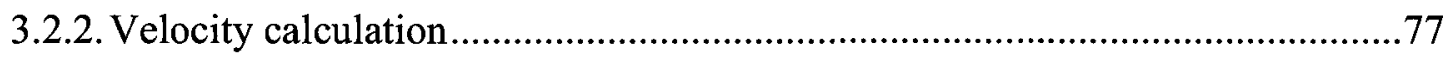

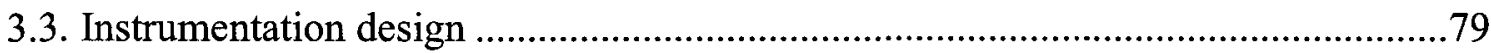

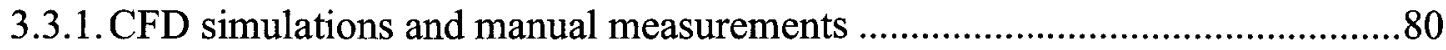

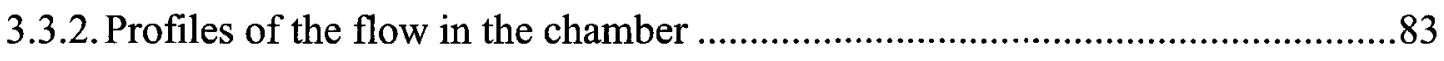

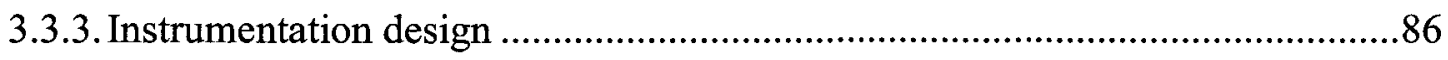

3.4. Real-time calculation of Heat Release Rate ……..................................................90

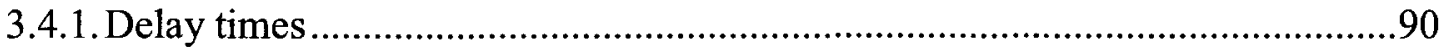

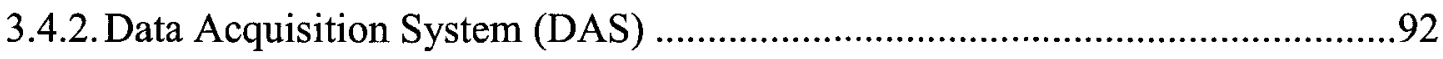

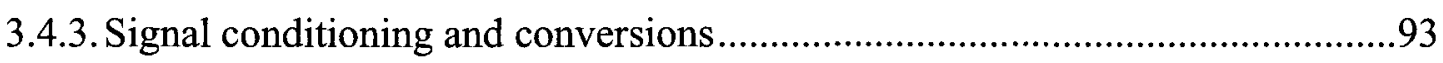


3.4.4. Data processing and HRR calculations .........................................................94

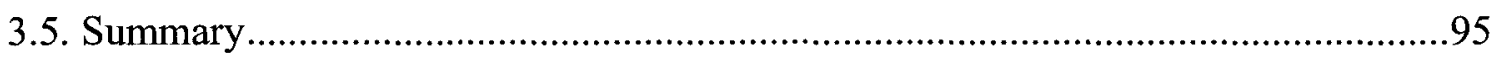

Chapter 4. CALIBRATION OF THE HRR MEASUREMENT SYSTEM ……............97

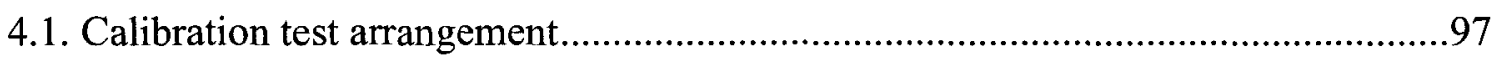

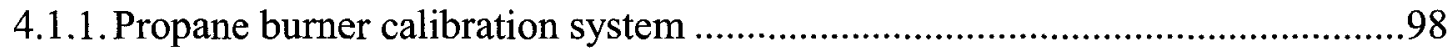

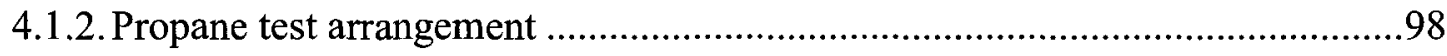

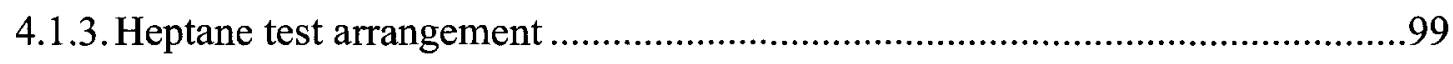

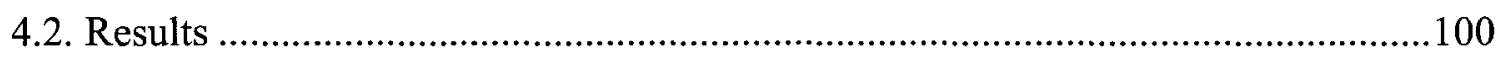

4.2.1. Overall results for the HRR, flow rates and gas concentrations ....................100

4.2.2. HRR measurement system response ……………........................................103

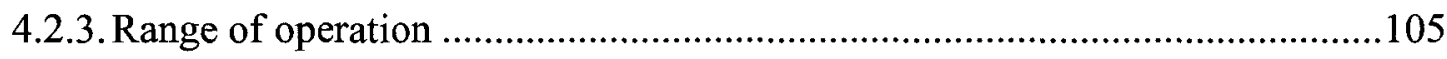

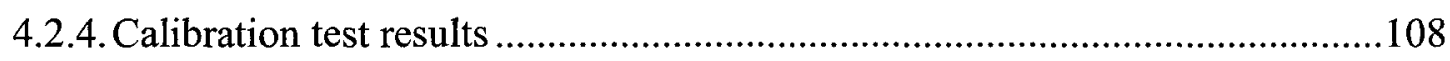

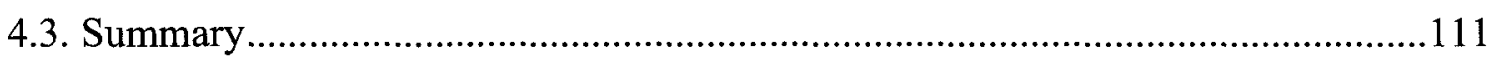

Chapter 5. UNCERTAINTY ANALYSIS OF HRR MEASUREMENTS ...................112

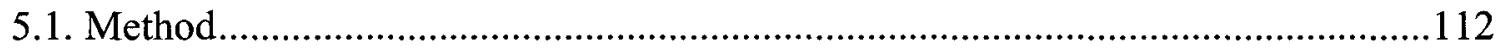

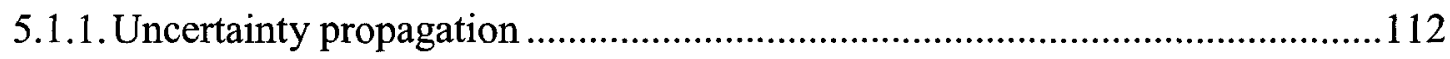

5.1.2. Kragten spreadsheet ………………………..........................................115

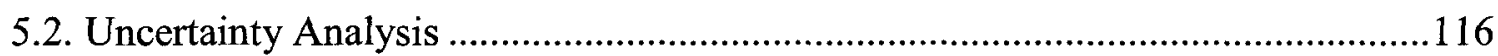

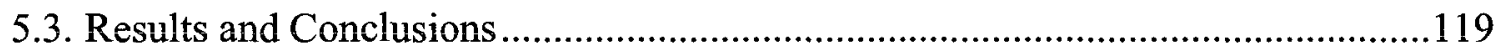

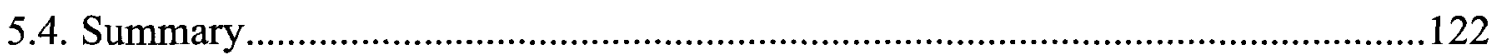

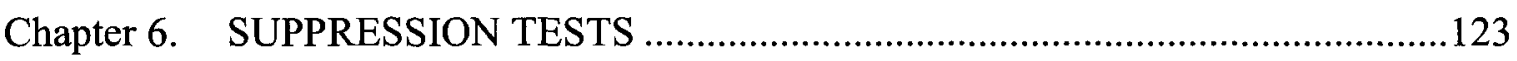

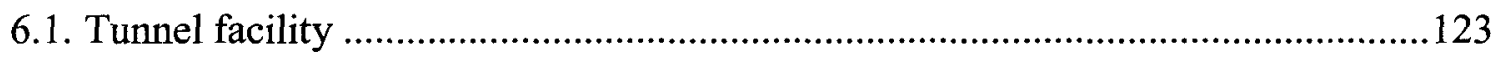

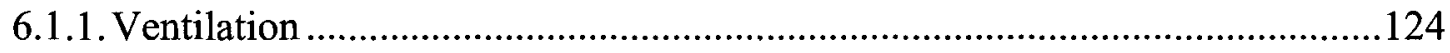

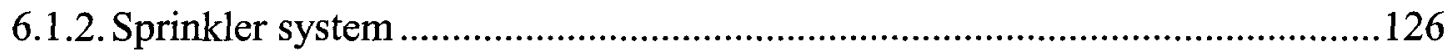

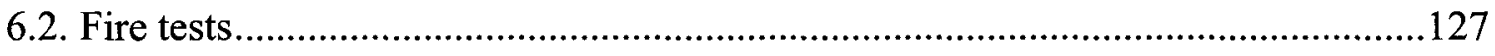

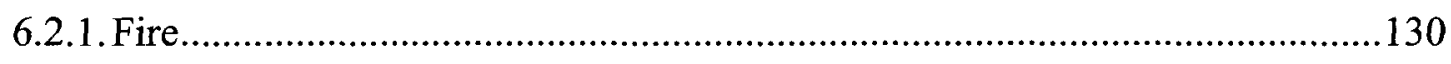

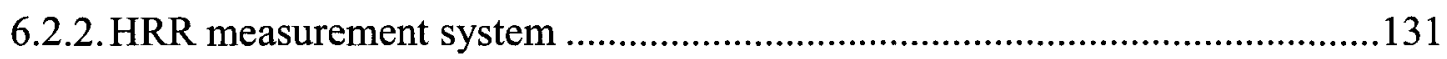

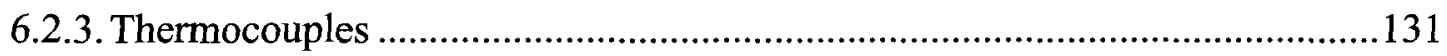

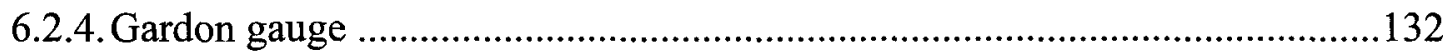

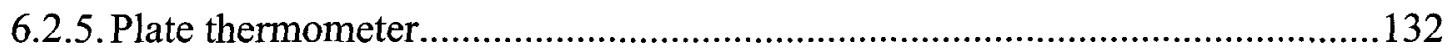

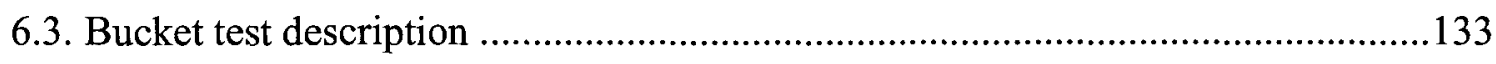

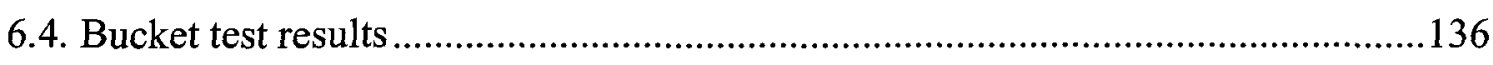

viii 
6.5. Fire test results

6.5.1.HRR measurements and gas concentrations in the fan chamber.....................139

6.5.2. Longitudinal ceiling temperature profile......................................................144

6.5.3. Vertical temperature profile - Upstream.........................................................146

6.5.4. Vertical temperature profile - Downstream.......................................................148

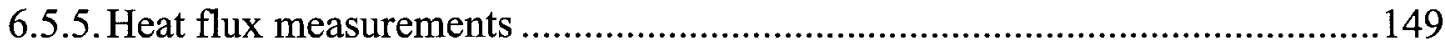

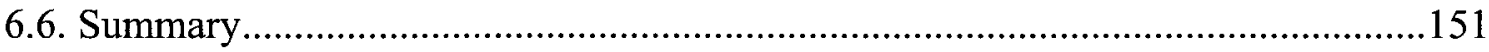

Chapter 7. HRR MEASUREMENTS DURING SUPPRESSION ………...................153

7.1. Analysis of HRR measurements during suppression .............................................153

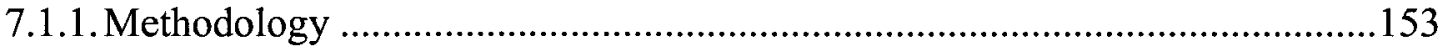

7.2. Analysis of temperature vs. the oxygen depletion factor …………........................157

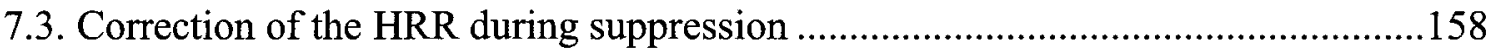

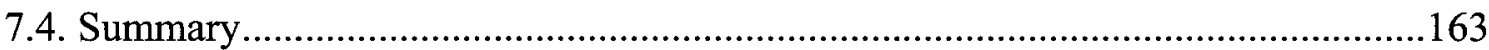

Chapter 8. CFD SIMULATIONS OF SUPPRESSION TESTS ................................164

8.1. Description of CFD SIMULATIONS .....................................................................164

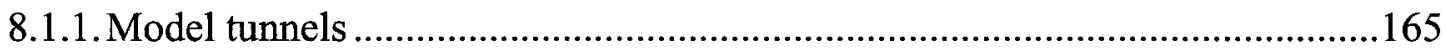

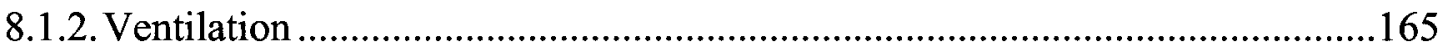

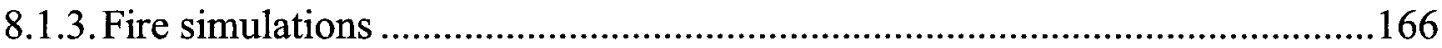

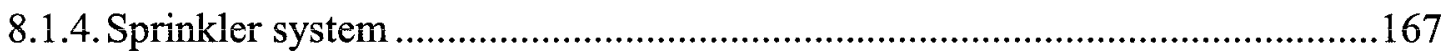

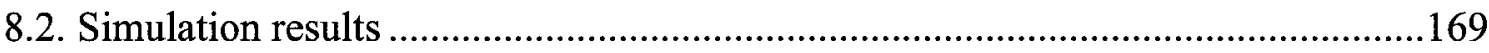

8.2.1. Comparison of simulated results with experimental results without the

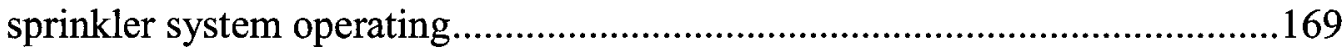

8.2.2. Comparison of the spray pattern .................................................................171

8.2.3. Comparison between the simulated results and the experimental results with the sprinkler system operating.................................................................173

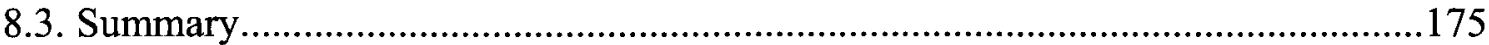

Chapter 9. THE EFFECT OF THE USE OF WFFFS AND LONGITUDINAL VENTILATION SYSTEMS IN TUNNELS ………………………........177

9.1. Analysis of the cooling effect of the sprinkler system under longitudinal

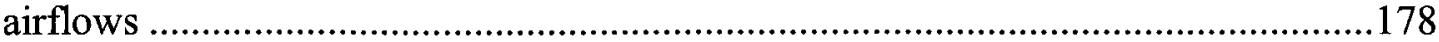

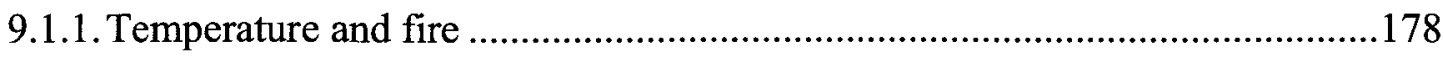

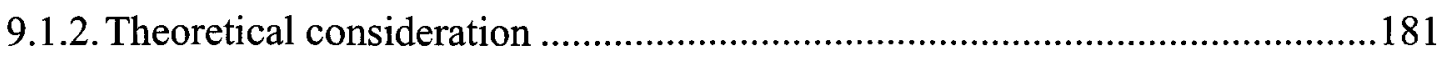

9.1.3. Maximum ceiling temperature without a suppression system operating ........183 
9.1.4. The maximum ceiling temperature with a suppression system operating.......186

9.1.5. Ceiling temperatures downstream of the fire ..................................................18

9.2. Analysis of the impact of sprinkler systems on the effectiveness of the longitudinal ventilation systems

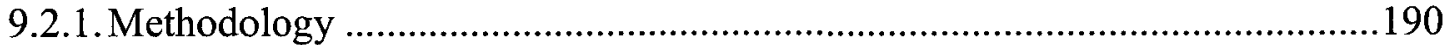

9.2.2. Backlayering without suppression...................................................................191

9.2.3. Backlayering during suppression ...............................................................192

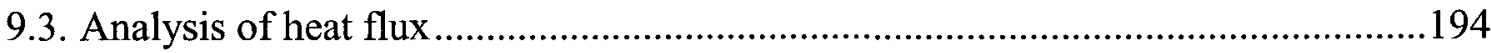

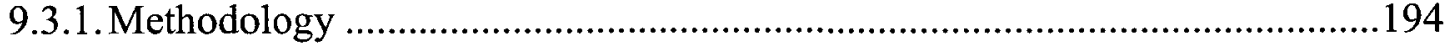

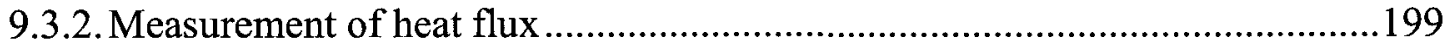

9.3.3. Estimation of heat flux under ventilation ......................................................202

9.3.4. Radiation attenuation by water spray ..........................................................204

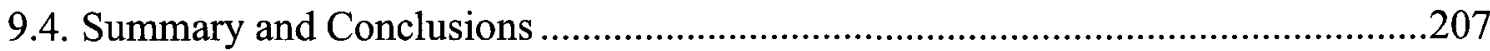

9.4.1.The cooling effect of the sprinkler system along with the longitudinal ventilation system

9.4.2. Control of smoke backlayering using the sprinkler system and longitudinal ventilation system

9.4.3. Radiation attenuation by the sprinkler system.................................................210

Chapter 10. Summary, Conclusions and Recommendations ...........................................212

10.1. Development of a HRR measurement system …….........................................212

10.2. Investigation of the effect of the use of WFFFS under longitudinal air flows on tunnel fires

References 219

Appendix A: Velocity probe combinations 229

Appendix B: Velocity error of all probe combinations..................................................230

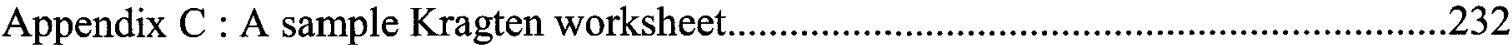

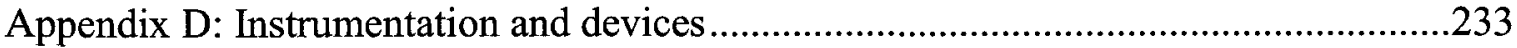

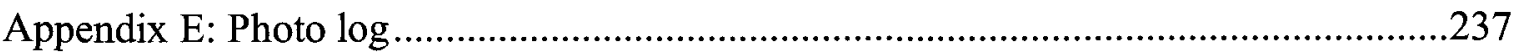




\section{LIST OF TABLES}

Table 2-1 HRR suggested by various studies and standards for tunnel fires [5] ............. 23

Table 2-2 Summary of previous tunnel tests .................................................................. 45

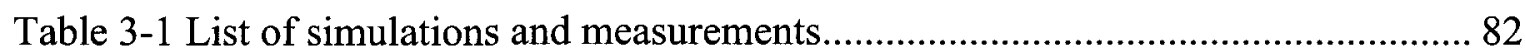

Table 3-2 A list of equations used in the real time HRR measurement system................ 93

Table 4-1 A list of calibration tests and summary of results ......................................... 110

Table 5-1 The general scheme of Kragten spreadsheet [100] ........................................ 116

Table 5-2 A list of parameters and measurement variables; the mean and the relative sensitivity coefficient are obtained for the test of $10 \mathrm{MW}$ with $50 \%$ fan speed.

Table 5-3 Results of uncertainty analysis for two different sample data sets obtained from different test conditions............................................................................. 121

Table 6-1 Tested sprinkler water spray rates ................................................................ 127

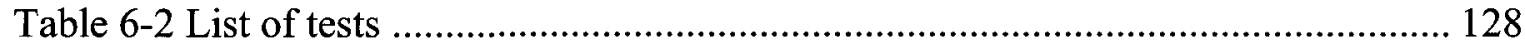

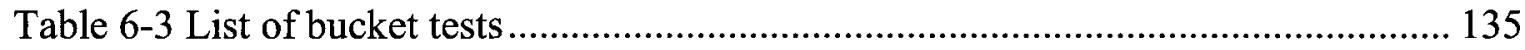

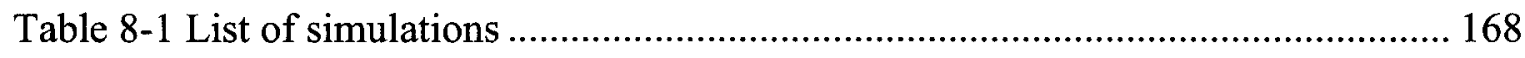

Table 9-1 Summary of previous tunnel fire tests ............................................................ 181 


\section{LIST OF FIGURES}

Figure 2-1 Tunnel fires (a) Mont Blanc tunnel fire (b) Gottard tunnel fire (c) Taurun tunnel fire (d) I-5 tunnel fire [7] ................................................................... 13

Figure 2-2 Emergency ventilation systems in Tunnels ................................................ 16

Figure 2-3 Experimental data of critical velocity in tunnel fires [19] ........................... 17

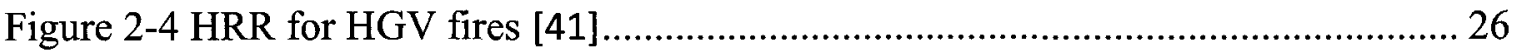

Figure 2-5 Fire development for a simulated HGV under different ventilation conditions [37]

Figure 2-6 Comparison of temperature-time curves for different type of fires in tunnels [46] 29

Figure 2-7 Gas temperature measured near the fire from high severity HGV fires [40] .. 29

Figure 2-8 Temperature propagation along the tunnel for different vehicle fires [46]

Figure 2-9 Temperature $\left({ }^{\circ} \mathrm{F}\right)$ profile with transverse ventilation for a fire size of $20 \mathrm{MW}$ [47]. 32

Figure 2-10 Temperature $\left({ }^{\circ} \mathrm{F}\right)$ profile with longitudinal ventilation for a fire size of 50 MW [47]. 32

Figure 2-11 Gas temperature measured (a) upstream of the fire (b) downstream of the fire [40] 34

Figure 2-12 Comparisons of HRR calculations [60] …………….................................. 38

Figure 2-13 Spectrum of droplet diameters [4]......................................................... 41

Figure 2-14 Fire sizes and water flow density tested in previous studies........................ 45

Figure 2-15 2nd Benelux sprinkler test arrangement [37] .............................................. 47

Figure 2-16 UPTUN DMT tunnel tests [72] ............................................................. 49

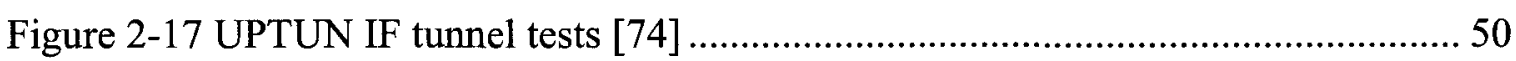

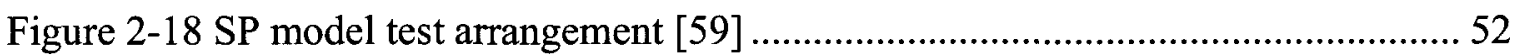

Figure 2-19 The mitigated HRR of a pool fire compared with a reference test. (Water

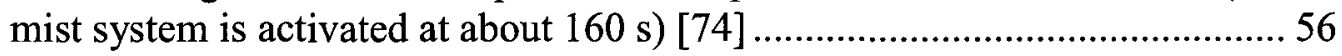

Figure 2-20 The mitigated HRR of wood crib fires (a) SP model scale tests [78] (b) The San Pedro de Anes tunnel test [77] ............................................................... 56

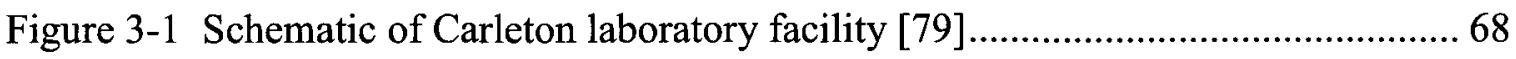

Figure 3-2 Velocity profile transitions through the fan chamber (simulation results with a $20 \mathrm{MW}$ fire in the tunnel with $50 \%$ fan speed)

Figure 3-3 Schematics of HRR Measurement System [79] ......................................... 70

Figure 3-4 Schematics of oxygen calorimetry ............................................................... 72 
Figure 3-5 (a) Probe constant as function of $\operatorname{Re}$ (b) standard design of the probe [88].. 79

Figure 3-6 Bi-directional probe dimensions used in the current study $(D=24.6 \mathrm{~mm}$,

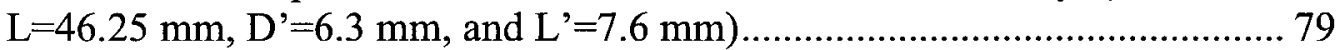

Figure 3-7 Model geometry ........................................................................................ 81

Figure 3-8 Vertical temperature profiles from a $10 \mathrm{MW}$ fire in the tunnel under different fan speeds (Note: -1.25 and 1.25 refer $1.25 \mathrm{~m}$ left and $1.25 \mathrm{~m}$ right from the centre, respectively)[79].............................................................................. 84

Figure 3-9 Vertical profiles of oxygen mass fraction of the flow from a $10 \mathrm{MW}$ fire in the tunnel under different fan speeds (Note: -1.25 and 1.25 refer $1.25 \mathrm{~m}$ left and $1.25 \mathrm{~m}$ right from the centre, respectively) [79] 85

Figure 3-10 Vertical velocity profiles at $50 \%$ fan speed without and with a $2.5 \mathrm{MW}$ fire in the tunnel (Note: -1.25 and 1.25 refer $1.25 \mathrm{~m}$ left and $1.25 \mathrm{~m}$ right from the centre, respectively) [79] 85

Figure 3-11 Vertical velocity profiles at $50 \%$ fan speed from a atrium simulation and manual measurements (Note: -1.25 and 1.25 refer $1.25 \mathrm{~m}$ left and $1.25 \mathrm{~m}$ right from the centre, respectively) [79] ................................................................ 86

Figure 3-12 the fire most accurate velocity probe combinations [79] ............................. 88

Figure 3-13 Comparison of the fire most accurate velocity probe combinations [79] ..... 88

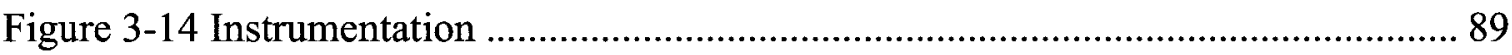

Figure 3-15 Diagram of measurement equipments.................................................... 90

Figure 3-16 Real-time HRR calculations and display system flow chart ......................... 92

Figure 4-1 Test arrangement for Heptane and propane fire............................................ 99

Figure 4-2 The front panel of the real time HRR measurement calculation and display

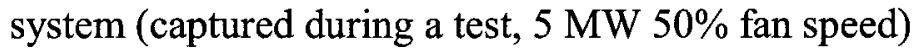

Figure 4-3 HRR results from a calibration test A5 of the HRR measurement system using propane burners $(50 \%$ fan speed, $5 \mathrm{MW})$ 102

Figure 4-4 The correction factor matching $\int \mathrm{Q}$ to $\mathrm{E}$ from a calibration test A5 (50\% fan speed, $5 \mathrm{MW}$ ). 102

Figure 4-5 Comparisons of the system response to $5 \mathrm{MW}$ calibration fire for different fan speeds 104

Figure 4-6 Results from a calibration test P13 of the HRR measurement system using propane burners ( $100 \%$ fan speed, $13 \mathrm{MW}$, for 40 seconds) 104

Figure 4-7 Results from a calibration test of the HRR measurement system using propane burners and heptane pool fire (100\% fan speed, $23 \mathrm{MW})$. 107

Figure 4-8 Correction factors with respect to $\mathrm{O} 2$ concentration 109 
Figure 4-9 Corrected HRR calculation for Test B11 (25\%, 8-2 MW Type B propane test, correction factor $=0.83$ )

Figure 5-1 Uncertainty contributions by each component (averaged results from 11 tests)

Figure 5-2 Performance of the HRR measurement system........................................... 120

Figure 6-1 Test set-up in the tunnel ....................................................................... 125

Figure 6-2 Flow straightening vanes at the main opening ........................................ 125

Figure 6-3 Sprinkler system and instrumentation in the tunnel................................... 129

Figure 6-4 The propane burners and heptane pool for the fire test of $15 \mathrm{MW}$............... 131

Figure 6-5 Plate thermometer (the manufacture provided)........................................... 133

Figure 6-6 Arrangement of buckets .............................................................................. 134

Figure 6-7 Bucket test .......................................................................................... 135

Figure 6-8 The collected water spray rate normalised to the nominal water spray rate of

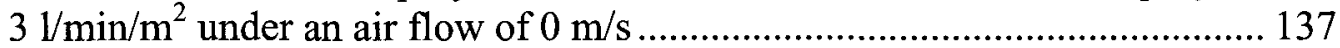

Figure 6-9 The collected water spray rate normalised to the nominal water spray rate of $31 / \mathrm{min} / \mathrm{m}^{2}$ under an air flow of $2.7 \mathrm{~m} / \mathrm{s}$ (Fan speed 100\%) ........................ 137

Figure 6-10 The collected water spray rate normalised to the nominal water spray rate of

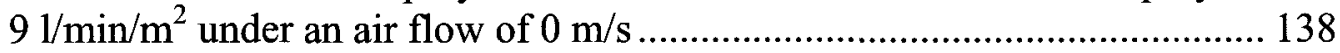

Figure 6-11 The collected water spray rate normalised to the nominal water spray rate of $9 \mathrm{l} / \mathrm{min} / \mathrm{m}^{2}$ under an air flow of $2.7 \mathrm{~m} / \mathrm{s}$ (Fan speed 100\%) ......................... 138

Figure 6-12 A photo taken during the suppression test ................................................. 139

Figure 6-13 The measured HRR and $\mathrm{O}_{2}$ concentration over time for $10 \mathrm{MW}$ fire with a $100 \%$ fan speed and water spray densities of $31 / \mathrm{min} / \mathrm{m}^{2}$ and $91 / \mathrm{min} / \mathrm{m}^{2}$ (Note: the fan speed was gradually increased from $50 \%$ to $100 \%$, and at $400 \mathrm{~s}$ the fan speed reached $100 \%$ ) ................................................................................... 140

Figure 6-14 The measured $\mathrm{CO}$ and $\mathrm{CO}_{2}$ concentration over time for $10 \mathrm{MW}$ fire with a $100 \%$ fan speed and water spray densities of $31 / \mathrm{min} / \mathrm{m}^{2}$ and $91 / \mathrm{min} / \mathrm{m}^{2}$ (Note: the fan speed was gradually increased from $50 \%$ to $100 \%$, and at $400 \mathrm{~s}$ the fan speed reached $100 \%)$

Figure 6-15 The measured HRR and $\mathrm{O}_{2}$ concentration over time for $10 \mathrm{MW}$ fire with a $25 \%$ fan speed and a water spray density of $91 / \mathrm{min} / \mathrm{m}^{2}$ 142

Figure 6-16 The measured $\mathrm{CO}$ and $\mathrm{CO}_{2}$ concentration over time for $10 \mathrm{MW}$ fire with a $25 \%$ fan speed and a water spray rate of $91 / \mathrm{min} / \mathrm{m}^{2}$ 143

Figure 6-17 The measured HRR and $\mathrm{O}_{2}$ concentration over time for $15 \mathrm{MW}$ fire with a $25 \%$ fan speed and a water spray density of $91 / \mathrm{min} / \mathrm{m}^{2}$ 143 
Figure 6-18 Longitudinal ceiling temperature profiles $(\Delta \mathrm{T})$ from the $10 \mathrm{MW}$ fire for different fan speeds without the sprinkler system operating........................... 144

Figure 6-19 Longitudinal ceiling temperature profiles $(\Delta \mathrm{T})$ from the $10 \mathrm{MW}$ fire at $50 \%$ fan speed with the sprinkler system operating. 145

Figure 6-20 A comparison of longitudinal ceiling temperature profiles $(\Delta \mathrm{T})$ for different fan speeds (10 MW fire during suppression with a water spray rate of 6 $\left.1 / \mathrm{min} / \mathrm{m}^{2}\right)$ 146

Figure 6-21 A comparison of vertical temperature $(\Delta \mathrm{T})$ profiles $10 \mathrm{~m}$ upstream of the 10 MW fire with and without the sprinkler system operating (50\% fan speed) . 147

Figure 6-22 A comparison of vertical temperature $(\Delta \mathrm{T})$ profile $10 \mathrm{~m}$ upstream of the 10 MW fire with different fan speeds ( with a water spray density of $61 / \mathrm{min} / \mathrm{m}^{2}$ ) 148

Figure 6-23 Vertical temperature $(\Delta \mathrm{T})$ profile $17 \mathrm{~m}$ downstream of a $10 \mathrm{MW}$ fire for different water spray rates

Figure 6-24 A comparison of heat flux $\left(\mathrm{q}_{+8}\right)$ measured $8 \mathrm{~m}$ downstream and heat flux $\left(\mathrm{q}_{-8}\right)$ measured $8 \mathrm{~m}$ upstream of the $10 \mathrm{MW}$ fire (Fan $25 \%$, water spray density 6 $1 / \mathrm{min} / \mathrm{m}^{2}$ ) 150

Figure 6-25 A comparison of Gardon gauge heat flux measurements and temperature measurements by a plate thermometer at the same location, $8 \mathrm{~m}$ downstream of a $10-\mathrm{MW}$ fire with a $50 \%$ fan speed and water spray density of $6 \mathrm{1} / \mathrm{min} / \mathrm{m}^{2}$ 150

Figure 7-1 A comparison between the temperature rise $(\Delta \mathrm{T})$ of exhaust gas and the oxygen depletion factor $(\Phi)$ ( Test results from a calibration test \#16, a $24 \mathrm{MW}$ fire combined of propane burners and a heptane pool, $100 \%$ fan speed) ...... 158

Figure 7-2 $\Delta \mathrm{T}_{\mathrm{e}}$ as a function of $\Phi$ 158

Figure 7-3 A comparison of oxygen depletion factor with the actual $\Delta \mathrm{T}_{\mathrm{ev}}$ and $\Delta \mathrm{T}_{\mathrm{e}}$ resulted from the $10 \mathrm{MW}$ fire test under $50 \%$ fan speed and water spray rate of 3 and 9 $1 / \mathrm{min} / \mathrm{m}^{2}$ 159

Figure 7-4 Corrected HRR, Qnew, compared with Q (a $10 \mathrm{MW}$ fire under $50 \%$ fan speed with a water spray rate of 3 and $9 \mathrm{l} / \mathrm{min} / \mathrm{m}^{2}$ ) 159

Figure 7-5 Corrected HRR, Qnew, compared with Q (a $10 \mathrm{MW}$ fire under $25 \%$ fan speed with a water spray rate of $91 / \mathrm{min}^{2}$ ). 160

Figure 7-6 A comparison of $\mathrm{Q}$ and $\mathrm{Q}_{\text {new }}$ for the test of $15 \mathrm{MW}$ fire (heptane and propane fire) under $50 \%$ fan speed and water spray rate of $91 / \mathrm{min} / \mathrm{m}^{2}$

Figure 7-7 A comparison of performance of $Q_{\text {new }}$ and $Q$.......................................... 162

Figure 8-1 (a) Model laboratory tunnel and (b) $53 \mathrm{~m}$ long model tunnel....................... 166

Figure 8-2 Comparisons of the temperature profile along the tunnel without the sprinkler system operating (10 MW fire, $50 \%$ fan speed) 170 
Figure 8-3 Comparison of vertical temperature profiles $10 \mathrm{~m}$ upstream of the $10 \mathrm{MW}$ fire without the sprinkler system operating

Figure 8-4 Comparison of vertical temperature profiles $17 \mathrm{~m}$ downstream of the $10 \mathrm{MW}$ fire without the sprinkler system operating 171

Figure 8-5 The influence of the longitudinal air flow on the water spray pattern in the case of water spray density of $61 / \mathrm{min} / \mathrm{m}^{2}$ under an air flow of $1.4 \mathrm{~m} / \mathrm{s}$ (Fan speed 50\%)

Figure 8-6 Ceiling temperature drops by the sprinkler system with different water flow densities. 173

Figure 8-7 Vertical temperature profiles $10 \mathrm{~m}$ upstream with the suppression system operating with various water spray densities ( $5 \mathrm{MW}$ fire with $50 \%$ fan speed)

Figure 8-8 Vertical temperature profiles $10 \mathrm{~m}$ upstream with the suppression system operating with a water spray density of $61 / \mathrm{min} / \mathrm{m}^{2}(10 \mathrm{MW}$ fire with $50 \%$ fan speed) 175

Figure 9-1 Temperature with respect to HRR 180

Figure 9-2 Maximum ceiling temperature without water sprays as a function of $\mathrm{Q}^{*}, \mathrm{~V}^{*}$ 185

Figure 9-3 A comparison with the model by Kurioka …………................................. 185

Figure 9-4 Maximum ceiling temperature during suppression. 187

Figure 9-5 Ceiling temperature $21 \mathrm{~m}$ downstream of the fire with the sprinkler system operating 189

Figure 9-6 $\mathrm{Ri}^{*}$ of smoke $10 \mathrm{~m}$ upstream of the fire with respect to $\mathrm{V} / \mathrm{V}_{\mathrm{c}}$ 192

Figure 9-7 Backlayering during suppression as a function of $Q^{*}, \omega, V^{*}$ 193

Figure 9-8 $\mathrm{k}$ values with respect to air flow velocities 201

Figure 9-9 A comparison of heat flux measurements between a plate thermometer and Gardon gauge ( heat flux $8 \mathrm{~m}$ upstream of a $10 \mathrm{MW}$ fire under $25 \%$ fan speed and a water spray rate of $91 / \mathrm{min} / \mathrm{m}^{2}$ ). 201

Figure 9-10 A comparison of calculated heat flux with Gardon measurements............ 202

Figure 9-11 Radiation heat flux with respect to Q ........................................................ 204

Figure 9-12 Fraction of transmitted radiation for measurement $8 \mathrm{~m}$ upstream of the fire with respect to water spray rates .................................................................... 205

Figure 9-13 Fraction of transmitted radiation for measurement $8 \mathrm{~m}$ downstream of the fire with respect to water spray rates ................................................................ 205

Figure 9-14 Fraction of transmitted radiation for measurements $8 \mathrm{~m}$ downstream of the fire 206 


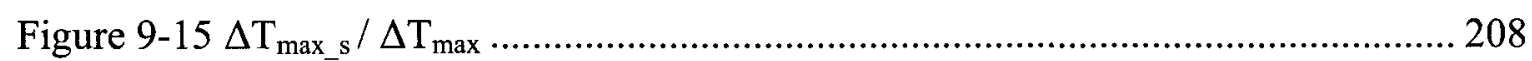

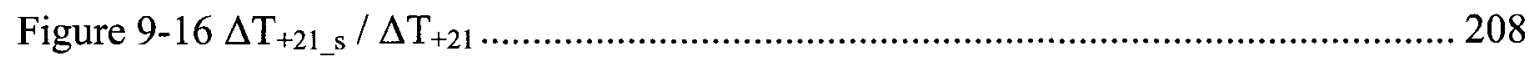

Figure 9-17 The required velocity to prevent the backlayering with the suppression system operating ............................................................................... 210

Figure 9-18 Fraction of transmitted radiation downstream of the fire with respect to $\omega V *$ 


\section{NOMENCLATURE}

\begin{tabular}{|c|c|}
\hline$A$ & the cross-section of the tunnel $\left(\mathrm{m}^{2}\right)$ \\
\hline$a$ & Absorptivity \\
\hline B & Bi-directional probe \\
\hline$C$ & relative sensitivity coefficients \\
\hline$C_{p}$ & the specific heat $(\mathrm{KJ} / \mathrm{kg} / \mathrm{K})$ \\
\hline $\operatorname{COV}$ & covariance \\
\hline$d$ & Droplet diameter $(\mu \mathrm{m})$ \\
\hline$D$ & Flow layer depth $(\mathrm{m})$ \\
\hline$E_{O 2}$ & heat release per unit mass of $\mathrm{O}_{2}$ consumed in the reaction $\left(\mathrm{MJ} / \mathrm{kg}\right.$ of $\left.\mathrm{O}_{2}\right)$ \\
\hline$E_{C o}$ & $\begin{array}{l}\text { heat release per unit mass of } \mathrm{O}_{2} \text { consumed for combustion of } \mathrm{CO} \text { to } \mathrm{CO}_{2} \\
\left(17.6 \mathrm{MJ} / \mathrm{kg} \text { of } \mathrm{O}_{2}\right)\end{array}$ \\
\hline$E$ & the theoretical fuel energy (MJ) \\
\hline $\mathbb{E}$ & Expected value of a random variable \\
\hline$F$ & Configuration factor \\
\hline$f$ & incomplete combustion factor \\
\hline Fr & Froude number (dimensionless) \\
\hline$g$ & Acceleration due to gravity $\left(\mathrm{m} / \mathrm{s}^{2}\right)$ \\
\hline$h$ & Convective heat transfer coefficient $\left(\mathrm{W} / \mathrm{m}^{2} / \mathrm{K}\right)$ \\
\hline $\bar{H}$ & Hydraulic height of the tunnel (m) \\
\hline$H_{c h}$ & Effective Heat of Combustion (MJ/kg) \\
\hline$H_{C h}$ & Net Heat of Combustion (MJ/kg) \\
\hline$H_{C O}$ & Net Heat of Combustion of $\mathrm{CO}(\mathrm{MJ} / \mathrm{kg})$ \\
\hline$I$ & Electrical current signals $(A)$ \\
\hline$k$ & Conductivity $(\mathrm{W} / \mathrm{m} / \mathrm{K})$ \\
\hline$K_{\text {cond }}$ & Conduction correction factor $\left(\mathrm{W} / \mathrm{m}^{2} / \mathrm{K}\right)$ \\
\hline$k_{p}$ & Bi-directional probe constant \\
\hline$H_{C} / k_{C O}$ & net heat of combustion of fuel per unit mass of $\mathrm{CO}$ produced $(\mathrm{MJ} / \mathrm{kg})$ \\
\hline$H_{C} / k_{C O 2}$ & net heat of combustion of fuel per unit mass of $\mathrm{CO} 2$ produced $(\mathrm{MJ} / \mathrm{kg})$ \\
\hline$L$ & characteristic length of the surface (m) \\
\hline$\ell$ & Path length (m) \\
\hline$M$ & molecular weight $(\mathrm{g} / \mathrm{mol})$ \\
\hline $\mathbb{M}$ & The mass of the water per unit volume in the attenuating medium \\
\hline$\dot{m}$ & mass flow rate $(\mathrm{kg} / \mathrm{s})$ \\
\hline$\dot{m}_{b}$ & Burning rate $(\mathrm{kg} / \mathrm{s})$ \\
\hline$\dot{n}$ & Mole flow rate \\
\hline $\mathrm{n}$ & pipe flow exponent \\
\hline
\end{tabular}




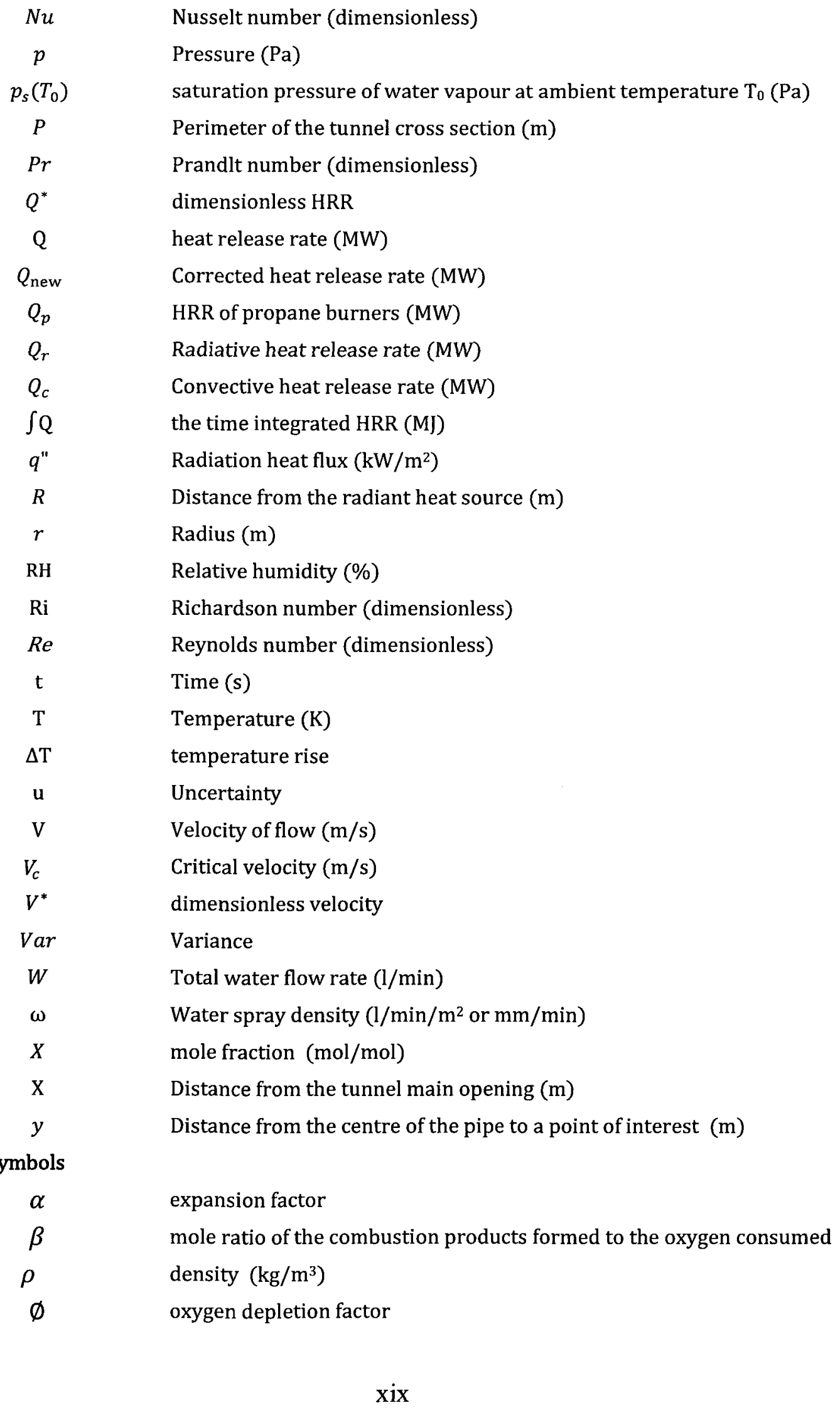


Mass flow rate correction factor

$\psi$

Rate of evaporation

$\mu$

Mean value

$\sigma$

Stefan-Boltzmann constant $\left(5.67 \times 10^{-8} \mathrm{~W} \mathrm{~m}^{-2} \mathrm{~K}^{-4}\right)$

$\sigma$

Standard deviation

$\bar{\sigma}$

Log normal distribution parameter

$\gamma$

Rosin-Rammler distribution parameter

$\delta$

Thickness (m)

$\varepsilon$

emissivity

\section{List of subscripts/ superscripts}

A

a

act

avg

CO

$\mathrm{CO}_{2}$

$d$

dry

e

$e v$

$f$

$\mathrm{H} 2 \mathrm{O}$

$\mathrm{m}$

$\max$

$\mathrm{N}_{2}$

0

$\mathrm{O}_{2}$

$\mathrm{p}$

$P T$

$r$

S

st

$\mathrm{t}$

$\mathrm{T}$

$v$

w measured by gas analyser

air

actual

average

Carbon monoxide

Carbon dioxide

droplet

Dry condition

Exhaust gas

Exhaust gas including water vapour produced by suppression Gas film

Water vapour

Median value

Maximum value

Nitrogen

Incoming/ ambient value

Oxygen

Plume

Plate thermometer

radiative

with suppression system operating

Inconel metal plate

total

target

water vapour produced by suppression

water 


\section{CHAPTER 1. INTRODUCTION}

A number of catastrophic tunnel fires that have occurred throughout the world have raised questions about the current understanding of the severity of tunnel fires and about the effectiveness of fire safety systems currently used in tunnels. The estimated Heat Release Rates (HRR) from fires in some previous accidents in road tunnels are about 100-200 MW, which are equivalent to the heat intensity from a gas tanker fire. Large

fires severely damage the tunnel structure and hinder firefighting efforts [1]. For example, in 2007, in the I-5 tunnel fire in California, 33 trucks including Heavy Good Vehicle (HGV) trailers and a car were involved in the fire accident, and the heat generated by the fire was too intense for the fire service to reach the fire scene [2].

Early fire fighting before the fire spreads and grows to an unmanageable size is the best way to minimize losses. However, mitigating the effects of tunnel fires depends mostly on mechanical ventilation systems, which are meant to extract hot smoke out of the tunnel. Active fire safety systems such as Water-based Fixed Fire Fighting Systems (WFFFS) have not been considered in the majority of tunnels in the world.

\subsection{Objectives}

This study aims to develop a HRR measurement system to be used in tunnel fire safety research and to evaluate the mitigation effect of WFFFS under longitudinal airflows. 
1.1.1. Development of a HRR measurement system to estimate HRR of tunnel fires

While there is a long list of research needs in the area of tunnel fire safety, identifying the Heat Release Rates (HRR) of different types of transportation vehicles is an important first step in improving fire safety in tunnels. An objective of the present study is to develop a HRR measurement system that can accurately measure HRR under various ventilation conditions as well as during suppression activation. A HRR measurement was developed in the full-scale laboratory tunnel of Carleton University. The present study also aims to calibrate and evaluate the measurement system under various conditions so that the system can be used in a broad range of tunnel fire research experiments.

1.1.2. Investigation of the effect of the use of WFFFS under longitudinal air flows on tunnel fires

The second objective of the present study is to investigate the effects of using WFFFS together with a longitudinal ventilation system on tunnel fires. Full-scale suppression tests were conducted in the laboratory tunnel. The overall goal of this study is to determine whether and how WFFFS can be used to increase fire safety in tunnels. The present study also aims to propose a design method for both WFFFS and longitudinal ventilation system for tunnel application.

\subsection{HRR of tunnel fires}

HRR is often used to characterize fire size and fire development [3]. HRR also provides necessary information for the design of fire safety systems, such as ventilation systems and suppression systems. The design method for ventilation systems is based on HRR, 
and the mitigation effect of water-based suppression systems on fire hazards can be measured in terms of the reduction in HRR. There is a strong demand from fire safety engineers and code authorities for characterizing fire sizes to be used in designing fire safety systems for various types of tunnel fires.

Oxygen consumption calorimetry is often employed as the most common, accurate and reliable method for measuring the HRR of fires. This method has been used in smallscale calorimeters, single-item burning tests and room-fire tests to measure fire sizes up to $10 \mathrm{MW}$. Generally, an exhaust fan collects all combustion products in a hood, and all necessary measurements are taken at one instrumentation station in the duct system.

\subsubsection{Problems}

The method of oxygen calorimetry can be used in measuring HRRs of tunnel fires. The difficulty in measuring the HRR of tunnel fires involving passenger vehicles or Heavy Good Vehicles (HGV) is the fact that those fires are very large and require a large-scale measurement system including a duct system with a capacity large enough to handle a huge amount of smoke. Due to the turbulence of the flow inside the large duct, accurate measurements of HRR are challenging in a large-scale system.

Another problem in measuring the HRR of fires is applying the principle of the oxygen calorimetry to fires during suppression. A large quantity of water vapour generated by the suppression system can affect the accuracy of the measurements. There is no study that has evaluated the measurements of large-scale fires during suppression for various water spray rates and ventilation conditions. 


\subsubsection{Methodology}

1) Instrumentation design

The laboratory tunnel is equipped with a large capacity fan system that draws smoke from the tunnel via a large fan chamber. In order to design instrumentation in the fan chamber, extensive Computational Fluid Dynamics (CFD) simulations as well as manual measurements were carried out. Based on the examination of the flow in the fan chamber under various conditions, the instrumentation was designed with the optimal amount of instrumentation that ensured reasonable accuracy.

2) Calibration test program

In order to ensure accurate and reliable measurements under different ventilation conditions, a series of calibration tests was conducted.

3) Uncertainty analysis

Results from the calibration tests were analysed to determine uncertainty in the HRR estimations, as well as the uncertainty associated with each measurement variable. The results of the analysis identified the major sources of uncertainty and assisted in improving the system design.

4) Analysis of HRR measurements during suppression and development of a simple method to correct the HRR measurements during suppression

Using data obtained from the suppression test program, further evaluations were undertaken to assess the performance of the measurement system during the suppression 
of fires. HRR measurement results were analysed and uncovered a systematic error. A simple method is proposed to correct HRR measurements during suppression.

\subsection{The effect of the use of WFFFS and longitudinal ventilation systems}

Currently, mitigating the effects of tunnel fires mostly depends on mechanical ventilation systems that either direct the hot smoke to the exit portal downstream of the fire or exhaust smoke throughout the tunnel (see Chapter 2.1.3 for different schemes for the mechanical ventilation system). Longitudinal mechanical ventilation systems are commonly used in tunnels because they are effective in clearing smoke upstream of the fire, where motorists are likely to be queued due to the fire, and resisting smoke backlayering (i.e. smoke flow against the direction of the ventilation air flow). However, there are some issues with the longitudinal ventilation system. The system does not fight (suppress) fires and is not capable of preventing fire spread. Actually, the system can boost fire growth as it provides fresh air into the fire and, in turn, may result in fire spread to other vehicles queued in the tunnel.

Suppression systems have been widely used in various built environments other than tunnels for their proven abilities to suppress fires, control fire growth and prevent fire spread. The use of Water-based Fixed Fire Fighting Systems (WFFFS) has not been considered for many years, mainly because of a lack of knowledge about the effectiveness of the system as well as some disadvantages of the system for application to tunnels. The main concern regarding the use of WFFFS in tunnels is that water spray can disturb the smoke layer and destroy the stratification so that the cooled smoke layer can cover the whole tunnel causing poor visibility. 


\subsubsection{Problems}

If both WFFFS and longitudinal ventilation systems are used, they can compensate for each other system's weakness, and this strategy offers significant advantages for controlling smoke, preventing fire spread and mitigating hazards in the case of tunnel fires. However, there is no design guide or method available for this strategy.

Although there is no study that has examined the effect of both systems, the effect of each system separately has been researched. Several small-scale and full-scale experimental studies have produced a design method to calculate the critical velocity, which is defined as the minimum velocity required for the longitudinal ventilation system to resist flow of smoke upstream of the fire. Also many research projects have been conducted recently as WFFFS has gained much attention as a solution for mitigating tunnel fires. These studies verified that a WFFFS can control the HRR, cool the smoke, and prevent fire spread.

However, it is questionable if these design methods and knowledge are applicable to the situation where both systems are active. Therefore, it is necessary to study the impact of suppression and ventilation systems on each other; and to develop a design method to incorporate both systems into the tunnel fire safety system. In this regard, some questions need to be addressed.

- How does each system impact the effectiveness of the other system?

- Does the longitudinal ventilation system effectively control smoke with WFFFS active? Is the current critical velocity concept used in longitudinal ventilation design still applicable when both WFFFS and longitudinal ventilation systems are used? 
- How effective are WFFFS and ventilation systems when used simultaneously in mitigating the severity of tunnel fires?

- How effective is the use of both systems in cooling smoke and preventing fire spread?

\subsubsection{Methodology}

1) Full-scale suppression test program

The most reliable method of studying the performance of WFFFSs, and their interaction with fire and smoke is to conduct full-scale tests [4]. Full-scale suppression tests were conducted in this research to investigate the effect of a WFFFS under longitudinal air flows. Tests were conducted in the laboratory tunnel of Carleton University using a sprinkler system generating large water droplets. Various fire sizes up to $15 \mathrm{MW}$ were employed to examine the interaction of longitudinal air flow and WFFFSs for different water spray rates and longitudinal airflows. The performance of each system and the combined mitigation effects of both systems were investigated.

2) Investigation of interaction of WFFFS and longitudinal air flows

Bucket tests were conducted to examine the interaction between WFFFS and longitudinal air flows that are induced by ventilation systems. The influence of longitudinal air flows on the water spray pattern was examined, for air flow velocities up to $3 \mathrm{~m} / \mathrm{s}$. 
3) CFD simulations of suppression tests

CFD (Computational Fluid Dynamics) simulations were conducted to extend the experimental data, to gain understanding of the conditions inside the tunnel and to observe the interaction of water spray and gas flows in the tunnel.

4) Analysis of cooling effect of WFFFS along with longitudinal air flows

Gas temperatures near the ceiling in the vicinity of the fire are of interest in predicting the severity of heat that the tunnel structure would experience in the event of a fire. The maximum ceiling temperature data obtained from the suppression test program were analysed to develop a tool to estimate the cooling effect of the sprinkler system together with the longitudinal ventilation system on the temperature in the vicinity of the fire.

5) Analysis of backlayering during suppression along with longitudinal air flows The temperature data upstream of fires obtained from the suppression test program was examined to find whether the well-established current design method used for the longitudinal ventilation is applicable when WFFFS is used. Based on the analysis of temperature data, a method to estimate the degree of backlayering with suppression operating was proposed.

6) Analysis of radiation attenuation by WFFFS

Estimating radiative heat flux is important because fire spread is an issue in tunnel fires. In the suppression test program, heat fluxes were measured using different devices to ensure accurate measurements of radiative heat flux in mixed radiative and convective 
conditions. The collected data were analysed to investigate the effect of radiation attenuation by the water spray.

\subsection{Contributions of this study}

The main contributions of this study are the following:

The present study developed a large-scale HRR measurement system, which will be used in future tunnel fire research projects. The system was designed to accurately measure large tunnel fires under various ventilation conditions including cases with the suppression system operating. The present study also studied the uncertainty propagation of more than 20 parameters involved in the calculation of HRR.

It was identified that the method of oxygen consumption calorimetry during suppression resulted in an overestimation of the heat release rate, which is due to the water vapour introduced by the suppression system. A simple method to correct this was developed, which successfully calculates the HRR during suppression. This method is based on temperature measurements and the relationship between the gas temperature and the oxygen depletion factor.

Based on extensive experimental evaluation of the effect of use of WFFFS together with longitudinal ventilation systems in tunnels, methods to estimate the cooling effect and radiation attenuation by both systems were proposed based on test data from the present study. These methods give relatively good predictions over a wide range of fire sizes and velocities, as well as water spray rates of the WFFFS. 
The present study demonstrated that with a suppression system operating, the smoke backlayering control can be achieved with a lower velocity than the critical velocity required by the current design method for longitudinal ventilation systems. A new method to estimate the critical velocity for tunnels that include both a longitudinal ventilation system and a WFFFS is proposed. The proposed method considers the effects of water spray rate and design fire size. 


\section{CHAPTER $2 . \quad$ LITERATURE REVIEW}

The literature review presented in this chapter focuses on the following topics;

- Introduction to tunnel fires; that includes tunnel fire dynamics, tunnel fire-safety systems and system regulations.

- The severity of tunnel fires; that includes HRR and temperature measurements from previous fire tests, as well as HRR measurement methods used in previous tunnel fire studies

- The performance of Water-Based Fixed Fire Fighting Systems; that includes detailed descriptions of previous suppression tunnel tests and the effect of WFFFS on tunnel fires

\subsection{Introduction to Tunnel Fires}

This section summarizes major tunnel fire accidents that have occurred in recent years, reviews the fundamentals of how tunnel fires grow, and compares tunnel fires with compartment fires. In the following section, a brief review is also given with regard to tunnel fire-safety systems and the system regulations.

\subsubsection{Tunnel fire accidents}

Tunnel fire safety became a major issue at national and international levels after a number of catastrophic fires (see Figure 2-1) occurred throughout the world [5].

- The Channel tunnel fire (France/UK 1996) involved 10 HGVs. The estimated Heat Release Rate (HRR) was about $370 \mathrm{MW}$, and the fire severely damaged the tunnel structure and facilities. 
- The Mont Blanc tunnel fire (Italy/France 1999) involved 15 HGVs and 9 cars. The estimated HRR was about 300 380 MW which lasted about 9 13 hours. It caused 39 fatalities.

- The Tauern tunnel fire (Austria 1999) involved $16 \mathrm{HGVs}$ and 24 cars. The estimated HRR was about 300 400 MW and the fire caused 12 fatalities.

- The St. Gotthard tunnel fire (Switzerland 2001) involved 13 HGVs and 10 cars. The estimated HRR was $200 \mathrm{MW}$, and the fire caused 11 fatalities.

- The Daegu subway fire (South Korea 2003) caused 196 fatalities and 148 injuries.

- The Frejus tunnel fire (France/Italy 2005) involved 4 HGVs and 3 fire fighting vehicles. The estimated HRR was $200 \mathrm{MW}$, and the fire caused 2 fatalities.

- The I-5 tunnel fire (California, US 2007) involved 33 trucks and a car; and killed three people.

While the fire-safety systems in these fires failed, in the Burnley tunnel fire (Melbourne Australia 2007), the deluge sprinkler system kept the fire under control and helped people safely escape the tunnel. The fire started with a road traffic accident involving four cars and three heavy goods vehicles, but only three people died from the traffic accident not from the fire [6].

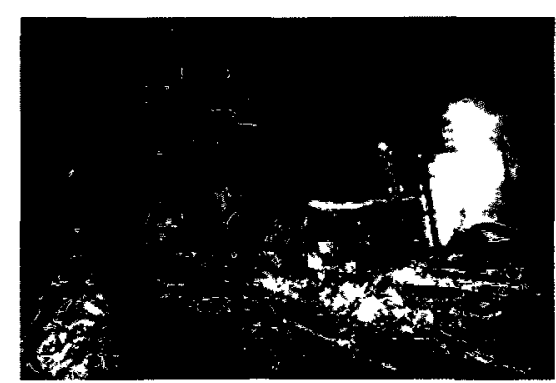

(a) Mont Blanc tunnel fire

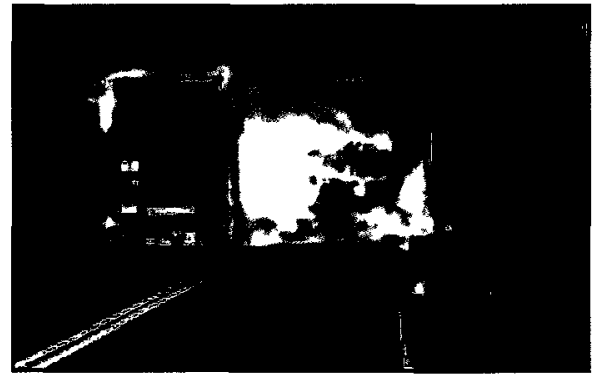

(b) Gottard tunnel fire 


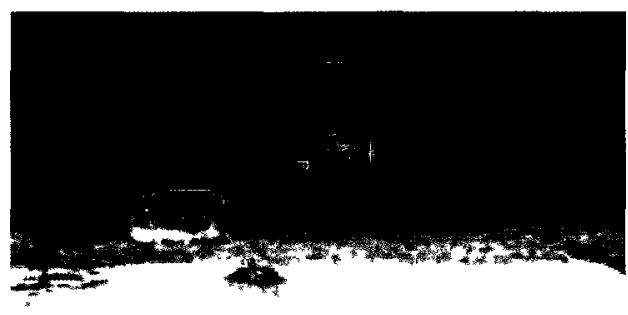

(c) Taurun tunnel fire

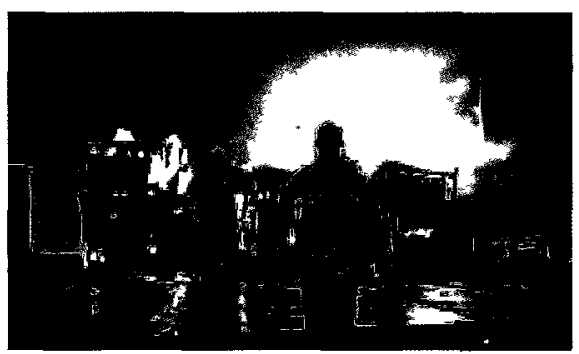

(d) I-5 tunnel fire

Figure 2-1 Tunnel fires (a) Mont Blanc tunnel fire (b) Gottard tunnel fire (c) Taurun tunnel fire (d) 1-5 tunnel fire [7]

\subsubsection{Understanding tunnel fires}

Burning a fuel in an enclosed space, such as a tunnel, results in different fire behaviour than burning it in the open. Once ignited, the fuel in the open sustains burning by radiation feedback from its own flame. If the fuel is in an enclosure, the radiation feedback to the fuel is enhanced, and the burning becomes more vigorous. The enhanced burning of the fuel results in a greater size of flame and higher peak heat release rate than in the open. Carvel et al. [8-10] studied the effects of tunnel confinement on tunnel fires. Using the Bayesian methodology, HRR data from tunnel fires were compared with HRR data from similar fires in the open. It was found that the HRR of tunnel fires was influenced largely by the width of the tunnel.

Compartment fires and tunnel fires are similar in that the fire is affected by the confinement. The burning can be enhanced depending on the degree of confinement, but it can also be restricted by the confinement if there is not sufficient ventilation. If oxygen is readily available or oxygen supplied through an opening in the enclosure is enough, the fire grows, and the burning mechanisms depend mainly on the characteristics of the fuel and the radiation feedback. This 'fuel-controlled' burning is sustained until the air to fuel ratio drops below the stoichiometric air to fuel ratio. If the burning grows and demands 
more air than the enclosure can supply, the rate of heat release is governed by the ventilation. In this ventilation controlled burning, the growth of HRR levels off at a level governed by the ventilation of the enclosure. The maximum HRR in the enclosure is then calculated based on the amount of fresh air supplied.

Tunnel fires are likely to entail 'fuel-controlled' burning, as the fire is under continuous air flow induced by forced ventilation systems often present in tunnels. For instance, a longitudinal ventilation system with an air flow of $3 \mathrm{~m} / \mathrm{s}$ can theoretically feed a fire of up to $390 \mathrm{MW}$ in a tunnel having a cross section area of $50 \mathrm{~m}^{2}$. Carvel et al. $[8,11,12]$ studied the effects of tunnel ventilation on tunnel fire sizes and fire growth, and they suggested estimates of the influence of the longitudinal air flow on HRR of tunnel fires. Ingason [13] pointed out the differences in natural ventilation airflow between a compartment fire and a tunnel fire. The natural ventilation for a compartment fire is governed by the ventilation factor $\left(A_{v} \sqrt{H_{v}}\right)$, while the natural ventilation for a tunnel fire is affected by the fire size, the tunnel slope, the cross-sectional area, length, type of tunnel, and meteorological conditions at the portal.

In a room fire, one can observe the rapid growth of the HRR when the fire quickly spreads to all fuels in the compartment (defined as 'flashover'). However, flashover can hardly occur in tunnel fires because of the different formation of the smoke layer [13]. For a compartment fire, the buoyant hot smoke forms an upper layer, which is called smoke stratification. The radiation from this hot thick upper layer causes all combustible materials to rapidly get involved in fire (i.e. flashover). A buoyant hot smoke layer can 
also be observed in tunnel fires in the early stage when there is no forced ventilation systems activated. However, the hot smoke layer moves along the tunnel length as there is no containment. Eventually, the smoke layer loses heat and buoyancy as it moves along the length of the tunnel, and at some distance from the fire the smoke layer descends down to the tunnel floor.

\subsubsection{Fire safety systems in tunnels}

Ventilation systems are the most commonly used smoke-mitigation systems in tunnels. The use of water-based fixed fire fighting systems (WFFFS), on the other hand, has not been accepted for many years mainly because of a lack of knowledge about the effectiveness of the system as well as some possible secondary effects.

\section{1) Ventilation systems}

Ventilation systems are used to remove contaminants in tunnels during normal operation and to provide safe egress for tunnel users in fire emergencies. Emergency ventilation systems (EVS) are required for long and heavy-traffic tunnels. NFPA (National Fire Protection Association) 502 [14] requires EVS for a tunnel length of 300 meters or greater. In PIARC (World Road Association) report 1999 [15], no specific application criteria are specified. EU (European Union) directive [16] requires EVS when the tunnel is $1000 \mathrm{~m}$ or greater and the traffic flow is more than 2000 vehicles/day.

There are three different mechanical ventilation schemes: longitudinal, semi-transverse and fully-transverse systems. Figure 2-2 shows the different schemes of the EVS. 
- The longitudinal ventilation system, often using ceiling jet fans, blows the hot smoke to the exit portal. Smoke stratification cannot be expected. In unidirectional traffic tunnels, a successful system provides a smoke-free environment upstream of the fire where motorists are likely to be queued due to the fire.

- The transverse ventilation system directs the air movement in the tunnel perpendicular to the traffic direction. Fully-transverse ventilation comprises both a supply and an exhaust system. A semi-transverse ventilation system can be either a supply or an exhaust system. In a fire emergency, dilution by supplying air is not effective so that extraction should be incorporated and maximized for effective smoke control, NFPA 502 [14]. The system is suitable in tunnels with bi-directional traffic where there can be motorists on both sides of the fire. EU guidelines [16] recommend transverse ventilation system for tunnels with more than 2000 vehicles/day and a length greater than $3 \mathrm{~km}$.

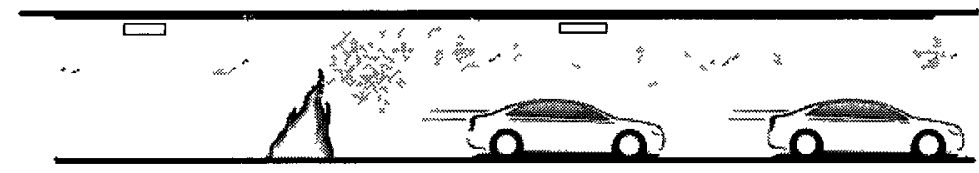

(a) Longitudinal ventilation

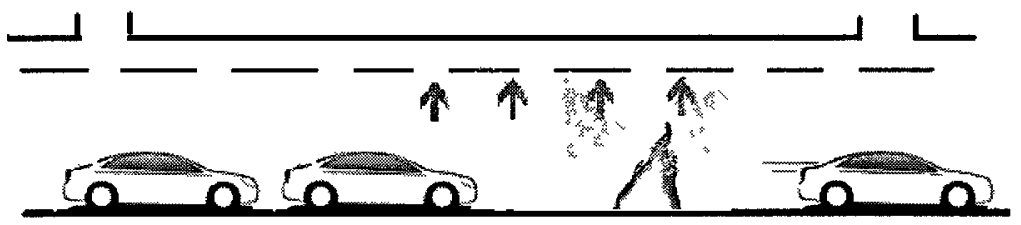

(b) Transverse ventilation

Figure 2-2 Emergency ventilation systems in Tunnels

2) Longitudinal ventilation system and critical velocity

The air flow induced by the longitudinal ventilation system should be strong enough to resist smoke flow in the upstream direction. Smoke flow against the direction of the ventilation air flow is called backlayering. The critical velocity is the minimum air flow velocity required to prevent smoke backlayering. Figure 2-3 shows a plot of tunnel test data for the critical velocity with respect to the HRR of the fire. It shows that the critical 
velocity depends on the HRR. Test data from the Memorial tunnel tests, however, showed that the critical velocity levels off as HRR increases. By introducing a dimensionless velocity $\left(V_{c}^{*}\right)$ and $\operatorname{HRR}\left(Q^{*}\right)$, more adequate models for predicting the critical velocity were suggested by many researchers, Oka and Atkison [17], Wu and Bakar [18], Hwang and Edwards [19, 20]. $\bar{H}$ is the hydraulic tunnel height that is defined as the ratio of 4 times the tunnel cross- sectional area to the tunnel perimeter.

$$
\begin{gathered}
V_{c}^{*}=0.4\left(\frac{Q^{*}}{0.2}\right)^{1 / 3}, \text { for } Q^{*} \leq 0.2 \\
V_{c}^{*}=0.4 \quad, \text { for } Q^{*}>0.2 \\
\text { where } \quad Q^{*}=\frac{Q}{\rho_{o} C_{p} T_{\mathrm{o}} g^{1 / 2} \bar{H}^{5 / 2}} \\
V_{c}^{*}=V_{c} / \sqrt{g \bar{H}}
\end{gathered}
$$

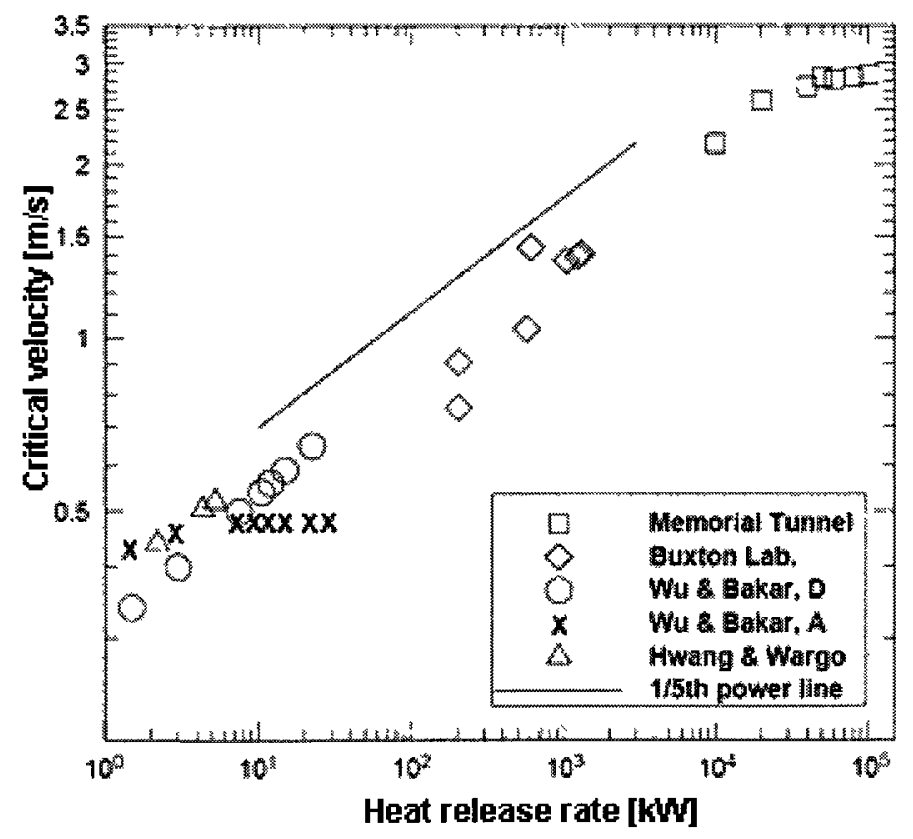

Figure 2-3 Experimental data of critical velocity in tunnel fires [19] 
3) Water-based Fixed Fire Fighting Systems (WFFFS)

For decades, WFFFS have not been used in tunnels in Europe as well as in North America, and the systems are not recommended by the World Road Association (PIARC) or NFPA. In Fact, PIARC listed concerns about the use of water suppression systems in tunnels in the 1999 publication of "Fire and smoke control in road tunnels "[15] as follow;

- The efficiency of the suppression effect is low on tunnel fires which are often shielded inside passenger compartments, engine compartments or HGV trailers.

- Water spray can disturb the smoke layer and break stratification.

- The cooled smoke layer can cover the whole tunnel and lower visibility.

- Superheated steam can hurt people.

- There is a risk of deflagration for petrol fuels.

- Maintenance can be costly.

In addition, the following concerns are also listed in NFPA guidelines [21]

- Water can carry flammable liquids resulting in fire spread.

- False activation of WFFFS could cause accidents.

On the other hand in Japan, tunnel fire mitigation by water suppression systems has been used for nearly four decades, and guidelines for the use of water suppression systems have been developed as part of road tunnel safety facilities. In recent years, there has been broad reconsideration and research on the use of water suppression systems in tunnels. The 2011 edition of NFPA 502 [22] and PIARC [23] now recognize the mitigation effects of fixed fire-fighting systems in road tunnels, which can effectively 
control fires and prevent fire spread by reducing the heat release rate (HRR) and cooling the hot gases.

\section{Japanese guidelines [24]}

Japanese guidelines articulate that the main objectives of the use of WFFFS are (1) to suppress and cool the fire; (2) to prevent fire spread in the direct vicinity of the fire; (3) to protect the tunnel structure and its facilities; and (4) to support firefighting activities. The guidelines state that evacuation is not affected by the system operation (automatic operation) in real incidents. The guidelines require WFFFS in tunnels with a length of $3000 \mathrm{~m}$ or longer and with traffic volumes of 4000 vehicles/day or more. The standard water application rate (density) is $61 / \mathrm{min} / \mathrm{m}^{2}$ with a minimum discharge pressure of 0.34 MPa. One spray section is to be $50 \mathrm{~m}$ in longitudinal length and the water supply must be longer than 40 minutes.

\section{Design guidelines: State of the art}

PIARC [23] recognized the need to adopt water suppression system in the recent publication of "Road tunnels: an assessment of fixed fire fighting systems". In the document, impacts of WFFFS on tunnel safety are discussed and information about types of systems available is provided. It states that the system can be used to slow fire development and to reduce or completely prevent fire spread, with the aim of improving conditions for escape and rescue. However, the effectiveness of the system must be verified on a "project-specific basis". They recommend conducting a feasibility study, risk analysis, and cost-benefit analysis. 
The NFPA 502 standard has also evolved and the current edition is more positive about the use of water suppression. The 2008 edition of NFPA 502 [14] reconsidered the incorporation of WFFFS in road tunnels in Annex E, and it responds to the concerns expressed in the past. It recognises that the purpose of the system is not to extinguish the fire but to prevent fire spread. Steam hazard can be avoided by proper design to ensure fast activation and sufficient cooling. Regarding the concerns of de-stratification and low visibility, it says smoke does not usually form a layer at the top of the tunnel but quickly fills the cross-section even under normal conditions.

In the 2011 edition of NFPA 502 [22], a new chapter on active fire protection systems has been added (Chapter 9: Water-based Fire-Fighting System (WFFS)), although detailed discussion about WFFFS remains in the annex. In the chapter, it states that "when WFFS are installed in road tunnels, WFFFS shall be installed, inspected, and maintained..." Design objectives of WFFS are defined to slow, stop, or reverse the rate of fire growth and to mitigate the impact of fire. The aims are (1) to improve tenability for tunnel occupants during a fire and aid evacuation; (2) to enhance the ability of first responders to engage in manual fire fighting; and (3) to protect the major structural elements of the tunnel.

This means that WFFFS can be used not only for protecting the tunnel infrastructure but also for life safety. Recognising the importance of early activation of the system is great progress since the statement made in 1999 PIARC [15] that "sprinklers or deluge systems can be installed in special circumstance - if they are installed - must not be activated until all occupants have been evacuated". 
At the moment, regulations and guidance for WFFFS in tunnels are performance-based, which requires engineering analysis of the system to show an acceptable level of performance based on full-scale tests $[25,26]$.

\subsection{Severity of Tunnel Fires}

In this section, HRR and temperature measurements from previous studies are reviewed for different types of tunnel fires, and HRR measurement methods used in the previous tunnel studies are also reviewed.

\subsubsection{Tenability criteria}

Temperature, radiation and toxic gas levels should be considered for the safe evacuation of people, ease of fire fighting by a fire brigade, as well as protection of the tunnel structure. In particular, one of the main concerns during tunnel fires is visibility reduction.

For safe evacuation of occupants in tunnels, the following hazardous condition criteria are proposed [27];

- Gas temperature $\leq 60^{\circ} \mathrm{C}$

- Radiation flux $\leq 2 \mathrm{~kW} / \mathrm{m}^{2}$

- Visibility $\geq 10 \mathrm{~m}$

- Fractional Incapacitation dose $\left(\mathrm{FI}_{\mathrm{tot}}\right)$, which is calculated by the human incapacitation model developed by Purser [28] $<1$

In a moist environment, a tenable temperature limit is about $50^{\circ} \mathrm{C}[28]$

Suggested criteria for the safety of firefighters in tunnels are [27] 
- Gas temperature $\leq 100^{\circ} \mathrm{C}$

- Radiation flux $<5 \mathrm{~kW} / \mathrm{m}^{2}$

For structural protection, the maximum temperature of the hot gas near the ceiling can be a direct threat. Explosive spalling may start after a concrete temperature reaches about $150^{\circ} \mathrm{C}$ to $200^{\circ} \mathrm{C}[15]$.

\subsubsection{HRR of tunnel fires}

Three types of fire scenarios are encountered in road tunnel fires;

- Passenger vehicle fires caused by a collision, or by vehicle failures.

- Heavy good vehicle (HGV) fires, which develop quickly and release enormous heat depending on the materials in the trailers.

- A liquid pool fire caused by fuel leaks from a vehicle or by a collision. The fire develops very quickly, and the fire releases huge amounts of heat if it involves a fuel tanker.

Table 2-1 shows the HRR suggested by various studies and standards. The range of fire sizes can be classified into passenger vehicle fire size (2.5 MW-8 MW), van or bus fires (15-20 MW), and HGV or tanker fires (20-600 MW). However, to properly asses the severity of a fire, it is also necessary to know its growth rate. 
Table 2-1 HRR suggested by various studies and standards for tunnel fires [5]

\begin{tabular}{|c|c|c|c|c|c|c|c|c|c|}
\hline \multirow{4}{*}{ Fire ategery } & \multicolumn{9}{|c|}{ Hest Release Rates [MW] } \\
\hline & \multicolumn{5}{|c|}{ Rerommandations by institutions ${ }^{\prime \prime}$} & \multicolumn{3}{|c|}{ Fire lests } & \multirow{3}{*}{$\begin{array}{c}\text { Estimates from } \\
\text { largz } \\
\text { accidents }\end{array}$} \\
\hline & \multicolumn{2}{|c|}{ PLARC } & \multirow{2}{*}{$\begin{array}{c}\text { RABT } \\
\text { (D) } \\
1994^{*}\end{array}$} & \multirow{2}{*}{$\begin{array}{l}\text { CETC (7) } \\
\text { Proposals } \\
\text { 10060109? }\end{array}$} & \multirow{2}{*}{$\begin{array}{l}\text { SFPA 502 } \\
\text { [USA) } \\
1958\end{array}$} & \multicolumn{2}{|c|}{$\begin{array}{l}\text { EUREKA } \\
\text { research: }\end{array}$} & \multirow{2}{*}{$\begin{array}{l}\text { Memorial: } \\
\text { adopted } \\
\text { fire sizes }\end{array}$} & \\
\hline & 1087 & 1909 & & & & $\begin{array}{c}\text { Ieal } \\
\text { fires }\end{array}$ & $\begin{array}{l}\text { Ieport } \\
\text { Ingarsan }\end{array}$ & & \\
\hline Passenger car & 5 & \multirow{5}{*}{$25-8$} & - & 35 & 5 & $1.5-24$ & \multirow{5}{*}{250} & - & \multirow{5}{*}{$3-10$} \\
\hline Passenger car (lasge) & - & & - & 5 & $=$ & - & & - & \\
\hline passenger yaw (plastic) & - & & - & - & -. & $5-6^{\frac{x^{2}}{2}}$ & & - & \\
\hline $1-2$ pssegnger cars & - & & $3-10$ & - & $\overline{-}$ & - & & - & \\
\hline $2-\frac{3}{2}$ passengar cars & - & & - & 8 & $\overline{-}$ & $\overline{-}$ & & $\overline{-}$ & \\
\hline $1 \mathrm{van}$ & - & 15 & - & 15 & $\overline{-}$ & - & $\overline{-}$ & - & - \\
\hline ipublic bows & - & 20 & $\overline{-}$ & $\overline{-}$ & $\overline{-}$ & $29-34^{38}$ & $29-34$ & $\overline{-}$ & 36 \\
\hline $\begin{array}{l}1 \text { bus or } 1 \text { lorry (fregat of lory got } \\
\text { bsardous) }\end{array}$ & 30 & - & $20-30$ & 20 & 20 & - & - & 20 & - \\
\hline heary goods vehicle & - & - & - & 30 & - & $100-130^{2}$ & 128 & - & 15060 \\
\hline petroliggsoling tanker with o leat & 100 & 100 & $50-100$ & 30 & 100 & - & $20-100$ & $\overline{-}$ & $120-300$ \\
\hline fammoble spill of 4 the bers & - & - & - & - & - & - & - & 50 & - \\
\hline $\begin{array}{l}\text { Armmoble spillof 800 liters or azzardous } \\
\text { Enaterial }\end{array}$ & - & - & - & - & - & - & - & 100 & - \\
\hline 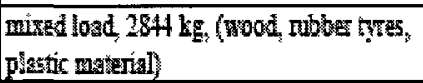 & - & - & - & - & - & $15-17^{3 ;}$ & - & - & - \\
\hline cariage & - & - & $\overline{-}$ & -- & - & $\overline{-}$ & $12-47$ & $\overline{-}$ & $3-100$ \\
\hline
\end{tabular}

1) Vehicle fires

There is a great deal of HRR data available for passenger vehicles. Mangs et. al. [29, 30] measured the HRR of passenger cars under a hood calorimeter. They found that the peak HRR of a burning car was about $1.5 \sim 2 \mathrm{MW}$, and the fire developed slowly taking more than 10 min to reach the maximum HRR. Numerous HRR measurements of vehicle fires were made in a closed car parks project [31-33]. It was found that the fire intensity from a vehicle fire is about $4 \mathrm{MW}$; Modern cars with more combustible body types were found to have greater fire intensity reaching over $8 \mathrm{MW}$ for one car. Fire spread to adjacent cars was observed via external plastic and tires between 12 to $30 \mathrm{~min}$ [31-33].

As discussed earlier, burning of cars in a tunnel might be different than in the open or in car parks due to the impact of the confinement and the air flow in the enclosed space. 
Real vehicles were tested in the Repparfjord tunnel $[34,35]$, which had a relatively small cross section of approximately $25 \mathrm{~m}^{2}$. HRR from a passenger car and a school bus were measured under natural ventilation. HRRs were calculated based on convective heat flow; and $\mathrm{CO}$ and $\mathrm{CO}_{2}$ measurements were made on both sides of the fire [34]. They found that the peak HRR of a vehicle was about $6 \mathrm{MW}$ about $8 \mathrm{~min}$ after ignition for a passenger car. The peak HRR from a school bus fire was about $30 \mathrm{MW} 8 \mathrm{~min}$ after ignition.

More intense HRR from passenger vehicle fires were measured in the $2^{\text {nd }}$ Benelux tunnel having a tunnel cross section of $50 \mathrm{~m}^{2}$. The HRR was calculated based on the mass loss rate of the fuel, assuming a heat content of cars of $25 \mathrm{MJ} / \mathrm{kg}$. Under natural ventilation conditions, they measured a peak HRR of about $13 \mathrm{MW} 11$ min after ignition.

\section{2) Heavy Good Vehicle fires}

As the HRR of HGV fires depends mainly on the materials in the trailers, many studies has been carried out using a mock-up truck trailer loaded with different types of materials. Figure 2-4 shows the measured HRR from these previous studies. The measured intensity of $\mathrm{HGV}$ fires varies from $10 \mathrm{MW}$ to $200 \mathrm{MW}$ depending mainly on the energy content of the goods being transported as well as on the longitudinal air velocity in the tunnel.

In a project called EUREKA $499[35,36]$ a test was conducted using a real trailer with a mixed furniture load with a total heat content of $87 \mathrm{GJ}$, under varying longitudinal ventilations in the Repparfjord tunnel. The $\mathrm{HRR}$ was calculated using the $\mathrm{CO}$ and $\mathrm{CO}_{2}$ 
ratio technique (see Chapter 3)). Due to the relatively high longitudinal air flow of $5 \sim 6$ $\mathrm{m} / \mathrm{s}$ in the initial stage, the fire developed quickly reaching a peak HRR of $120 \mathrm{MW}$ at 13.5 min (see Figure 2-4). Low severity HGV fires with HRRs up to $20 \mathrm{MW}$ were attained in fire tests of a shielded load of $10 \mathrm{GJ}$ of wood pallets in the second Benelux tunnel [37-39]. A peak HRR of $16 \mathrm{MW}$ was reported in EUREKA 499 for the Repparfjord tunnel test of a simulated truck load of 65 GJ of wood cribs, rubber tyres and plastic materials under natural ventilation.

High severity HGV fires that produce much larger HRR than those suggested by PIARC and NFPA guidelines (given in the range of 20 30 MW) were realized in the Runehamar tunnel (about $40 \mathrm{~m}^{2}$ cross section area) tests. Four HGV trailer mock-ups that consisted of a steel rack system loaded with different burning goods were tested under longitudinal ventilation of 2.9-3.4 m/s [40]. Peak HRRs in the range of $66-202 \mathrm{MW}$ were measured depending on the burning goods. The time to obtain a peak HRR was found to be in the range of 7-18.5 min after ignition. The growth rate was about $25 \mathrm{MW} / \mathrm{min}$ for all tests (i.e. only taking account of the growth phase exempting the early stage of smouldering). The method used to estimate the HRR was $\mathrm{O}_{2}$ calorimetry measuring the flow and oxygen profiles over a cross section downstream from the fire. The test results show that a truck load fire can be as severe as an oil tanker fire. 


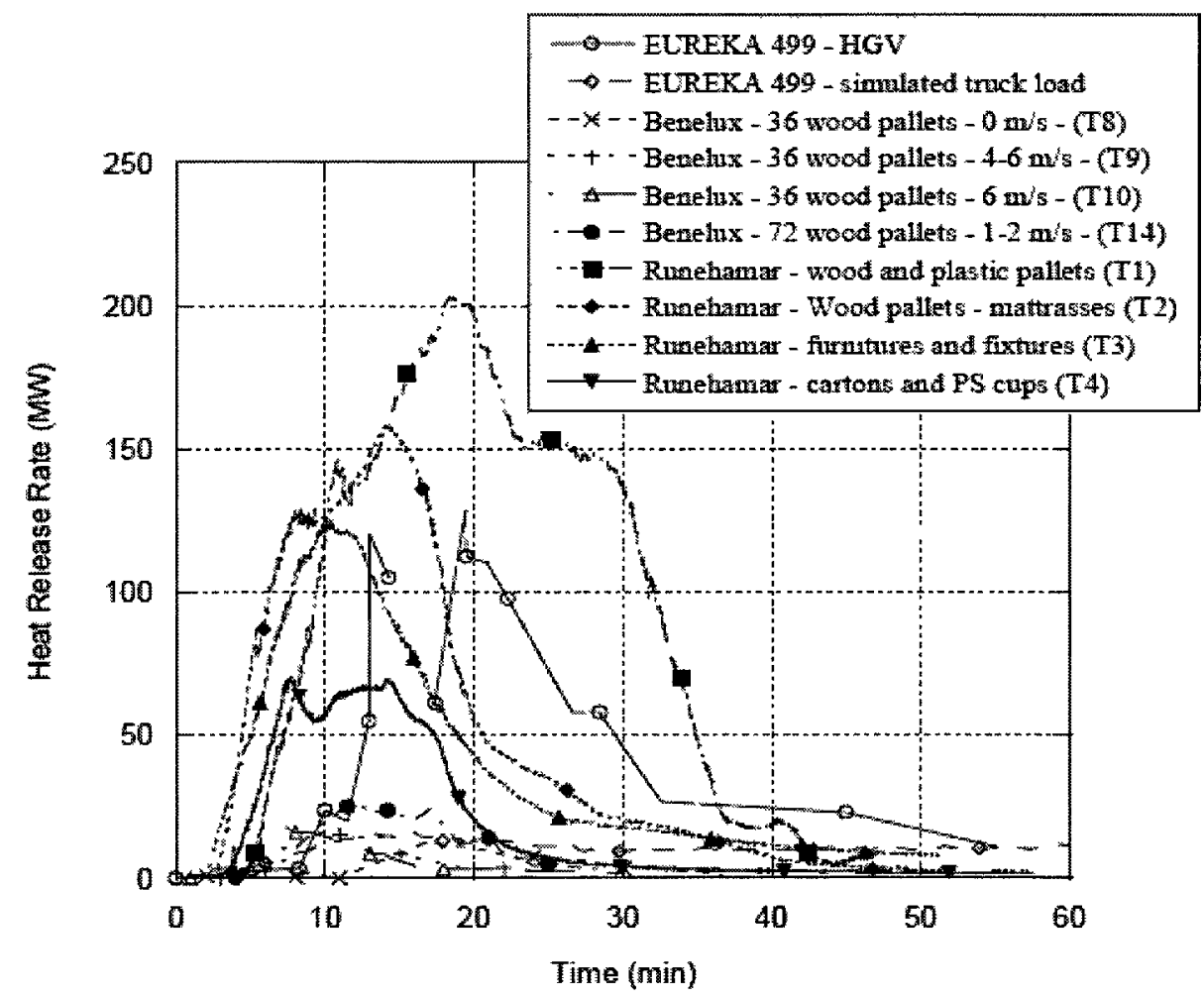

Figure 2-4 HRR for HGV fires [41]

3) Effect of longitudinal airflows on tunnel fire development

The growth rate of the fire depends on the longitudinal air flow in the tunnel. Carvel et al. $[8,11,12,42]$ studied the influence of the longitudinal air flow on HRR of tunnel fires. They estimated using the Bayesian methodology that $3 \mathrm{~m} / \mathrm{s}$ air flow increases the fire growth rate by a factor of 10 and the peak HRR by a factor of 5 compared to HRR in absence of forced air flow. For $6 \mathrm{~m} / \mathrm{s}$ airflow, they suggested that it increases the peak HRR by a factor of 8 and the growth rate by a factor of 20 .

However, the actual influence of the longitudinal air flow on fires that are shielded in a vehicle body or cargo trailer can be less than the estimation by Carvel et al. In the second Benelux tests $[37,39,43]$, the influence of longitudinal ventilation of $6 \mathrm{~m} / \mathrm{s}$ and $0 \mathrm{~m} / \mathrm{s}$ on 
the HRR of a vehicle fire was examined. The test results disagree with the estimation by Carvel. The study concluded that the burning rate of a passenger vehicle increases with the increase in air velocity; however, the effect depends on the type of combustibles and the degree to which ventilation actually reaches the fire.

The influence of ventilation on $\mathrm{HGV}$ fires of closed loads were examined in the second Benelux tunnel. A simulated HGV with shielded loads (with the back of the simulated cargo was open) of wood pallets of $10 \mathrm{GJ}$ was tested under three different air flows of 0 , $4 \sim 5$, and $6 \mathrm{~m} / \mathrm{s}$. As shown in Figure 2-5, the peak HRR was $13.5 \mathrm{MW}$ without ventilation, $19 \mathrm{MW}$ with $4 \sim 5 \mathrm{~m} / \mathrm{s}$ ventilation and $16.5 \mathrm{MW}$ with $6 \mathrm{~m} / \mathrm{s}$. The test results show that the fire growth rate with ventilation was approximately $4 \sim 5$ times faster than the fire growth rate without ventilation. The ventilation effect is significant on fire growth during the initial stage of the fire.

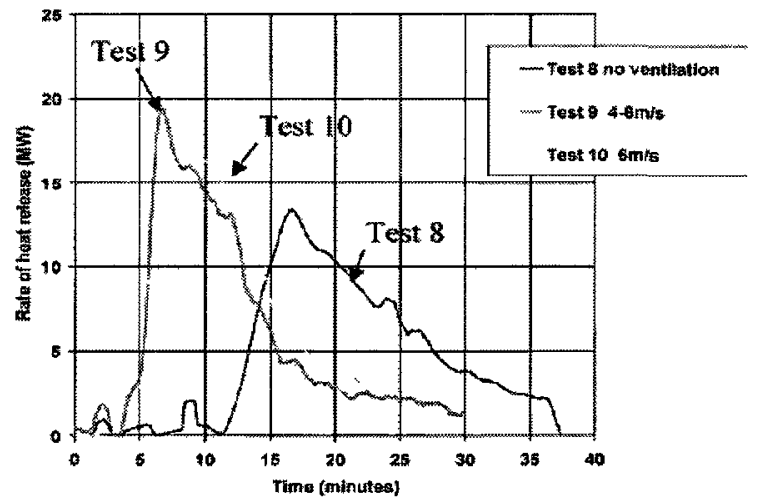

Figure 2-5 Fire development for a simulated HGV under different ventilation conditions [37] A recent study by Carvel [44] found that the fire growth rate resulted from an air velocity of $2.5 \mathrm{~m} / \mathrm{s}-3 \mathrm{~m} / \mathrm{s}$ was higher than the growth rates resulted from air velocities of $1 \mathrm{~m} / \mathrm{s}$ 
and $6 \mathrm{~m} / \mathrm{s}$. An air velocity of $3 \mathrm{~m} / \mathrm{s}$ is, ironically, the critical velocity of longitudinal ventilation required to prevent backlayering of smoke.

\subsubsection{Temperatures}

Temperature development of the fire and the spread of hot gases in the tunnel is important in assessing thermal impact on the tunnel structure as well as in assessing tenability conditions in tunnels.

1) The maximum ceiling temperature in tunnels

The maximum temperature of the hot gas near the ceiling can be a direct threat to the tunnel structure. After the concrete temperature reaches about $220^{\circ} \mathrm{C}$ to $245^{\circ} \mathrm{C}$, explosive spalling may occur [45]. Figure 2-6 shows the maximum temperature in the vicinity of fires measured from the EUREKA 499 tests. In most fire scenarios, the tunnel structure was exposed to temperatures greater than $200^{\circ} \mathrm{C}$. Temperature in the vicinity of the fire reached levels well above $500^{\circ} \mathrm{C}$ in most cases other than passenger vehicle fires. The $\mathrm{HGV}$ fires showed temperatures as high as $1000^{\circ} \mathrm{C}$ near the fire. 


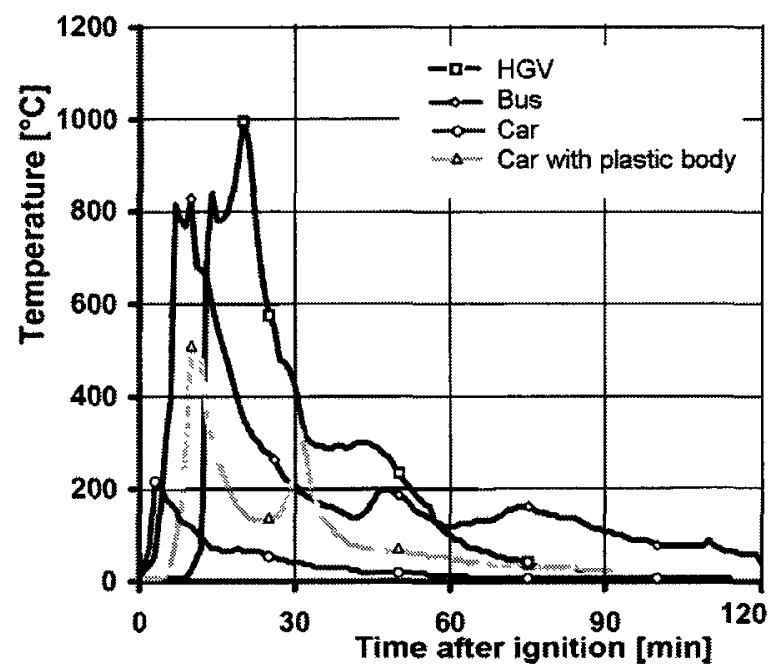

Figure 2-6 Comparison of temperature-time curves for different type of fires in tunnels [46] The high severity HGV fires tested in the Runehamar tunnel tests (T2, T3, T4) [40] reached temperatures up to $1300^{\circ} \mathrm{C}$ at the fire location $(0 \mathrm{~m})$, as shown in Figure 2-7. The flames were very large, reaching $10 \mathrm{~m}$ downstream of the fire $(+10 \mathrm{~m})$ when the fire size was $200 \mathrm{MW}$ (test T1).

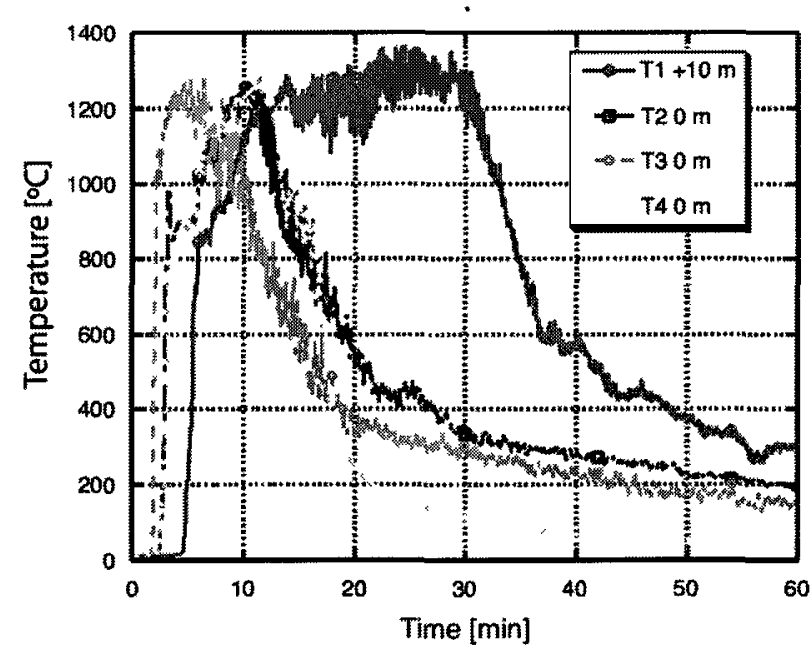

Figure 2-7 Gas temperature measured near the fire from high severity HGV fires [40] 
2) Characteristics of smoke spread under natural ventilation

Spread of smoke in a tunnel under natural ventilation can be characterized by the following two aspects;

- Buoyant hot smoke rises and spreads horizontally in two opposite directions along the length of the tunnel. Thus, the smoke flow in the tunnel can be simply analysed in two-dimensions.

- Accumulation of smoke would not likely occur in the tunnel as smoke moves channelling under the tunnel ceiling. The stratified smoke layer loses its heat to the tunnel environment, and it finally drops and fills the tunnel.

In the EUREKA 499 tests, the propagation of smoke and development of temperatures along the length of the tunnel were measured in fire tests of passenger vehicles, a bus and a HGV [46]. These tests were conducted under natural ventilation (measured air velocity between $0.3 \sim 0.5 \mathrm{~m} / \mathrm{s}$ ). Figure 2-8 shows the maximum gas temperatures in the ceiling area of the tunnel during tests. Under natural ventilation, the smoke traveled uniformly in both directions. The temperature dropped quickly within the first $20 \mathrm{~m}$ from the fire. At $50 \mathrm{~m}$ away from the fire, the temperature during the passenger vehicle fires dropped to a value between $80 \sim 120^{\circ} \mathrm{C}$. During the bus fire, the temperature dropped to about $300^{\circ} \mathrm{C}$ at $50 \mathrm{~m}$ away from the fire. For the HGV truck fire, the temperature at $50 \mathrm{~m}$ away from the fire was still high at about $600^{\circ} \mathrm{C}$. 


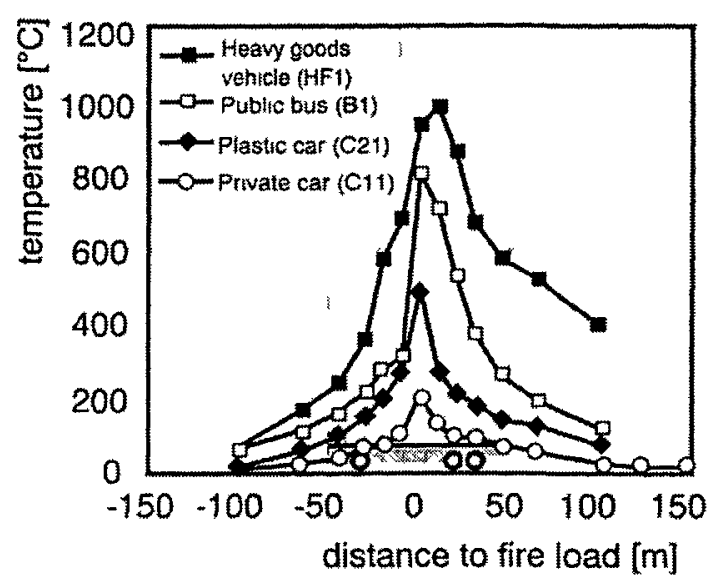

Figure 2-8 Temperature propagation along the tunnel for different vehicle fires [46]

In the second Benelux tests [39], detailed analysis of smoke stratification was conducted along the length of the tunnel to assess tenability. Under natural ventilation, the observed stratification provided a smoke free and safe area between $30 \mathrm{~m}$ and $100 \mathrm{~m}$ downstream of the fire up to 20 min during the passenger vehicle fire (about $5 \mathrm{MW}$ ) as well as for the simulated HGV fire (about $13 \mathrm{MW}$ ) size. Note that the hazards should be analyzed by considering temperature and the associated radiant heat, reduction of visibility, as well as gas concentrations. Smoke control in long tunnels should not, however, rely on stratification since the stratification breaks up, and the smoke layer descends and mixes with the lower layer.

3) Smoke spread with a ventilation system

The spread of heat and smoke in the tunnel is affected to a large extent by the ventilation conditions. A comprehensive study has been done in the Memorial tunnel in West Virginia, USA [47]. This tunnel is approximately $9 \mathrm{~m}$ wide, $853 \mathrm{~m}$ long and has a $3.2 \%$ up-grade from the south to the north. A number of full-scale tests were conducted in the 
tunnel with pool fires ranging from $10 \mathrm{MW}$ to $100 \mathrm{MW}$. Full transverse, partial transverse, longitudinal and natural ventilation methods were investigated.

The study demonstrated that for effective smoke control by transverse ventilation systems a longitudinal airflow should be induced in the tunnel [14]. The smoke and heat movement were affected by the system extraction rate and location of the fire. The ability of the transverse system in managing smoke and facilitating two way traffic operations was enhanced with additional single-point extraction openings or oversized ports at a location close to the fire $[48,49]$.

Figure 2-9 shows the steady-state temperature conditions from a $20-\mathrm{MW}$ fire under a transverse ventilation system with $70 \mathrm{cfm} / \mathrm{lf}\left(0.1 \mathrm{~m}^{3} / \mathrm{s} / \mathrm{m}\right)$ exhaust ventilation rate. The system extracted smoke along the ceiling, which is effective in preventing spread along the length of the tunnel.

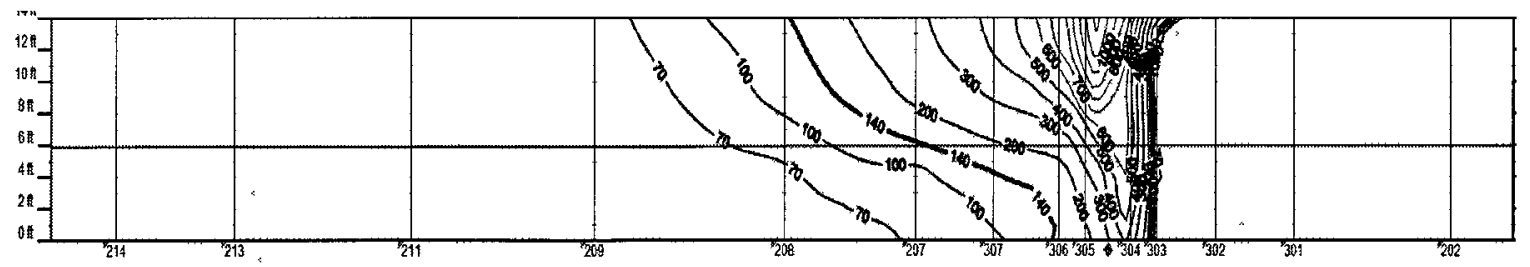

Figure 2-9 Temperature $\left({ }^{\circ} \mathrm{F}\right)$ profile with transverse ventilation for a fire size of $20 \mathrm{MW}$ [47]

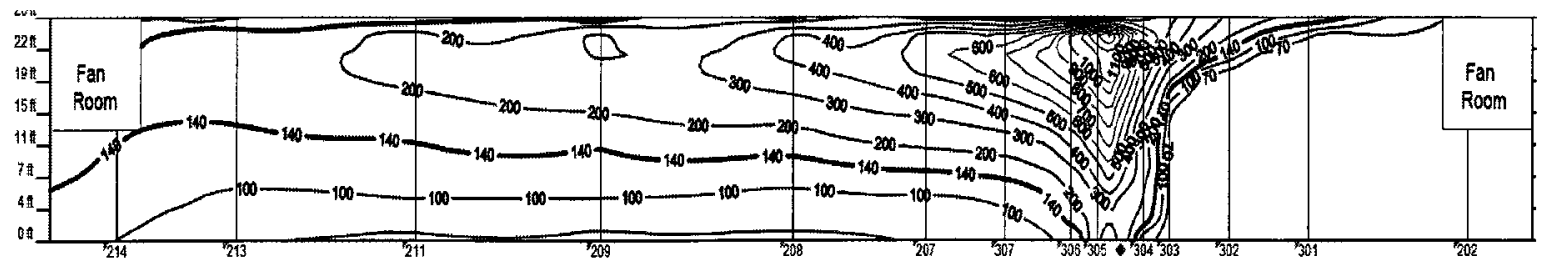

Figure 2-10 Temperature $\left({ }^{\circ} \mathrm{F}\right)$ profile with longitudinal ventilation for a fire size of $50 \mathrm{MW}$ [47]

Figure 2-10 shows the temperature profile along the tunnel for a fire size of $50 \mathrm{MW}$ under longitudinal ventilation condition. The longitudinal ventilation completely 
destroyed the stratification and lowered visibility downstream of the fire. The temperature downstream of the fire at a height of $1.5 \mathrm{~m}$ was about $38^{\circ} \mathrm{C}\left(100^{\circ} \mathrm{F}\right)$. Backlayering was controlled in this test. The study concluded that, for a fire with HRR not exceeding $100 \mathrm{MW}$, a longitudinal air flow velocity of $3 \mathrm{~m} / \mathrm{s}$ (the critical velocity) is sufficient to prevent backlayering in a tunnel with a slope lower than $4 \%$ [50].

In the Runehamar tunnel tests, the smoke spread from high severity HGV fires greater than $100 \mathrm{MW}$ were tested under a longitudinal air flow of $3 \mathrm{~m} / \mathrm{s}$. High temperatures were measured in these tests not only in the downstream area but also in the upstream area. Figure 2-11 shows temperature results measured in the test (T1) where the HGV fire released a peak HRR of $200 \mathrm{MW}$ (time to peak was about $20 \mathrm{~min}$ ). Despite the presence of the longitudinal ventilation of $3 \mathrm{~m} / \mathrm{s}$ (the critical velocity), the temperature $70 \mathrm{~m}-100$ $\mathrm{m}$ upstream of the fire reached values up to $100^{\circ} \mathrm{C}$. The conditions downstream of the fire were more severe as flames reached almost $70 \mathrm{~m}$ downstream, and the temperature $460 \mathrm{~m}$ downstream of the fire was greater than $100^{\circ} \mathrm{C}$ during the entire duration of the fire [40]. 

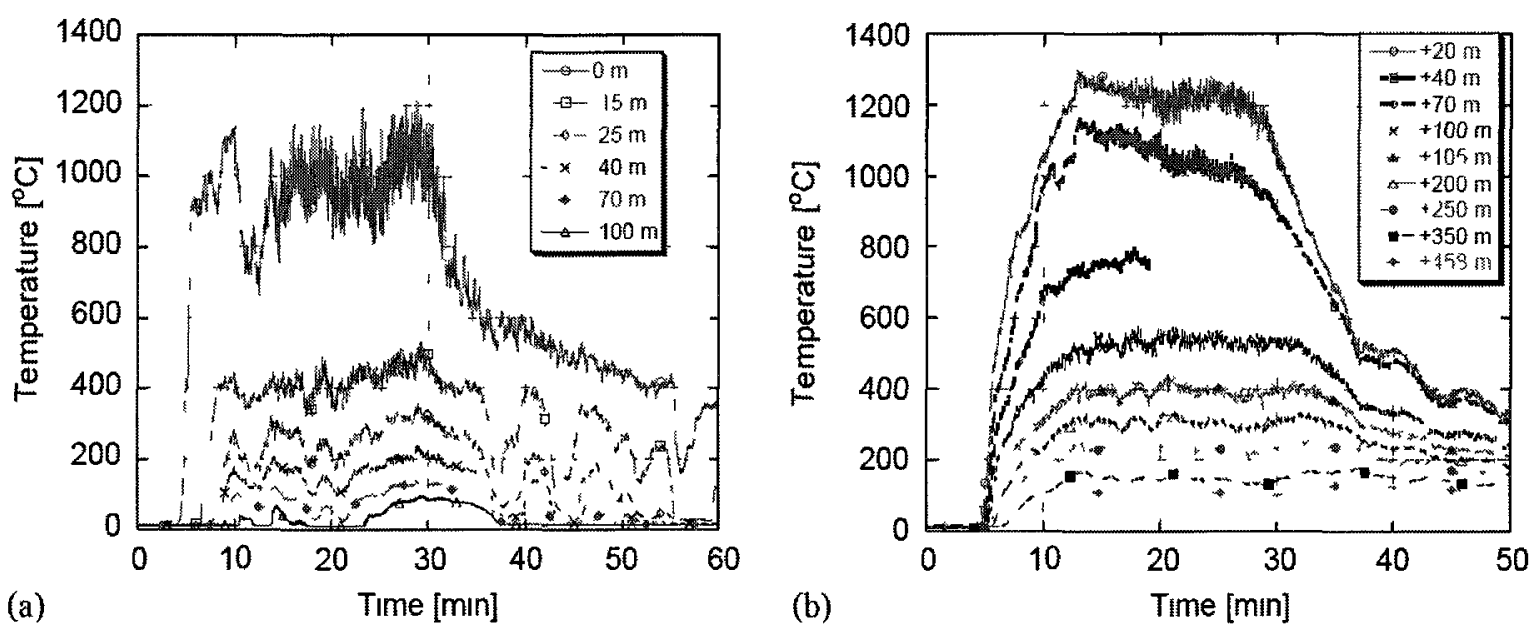

Figure 2-11 Gas temperature measured (a) upstream of the fire (b) downstream of the fire [40]

2.2.4. Measurement of HRR of tunnel fires

1) Estimations based on burnıng rates

The heat release rate (Q) of a gas or liquid fuel fire can be simply calculated using Eq 4 assuming a constant effective heat of combustion $\left(H_{c h}\right)$ of the fuel.

$$
Q=H_{c h} \dot{m}_{b}
$$

Eq 4

The calculation gives a fair estimation of the HRR, but has some limitations. As the burning rate $\left(\dot{m}_{b}\right)$ is affected by radiation heat feedback from the flame and the temperature of the environment, the heat of combustion also varies depending on temperature and availability of oxygen (equivalence ratio). Moreover, it is often difficult to quantify the heat release rate of charring materials or complex fuels, like a vehicle, whose heat of combustion or burning rates are unknown. In this regard, more accurate ways of HRR measurements are often used in fire research. 


\section{2) Oxygen calorimetry}

Oxygen consumption calorimetry is often employed as the most accurate and reliable method for measuring the HRR of fires. The concept of oxygen consumption calorimetry is that for any burning item, the same amount of heat is released for each unit of oxygen consumed in the combustion reaction [51]. This method has been used to measure the HRR of fires up to $10 \mathrm{MW}$ in many different applications [52] from small-scale calorimeters $[53,54]$ to single-item burning tests, room fire tests and large scale experiments [55]. In order to calculate the HRR using this method, all combustion products must be collected, and the mass flow rate of smoke and $\mathrm{O}_{2}$ concentration must be measured. Generally, an exhaust fan collects all combustion products in a large hood [56], and all necessary measurements are taken in one instrumentation station in the duct system.

In tunnel fires, similar principles are applied. Ingason [57] measured the HRR of vehicle (train, bus and HGV) fires and wood crib fires under natural ventilation conditions. Data measurements were made with a dense net of thermocouples and bi-directional probes covering the cross section about $30 \mathrm{~m}$ away from the fire area, at both sides of the tunnel. However, the flow conditions inside the tunnel required more measuring probes to obtain accurate HRR since the flow was greatly stratified. Another problem was smoke reentrained into the plume, which degraded the accuracy of oxygen concentration. However, Ingason [57] concluded that the estimation is reasonable based on the comparison of the time integrated HRR $\left(\int \mathrm{Q}\right)$ and the theoretical fuel energy $(\mathrm{E})$. 
Under longitudinal ventilation, a more accurate estimation was possible due to small variations of flow velocity and temperature in a cross section of a tunnel. HRRs were successfully measured for HGV fires with different fuel loads up to $200 \mathrm{MW}$ in the Runehamar tunnel tests [40]. With the longitudinal air flow, one station was used for the data measurements, $458 \mathrm{~m}$ downstream of the fire. The time integrated HRRs ( $\mathrm{Q}$ ) were very close to the theoretical fuel energy values (E); however, the integrated HRR was slightly higher by about $4 \%$ than the theoretical fuel energy values. Uncertainty analysis carried out showed that the contributions of uncertainty of HRR mainly came from the mass flow rate calculations $(6.7 \%)$ and the oxygen measurements $(2.1 \%)$.

\section{3) $\mathrm{CO} / \mathrm{CO}_{2}$ ratio technique}

Tewarson [58] developed a semi-empirical correlation (Eq 5) which relates the rate of heat release to the production of $\mathrm{CO}$ and $\mathrm{CO}_{2}$. The method requires most measurements necessary for $\mathrm{O}_{2}$ calorimetry, such as volumetric flow rate and temperature of gases as well as concentrations of $\mathrm{CO}$ and $\mathrm{CO}_{2}$, except oxygen concentrations. The advantage of this method is that it is easier to measure $\mathrm{CO}$ and $\mathrm{CO}_{2}$ because their spans are much broader than $\mathrm{O}_{2}$. However, the method uses net heat of combustion of fuel per unit mass of $\mathrm{CO}\left(\frac{H_{C}}{k_{C O}}\right)$ and net heat of combustion of fuel per unit mass of $\mathrm{CO}_{2}\left(\frac{H_{C}}{k_{C O 2}}\right)$ which vary depending on the fuel type.

$$
Q=\dot{m}_{C O 2}\left(\frac{H_{C}}{k_{C O 2}}\right)+\dot{m}_{C O}\left(\frac{H_{C}}{k_{C O}}-H_{C O}\right)
$$

Using the method, Grant and Drysdale [36] estimated the HRR from large-scale tunnel fires conducted in the Repparfjord tunnel. Fuels involved in the fire were an HGV lorry 
with a mixed load of fuels. Under varying longitudinal ventilations of $2-7 \mathrm{~m} / \mathrm{s}$, the HRR was calculated using data measured at $30 \mathrm{~m}$ and $100 \mathrm{~m}$ downstream of the fire. The mean values of combustion parameters for wood cribs, PVC and kerosene suggested by Tewarson [58] were used to calculate the HRR of the mixed load of HGV fire. The HRR estimation was found to be reasonable.

4) Convective heat calculations

A simple check of HRR can be made by calculating the convective heat flow of the smoke and air mixture transported by longitudinal ventilation. The convective heat flow gradually decreases further downstream of the fire due to heat losses to the bounding walls and ceiling of the tunnel. The convective heat $\left(Q_{c}\right)$ can be calculated using the average temperature rise $\left(\Delta \mathrm{T}_{\text {avg }}\right)$ of smoke across the cross section and the mass flow rate of smoke (m) data obtained downstream of the fire as shown in Eq 6.

$$
Q_{c}=C_{p} \dot{\mathrm{m}} \Delta T_{a v g}
$$

In the second Benelux tests [39], the HRR was calculated by measuring the fuel mass loss. The convective heat flows were also calculated to check HRR. The convective heat flow was found to be about 0.8 and 0.5 of the calculated HRR for no-ventilation and for $2 \mathrm{~m} / \mathrm{s}$ ventilation, respectively. However, after the activation of the suppression system, it was difficult to predict or estimate the HRR since the convective heat flow was found to drop significantly due to the cooling effect of suppression. 
5) HRR measurement during suppression

The oxygen consumption calorimetry has been used in many studies even for suppression tests. In some tunnel suppression tests [59], oxygen calorimetry was used with no adjustment for the use of the suppression system. Due to the large quantities of water vapour generated by the suppression system, the calculations of HRR by oxygen calorimetry should be re-examined.

Dlugogorski [60] derived a formula taking into account all sources of water vapour, including incoming air, combustion reaction, and evaporation due to suppression. Two other simplified formulas were also derived; one neglecting all humidity, the other considering only the humidity of incoming air. These sets of calculations were compared for different conditions of water vapour (See Figure 2-12). It was concluded that both simplified equations yielded HRR with no significant error for $7 \%$ or less water vapour. When the water vapour conditions were greater than $7 \%$, measurement of water vapour is required, and the full equation should be used.

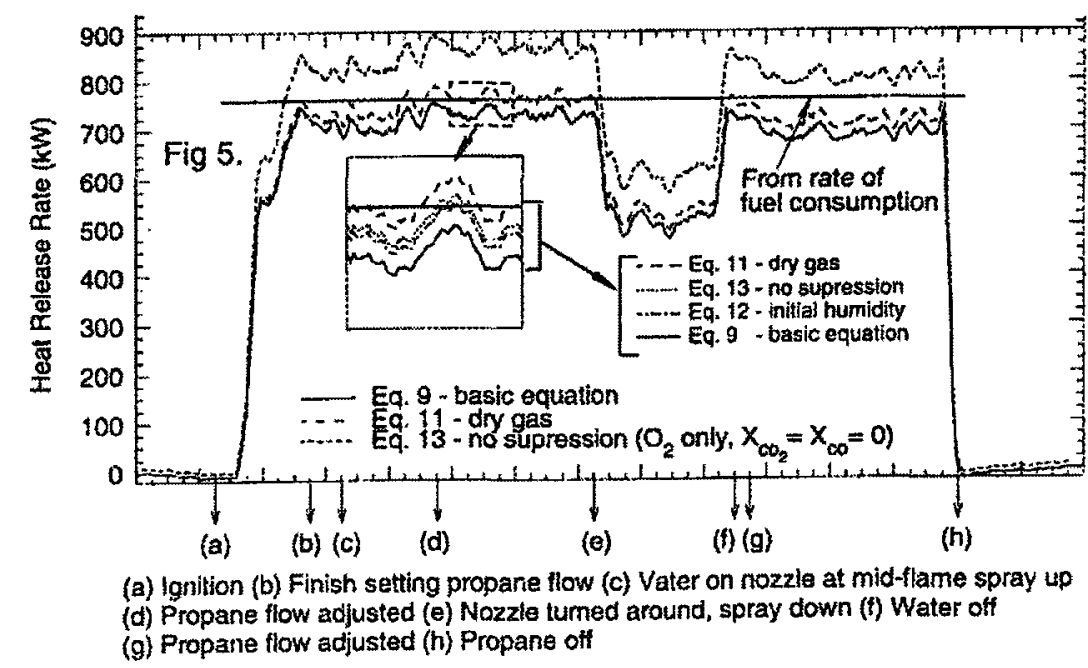

Figure 2-12 Comparisons of HRR calculations [60] 
Bing et al. [61] modified the formula to calculate HRR by oxygen calorimetry when conducting water mist experiments right under a small-scale Cone Calorimeter. They found that the water vapour fraction of incoming gas, $X_{\mathrm{H}_{2} \mathrm{O}}^{o}$, was the only variable to be affected by the significant amount of water vapour. The term was modified as in Eq 7 . $W \psi$ is the water vapour in the exhaust gas which is the total water flow rate $(W)$ multiplied by the rate of evaporation $(\psi)$, and $\dot{m}_{t}$ is the total incoming air which is a mixture of air and water vapour $\left(\dot{m}_{a}+W \psi\right) . M_{a}$ is the molecular weight of air, and $M_{\mathrm{H}_{2} \mathrm{O}}$ is the molecular weight of water vapour.

$$
\mathrm{Q}_{\mathrm{s}}=\mathrm{Q}\left[1-\frac{M_{a}}{M_{\mathrm{H}_{2} O}} \frac{W \psi}{\dot{m}_{t}\left(1-X_{H_{2} O}^{o}\right)}\right]
$$

The study found the maximum of $6.4 \%$ overestimation by the original method, $Q$, from small-scale cone calorimetry tests. No method was suggested for estimations of the rate of evaporation $(\psi)$.

\subsection{Water-based fixed fire fighting systems in tunnels}

As WFFFS are now considered to be an option for mitigating the effects of tunnel fires, a number of research projects has been initiated to examine the effect of WFFFS on tunnel fires. This section presents a brief review of WFFFS in general and reviews results from tunnel suppression tests conducted in recent years.

\subsubsection{Water-based suppression systems}

Although there are different fire suppression agents available, water appears to be the most suitable fire suppression agent in tunnel applications. Halon and carbon dioxide are 
very effective in inhibiting combustion of many different types of fuels. However, Halon has been banned for use since it breaks up the ozone layer of the upper atmosphere of the earth [62], and carbon dioxide is only used for non-occupied spaces [62]. Newly developed suppression systems using new agents such as inert gaseous agents are also available [63].

The most commonly used agent to suppress fires is water. Due to its high thermal capacity (latent heat of vaporization), it effectively cools the fuel surface as well as the flame zone; and it suffocates the flame by the large volume of steam produced when interacting with the fire [4]. Water is known to be inappropriate for certain water reactive materials that, when brought into contact with water, produce heat, cause explosions and in some cases produce flammable (or toxic) gases. Since water is denser than most hydrocarbon fuels, it should not be used to suppress liquid fires as the liquid fuel can float and spread with water. Applying water in a fine mist can be a solution in this case. In tunnel applications, the cooling effect of WFFFS can be expected although the systems cannot directly suppress fires if they are shielded inside the vehicle body. Nonetheless, WFFFS can effectively control the fire, protect the tunnel structure and prevent the spread of the fire by reducing radiation [22].

WFFFS can be classified based on the size of droplets as follows:

- Water mist systems use very fine droplets. A water mist system is defined as a system that produces droplets with a diameter below $1000 \mu \mathrm{m}$ in $99 \%$ of the total volume $[64,65]$. High pressure water mist systems deliver droplets with a diameter approximately $100 \mu \mathrm{m}$, creating water fog in the protected space. 
- Sprinkler systems generate relatively large droplets

Depending on the type of nozzles and the pressure supplied, droplet sizes vary. Water droplet size fundamentally affects cooling capacity, interaction with ventilation air flow inside the tunnel, heat transfer, and kinetic energy of the droplets (the aerodynamic resistance). The spectrum of droplet size is shown in Figure 2-13.

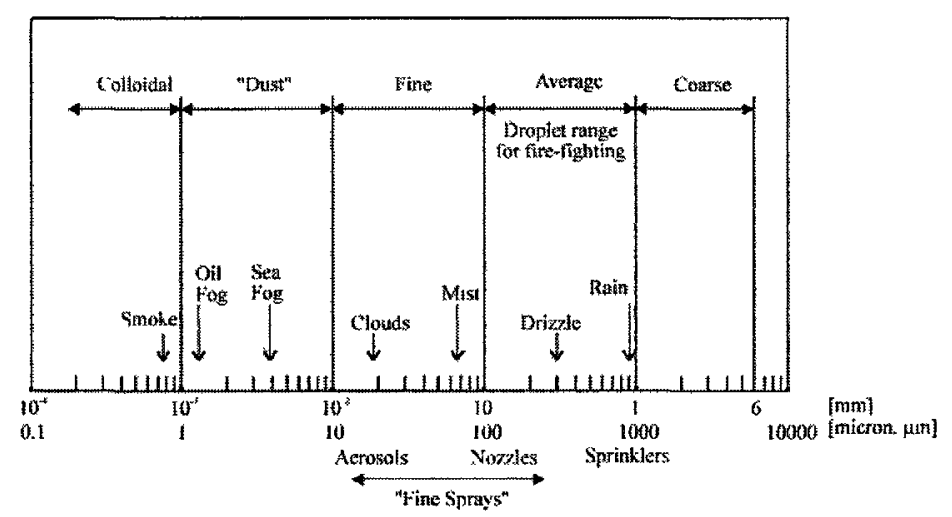

Figure 2-13 Spectrum of droplet diameters [4]

Depending on the method of system activation, a system can be classified as

- Automatic thermal activation system

- Open deluge system

1) Suppression mechanisms

The principal mechanisms of water-based suppression system suppressing fires are $[4,66$, 67],

- Cooling the fuel surface

This is effective for solid fuels as it lowers the fuel surface temperature below the temperature of volatilization. Large droplets are more effective in cooling the fuel 
surface since small droplets may not reach the fuel surface, but if they do they evaporate faster.

- Cooling the flame zone

The combustion reaction heat is removed from the gases as the water droplets evaporate by absorbing heat. Therefore, the temperature at the flame zone decreases. Significant cooling of the flame zone can occur even when there is minimal evaporation of the water. [68]

- Volumetric displacement of the oxidant with water vapour in the combustion area. When the water evaporates, its volume increases by 1640 times so that the water vapour suffocates the flame as oxygen is displaced from the combustion area.

The dominant mechanism depends on the type of fuel, fire size as well as degree of confinement, and droplet size. In tunnel applications of WFFFS, direct cooling of the fuel surface or the flame zone might be difficult to achieve. However, cooling of the air and gases around a fire can be effective. The cooling effect is possibly improved if the droplet size is small as the interaction surface between the flame and water is increased [4].

In addition to the suppressing and cooling mechanisms described above, WFFFS has other effects;

- Attenuation of radiation [69]

Water droplets are effective in attenuating and scattering radiation since they separate the flame zone from the environment and shield the combustion zone. This mechanism is not sufficient to prevent radiation feedback from the flame to the fuel surface; however, it can effectively reduce the incident radiation to a vehicle near the fire.

- Scrubbing effect 
WFFFS is known to have a scrubbing effect that removes smoke and toxic gases. Water mist systems that are effective in extinguishing Class $\mathrm{C}$ fires (i.e. electrical equipment fires) are known to be also effective in reducing soot damage to electrical equipment. However, the effect is small, and insoluble toxic gases like CO cannot be removed [70].

2) Fire suppression in tunnels

It has been discussed in Chapter 2.1.2, that tunnel fire dynamics are affected by the tunnel geometry and ventilation condition in the tunnel. Suppression of tunnel fires is also influenced by the degree of confinement and ventilation conditions.

Suppressing an open fire needs more water than a similar fire in an enclosure. The critical water application rates, below which the fire cannot be extinguished [4], are less for a fire in an enclosure than in the open. This is because water vapour quickly fills the enclosure and smothers the fire. The critical water application rate to extinguish a fire increases with the volume of the enclosure. It is reported that the amount of water required for extinguishment can be equal to that required to displace the gaseous contents of the enclosure by water vapour under normal ventilation conditions [4].

The effectiveness of suppression is also greatly influenced by the rate of ventilation. The greater the ventilation rate, the greater the water consumption or the time to extinguish the fire. In tunnel application of WFFFS, the combustion of a tunnel fire is fuel-controlled under forced longitudinal ventilations. This indicates that the most effective mechanism to suppress the fire is the cooling of the fuel surface as the interaction between the water droplets and flame is significantly intervened by the air flow. However, direct cooling of the fuel surface is hard to achieve since the tunnel fire 
is often shielded by the vehicle body. The oxygen depletion mechanism cannot be very effective in tunnel fires as the fire is under continuous air flow. Thus, the dominant mechanism to be expected in tunnel fire suppression is cooling the hot gases and the surroundings of the fire.

\subsubsection{Suppression tests in tunnels}

A broad range of research activities have been initiated including the study of the use of suppression systems in tunnels to evaluate WFFFS currently available, such as traditional sprinkler systems, low pressure water mist systems, high-pressure water mist systems, Compressed Air Foam (CAF) systems as well as some new innovative systems. Table 2-2 shows a summary of each study.

Most of the studies adopted scenarios where the fire was shielded by the vehicle body. Pool fires and wood crib fires which were shielded or half shielded were used as fire sources. Real vehicle fires as well as simulated HGV fires were also tested, and in some tests, some obstructions were placed to simulate possible traffic conditions. Figure 2-14 shows design fire sizes and water flow densities used in the studies. Design fire sizes were in the range of $2 \mathrm{MW}-25 \mathrm{MW}$ for real-scale tests. Water flow densities tested in the range of $1-13 \mathrm{l} / \mathrm{min} / \mathrm{m}^{2}$. In reduced-scale model tests, simulated fires up to $300 \mathrm{MW}$ were considered. Many of the tests were conducted under longitudinal ventilation. No test with transverse ventilation was performed.

This section gives detailed descriptions of each study, and the overall results found from these studies are discussed in Chapter 2.3.3. 
Table 2-2 Summary of previous tunnel tests

\begin{tabular}{|c|c|c|c|c|c|c|c|c|}
\hline Project & $\begin{array}{c}\text { Tunnel } \\
W(m) \times H(m) \times L(m)\end{array}$ & Fire & $\begin{array}{c}\text { Fire size } \\
\text { [MM] }\end{array}$ & \begin{tabular}{|c|} 
ventilation \\
{$[\mathrm{m} / \mathrm{s}]$}
\end{tabular} & WFFFS & $\begin{array}{l}\text { Water density } \\
1 / \mathrm{m} \text { in } \mathrm{m} 2\end{array}$ & $\begin{array}{c}\text { Water rate } \\
\mathrm{I} / \mathrm{min}\end{array}$ & Activation time \\
\hline $\begin{array}{l}\text { Ofenegg } \\
\text { [67] }\end{array}$ & $4 \times 6 \times 190$ & Petrol pool & $\begin{array}{l}(6.6 \mathrm{~m} 2) \\
(47.4 \mathrm{~m} 2) \\
(95 \mathrm{~m} 2) \\
\end{array}$ & & Sprinkler & 19 & & \\
\hline $\begin{array}{c}\text { 2nd Benelux } \\
{[35,37,41]}\end{array}$ & $9.8 \times 5.1 \times 840$ & $\begin{array}{|cc|}\text { Van } & \\
\text { Simulated HGV } & \text { shielded } \\
\text { Wood crib } & \text { open }\end{array}$ & $\begin{array}{l}10 \\
14 \\
25\end{array}$ & $\begin{array}{c}0-1 \\
0-1 \text { and } 3 \\
0-1\end{array}$ & Sprinkler & 12.5 & $5500 / 2750$ & $\begin{array}{l}14 \mathrm{~min} \\
4 \mathrm{~min} \\
10 \mathrm{~min} \\
21 \mathrm{~min}\end{array}$ \\
\hline $\begin{array}{l}\text { UPTUN DMT } \\
{[68]}\end{array}$ & $3.2 \times 3.0 \times 69$ & Gasoline pool Half covered & $5,10,20$ & $0,1,3$ & $\begin{array}{c}\text { Sprinkler } \\
\text { Water mist } \\
\text { Water curtain } \\
\end{array}$ & $\begin{array}{l}71.79 \\
7.69 \\
61.54 \\
\end{array}$ & $\begin{array}{c}1400 \\
150 \\
1200 \\
\end{array}$ & $\begin{array}{c}90 \mathrm{~s}, 120 \mathrm{~s} \\
30 \mathrm{~s} \\
\end{array}$ \\
\hline $\begin{array}{l}\text { SP model } \\
1: 23 \text { scale } \\
{[56]}\end{array}$ & $\begin{array}{l}(0.4 \times 0.2 \times 10) \\
9.4 \times 4.6 \times 230\end{array}$ & Wood crib & $\begin{array}{l}250 \\
390\end{array}$ & 3 & $\begin{array}{c}\text { Water mist } \\
\text { Water curtain }\end{array}$ & $\begin{array}{c}3.5 \\
5 \\
7\end{array}$ & $\begin{array}{c}888 \\
1268 \\
1700 \\
431 / 558 \\
\end{array}$ & $4 \mathrm{~min} 40 \mathrm{~s}$ \\
\hline $\begin{array}{l}\text { Chen }[71] \\
1: 10 \text { scale }\end{array}$ & $\begin{array}{c}(1.2 \times 1.2 \times 7.5) \\
12 \times 12 \times 75 \\
\end{array}$ & Wood crib & $\begin{array}{l}3.8 \\
5.7\end{array}$ & & Water mist & & $\begin{array}{c}6.9 \\
10.4 \\
\end{array}$ & $200 \mathrm{~s}$ \\
\hline $\begin{array}{c}\text { UPTUN IF } \\
{[70]}\end{array}$ & $8.07 \times 5.05 \times 100$ & $\begin{array}{l}\text { Pool, wood crib covered } \\
\text { Vehicle }\end{array}$ & $5,10,20$ & $\begin{array}{c}2.5 \\
1 \\
6-3 \\
\end{array}$ & \begin{tabular}{|l|} 
Water mist \\
Low pressure \\
High pressure \\
\end{tabular} & $0.5 \sim 3.3$ & $\begin{array}{l}221-695 \\
140-695 \\
\end{array}$ & $\begin{array}{c}120 / 180 \mathrm{~s} \\
250 / 720 \mathrm{~s} \\
320 \mathrm{~s} \\
\end{array}$ \\
\hline A86 [73] & $9 \times 2.5$ & Vehicles in traffic & & & Water mist & & & \\
\hline $\begin{array}{c}\text { San pedro de } \\
\text { Anes fire tests }[72]\end{array}$ & $9.5 \times 5.2 \times 600$ & $\begin{array}{cc}\text { Wood pallet } & \text { covered } \\
\text { Wood pallet }+ \text { PE } & \text { covered }\end{array}$ & $30-100$ & $\overline{1.9-3.4}$ & Water mist & $\begin{array}{l}3.69 \\
426 \\
\end{array}$ & & \\
\hline Memorial [44] & $8.8 \times 7.9 \times 853.7$ & Pool open & $10,20,50,100$ & & Foam water & $2.4-3.8$ & & \\
\hline
\end{tabular}

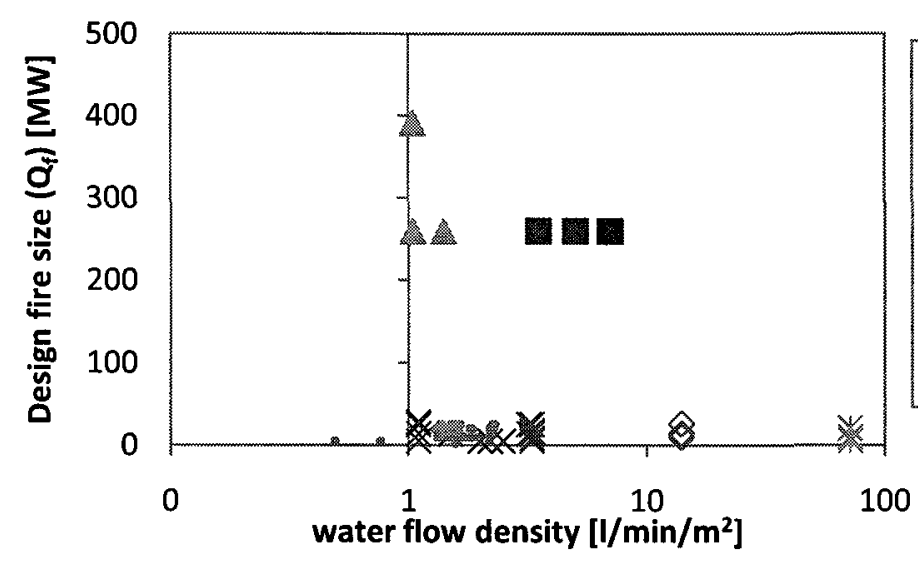

Figure 2-14 Fire sizes and water flow density tested in previous studies 
1) Ofenegg tunnel in 1965 [71]

In 1965 , simulated oil tanker fires were run to examine the danger to people, possibility of rescue and effects of the fire on tunnels. Three sprinkler tests were conducted to examine the influence on petrol pool fires in the Ofenegg tunnel, which was about $6 \mathrm{~m}$ high, $4 \mathrm{~m}$ wide, and $190 \mathrm{~m}$ long. One end of the tunnel was closed, and tests were conducted with no ventilation system activated. A sprinkler system with a water capacity of $19 \mathrm{l} / \mathrm{s} / \mathrm{m}^{2}$ was installed over pool fires with three different areas of $6.6 \mathrm{~m}^{2}, 47.4 \mathrm{~m}^{2}$ and $95 \mathrm{~m}^{2}$. The suppression system extinguished the fires within a short time, and cooled the smoke. Temperature, $\mathrm{CO}$ and $\mathrm{O}_{2}$ measurements were evaluated with respect to the distance from the fire. The results showed that the critical no-survival distance was shortened with the use of sprinklers.

2) The Second Benelux tunnel tests $[37,39,43]$

Fourteen full-scale fire tests were carried out during 2000/2001 in the Second Benelux Tunnel in the Netherlands. The effect of fire safety systems on the tenability conditions was investigated including four tests with a sprinkler system. The tests were performed in the tunnel having a rectangular cross section with a height of $5.1 \mathrm{~m}$, a width of $9.8 \mathrm{~m}$ and a length of $840 \mathrm{~m}$. The tunnel has a maximum slope of $4.4 \%$ and accommodates two uni-directional traffic lanes. Fire scenarios used were two simulated HGVs with loads of wood pallets, a van loaded with wood pallets, and a stack of wood pallets in the open. Figure 2-15 illustrates the test setups. The fire was located between a tanker and a container which simulated traffic. The tanker was placed downstream and the container was placed upstream of the fire. 


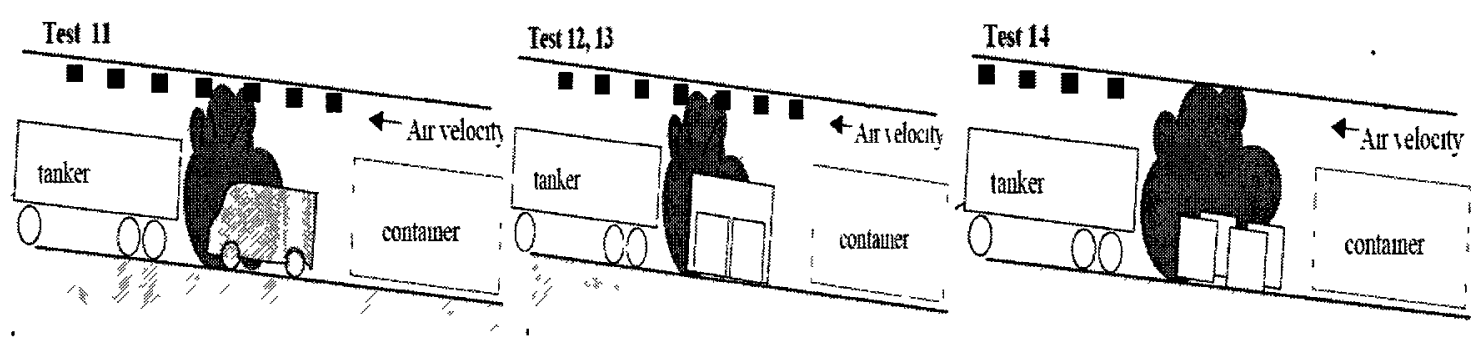

Figure 2-15 2nd Benelux sprinkler test arrangement [37]

An open deluge sprinkler system with a flow rate of $12.51 \mathrm{1} / \mathrm{min} / \mathrm{m}^{2}$ was installed in two zones; the fire area and $17.5 \mathrm{~m}$ downstream of the fire (over the tanker). Sprinklers in both zones were activated during the tests except in one test (Test 14) where only the zone downstream of the fire area was activated. The activation times were varied for different tests from 4 to $21 \mathrm{~min}$. Temperatures, radiation levels and optical densities in the tunnel were measured from $50 \mathrm{~m}$ upstream to $200 \mathrm{~m}$ downstream of the fire; and gas velocities and heat release rates were also measured. They found that the sprinkler system was very effective in suppressing the fires.

\section{3) UPTUN DMT laboratory tunnel tests [72]}

In Europe, a joint research project, UPTUN, with 19 EU member states participating, has been conducted since 2002 in order to overcome fire safety issues emerging from the tragic tunnel accidents [73]. UPTUN stands for 'Cost effective sustainable and innovative UPgrading methods for fire safety in existing TUNnels'. As a part of UPTUN, a series of laboratory tunnel tests were conducted to evaluate existing water suppression systems as well as new innovative mitigating systems in order to find the most efficient and cost effective solution. A sprinkler system and a water mist system as well as a water curtain system were tested in the DMT laboratory tunnel (see Figure 2-16) 
in Germany, which has a height of $3.0 \mathrm{~m}$, a width of $3.2 \mathrm{~m}$ and a length of $69 \mathrm{~m}$. Tests were conducted under various longitudinal ventilations of 0,1 and $3 \mathrm{~m} / \mathrm{s}$.

The fire source was a diesel pool divided into 4 sections, each section being $1.6 \mathrm{~m} \times 1.2$ m. An obstruction was constructed at the height of $1.8 \mathrm{~m}$, to partially cover the front half of the pool. The estimated fire size was $5 \mathrm{MW}$ for one section and $20 \mathrm{MW}$ for four sections of the pool.

A sprinkler system was installed over the pool at a height of $2.5 \mathrm{~m}$ from the floor. The total water flow rate through all nozzles was about $1400 \mathrm{l} / \mathrm{min}$. Water density calculated based on the given information appears to be very high (about $701 / \mathrm{min} / \mathrm{m}^{2}$ ). The total water flow rate of the low pressure water mist system was about $1501 / \mathrm{min}$. To investigate the influence of installation locations, the system was also tested $10 \mathrm{~m}$ downstream of the fire source.

Water curtains were installed $15 \mathrm{~m}$ upstream and $15 \mathrm{~m}$ downstream of the fire. Each curtain comprised of 3 nozzles, which were specially designed to produce a twodimensional cone of water droplets. The main objective of the system was the compartmentation of the fire and smoke, as well as to facilitate rescue operations.

Temperatures were measured along the length of the tunnel, and a gas analyser was installed $21 \mathrm{~m}$ downstream of the fire. The test results from this study could not easily be extrapolated to a real application since the cross section of the tunnel was only about 10 $\mathrm{m}^{2}$, and the sprinkler system was installed $2 \mathrm{~m}$ above the fire source which is in fact not very realistic. 


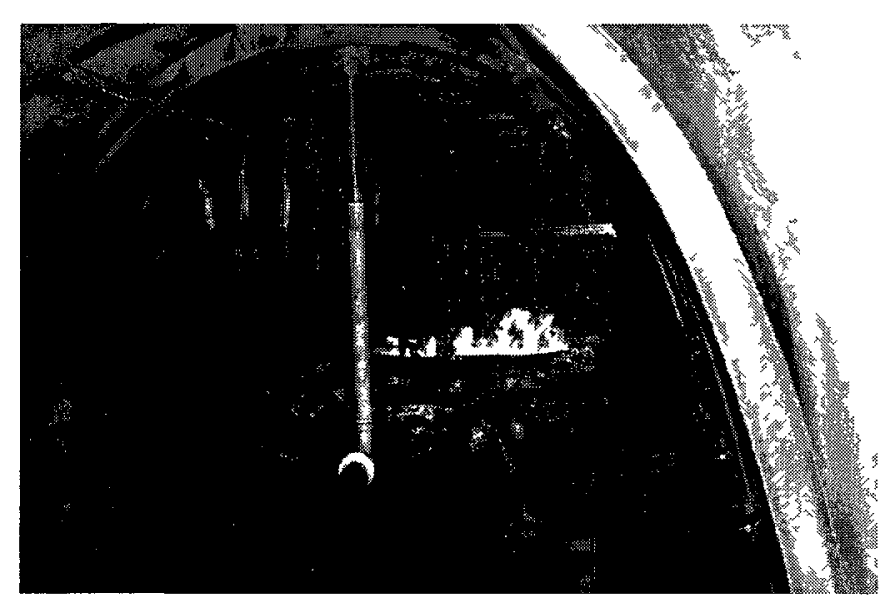

Figure 2-16 UPTUN DMT tunnel tests [72]

4) UPTUN If tunnel tests [74]

The purpose of the UPTUN If tunnel tests was to evaluate the efficiency of a water mist system. A total of 19 tests using a low pressure water mist system and a total of 56 tests using a high pressure water mist system were run in the "If-sikkerhetssenter" tunnel (see Figure 2-17) which is arched, $8.07 \mathrm{~m}$ wide, $5.05 \mathrm{~m}$ high, and $100 \mathrm{~m}$ long. The fire scenarios used in the tests were similar to the ones used in the UPTUN DMT tunnel tests. They used a pool fire divided with four vessels. The half of the pool area was covered. Each pool vessel could generate a HRR of 4-5 MW; however, the fire sizes were affected by the ventilation conditions as well as by the pool cover. In addition to the pool fires, wood pallet fires generating 20 25 MW and real vehicle fires were also tested.

The layout of the water mist system was designed to cover the pool fire area as well as 14 $m$ downstream of the fire. Parameters tested in the study were the droplet distribution and droplet sizes as well as the discharge rates. For the low pressure water mist system, a total of 30 40 nozzles covering an area of $140 \sim 210 \mathrm{~m}^{2}$ was distributed at the ceiling of the tunnel. Total water flow rates ranged from 221 to $683 \mathrm{l} / \mathrm{min}$. For the high pressure 
water mist system, a total of 7 to 14 nozzles were used covering an area of $230 \sim 290 \mathrm{~m}^{2}$ and the total water flow rates ranged from $140 \mathrm{l} / \mathrm{min}$ to $550 \mathrm{l} / \mathrm{min}$.

HRR, gas concentrations, and smoke density were measured. The temperatures in the fire area and $25 \mathrm{~m}$ downstream of the fire were also measured. Results showed satisfactory mitigation of the fires with a fraction of water discharge rates of traditional sprinklers systems.
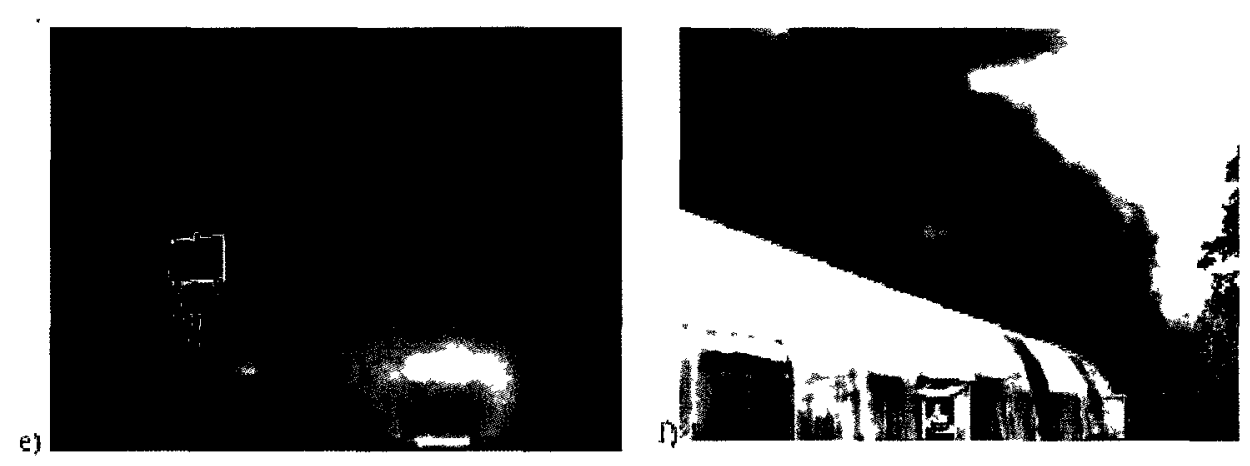

Figure 2-17 UPTUN IF tunnel tests [74]

5) Ingason [59]

Ingason used small-scale tests to obtain data to be used for modelling work since it was impossible to draw any general conclusions from the previous large-scale tests. The Froude scaling technique was used so that the HRR, time, water flow rate, and droplet diameter are scaled. However, the technique does not properly scale the interaction between the water droplets and plume; attenuation of thermal radiation; and evaporation of water droplets.

Small-scale tests were conducted using 1:23 scale model tunnel, $10 \mathrm{~m}$ long, $0.4 \mathrm{~m}$ wide and $0.2 \mathrm{~m}$ high, which is equivalent to $230 \mathrm{~m}$ long, $9.2 \mathrm{~m}$ wide and $4.6 \mathrm{~m}$ high. A 
ventilation fan supplied air at the entrance of the tunnel, and the exhaust duct system extracted the fire gases through a ceiling opening at the end of the tunnel. Longitudinal ventilation with a velocity of $0.62 \mathrm{~m} / \mathrm{s}(3 \mathrm{~m} / \mathrm{s}$ in real scale) was mainly tested, and one test with a velocity of $0.42 \mathrm{~m} / \mathrm{s}(2 \mathrm{~m} / \mathrm{s}$ in real scale) was also tested to examine the effect of ventilation speed.

A constant size wood-crib fire was tested under longitudinal ventilation with various conditions for the water suppression system (see Figure 2-18). The wood crib was covered by a flanged steel plate so that the water spray could not directly hit the fuel. In the control test, the peak HRR generated from the wood crib fire source was $100 \mathrm{~kW}$, equivalent to $250 \mathrm{MW}$ in large scale. To study fire spread, another wood crib was placed as a target next to the fire at a distance of $0.65 \mathrm{~m}(15 \mathrm{~m}$ in large scale). The second wood crib was ignited and burned with no water spray system, and both cribs together generated a peak HRR about $140 \mathrm{~kW}$.

The water suppression system was designed to test both a deluge water spray system as well as a water curtain system. 14 nozzles were mounted on the ceiling above the wood crib fire. For the normal water spray system mode, active suppression over the wood crib fire area was tested using 12 nozzles. To examine the cooling effect of the system, the system was used in water curtain mode using four nozzles mounted on the last two pipes located $0.3 \mathrm{~m}$ from the downstream edge of the wood crib.

In the deluge system tests, the equivalent total water flow rate in large scale were 888 , 1268 , and $1700 \mathrm{l} / \mathrm{min}$ (water spray density $3.5,5$ and $71 / \mathrm{min} / \mathrm{m}^{2}$ in large scale). For the 
water curtain system, the total water flow rates were $4311 / \mathrm{min}$ and $558 \mathrm{1} / \mathrm{min}$ in large scale.

The time of activation of the water system was consistent at $1 \mathrm{~min}$ (about $4 \mathrm{~min} 40 \mathrm{~s}$ in large scale), which was the time the HRR of the wood crib reached 50 75 MW in large scale.

Data measured in the exhaust duct were used to calculate the HRR using oxygen calorimetry, and HRR was also estimated using a load cell. The study found that the mitigation effect of the water spray system on temperature, heat fluxes, and HRR linearly correlated with the rate of heat absorbed by water relative to the maximum HRR of fire in a free burn test.

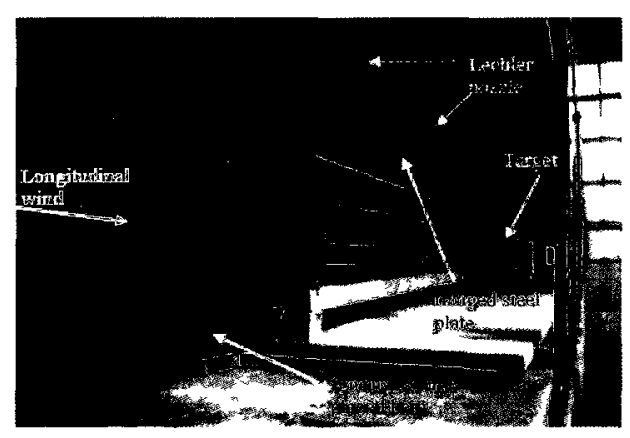

Figure 2-18 SP model test arrangement [59]

6) Chen [75]

Chen studied the effect of longitudinal air velocities on the fire suppression efficiency of water mist systems in terms of fire extinguishing time. Small-scale experiments were carried out in a tunnel having a hydraulic diameter of $1.2 \mathrm{~m}$. A nozzle was installed at the ceiling in the middle of the tunnel. Two different mist nozzles were tested to investigate the influence of mist characteristics such as mist droplet diameter and water 
fluxes with water flow rates of $6.91 / \mathrm{min}$ and $10.41 / \mathrm{min}$. Wood crib fires of $12 \mathrm{~kW}$ to 18 $\mathrm{kW}$ (3.8 to 5. $7 \mathrm{MW}$ in real scale) were tested. The fire source was placed downstream of the nozzle, at various horizontal distances; $0 \mathrm{~m}, 0.3 \mathrm{~m}, 0.6 \mathrm{~m}$ and $0.9 \mathrm{~m}$. Longitudinal ventilation systems with seven different velocities ranged from 0.4 to $3.3 \mathrm{~m} / \mathrm{s}$ were tested (1.5 to $11 \mathrm{~m} / \mathrm{s}$ in large-scale). Results showed that the fire extinguishing time was affected by the longitudinal air velocities

7) The San Pedro de Anes tests [76]

High pressure water mist tests were carried out in the San Pedro de Anes test facility in Asturias, Spain, in 2006 . The tunnel facility was $9.5 \mathrm{~m}$ wide and $600 \mathrm{~m}$ long, and the ceiling height was $5.2 \mathrm{~m}$. Stacks of wood pallets with potential maximum HRRs from 30 MW and up to $100 \mathrm{MW}$ were tested with longitudinal air velocities between 1.9 and 3.4 $\mathrm{m} / \mathrm{s}$. The water mist system was installed directly over the fire, and the application density of the water mist system was in the range between 3.69 and $4.261 / \mathrm{min} / \mathrm{m}^{2}$. The HRR and temperature along the tunnel were measured. The study showed that the water mist system greatly reduced the HRR of the fire and temperature in the tunnel.

8) A86 tunnel tests [77]

A high pressure water mist system was tested for passenger vehicle fires in tests conducted in the Hagerbach tunnel research facility in Sargans, Switzerland, which was recreated to simulate an 'A86' tunnel of $9 \mathrm{~m}$ wide and $2.5 \mathrm{~m}$ high. A realistic fire scenario was tested in the test program. In the scenario, a fire involving three vehicles was arranged, and, to examine fire spread, many other passenger vehicles were placed close to the fire. Air flow inside the tunnel at the time of ignition was $6 \mathrm{~m} / \mathrm{s}$ and later was reduced 
to $3 \mathrm{~m} / \mathrm{s}$. Tenability conditions in the tunnel were examined using data for temperatures and gas concentrations. Results showed that the water mist system prevented fire propagation and reduced the radiative heat flux. It was also observed that the visibility downstream of the fire improved with the water mist system.

9) The Memorial test series [47]

In the Memorial tunnel tests, foam-water sprinkler systems were tested for gasoline pool fires of 20,50 and $100 \mathrm{MW}$. The Memorial tunnel is $8.8 \mathrm{~m}$ wide, $7.9 \mathrm{~m}$ high and 853.7 $\mathrm{m}$ long with a $3.2 \%$ uphill grade. Water densities from 2.4 to $3.8 \mathrm{1} / \mathrm{min} / \mathrm{m}^{2}$ were tested with foam additives of $3 \%$. The pool fires were extinguished in less than $30 \mathrm{~s}$ in all four tests in the Memorial tunnel. Note that the suppression systems was not able to suppress the pool fires in the UPTUN DMT and IF tunnel tests because the pool fires were partially shielded.

\subsubsection{Effect of suppression systems}

1) Suppression effect on heat release rate

Overall test results showed that the effectiveness of WFFFS in reducing HRR is dependent on the type of fuel, time of activation as well as water discharge rate. Few studies conducted tests burning real vehicles or simulated HGVs. In the UPTUN IF [74] tunnel tests, suppression tests for real vehicle fires were conducted, but suppression effects were not measured. In the second Benelux tests, the effect of sprinkler system was tested in reducing HRR of a van fire and simulated HGVs. Results showed that the system could hardly extinguish the fire inside the vehicle or cabin particularly in the case 
of early activation of the system. However, the fire size was controlled at a certain level. The water sprinkler system reduced the HRR from 7.5 MW to about $5 \mathrm{MW}$ for a van fire. In the case of the simulated HGV fires, the delayed system operation rapidly extinguished the fire $\left(t_{a}=10 \mathrm{~min}\right.$ and $\left.Q_{a}=13 \mathrm{MW}\right)$ because, when the system was activated, the cabin had been destroyed by the fire so the fire was not shielded. When the system was activated relatively early at about $4 \mathrm{~min}$, the fire size in the cabin was reduced from 8 MW to about $1 \mathrm{MW}$, and the cabin was not damaged. Note that the back of the cabin was open.

A series of pool fire tests was conducted in UPTUN DMT tunnel tests [72] as well as UPTUN IF tunnel tests. Results from these tests showed that the system significantly reduced the pool fire burning; however, the system was not able to suppress the fire. The HRR was measured in the UPTUN If tunnel tests. The study found that the effect of the suppression was more significant for large fires than small fires. For large fire scenarios (about $20 \mathrm{MW}$ ), the low pressure system reduced the HRR by $70 \sim 80 \%$, and the high pressure system reduced the HRR by $10 \sim 70 \%$.

Figure 2-19 compares the HRR (dotted line) of a pool fire during suppression with the reference test (solid line). The pool fire quickly developed over the designated pool area and reached the steady burning quickly. During suppression, the HRR was reduced quickly. 


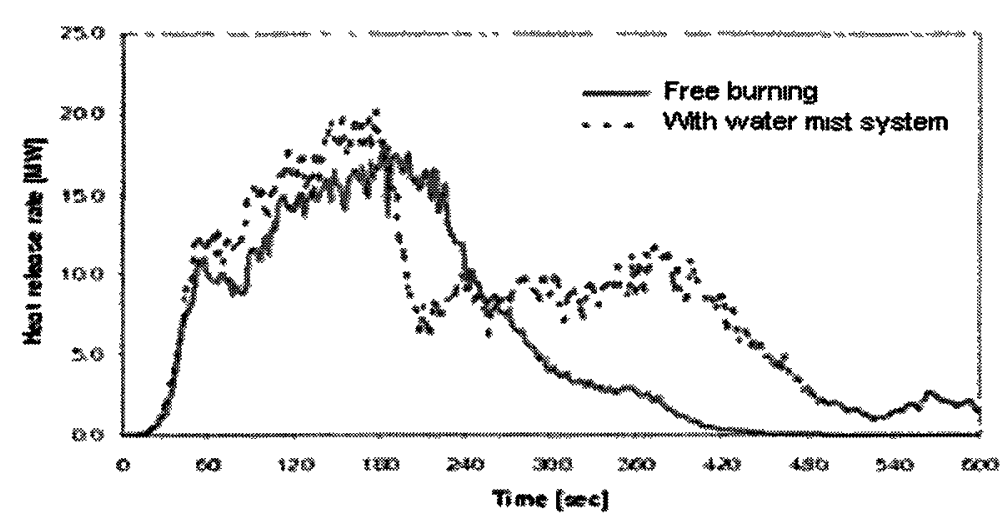

Figure 2-19 The mitigated HRR of a pool fire compared with a reference test. (Water mist system is activated at about $160 \mathrm{~s})$ [74]
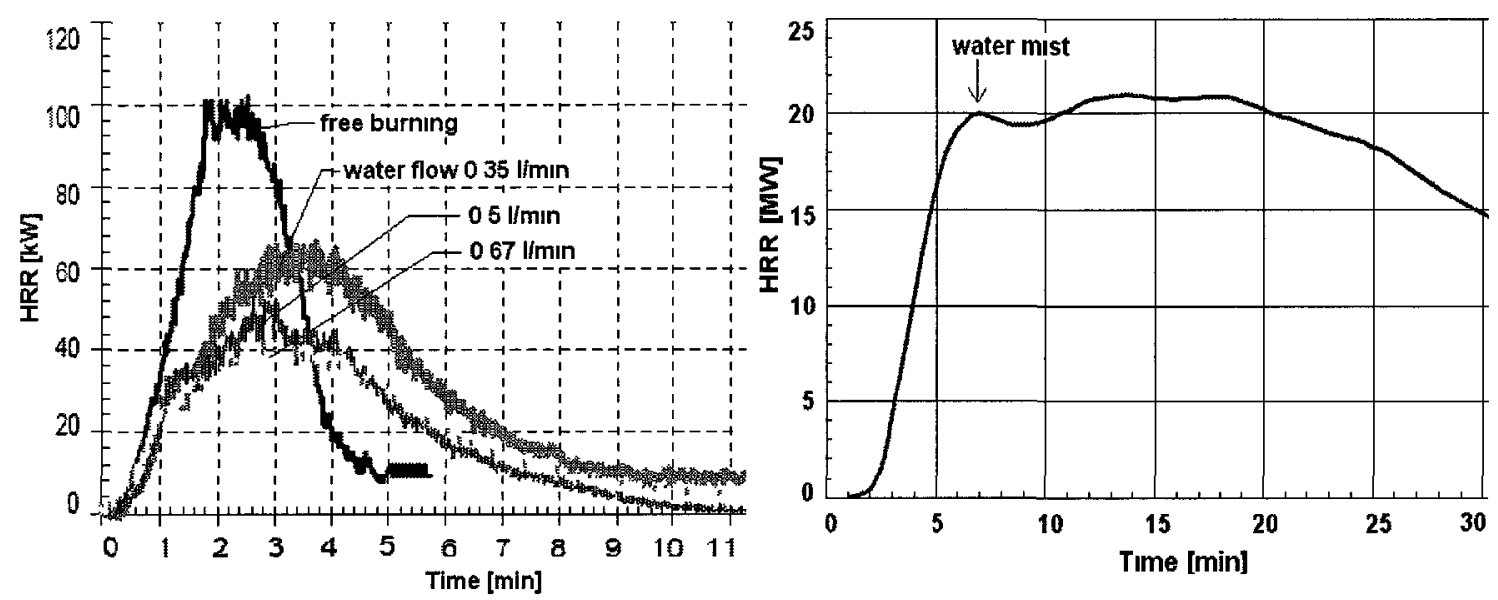

Figure 2-20 The mitigated HRR of wood crib fires (a) SP model scale tests [78] (b) The San Pedro de Anes tunnel test [77]

Unlike pool fires, the free burning of wood cribs resulted in air-rich combustion so that the fire grows fully and then decays. The effectiveness of the suppression system in this case was mainly at controlling the growth rate. Figure 2-20(a) shows HRR results obtained from the SP small-scale tests [78]. Wood crib fires grew slower in suppression tests with a reduced maximum HRR than in the free burn test, yet the total time of burning was increased. The controlling ability of WFFFS is demonstrated in Figure 2-20(b) where the system arrested the growth of the fire and kept the HRR constant at its value at the time of activation. This resulted from a test (test1 of the San Pedro de Anes 
study) [77] where the water mist system with a flow spray density of $4.261 / \mathrm{min} / \mathrm{m}^{2}$ (total flow rate $1128 \mathrm{l} / \mathrm{min}$ ) was tested for a wood pallet fire with a potential peak HRR of 40 MW. The air flow velocity in the tunnel was less than $2.0 \mathrm{~m} / \mathrm{s}$. The fuel was not covered (with no tarpaulin covering the pallets).

Ingason used data from the small-scale tests on wood-crib fires to find a correlation of the reduction rate in HRR with water discharge rates. Ingason found that about $90 \%$ of the water didn't really affect the burning, yet $10 \%$ of the applied water influences the burning rate of wood crib fires under the shielding plate. The heat absorbed by the water was found to be about $1.5 \%$ to $3 \%$ of the maximum possible HRR (design fire size), and the system reduced the HRR from 40 to $60 \%$ of the design fire size. Note that the activation time was early, way before the possible maximum HRR.

2) Effect of suppression system on cooling smoke

When the system was applied directly over the fire area, the temperature dropped significantly mainly due to the reduced HRR and cooling of hot gases. As a consequence, the temperatures of hot gases downstream of the fire also decreased.

In the UPTUN DMT tunnel tests, temperatures immediately dropped to ambient level in the vicinity of the pool fire, as well at 20 and $30 \mathrm{~m}$ downstream of the fire due to the large water spray rate. An unexplainable outcome in the tests was reported that the temperature at the bottom in the vicinity of the fire was much higher $\left(130\right.$ to $\left.250^{\circ} \mathrm{C}\right)$ in the suppression tests than in the reference test (about $50{ }^{\circ} \mathrm{C}$ ). The report said that the 
reason for this effect was not known; however, it appears that the sprinkler activation can impact the temperature profile of the smoke layer.

The absolute cooling effect of the suppression system on the smoke field was investigated by locating the suppression system at some distance from the fire. In the UPTUN DMT tunnel tests, the sprinkler system was tested $10 \mathrm{~m}$ downstream of the fire. When the system was activated, the temperature at $10 \mathrm{~m}$ and $20 \mathrm{~m}$ downstream of the system, which is 21 and $32 \mathrm{~m}$ downstream of the fire, quickly dropped to ambient level from the ceiling to the floor, while the burning of the pool fires was not affected by the sprinkler system.

3) Suppression effect on preventing fire spread and attenuating radiation In the second Benelux tunnel tests, the effect of the system on a tanker located $5 \mathrm{~m}$ downstream of the fire was examined. The sprinkler system was installed directly over the tanker while the open wood crib fire (26 MW) was burning with no suppression system activated above it. Heat flux measured $10 \mathrm{~m}$ downstream of the fire, where the sprinkler system was performing, dropped to about $2 \mathrm{~kW} / \mathrm{m}^{2}$, which is enough to irritate human skin but can hardly cause fire spread. Heat fluxes measured $20 \mathrm{~m}$ downstream of the fire immediately dropped to almost zero at the time of activation of the sprinkler system.

In the small-scale tests by Ingason, a target wood crib was placed next to a fire source at a distance equivalent to $15 \mathrm{~m}$ in large scale. In the reference test, the target was ignited at about $8 \mathrm{~min}$ after the ignition. Using a deluge system, no fire spread to the target 
occurred. In the case with low water spray rate of 3.5 and $51 / \mathrm{min} / \mathrm{m}^{2}$ (in large scale), the target was charred but was not ignited. However, when using the water curtain system, fire spread occurred and the target burned out when using the lower water flow rate of $431 \mathrm{l} / \mathrm{min}$. When using $558 \mathrm{l} / \mathrm{min}$, fire spread did not occur. This indicates that the reduction in radiation depends on water flow rates of the system as well as the layout of the system. The radiation heat flux measured $86 \mathrm{~m}$ downstream of the fire was reduced by about $85 \%$ and $65 \%$ when using 5 and $3.51 / \mathrm{min} / \mathrm{m}^{2}$ (in large scale) deluge system, respectively.

4) Effect of suppression system on smoke /scrubbing effect

The use of WFFFS is also very effective in reducing the toxic gas concentrations, not as rapidly as temperatures, but gradually within a couple of minutes. The decrease in toxic gas concentrations is mainly due to the reduction of the burning rate; nevertheless when the system was installed at some distance from the fire, the toxic gas concentrations were still reduced by the system. UPTUN DMT tunnel study reported that the sprinkler system installed $10 \mathrm{~m}$ downstream of the fire reduced gas concentration of $\mathrm{CO}$ and $\mathrm{CO}_{2}$ in the order of $25 \%$ of the reference test due to the scrubbing effect. Unlike the results obtained with the sprinkler system, the scrubbing effect of the water mist system was quite limited particularly for $\mathrm{CO}_{2}$, but scrubbed $\mathrm{CO}$ from the smoke layer to some extent. They concluded that the scrubbing capacity is related to the amount of water used.

The scrubbing effect, however, is limited. Some studies found that the water mist system did not significantly reduce smoke and concentrations of $\mathrm{CO}$ and $\mathrm{CO}_{2}$, which are in fact insoluble in water [70]. 
5) Suppression effect on stratification under natural ventilation

Suppression systems can disturb the stratification of the smoke not only at the section of application but also along the tunnel since the cooling effect of the sprinkler eventually destroys the stratification and results in descending of the smoke layer. The Ofenegg fire tests [71] reported a disturbance of stratification along with enhanced steam-forming. These effects resulted in a major reduction of visibility in the entire tunnel.

In the second Benelux tunnel, suppression tests were conducted under natural ventilation. To examine the influence of sprinkler systems on stratification, a mixing factor was calculated that is a relative temperature rise at a certain height compared to the average temperature rise over the cross section of the tunnel. The results showed that stratification existed up to $200 \mathrm{~m}$ downstream of the fire for about $10 \mathrm{~min}$ before the activation of a sprinkler system in both of a van fire (test \#11) and a simulated HGV test (test \#13).

After the activation of the system (at 14 and 10 min for test \#11 and \#13 respectively), the mixing factor showed a transition from stratification to mixing since the smoke layer was disturbed by the water discharge from the sprinklers and cooling of the smoke. In the HGV fire test (\#13), stratification started to fail right after suppression; by $20 \mathrm{~min}$ mixing as well as cooling were completed 10 and $20 \mathrm{~m}$ downstream of the fire. A similar result was reported in UPTUN DMT tunnel tests in which the gas concentrations were found to be uniform over the cross section of the tunnel. However, the de-stratification and mixing of the smoke are not indications of low visibilities and high toxicities. Due to 
the reduced HRR and dilution of the smoke, the visibility improved, and toxicity were reduced after some time.

6) Interaction with ventilation systems

When WFFFS is included as part of the overall fire safety design of a tunnel, the impact of this system on other systems should be evaluated. Some issues should be addressed; the integration of WFFFS with other systems, such as detection systems and ventilation, and operation procedures for a ventilation system and suppression system.

Previous studies examined the effect of ventilation system on the efficiency of the water suppression system. The sprinkler system used in UPTUN DMT tunnel tests produced relatively small water droplets in the order of $1000 \mu \mathrm{m}$. The temperature results measured above the pool showed that the effectiveness of sprinkler systems was not affected by the longitudinal air flow within the range of the velocities tested $(0-3 \mathrm{~m} / \mathrm{s})$. However, air velocity affected the mitigation efficiency of the low pressure water mist system, whose nozzles produced very fine droplets with sizes less than $0.1 \mathrm{~mm}$. Results showed that the water mist system was most effective in reducing temperature right above the pool at an air velocity of $0 \mathrm{~m} / \mathrm{s}$, and the mitigation effect decreased with increased air velocity. At the highest velocity of $3 \mathrm{~m} / \mathrm{s}$, the temperature above the pool of $20 \mathrm{MW}$ fire dropped to only $800^{\circ} \mathrm{C}$ from $1000^{\circ} \mathrm{C}$ while temperature dropped immediately to $80^{\circ} \mathrm{C}$ from $1000^{\circ} \mathrm{C}$ at a velocity of $0 \mathrm{~m} / \mathrm{s}$.

Chen [75] tested a wider range of longitudinal air velocities than the UPTUN DMT tests. The water mist system, which produced a relatively small size of droplets with sizes of 
$350 \mu \mathrm{m}$ and $170 \mu \mathrm{m}$ depending on the type of nozzle, was tested under various velocities from $0.4 \mathrm{~m} / \mathrm{s}$ to $3.5 \mathrm{~m} / \mathrm{s}$ (equivalent to $1.5 \mathrm{~m} / \mathrm{s}$ to $11 \mathrm{~m} / \mathrm{s}$ in large scale). The efficiency of the suppression system was measured in terms of the surface flame extinguishing time. Fire extinguishing time was affected by the longitudinal ventilation speed and the interval between the nozzle and the fire source.

Similar results were found in tests using deluge water spray system in the small-scale tests by Ingason [59]. The maximum burning rate with suppression active at a velocity of $0.21 \mathrm{~m} / \mathrm{s}$ (about $1 \mathrm{~m} / \mathrm{s}$ in large scale) was found to be much lower than that at a velocity of $0.62 \mathrm{~m} / \mathrm{s}$ (about $3 \mathrm{~m} / \mathrm{s}$ in large scale). However, the relative reduction in HRR should be compared to the corresponding free burn test to properly evaluate the effect of the air velocities.

7) Effect of the water curtain system

The design objectives of a water curtain system are compartmentation of the fire area, reduction in the spread of heat and prevention of smoke propagation. In the UPTUN IF tunnel tests [74], compartmentation of a section of $30 \mathrm{~m}$ around the fire was attempted by the water curtain system with a total water flow rate of $1200 \mathrm{l} / \mathrm{min}$. The results showed that the objectives were reached to some extent. The temperature outside of the compartment zone was decreased, and smoke spread to the outside of the compartment was prevented. However, under an air velocity of $3 \mathrm{~m} / \mathrm{s}$, heat and smoke were transported through the water spray curtain. 
In the small-scale tests by Ingason [59], the deluge system was tested in cooling mode similar to the water curtain system. The study found that the cooling effect of the water curtain system was quite efficient, which was dependent on the water flow rate. The water curtain system was effective in reducing the heat flux, which was reduced by about $60 \%$ at $20 \mathrm{~m}$ downstream of the fire when using $558 \mathrm{l} / \mathrm{min}$. However, the arrangement of the water curtain system was quite close to the fire so that the mitigation effects were not a result of providing compartmentation but mainly due to the cooling of the hot gases.

\section{8) Comparison of different systems}

UPTUN DMT tunnel study [72] made a qualitative comparison of different water spray systems used in the tests. Both sprinkler systems and water mist systems can mitigate the hazards from the fire. The investment costs of installing a sprinkler, water mist and water curtain system could be different. Also, the cost of operation of each system was different due to the various amounts of water discharge rates. The sprinkler system and water curtain system use larger amounts of water than the water mist system.

In the UPTUN If tunnel tests [74], high and low pressure water mist systems were tested; however, the test setup was not designed for a full quantitative comparison of these two systems. The study concluded that the expected mitigation was $40 \sim 60 \%$ and $50 \sim 70 \%$ for the low pressure system and the high pressure system, respectively. The low pressure system gave better results for pool fires, while the high pressure worked better for wood pallet fires. 
9) Time of activation

To investigate the influence of the time of activation, in the UPTUN DMT tunnel tests [72], the sprinkler system and the water mist system were activated at 120 or 90 seconds after the fire was fully developed. This did not show any impact since the pool fire used in the tests generated a constant HRR after the fire had become fully developed, and the severity at $90 \mathrm{~s}$ was basically not different from that at $120 \mathrm{~s}$.

An influence of the time of activation can be expected when the fire is in the growth phase, where the severity of the fire (HRR) increases every second.

10) Secondary effects

There is no recent tunnel study that reported dangers caused by steam formation and deflagration other than the Ofenegg tunnel study in 1965 . However, it was reported that it was difficult to enter the test tunnel immediately after suppression tests even though the temperatures downstream of a fire were reduced to tenable levels.

The Ofenegg tunnel study [71] reported some secondary effects when using a sprinkler system in pool fire tests. The large volume of steam pushed the hot smoke so that higher temperatures were observed in the neighbouring section. Even after extinguishment, fuel kept evaporating, and the fuel vapour spread along the tunnel. After about $20 \mathrm{~min}$, the critical concentration was reached; deflagration took place with a gust of wind up to 30 $\mathrm{m} / \mathrm{s}$. Some of the fuel vapour that caused the deflagration might have been generated by the water droplets while interacting with the fire (i.e. in the case of pool fires, fine mists of liquid fuel can be ejected when water droplets boil rapidly due to high temperatures). 
The deflagration may have occurred due to the large amounts of unburned fuel vapour generated in the under-ventilated condition. The study used particularly large pools of $47.4 \mathrm{~m}^{2}$ and $95 \mathrm{~m}^{2}$. The reported burning rates from these pool fires appeared to be significantly low $\left(0.8 \sim 0.91 / \mathrm{m}^{2} \mathrm{~min}\right)$ relative to the pool areas, indicating under ventilated combustion in the test tunnel. The paper does not discuss the deflagration much; however, this unfavourable secondary effect concerned many engineers who have considered the use of suppression systems in tunnels.

To examine the possible steam formation, a van loaded with $400 \mathrm{~kg}$ of wood pallets (15 MW) was tested right under a sprinkler system in the second Benelux tunnel study [39]. The activation of the sprinkler system was delayed until 14 min after ignition, and a low air velocity of $1 \mathrm{~m} / \mathrm{s}$ was maintained during the test to help steam formation. No significant steam formation was observed.

The steam formation can be affected by the weather condition. In cold weather, more steam can be produced in the tunnel.

\subsection{Summary}

- Tunnel fires can be very large. In particular, the HRR of Heavy Good Vehicle (HGV) fires was found to be in the range of 20-200MW.

- Longitudinal air flows affected the development of tunnel fires, although there is not enough test data available to estimate the influence of air flows on fire development.

- The HRR of tunnel fires was successfully measured using the method of oxygen calorimetry; however, accurate measurements of HRR require several measuring probes depending on the flow conditions. 
- The large quantity of water vapour generated by the suppression system can affect the accuracy of HRR measurements. However, there is no study that evaluated the measurements of large-scale fires during suppression with various water spray rates and ventilation conditions.

- A longitudinal ventilation system effectively controls smoke by pushing smoke downstream and clearing upstream of the fire. However, the development of fire can also significantly increase even when the longitudinal ventilation is about 3 $\mathrm{m} / \mathrm{s}$, which is ironically the critical velocity of the longitudinal ventilation system required to prevent backlayering of smoke.

- Previous suppression tests in tunnels show that WFFFS can arrest the development of a fire at the time of activation and keep the HRR constant at its value at the time of activation. It was also proven that WFFFS can reduce smoke temperature and radiation significantly. However, WFFFS disturbs the smoke stratification and lowers the smoke layer.

- The previous studies have examined the influence of the longitudinal air flow generated by ventilation systems on the effectiveness of WFFFS, but the influence of the WFFFS on the effectiveness of longitudinal ventilation systems has not been studied.

- There is no study that examined closely the effect of both WFFFS and longitudinal ventilation systems on cooling smoke temperature and attenuating radiation.

- There is no method to quantify the mitigation effect of WFFFS on tunnel fires, and there are no guidelines specifying design criteria to integrate WFFFS with other systems, such as ventilation system, into the overall tunnel fire safety system.

It is clear that the test data from the previous studies do not provide answers to some important questions regarding the use of both WFFFS and longitudinal ventilation systems. 


\section{CHAPTER 3. DESIGN OF HRR MEASUREMET SYSTEM FOR THE TUNNEL FACILTY}

From the literature review and the nature of the projects to be undertaken, the following requirements for the HRR measurement system for the Carleton tunnel facility have been indentified;

- The method of HRR measurement should be accurate and reliable under different ventilation conditions and with the suppression system operating.

- The system should require the least amount of instrumentation that ensures reasonable accuracy.

- The system should be able to calculate and display measurements in real time.

- The system should be able to measure various types of large tunnel fires larger than $20 \mathrm{MW}$

This chapter describes the tunnel facility, methodology used in the measurement system, instrumentation design and the programming of the real-time calculation system.

\subsection{The tunnel facility and the design of HRR measurement system}

A new fire research laboratory at Carleton University has been constructed in Almonte, Ontario, Canada. The facility houses a 10-storey atrium, a burn hall, and a $37.5 \mathrm{~m}$ long tunnel for performing large-scale fire experiments and smoke management research. Figure 3-1 shows a schematic of the facility.

The mechanical exhaust system that consists of three fans capable of exhausting a total of $132 \mathrm{~m}^{3} / \mathrm{s}(285,000 \mathrm{cfm})$ of gas is located on top of the tunnel. Two fans are located at the east end of the facility at the fan chamber level, and one fan is located at the attic level as 
shown in Figure 3-1. The exhaust fan system is designed to draw smoke selectively from the tunnel or the atrium through a large fan chamber, which is connected to each facility.

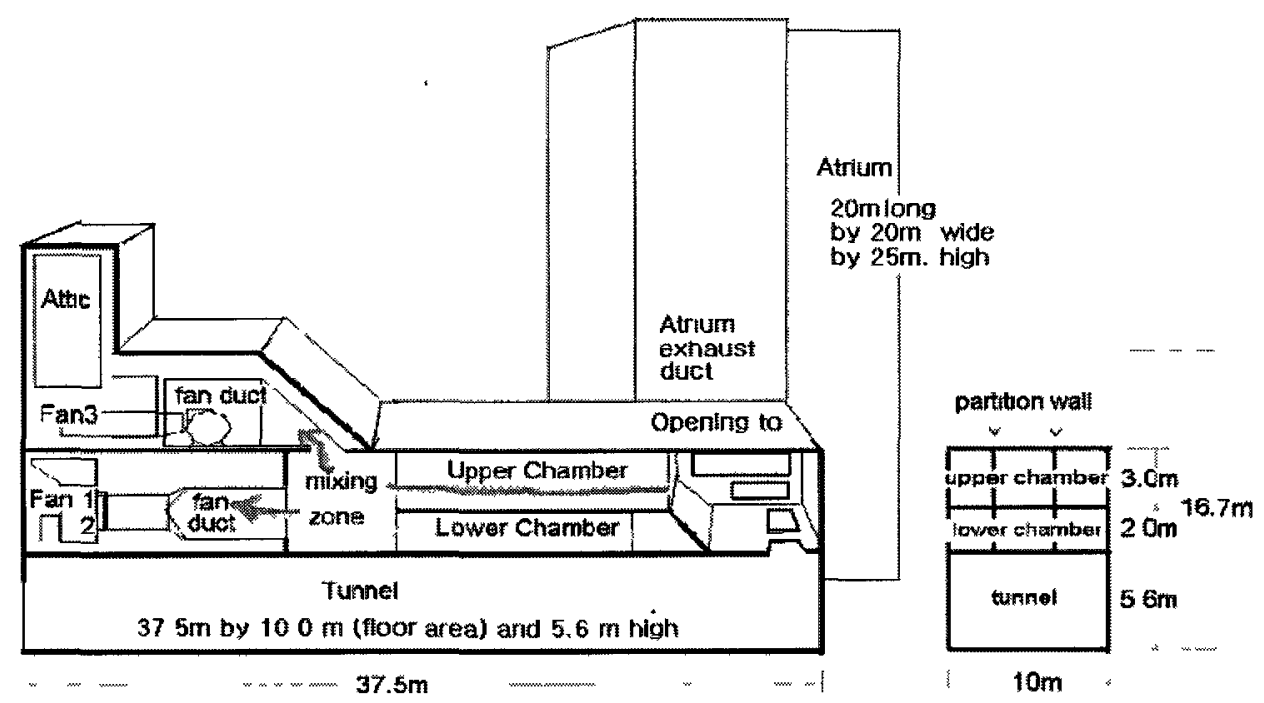

Figure 3-1 Schematic of Carleton laboratory facility [79]

To develop a HRR measurement system for the facility, a preliminary study was conducted to obtain insight into the flow characteristics in the fan chambers using Computational Fluid Dynamics (CFD) modelling of the facility. Detailed model descriptions are presented in Chapter 3.3.1. The fan chamber is divided into two levels; a lower chamber and an upper chamber, and each level is divided into three sections by partition walls as shown in Figure 3-1. Before entering into the fan ducts, the flow from both the lower and upper chamber mixes in the mixing zone, which is not subdivided by the slab and partition walls.

From the preliminary CFD study, it was found that the HRR estimation by oxygen consumption is feasible provided a suitable fan capacity is used for a specific fire. It was also found that it is necessary to direct smoke into a single chamber to avoid examining the flow in each sub-chamber for possible variance. Some delay is inevitable due to the 
size of the tunnel and exhaust system. The fan chamber is long enough for the velocity profile of the flow to be fully-developed so that the flow is reasonably uniform at the end of the chamber. Figure 3-2 shows the transition of velocity profile through the fan chamber. Therefore, the HRR measurement system can be developed by collecting data at the end of the upper middle chamber ( $5.66 \mathrm{~m}$ wide by $2.94 \mathrm{~m}$ high), by directing all combustion products through this design area, where the instrumentation measures various parameters of the gas. Figure 3-3 shows a schematic of the HRR measurement system using the oxygen consumption method for the facility.

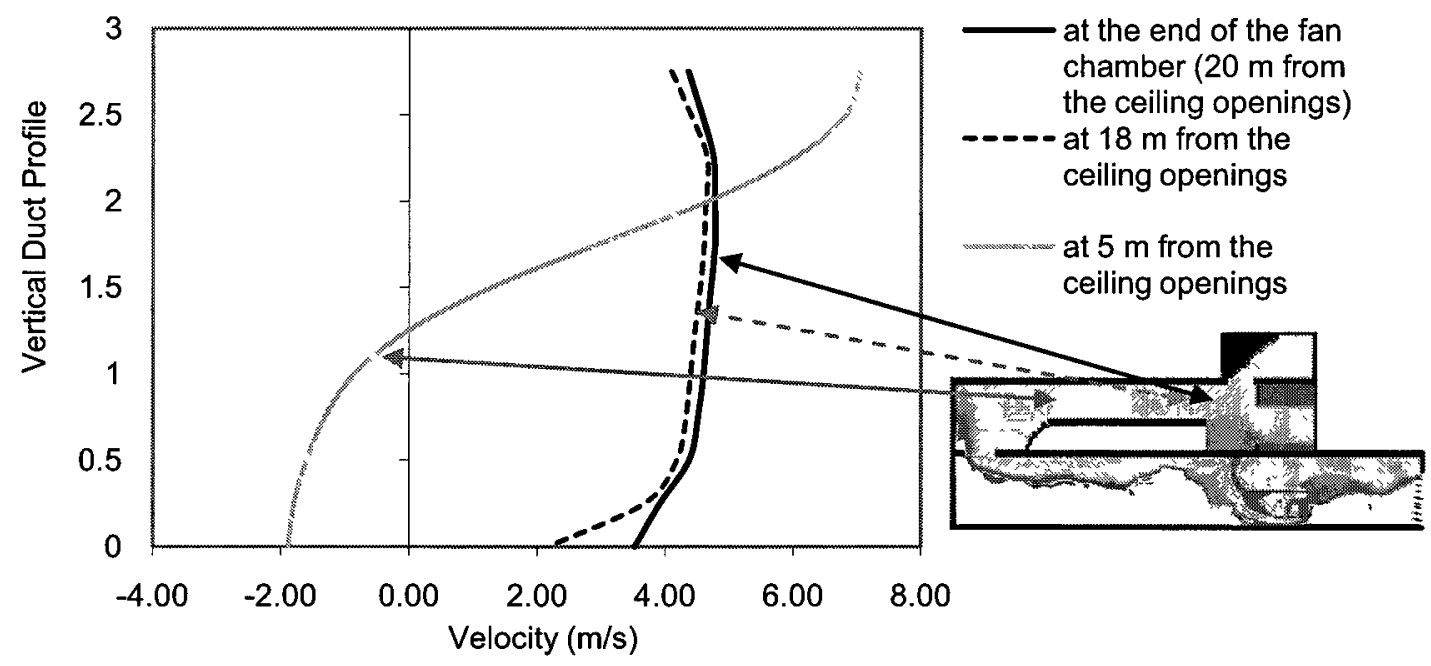

Figure 3-2 Velocity profile transitions through the fan chamber (simulation results with a $20 \mathrm{MW}$ fire in the tunnel with $50 \%$ fan speed) 


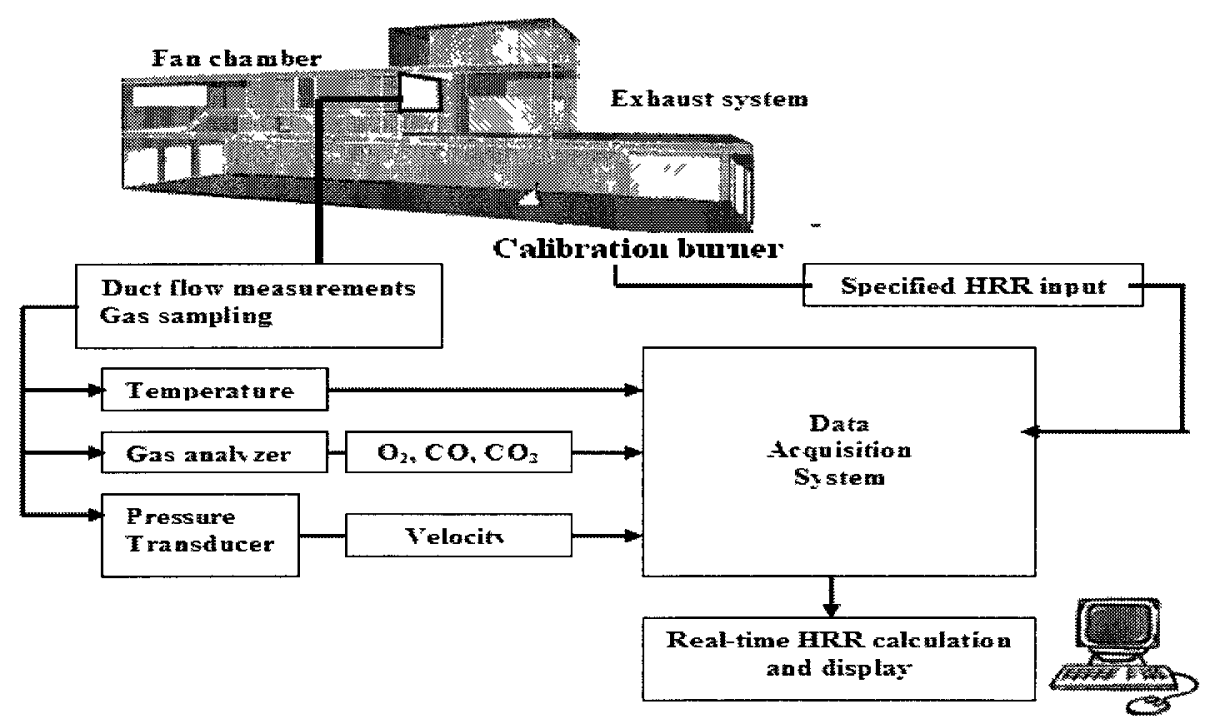

Figure 3-3 Schematics of HRR Measurement System [79]

\subsection{Methodology of oxygen consumption calorimetry}

Methods to calculate HRR using oxygen consumption calorimetry were developed by Janssen [80] and Parker [52], for various gas analysis configurations. In principle, HRR can be calculated by measuring the amount of oxygen consumed in the combustion process as for most organic materials, the same amount of heat $(E)$ is released per unit mass of oxygen consumed [51]. HRR can be calculated as shown in Eq 8, where $\emptyset$ is the oxygen depletion factor, and $\dot{\mathrm{m}}_{\mathrm{O}_{2}}^{\mathrm{o}}$ is the mass flow rate of oxygen in the incoming air.

$$
\mathrm{Q}=E\left(\varnothing \dot{\mathrm{m}}_{\mathrm{O}_{2}}^{\circ}\right)
$$

Eq 8

The calculation of HRR, however, can be overestimated in the case of incomplete combustion, as the heat released per unit mass of oxygen consumed in the formation of $\mathrm{CO}$ is much less than in the formation of $\mathrm{CO}_{2}$. The difference $\left(E_{C O}\right)$ of heat released of $\mathrm{CO}$ and $\mathrm{CO}_{2}(283 \mathrm{~kJ} / \mathrm{mol}$ of oxygen consumed $)$ must be accounted for in the calculation of HRR. Although the effect of $\mathrm{CO}$ is negligible when the concentration of $\mathrm{CO}$ is less 
than $10 \%$ of that of $\mathrm{CO}_{2}$ [51], large amounts of $\mathrm{CO}$ are possible in suppression tests and in under-ventilated fires. Taking into account the fraction $(f)$ of oxygen used for CO formation, $\mathrm{Eq} 8$ can be rewritten as $\mathrm{Eq} 9$.

$$
\mathrm{Q}=E_{O 2}(1+f)\left(\emptyset \dot{\mathrm{m}}_{O_{2}}^{\circ}\right)-E_{C O} f\left(\emptyset \dot{\mathrm{m}}_{O_{2}}^{\mathrm{o}}\right)=\left[E_{O 2}-\left(E_{C O}-E_{O 2}\right) f\right]\left(\emptyset \dot{\mathrm{m}}_{O_{2}}^{\mathrm{o}}\right) \quad \text { Eq } 9
$$

The mass flow rates of incoming oxygen $\left(\dot{\mathrm{m}}_{\mathrm{O}_{2}}^{\mathrm{o}}\right.$ ) should be expressed as $X_{O_{2}}^{o} \dot{m}_{a}^{o} \frac{M_{O_{2}}}{M_{a}}$ as the volumetric fraction of oxygen is measured in the system.

The equation becomes;

$$
\mathrm{Q}=\left[E_{O 2}-\left(E_{C O}-E_{O 2}\right) f\right] \emptyset \dot{m}_{a}^{o} \frac{M_{O_{2}}}{M_{a}} X_{O_{2}}^{o}
$$

We need to find expressions for the incomplete combustion factor $(f)$, oxygen depletion factor $(\emptyset)$, mass flow rate of the incoming air $\left(\dot{m}_{a}^{o}\right)$, and the volumetric fraction of oxygen in the incoming air $\left(X_{O_{2}}^{o}\right)$. Ultimately, these terms should be expressed using the gas concentration measurements made in the gas analysis system.

Some factors should be considered; first, gas concentrations measured by the gas analyser are not the actual gas concentrations in the exhaust system because most gas analyzers use gas coming from a sampling line which traps water vapour from the gas. The measured gas concentrations, therefore, do not represent the actual gas concentrations in the hot smoke due to the removal of the water vapour contents [52].

Second, the mass flow rate measured in the exhaust system is technically not the mass flow rate of incoming air because part of the incoming air is used in the combustion 
process. Figure 3-4 shows a schematic of the oxygen calorimetry measurement system. Note that superscript Ao indicates the value measured by the gas analysis system for incoming air, and superscript Ae indicates the value measured by the gas analysis system for the exhaust gas.

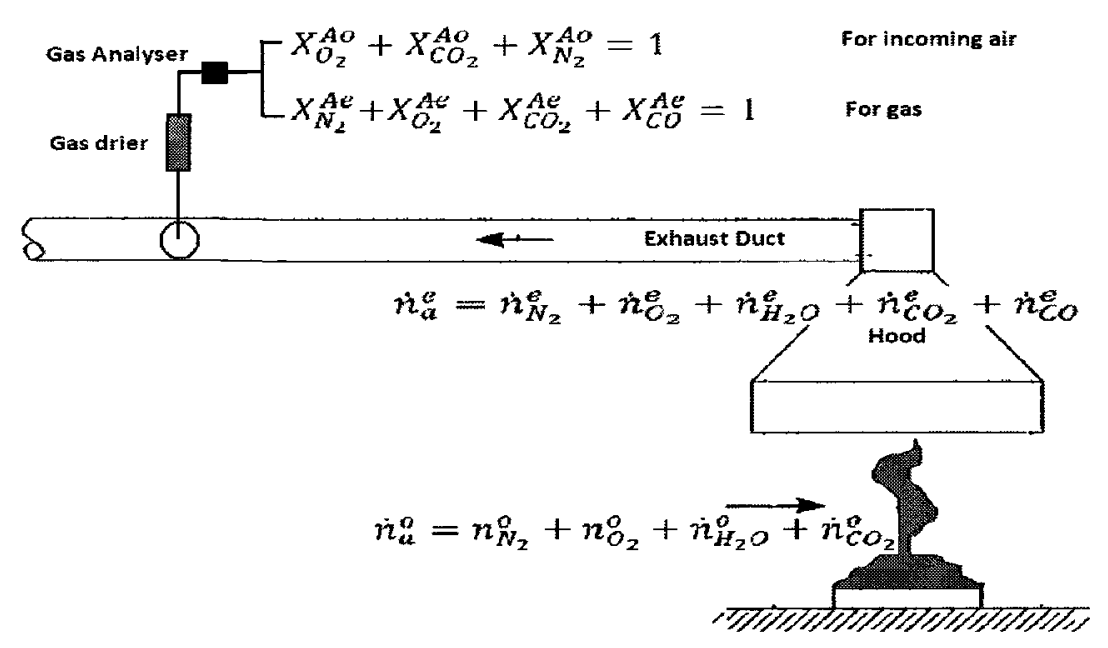

Figure 3-4 Schematics of oxygen calorimetry

Oxygen depletion factor $(\emptyset)$ : The oxygen depletion factor can be expressed as Eq 11 by definition. Ultimately, $\emptyset$ needs to be calculated based on gas concentration measurements made in the gas analyzer. As nitrogen is conserved $\left(\dot{m}_{N_{2}}^{o}=\dot{m}_{N_{2}}^{e}\right)$ through the combustion process, $\dot{n}_{a}^{o}$ and $\dot{n}_{a}^{e}$ can be expressed in terms of nitrogen as Eq 12. Here, we know that the measured gas concentrations by the gas analyzer are not the actual gas concentrations in the hot smoke (e.g. $X_{O_{2}}^{o} \neq X_{O_{2}}^{A o}, X_{N_{2}}^{e} \neq X_{N_{2}}^{A e}$ ). Nevertheless, the concentration ratio of oxygen and nitrogen measured in the analyzer is equal to the actual ratio of oxygen and nitrogen in the hot smoke $\left(\frac{X_{O_{2}}^{o}}{X_{N_{2}}^{o}}=\frac{X_{O_{2}}^{A o}}{X_{N_{2}}^{A o}}\right)$ [52]. As the concentration of 
nitrogen is not measured, $\emptyset$ can be rewritten as Eq 14 using $\left(X_{N_{2}}^{A e}=1-X_{O_{2}}^{A e}-X_{C O_{2}}^{A e}-X_{C O}^{A e}\right)[80][81]$.

$$
\begin{gathered}
\emptyset=\frac{\dot{n}_{O_{2}}^{o}-\dot{n}_{O_{2}}^{e}}{\dot{n}_{O_{2}}^{o}}=\frac{X_{O_{2}}^{o} \dot{n}_{a}^{o}-X_{O_{2}}^{e} \dot{n}_{a}^{e}}{X_{O_{2}}^{o} \dot{n}_{a}^{o}} \\
\dot{n}_{a}=\frac{1}{X_{N_{2}}} \frac{\dot{m}_{N_{2}}}{M_{N_{2}}} \\
\emptyset=\frac{X_{O_{2}}^{o} \frac{\dot{m}_{N_{2}}^{o}}{M_{N_{2}}^{o}}-\frac{X_{O_{2}}^{e}}{X_{N_{2}}^{e}} \frac{\dot{m}_{N_{2}}^{e}}{M_{N_{2}}}=\frac{\frac{X_{O_{2}}^{o}}{X_{N_{2}}^{o}}-\frac{X_{O_{2}}^{e}}{X_{N_{2}}^{e}}}{\frac{X_{O_{2}}^{o}}{X_{O_{2}}^{o}}}=\frac{\dot{m}_{N_{2}}^{o}}{X_{N_{2}}^{o}}=\frac{X_{N_{2}}^{A o}}{M_{N_{2}}^{A o}} \frac{X_{O_{2}}^{A e}}{X_{N_{2}}^{A e}}}{\frac{X_{O_{2}}^{A o}}{X_{N_{2}}^{A o}}} \\
\emptyset=\frac{X_{O_{2}}^{A_{2}^{o}}\left(1-X_{C O_{2}}^{A e}-X_{C o}^{A e}\right)-X_{O_{2}}^{A e}\left(1-X_{C O_{2}}^{A^{o}}\right)}{\left(1-X_{O_{2}}^{A e}-X_{C O_{2}}^{A e}-X_{C o}^{A e}\right) X_{O_{2}}^{A^{o}}}
\end{gathered}
$$

Incomplete combustion factor $(f)$ : In the case of incomplete combustion, a fraction of oxygen, $f\left(\dot{n}_{O_{2}}^{o}-\dot{n}_{O_{2}}^{e}\right)$, used in the combustion process generates $\operatorname{CO}\left(\frac{1}{2} \dot{n}_{C O}^{e}\right)$. Using the oxygen depletion factor $(\emptyset)$, the incomplete combustion factor $(f)$ can be simplified as below [52].

$$
f=\frac{\frac{1}{2} \dot{n}_{C O}^{e}}{\left(\dot{n}_{O_{2}}^{o}-\dot{n}_{O_{2}}^{e}\right)}=\frac{1}{2}\left(\frac{1-\emptyset}{\emptyset \dot{n}_{O_{2}}^{e}}\right) \dot{n}_{C O}^{e}=\frac{(1-\emptyset)}{2 \emptyset} \frac{\dot{n}_{C O}^{e}}{\dot{n}_{O_{2}}^{e}}=\frac{(1-\emptyset)}{2 \emptyset} \frac{X_{C O}^{A e}}{X_{O_{2}}^{\mathrm{Ae}}}
$$

Mass flow rate of incoming air in an open system $\left(\dot{m}_{a}^{o}\right)$ : While the mass flow rate of exhaust gas $\left(\dot{m}_{a}^{e}\right)$ is measured in the duct, the mass flow rate of the incoming air into the system $\left(\dot{m}_{a}^{o}\right)$ cannot be measured when the system is open [80], [81]. However, the mass flow rate of the incoming air can be found based on the relation shown in Eq 16. The number of moles of exhaust gas is not equal to the number of moles of incoming air since 
the fraction of moles $\left(\varnothing \dot{n}_{a}^{o}\right)$ that participated in the combustion process are replaced by a larger number of moles of combustion products. $\alpha$ is the chemical expansion factor defined in $\mathrm{Eq} \mathrm{18,} \mathrm{where} \beta$ is a mole ratio of the combustion products formed by the oxygen consumed [52]. Values of $\alpha$ varies from 1.00 to 1.21 depending on the burning materials. Parker suggested using 1.10 for $\alpha$ for unknown burning materials. Assuming $M_{a}^{e}=M_{a}^{o}$, Eq 16 becomes Eq 17.

$$
\begin{array}{cc}
\dot{n}_{a}^{e}=\dot{n}_{a}^{o}-\emptyset \dot{n}_{a}^{o}+\alpha \emptyset \dot{n}_{a}^{o} & \text { Eq } 16 \\
\dot{m}_{a}^{e}=\dot{m}_{a}^{o}-\emptyset \dot{m}_{a}^{o}+\alpha \emptyset \dot{m}_{a}^{o}=\{1+\emptyset(\alpha-1)\} \dot{m}_{a}^{o} & \text { Eq } 17 \\
\dot{m}_{a}^{o}=\frac{\dot{m}_{a}^{e}}{1+\emptyset(\alpha-1)} & \text { Eq } 18 \\
\text { Where } \alpha=X_{N_{2}}^{o}+X_{H_{2} O}^{o}+X_{C O_{2}}^{o}+\beta X_{O_{2}}^{o}=1+X_{O_{2}}^{o}(\beta-1) \approx 1.105 &
\end{array}
$$

In the case where measurements of water vapour are available, the expansion factor can be calculated based on the actual mole fraction of water vapour in the exhaust flow measured. The detailed equation can be found in the literature [80].

Volumetric fraction of oxygen $\left(X_{O_{2}}^{o}\right)$ : As water vapour is removed from the sampling gas, $X_{O_{2}}^{o}$ should be calculated using Eq 19.

$$
\begin{aligned}
& X_{O_{2}}^{o}=\frac{\dot{n}_{O_{2}}^{o}}{\dot{n}_{N_{2}}^{o}+\dot{n}_{O_{2}}^{o}+\dot{n}_{H_{2} O}^{o}+\dot{n}_{C O}^{o}+\dot{n}_{C O_{2}}^{o}} \\
& =\frac{\dot{n}_{O_{2}}^{o}}{\left(\dot{n}_{N_{2}}^{o}+\dot{n}_{O_{2}}^{o}+\dot{n}_{C O}^{o}+\dot{n}_{C O_{2}}^{o}\right)} \frac{\left(\dot{n}_{N_{2}}^{o}+\dot{n}_{O_{2}}^{o}+\dot{n}_{C O}^{o}+\dot{n}_{C O_{2}}^{o}\right)}{\left(\dot{n}_{N_{2}}^{o}+\dot{n}_{O_{2}}^{o}+\dot{n}_{H_{2} O}^{o}+\dot{n}_{C O}^{o}+\dot{n}_{C O_{2}}^{o}\right)} \\
& =X_{O_{2}}^{A^{o}}\left(1-X_{H_{2} o}^{o}\right)
\end{aligned}
$$


Finally, Eq 10 becomes Eq 20 using expressions for incomplete combustion factor $(f)$, oxygen depletion factor $(\varnothing)$, mass flow rate of the incoming air $\left(\dot{m}_{a}^{o}\right)$, and the volumetric fraction of oxygen $\left(X_{O_{2}}^{o}\right)$.

$$
\begin{gathered}
\mathrm{Q}=\left[E_{O 2}-\left(E_{C o}-E_{O 2}\right) f\right] \emptyset \dot{m}_{a}^{o} \frac{M_{O_{2}}}{M_{a}} X_{O_{2}}^{o} \\
=\left[E_{O 2}-\left(E_{C O}-E_{O 2}\right) \frac{(1-\emptyset)}{2 \emptyset} \frac{X_{C O}^{A e}}{X_{O_{2}}^{A e}}\right] \emptyset \frac{\dot{m}_{e}}{1+\emptyset(\alpha-1)} \frac{M_{O_{2}}}{M_{a}}\left(1-X_{H_{2} O}^{o}\right) X_{O_{2}}^{A^{o}} \\
\text { Where } \emptyset=\frac{X_{O_{2}}^{A^{o}}\left(1-X_{C O_{2}}^{A e}-X_{C O}^{A e}\right)-X_{O_{2}}^{A e}\left(1-X_{C O_{2}}^{A^{o}}\right)}{\left(1-X_{O_{2}}^{A e}-X_{C O_{2}}^{A e}-X_{C O}^{A e}\right) X_{O_{2}}^{A O}} \\
X_{H_{2} O}^{o}=\frac{R H p_{S}\left(T_{0}\right)}{p_{a}}=\frac{R H}{p_{a}} E X P\left(23.2-\frac{3816}{-46+T_{0}}\right) \\
M_{a}=M_{d r y}\left(1-X_{H_{2} o}^{o}\right)+M_{H_{2} O} X_{H_{2} O}^{o} O
\end{gathered}
$$

As water vapour concentrations are not measured in the gas analysis system, molar fractions of water vapour in the incoming air $\left(X_{\mathrm{H}_{2} \mathrm{O}}^{\mathrm{O}}\right)$ can be calculated using Eq 21 obtained from the Clausius-Clapeyron equation. $\mathrm{RH}$ is Relative humidity, $p_{s}\left(T_{0}\right)$ is saturation pressure of water vapour at ambient temperature $\mathrm{T}_{0}$, and $p_{a}$ is air pressure $(\mathrm{Pa})$. The molecular weight of incoming air needs to be calculated taking account water vapour concentrations using Eq 22 developed by Janssens [80].

\subsubsection{Mass flow rate calculation}

The accuracy of the oxygen calorimetry depends sensitively on correct measurements of the mass flow rates. In general, the shape of the velocity profile of a fully-developed 
turbulent flow in a pipe is uniform over the cross section, yet the velocity gradually decreases near the walls due to wall friction. For this reason, a correction factor $(\zeta)$ is required when calculating the mass flow rate of the flow in a duct [82].

$$
\dot{m}_{e}=\zeta A V \rho
$$

The correction factor is directly related to the velocity profile of the flow. The fundamental equation defining the relation between the wall friction and the velocity profile is established for pipe flows with Re in the range of $4 \times 10^{3}$ to $3.24 \times 10^{6}$ [83]. The degree of the velocity deflection from the centre of the pipe to pipe wall can be expressed using the exponent $\mathbf{n}$ in Eq 24. Then, the correction factor can be obtained using Eq 25, where the exponent $\mathrm{n}$ varies with the Re (Reynolds number). This means that the velocity profile of the flow with a large Re is fuller and more uniform than at a low Re.

$$
\begin{gathered}
\frac{V_{\text {at } y}}{V_{\text {centre }}}=\left(\frac{y}{r}\right)^{\frac{1}{n}} \\
\zeta=2 n^{2} /(n+1)(2 n+1)
\end{gathered}
$$

Where $\mathrm{y}$ is the distance from the centre of the pipe to a point of interest, and $\mathrm{r}$ is the radius of the pipe. Grant and Drysdale [36]; and Ingason [40] applied this equation in their calculation of HRR of tunnel fires, where they adopted $\zeta=0.817$ which is suggested by Schichting for flows with $\mathrm{n}=8.8$ for $\mathrm{Re}=1.1 \times 10^{6}$.

In the present study concerning fully-developed turbulent flow through the large rectangular fan chamber, the fundamental concept can be applied, but the correction factor must be found experimentally by examining flows under various conditions. In 
many applications of oxygen calorimetry, the correction factor was found by calibrating the system. Babrauskas [53] found a correction factor (orifice meter calibration constant) for the calculation of HRR in the bench-scale cone calorimeter. Brenden and Chamberlain [84] obtained a calibration constant from velocity mapping tests over the fire resistance test furnace for wall assemblies. Yeager [85], in a room fire test HRR measurement system, examined a proportional constant to adjust the mass flow rate measurements and found that the constant is dependent on fan speeds. NIST [55] used an empirical flow coefficient to calculate mass flow rates. For a HRR measurement system to be used for the Single Burning Item (SBI) Axelsson et al. [86] found a velocity profile correction factor from calibration test results.

\subsubsection{Velocity calculation}

Bi-directional probes are often used to measure velocities in fire tests because the measurement is quite accurate for low velocity and high temperature flows found in medium- and large-scale fire tests. In addition, they are insensitive to small changes in orientation (angle) and sooty environments unlike the hot wire anemometer or pitot tubes. A limitation of bi-directional probes is that measurements are incorrect for $\operatorname{Re}<200$ (Baker effect [87]), which makes it difficult to calibrate pressure transducers. As it measures pressure differences of the static pressure on one side and dynamic pressure on the other, the probes can measure velocities of the flow-in and flow-out. The measured pressure difference can be converted to a velocity based on the density and Reynolds number (Re) of the flow, as Eq 26. 


$$
V=\frac{1}{k_{p}} \sqrt{\frac{2 \Delta p}{\rho}}
$$

The original design of the probe (see Figure 3-5(b)) [88] has been considered as a standard and has been used in various fire experiments. The probe constant $\left(k_{p}\right)$ depends on Re. McCaffrey and Heskestad found a correlation of $k_{p}$ for Re in the range of 40 and 3800, which is in fact a bit lower than the Re experienced in the bi-directional probe for flows induced by large fires. Sette [89] explored the probe constant $\left(k_{p}\right)$ in the large $\mathrm{Re}$ range of 3000 and 21000 using the standard design probe as well as probes of slightly modified designs (one having $L<2 D$ ). The results showed that while the probe constant $\left(k_{p}\right)$ varies depending on the design, the differences are not significant, and the value of $k_{p}$ became independent of $\operatorname{Re}$ for $\operatorname{Re}>13000$ (the asymptotic value being 1.045).

In the present study, bi-directional probes were fabricated using copper tubes, and the dimensions were slightly modified as shown in Figure 3-6 for practical reasons ( $L<2 D$ and $D^{\prime} \neq 4.70 \mathrm{~mm}$ ). Based on the calibration of the bi-directional probes under limited conditions that can be encountered in the laboratory, we found that the probe constant $\left(k_{p}\right)$ is 1.1 , which is close to the asymptotic value of 1.08 (for $\mathrm{Re}>2500$ as in Figure 3-5 (a)) suggested by McCaffrey and Heskestad [88]. 

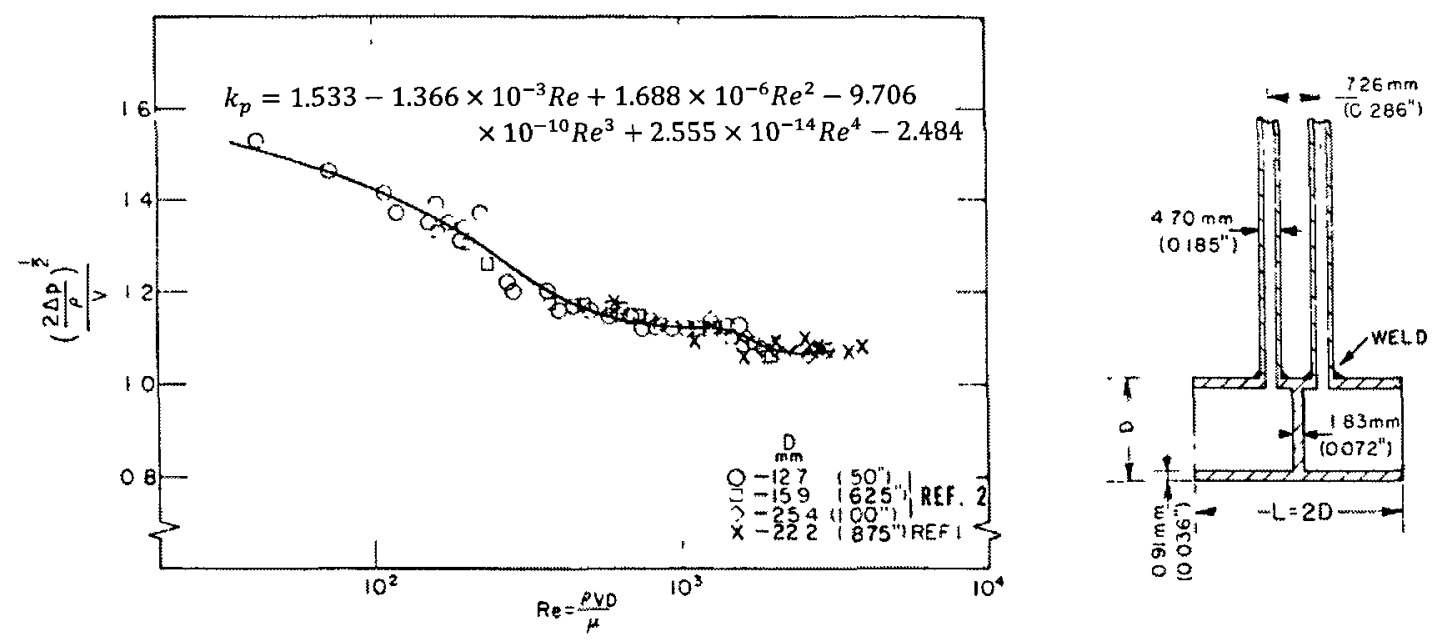

Figure 3-5 (a) Probe constant as function of Re (b) standard design of the probe [88]

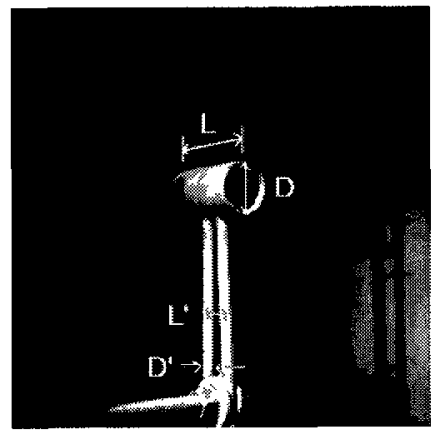

Figure 3-6 Bi-directional probe dimensions used in the current study $(D=24.6 \mathrm{~mm}, L=46.25 \mathrm{~mm}$, $D^{\prime}=6.3 \mathrm{~mm}$, and $\mathrm{L}^{\prime}=7.6 \mathrm{~mm}$ )

\subsection{Instrumentation design}

In order to measure the HRR of a burning item, all combustion products must be collected and directed through an area where instrumentation exists to measure various parameters of the smoke. Accurate measurements of the mass flow rate, $\mathrm{CO}_{2}, \mathrm{CO}$ and $\mathrm{O}_{2}$ concentrations are required to provide an estimation of HRR using oxygen calorimetry. HRR calculations are particularly sensitive to oxygen concentrations. In addition, accurate measurements of the mass flow rate of gases are challenging due to the nature of 
the flow inside the large chamber of the facility. Thus, the profile of the flow in the fan chamber must be examined carefully in order to determine where to place the various probes. The temperature and gas concentration profiles are relatively uniform because of a high amount of mixing and turbulence through the relatively long fan chamber. However, for the same reason, the velocity profile had to be looked at very closely to find an optimum combination of bi-directional probes. More details about this are published in [79].

The objectives of this task were;

- to design the instrumentation for accurate temperature, gas concentration and velocity measurements with the least number of devices; and

- to find permanent locations suitable for the measurements that can serve both the tunnel and the atrium.

The methods used for determining these locations were;

- Run CFD simulations for various fan speeds and ventilation arrangements for both the tunnel and the atrium.

- Obtain temperatures, gas concentrations, and velocity profiles over the measurement area.

- Where possible, validate simulated results with manual measurements.

- Analyse the results to determine the best combination of instrumentation.

\subsubsection{CFD simulations and manual measurements}

FDS5 [90] was used for simulating flows in the facility. Figure 3-7 shows the geometry used in the model, which has the same dimensions as the tunnel facility. A grid size of $0.25 \mathrm{~m}$ was applied to the entire computational domain since this grid size was found to 
yield reasonable values from previous studies [91] conducted for the tunnel facility. In addition, this resolution is in accordance with values that are suggested by the FDS guidelines [90] The fans were modelled as vents with constant volumetric flow rates corresponding to the actual fan capacities of the facility. A fire source was placed in the tunnel $9 \mathrm{~m}$ from the east end of the facility.

Seven sets of manual velocity measurements were carried out over the measurement area, the upper middle chamber, using $0.25 \mathrm{~m}$ grid spacing. Velocities at $25,50,75$ and $100 \%$ fan speeds were measured using a hand held anemometer at each point. Most measurements were made without a fire, yet one test was conducted with a $2.5 \mathrm{MW}$ fire in the tunnel.

A list of simulations and measurements is shown in Table 3-1. Simulations of the scenarios using the ventilation open to the atrium were conducted by Michel, and the details of the atrium simulations and results are in [92].

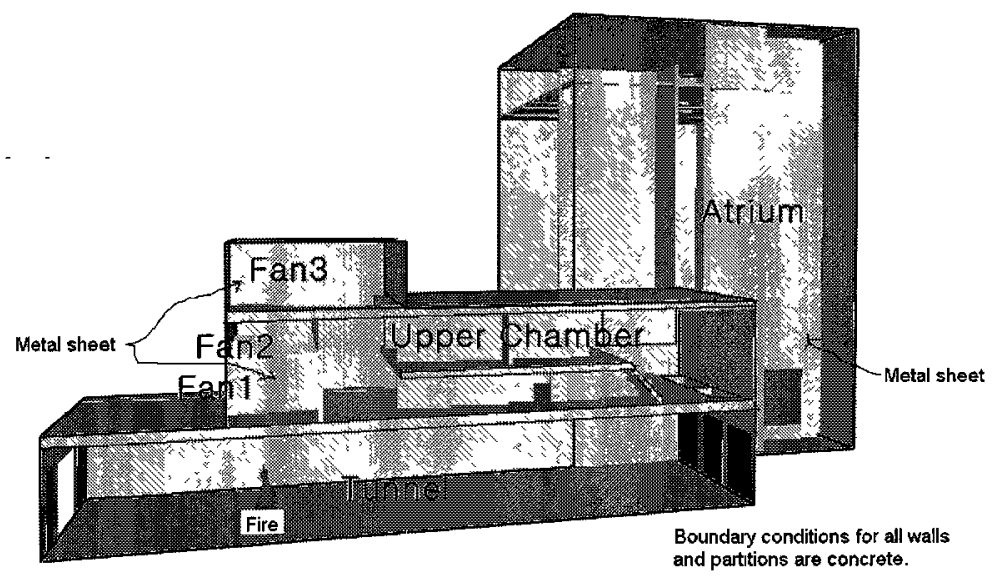

Figure 3-7 Model geometry 
Table 3-1 List of simulations and measurements

\begin{tabular}{|c|c|c|c|c|}
\hline Scenario & Fire Size & Ventilation open to & Fan capacity & Simulation/Measurement \\
\hline 1 & $0 \mathrm{MW}$ & Tunnel & $25 \%$ & Simulation \\
\hline 2 & $0 \mathrm{MW}$ & Tunnel & $25 \%$ & Measurement \\
\hline 3 & $2.5 \mathrm{MW}$ & Atrium & $25 \%$ & Simulation (OD) \\
\hline 4 & $0 \mathrm{MW}$ & Atrium & $25 \%$ & Simulation \\
\hline 5 & $0 \mathrm{MW}$ & Tunnel & $50 \%$ & Simulation \\
\hline 6 & $2.5 \mathrm{MW}$ & Tunnel & $50 \%$ & Simulation \\
\hline 7 & $10 \mathrm{MW}$ & Tunnel & $50 \%$ & Simulation \\
\hline 8 & $20 \mathrm{MW}$ & Tunnel & $50 \%$ & Simulation \\
\hline 9 & $0 \mathrm{MW}$ & Tunnel & $50 \%$ & Measurement \\
\hline 10 & $0 \mathrm{MW}$ & Atrium & $50 \%$ & Simulation \\
\hline 11 & $0 \mathrm{MW}$ & Atrium & $50 \%$ & Simulation (OD) \\
\hline 12 & $10 \mathrm{MW}$ & Atrium & $50 \%$ & Simulation (OD) \\
\hline 13 & $0 \mathrm{MW}$ & Atrium & $50 \%$ & Measurement \\
\hline 14 & $0 \mathrm{MW}$ & Atrium & $50 \%$ & Measurement (OD) \\
\hline 15 & $0 \mathrm{MW}$ & Tunnel & $75 \%$ & Measurement \\
\hline 16 & $0 \mathrm{MW}$ & Tunnel & $75 \%$ & Simulation \\
\hline 17 & $10 \mathrm{MW}$ & Atrium & $75 \%$ & Simulation (OD) \\
\hline 18 & $0 \mathrm{MW}$ & Tunnel & $100 \%$ & Simulation \\
\hline 19 & $0 \mathrm{MW}$ & Tunnel & $100 \%$ & Measurement \\
\hline 20 & $0 \mathrm{MW}$ & Atrium & $100 \%$ & Simulation \\
\hline 21 & $10 \mathrm{MW}$ & Atrium & $100 \%$ & Simulation \\
\hline 22 & $20 \mathrm{MW}$ & Atrium & $100 \%$ & Simulation (OD) \\
\hline 23 & $20 \mathrm{MW}$ & Atrium & $100 \%$ & Simulation \\
\hline 24 & $2.5 \mathrm{MW}$ & Tunnel & $50 \%$ & Measurement \\
\hline 25 & $10 \mathrm{MW}$ & Tunnel & $25 \%$ & Simulation \\
\hline 26 & $10 \mathrm{MW}$ & Tunnel & $100 \%$ & Simulation \\
\hline
\end{tabular}

Note: $O D$ refers to increased ventilation from opening of a second sliding door from the atrium duct into the fan chamber.

Note: Measurements were made only for velocities

Note: $25 \%$ fan speed, the fans were set to move $11.1 \mathrm{~m}^{3} / \mathrm{s}$ and for $100 \%$ they were set to exhaust $44.4 \mathrm{~m}^{3} / \mathrm{s}$ each 


\subsubsection{Profiles of the flow in the chamber}

All FDS simulations, as well as the manual observations, indicate that for any fire scenario, a long time is required for the gases to reach the measuring station. This is due to the large distance between the test section and the measuring station. Because of this, the temperatures in all scenarios were relatively uniform across the measurement area of the fan chamber. Figure 3-8 shows temperature profiles from the FDS simulations of 10 MW fires in the tunnel at different fan speeds.

As for the temperature profiles, one can assume that the profiles of gas concentrations are also uniform over the measurement area. All simulated results confirm that the gas concentrations are relatively uniform by the time the combustion gases reach the sampling location. Figure 3-9 compares vertical profiles of oxygen mass fraction of the flow with a $10 \mathrm{MW}$ fire in the tunnel under different fan speeds. It can be seen that the oxygen concentration is uniform both horizontally and vertically across the measurement area. The oxygen concentration of the flow for the lower fan speeds is lower than that from the $100 \%$ fan speed due to larger air entrainments. In principle, dilution by an unknown quantity of air does not affect the validity of the HRR measurements [51]. The fan chamber needs to collect all combustion products as well as the entrained air in order to obtain an accurate estimation of HRR.

Figure 3-10 compares the vertical velocity profiles of the flow drawn at $50 \%$ fan speed without a fire and with a $2.5 \mathrm{MW}$ fire in the tunnel. Regardless of the presence of the fire, a similar pattern of the velocity profile was obtained from all simulations. Manual velocity measurements show similar results. This indicates that the velocity is not 
affected much by the fire but is dominated by the exhaust fan speed and ventilation arrangements, i.e. whether it opens to the atrium or the tunnel. Both simulation and measurement results show that the velocities near the edge and corner are lower than the velocity in the centre. Also they show that the velocities in the lower part are higher because two fans are located below the measurement area and one fan is above. The impact of the fan location was found to be more significant for the velocity profiles with ventilation open to the atrium than to the tunnel (see Figure 3-11). This made it a challenge to find the appropriate probe locations using the least number of probes.
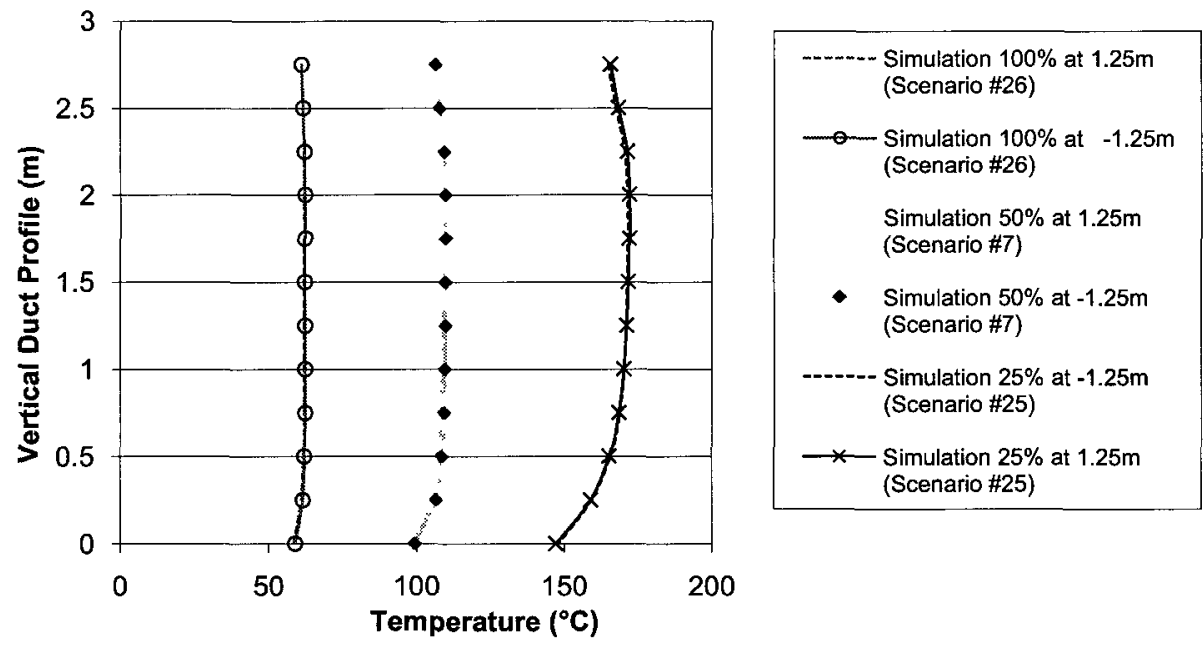

Figure 3-8 Vertical temperature profiles from a $10 \mathrm{MW}$ fire in the tunnel under different fan speeds (Note: -1.25 and 1.25 refer $1.25 \mathrm{~m}$ left and $1.25 \mathrm{~m}$ right from the centre, respectively)[79] 


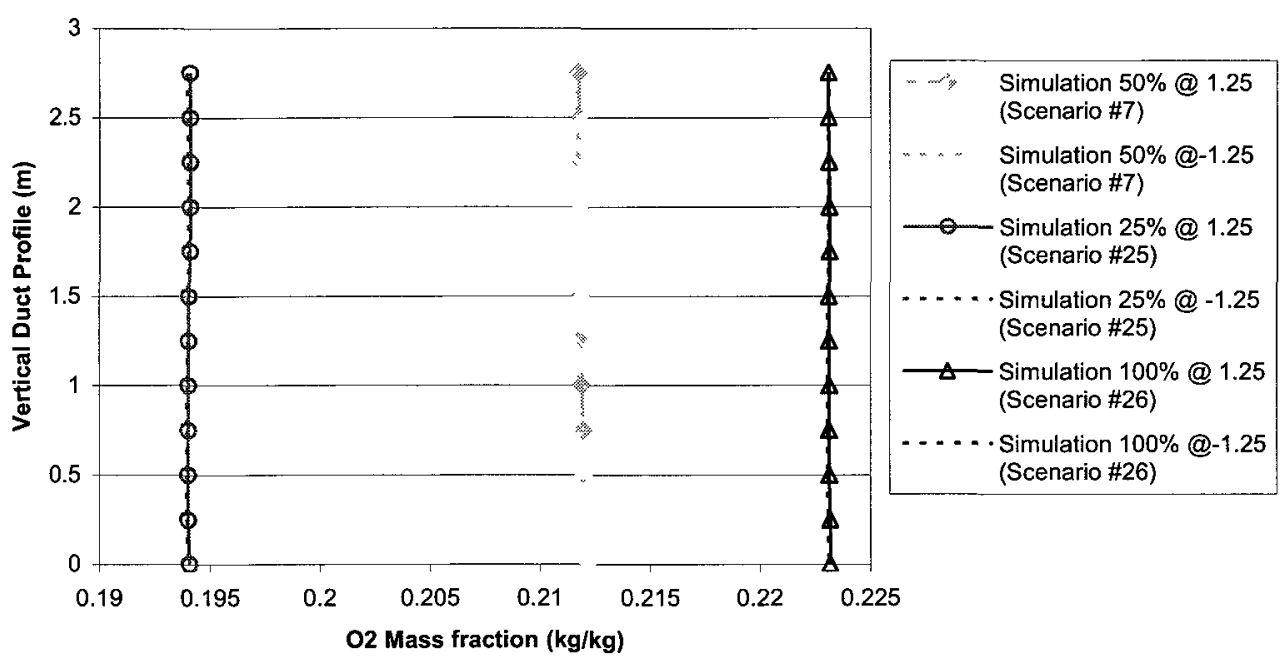

Figure 3-9 Vertical profiles of oxygen mass fraction of the flow from a $10 \mathrm{MW}$ fire in the tunnel under different fan speeds (Note: -1.25 and 1.25 refer $1.25 \mathrm{~m}$ left and $1.25 \mathrm{~m}$ right from the centre, respectively) [79]

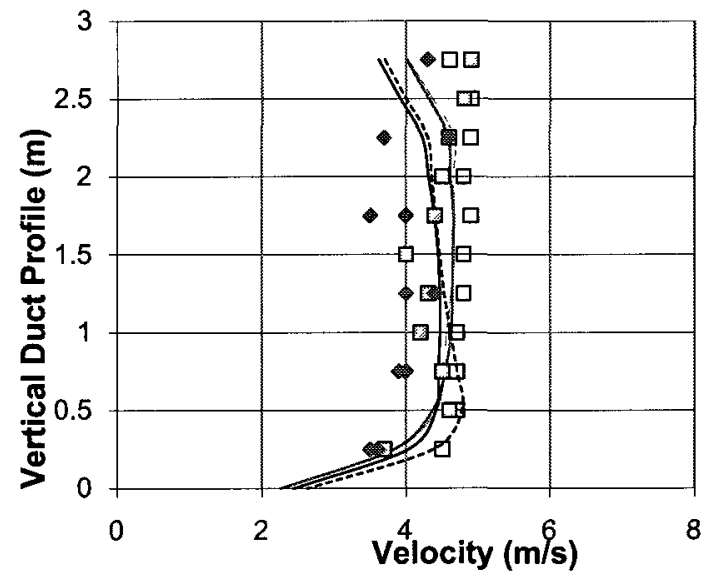

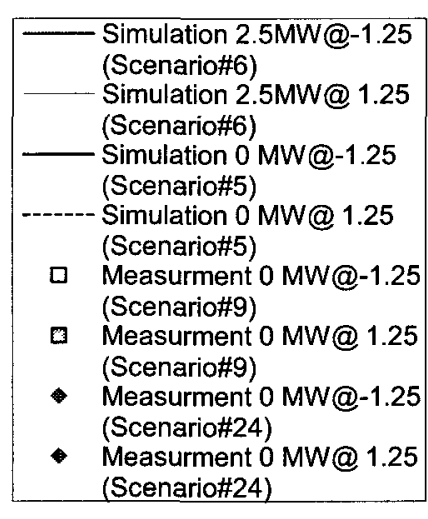

Figure 3-10 Vertical velocity profiles at 50\% fan speed without and with a $2.5 \mathrm{MW}$ fire in the tunnel (Note: -1.25 and 1.25 refer $1.25 \mathrm{~m}$ left and $1.25 \mathrm{~m}$ right from the centre, respectively) [79] 


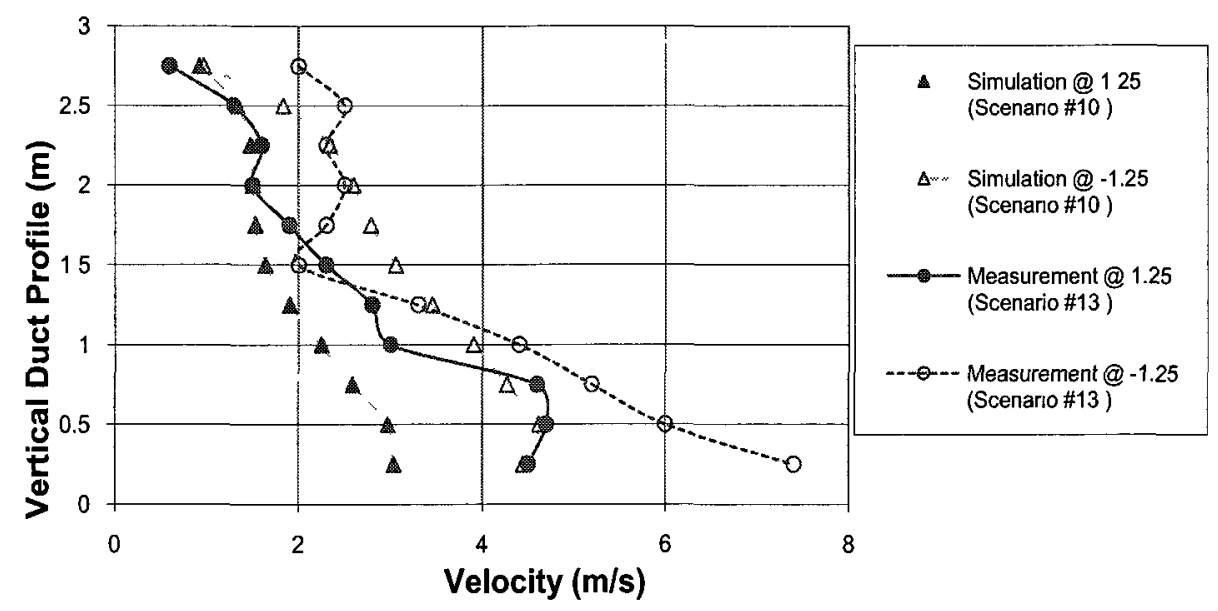

Figure 3-11 Vertical velocity profiles at $50 \%$ fan speed from a atrium simulation and manual measurements (Note: -1.25 and 1.25 refer $1.25 \mathrm{~m}$ left and $1.25 \mathrm{~m}$ right from the centre, respectively) [79]

\subsubsection{Instrumentation design}

Due to the variation of the velocity of the flow over the measurement area, the collected data sets from CFD simulations and manual measurements were analysed to find an optimum combination of velocity measurement points. The accuracy of mass flow rate measurements depends on how well a traverse is made to determine the average mass flow rate of combustion gas entering into the measurement area. Methods often used to measure velocity in a duct are the log-Tchebycheff rule or the equal-area method [93].

- The log-Tchebycheff rule provides the greatest accuracy since its recommended location of traverse points account for the effect of wall friction and the fall-off of velocity near wall ducts [93]. The method recommended for rectangular ducts with $\mathrm{H}$ and $\mathrm{W}>450 \mathrm{~mm}$; however, the number of probes according to this method is too high for the facility.

- The accuracy of the equal area method depends on the number of segments. 
Thus, it was decided to explore alternatives to the log-Tchebycheff rule to find an accurate and economical combination of velocity measurement locations. Various probe combinations were examined using the velocity data obtained from measurements and simulations, at every $0.25 \mathrm{~m}$ over the measurement area (a total of 231 measurements at each test/simulation). A total of 28 combinations (see Appendix A) were compared using different number of probes from 2 to 30 .

A performance analysis of those 28 combinations was conducted for different fan speeds and ventilation arrangements, by comparing relative absolute deviations for each scenario. In Appendix B, the calculated relative absolute deviations are compared for each scenario for different measurement probe combinations. And, based on the performance analysis, the five most accurate arrangements were found (see Figure 3-12). These included combinations with 30 and 25 probes arranged based on the Log-Tchebycheff rule; combinations with 20,8 , and 4 probes (see figure). Figure 3-13 compares the five most accurate combinations for all scenarios. Note that the $\mathrm{X}$-axis refers to the scenarios in Table 3-1, and the $\mathrm{Y}$-axis shows the measurement error relative to the average velocity (i.e. calculated by averaging all 231 measurements over $0.25 \mathrm{~m}$ grids). It shows that all five combinations perform similarly, yet probe combination $\# 22$ using only 4 probes stood out for its relative good accuracy compared to the number of probes used. The probe combination \#22 performs very well, comparable to other combinations using a large number of probes by the log-Tchebycheff rule. This combination was found to have an error of less than $6 \%$ for all scenarios analyzed, which is comparable even to the combinations with 20 or 30 probes. 


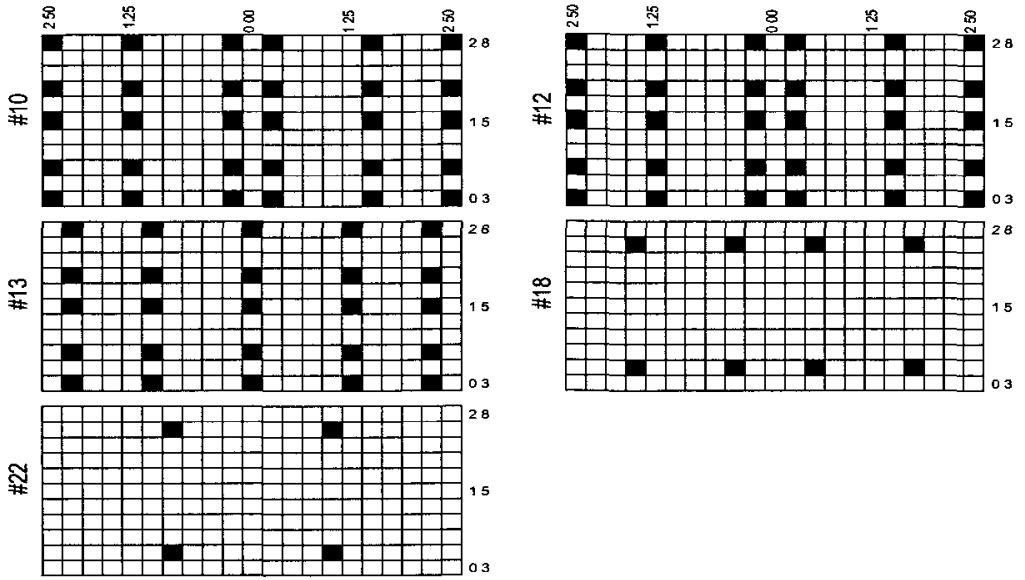

Figure 3-12 the fire most accurate velocity probe combinations [79]

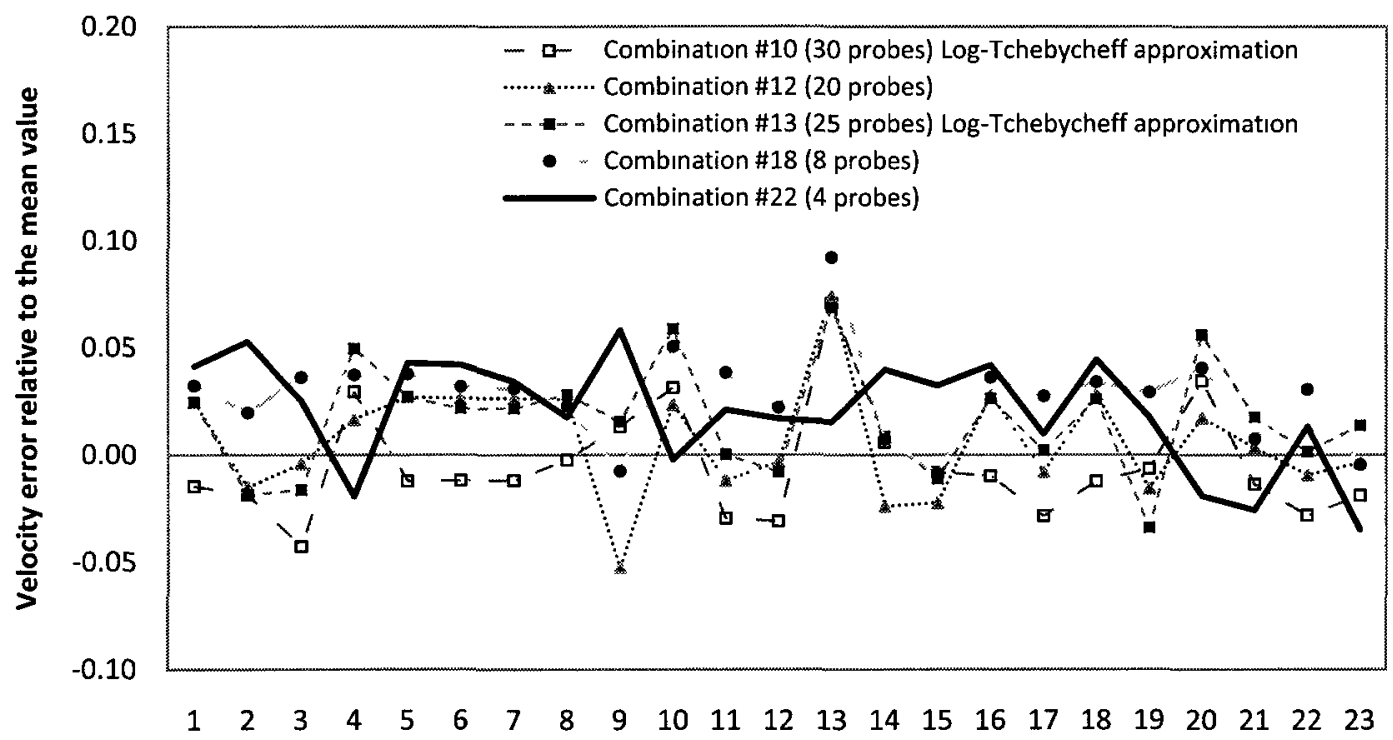

Figure 3-13 Comparison of the fire most accurate velocity probe combinations [79]

Figure 3-14 shows the final instrumentation for velocity, temperature, and gas concentrations over the measurement area in the fan chamber. Four bi-directional probes were installed at the locations of combination \#22. The probes are connected to the transducers which measure the pressure differences and convert them to electrical signals. Six thermocouples (Type J) were installed at locations shown in Figure 3-14. A steel gas sampling grid was installed to cover the measurement area of the fan chamber as shown in Figure 3-14. The gas enters through the holes on the downstream side of the steel tube 
and is mixed into a single outlet. The sample gas moves through a cotton soot filter, a condenser coil for cooling and a Diorite gas drying unit. Then, the sample enters the gas analyzer. A detailed diagram of the measuring devices used for temperature, velocity, and gas concentrations is shown in Figure 3-15. Each device used in the measurement was calibrated. The gas analyzer should be calibrated every day before a test, using zeroing and spanning gases.
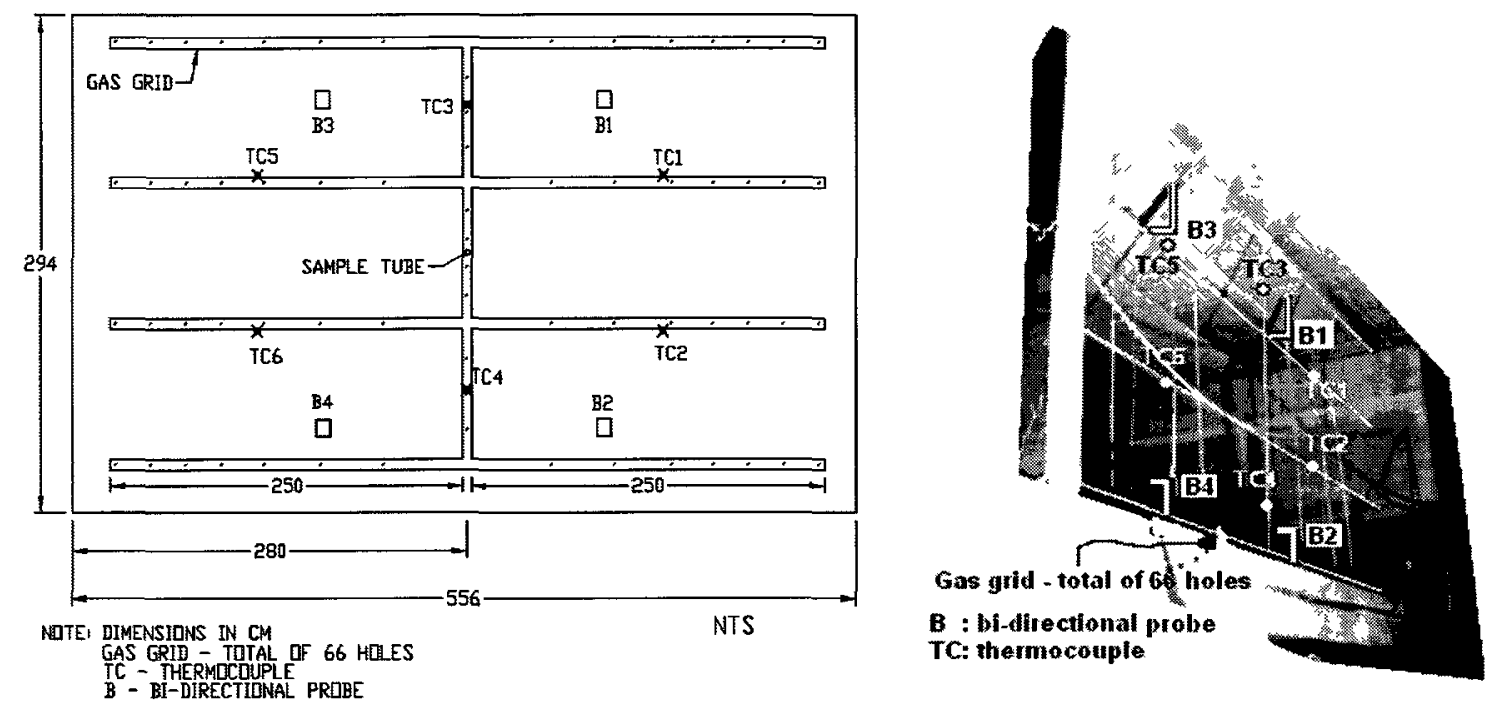

Figure 3-14 Instrumentation 


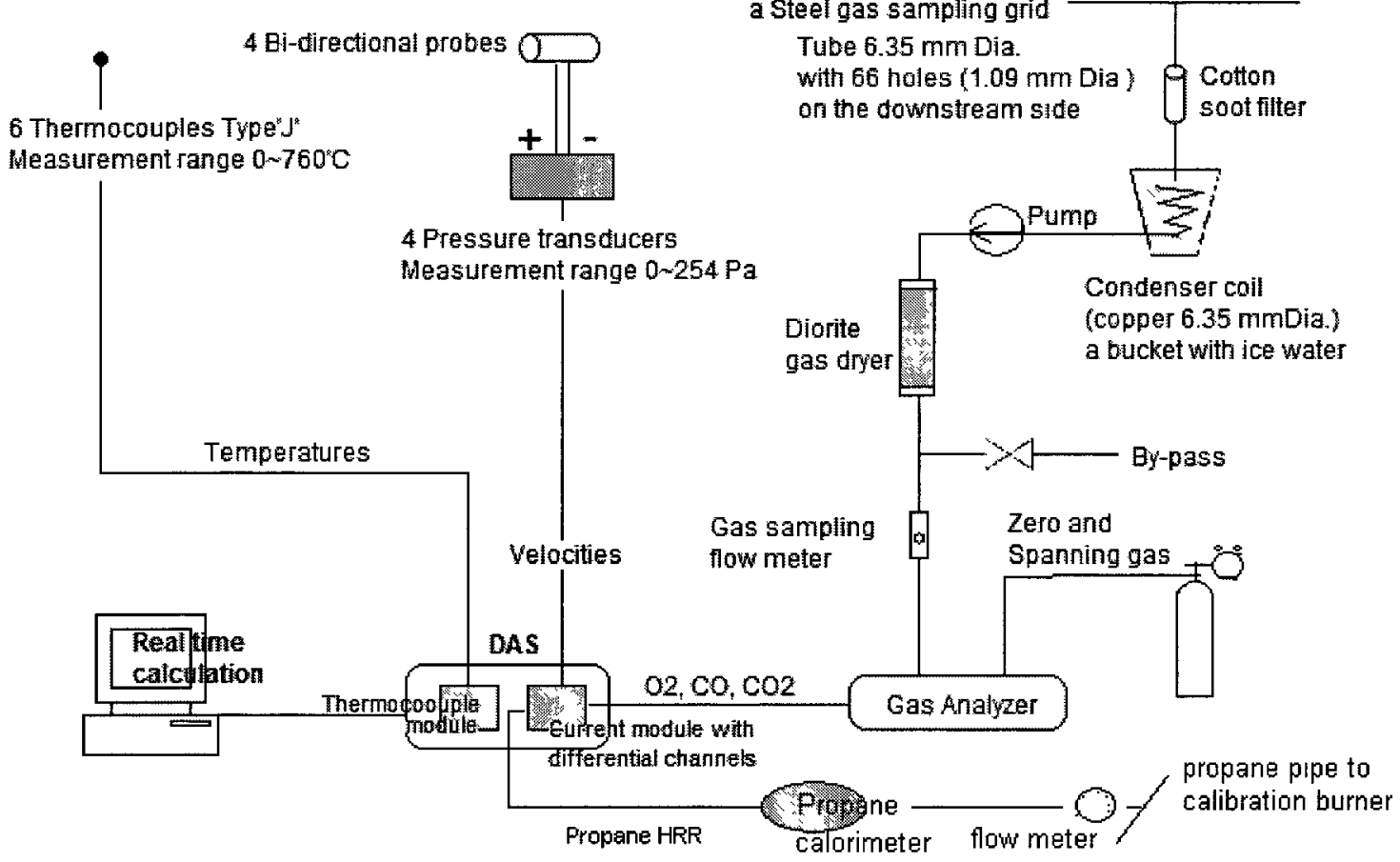

Figure 3-15 Diagram of measurement equipments

\subsection{Real-time calculation of Heat Release Rate}

\subsubsection{Delay times}

Using Labview (version 8.6), a real-time HRR calculation and display system was programmed. The computed HRR is displayed on the computer monitor yet after some delays, which are inevitable due to the measurement system and the scale of the facility. The delay times are the combined results of three types of lag;

- Transport time: It is the time for the combustion gases from a fire to reach the measurement area. It mainly depends on the fan speed. It is the delay to have the first response in the measurement system (detecting about $3 \%$ changes in temperature) [94]. 
- Transport lag time: It is the extra time required for the measurement system to have responses of ultimate measurement change (at least $90 \%$ of the actual heat being released [94]). This lag time is caused by the large scale of the facility and design of the exhaust system, as gases disperse, dilute, and drift in the geometry of the flow passage. Dilution and accumulation of combustion gases can occur in various locations along the path [95].

- Delay time for the gas analysis system: This delay represents the time for the gas analysis system to pump gases through the sampling line and to analyse gases through chemical process in the gas analyzer itself. This delay time is assumed to be constant as it is less dependent on fan speeds and fire sizes [94].

In programming the system, it was important to consider how these delay times influence data of each parameter used for the HRR calculation. The transport time causes a time shift to all parameters and the HRR consequently, but it does not affect the calculation. The transport lag time causes the response setback in the HRR calculation at the beginning of the test. The delay time for the gas analysis system, unlike the transport time and transport lag time, causes data offset only in gas concentrations. More discussion of delay times is made in Section 4.2.

If the delay time is large it can cause significant errors in the HRR calculations. Thus, the delayed data of $\mathrm{O}_{2}, \mathrm{CO}_{2}$ and $\mathrm{CO}$ concentrations must be shifted so that they are synchronized with other data of temperatures and velocities [94]. In this study, the delay time for the gas analysis system was found by directly injecting carbon monoxide into the sampling line which is at the centre of the gas sampling grid. A constant delay of 45 seconds was found as the sample gas was pumped at a constant flow rate of about 1.5 
$1 /$ min. The delay time of 45 seconds was programmed in the real-time HRR calculation and display system.

\subsubsection{Data Acquisition System (DAS)}

Figure 3-16 shows the flow chart of the real-time HRR calculation program, which converts the raw signals from the Data Acquisition System (DAS) to calculate the HRR. Signals from thermocouples, pressure transducers, as well as a propane flow meter are transmitted at real-time to the DAS. Signals from the gas analyzer are delayed for 45 seconds since the sample gas goes through each process in the gas analysis system (see Figure 3-15), which is later counted for real-time HRR calculations. The DAS contains a thermocouple module and a current module with 8 differential channels.

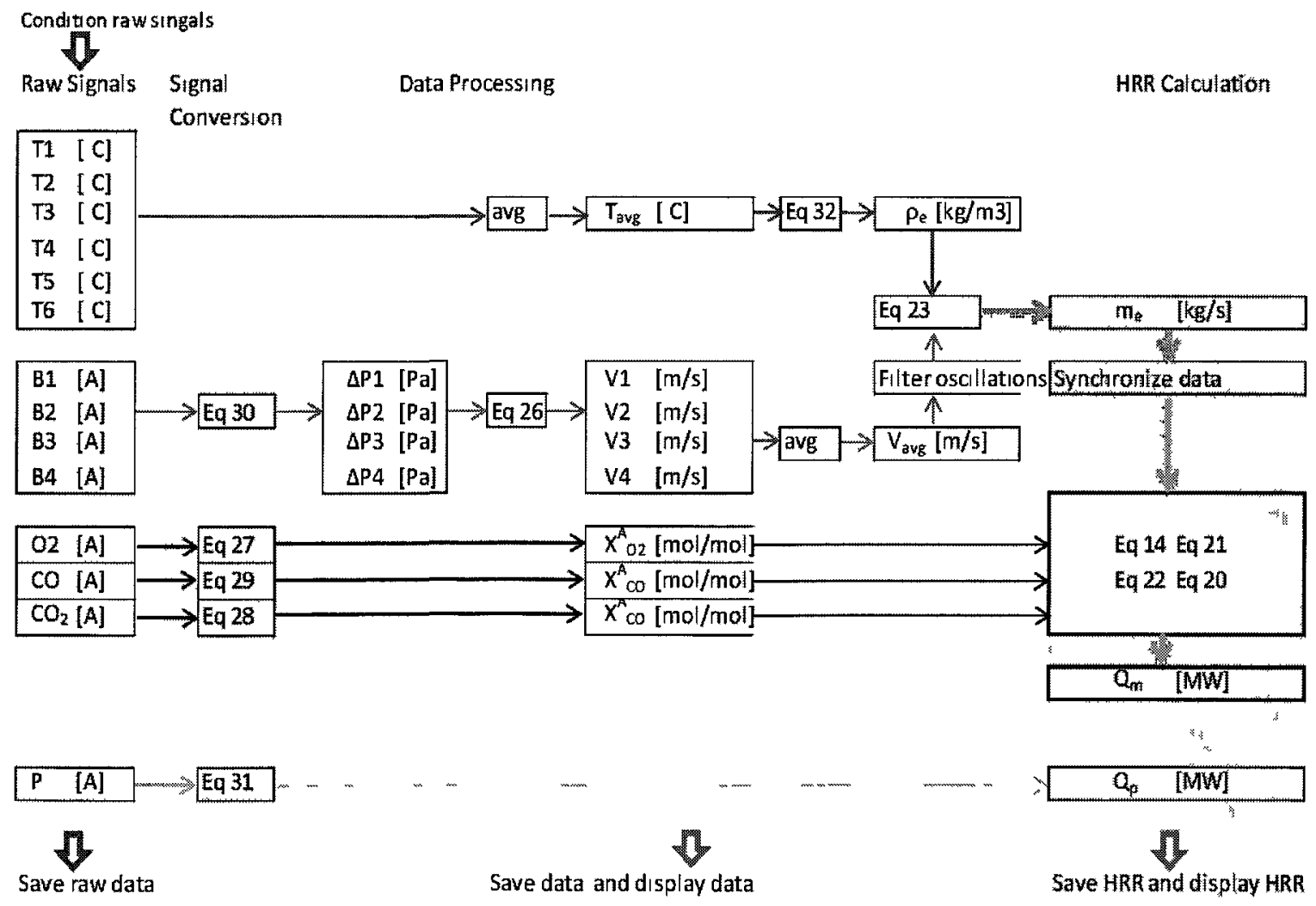

Figure 3-16 Real-time HRR calculations and display system flow chart 


\subsubsection{Signal conditioning and conversions}

To reduce noise, RFI (Ràdio Frequency Interference) [96], and prevent any cross-talk between the channels, shielded wires are used from the source to the DAS, and one end of each shielded wire is grounded. It was observed that noise was amplified when the fans were on. Thus, in the Labview program, the signals were conditioned at a frequency of $2000 \mathrm{~Hz}$, collecting 400 samples, yielding an average value every $0.2 \mathrm{~s}$. The filtered signals (I) in electrical current $[A]$ are converted to the actual value of each parameter (note that temperature data are received in $\left[{ }^{\circ} \mathrm{C}\right]$, no need for conversion). Table 3-2 shows equations used in the real time HRR measurement system including the equation used for signal conversion for each parameter.

Table 3-2 A list of equations used in the real time HRR measurement system

\begin{tabular}{|c|c|c|c|c|}
\hline \multicolumn{5}{|c|}{ Signal conversions } \\
\hline Data & $\begin{array}{l}\text { Measurem } \\
\text {-ent } \\
\text { range }\end{array}$ & $\begin{array}{l}\text { DAS } \\
\text { Signal } \\
\text { Range } \\
{[\mathrm{mA}]}\end{array}$ & Signal Conversions & \\
\hline $\mathrm{O} 2$ & $\begin{array}{l}0 \% \\
\sim 25 \%\end{array}$ & $4 \sim 20$ & $\mathrm{X}_{\mathrm{O}_{2}}^{\mathrm{A}}=\left[\frac{(25 \%-0 \%)}{(20 \mathrm{~mA}-4 \mathrm{~mA})} \times\left(\mathrm{I} \times 10^{3} \mathrm{~mA}-4 \mathrm{~mA}\right)\right] / 100$ & Eq 27 \\
\hline $\mathrm{CO} 2$ & $\begin{array}{l}0 \% \\
\sim 30 \%\end{array}$ & $4 \sim 20$ & $\mathrm{X}_{\mathrm{CO}_{2}}^{\mathrm{A}}=\left[\frac{(30 \%-0 \%)}{(20 \mathrm{~mA}-4 \mathrm{~mA})} \times\left(\mathrm{I} \times 10^{3} \mathrm{~mA}-4 \mathrm{~mA}\right)\right] / 100$ & Eq 28 \\
\hline $\mathrm{CO}$ & $\begin{array}{l}\text { 0ppm } \\
\sim \\
2000 \mathrm{ppm}\end{array}$ & $4 \sim 20$ & $\mathrm{X}_{\mathrm{CO}}^{\mathrm{A}}=\left[\frac{(2000 \mathrm{ppm}-0 \mathrm{ppm})}{(20 \mathrm{~mA}-4 \mathrm{~mA})} \times\left(\mathrm{I} \times 10^{3} \mathrm{~mA}-4 \mathrm{~mA}\right)\right] / 10^{6}$ & $\mathrm{Eq} 29$ \\
\hline B & $\begin{array}{l}0 \mathrm{~Pa} \\
\sim 254 \mathrm{~Pa}\end{array}$ & $4 \sim 20$ & $\Delta \mathrm{p}=\left[\frac{(0 \mathrm{~Pa}-254 \mathrm{~Pa})}{(20 \mathrm{~mA}-4 \mathrm{~mA})} \times\left(\mathrm{I} \times 10^{3} \mathrm{~mA}-4 \mathrm{~mA}\right)\right]$ & $\mathrm{Eq} 30$ \\
\hline $\mathrm{Q}_{\mathbf{P}}$ & $\begin{array}{l}0 \mathrm{MW} \\
\sim 22 \mathrm{MW}\end{array}$ & $4 \sim 20$ & $Q_{P}=\left[\frac{(0 M W-22 M W)}{(20 m A-4 m A)} \times\left(I \times 10^{3} m A-4 m A\right)\right]$ & $\mathrm{Eq} 31$ \\
\hline
\end{tabular}




\begin{tabular}{|c|c|}
\hline \multicolumn{2}{|l|}{ Equations to calculate HRR } \\
\hline$\rho_{\mathrm{e}}=\frac{1.203 \mathrm{~kg} / \mathrm{m}^{3} 293 \mathrm{~K}}{\mathrm{~T}_{\mathrm{e}}}$ & Eq 32 \\
\hline $\mathrm{V}=\frac{1}{\mathrm{k}_{\mathrm{p}}} \sqrt{\frac{2 \Delta \mathrm{p}}{\rho_{\mathrm{e}}}}=\frac{1}{1.1} \sqrt{\frac{2 \Delta \mathrm{p}}{\rho_{\mathrm{e}}}}$ & Eq 26 \\
\hline$\dot{m}_{\mathrm{e}}=A V \rho_{\mathrm{e}}=\left(16.3 \mathrm{~m}^{2}\right) V \rho_{\mathrm{e}}$ & Eq 23 \\
\hline$\emptyset=\frac{\mathrm{X}_{\mathrm{O}_{2}}^{\mathrm{A}^{\mathrm{O}}}\left(1-\mathrm{X}_{\mathrm{CO}_{2}}^{\mathrm{Ae}}-\mathrm{X}_{\mathrm{CO}}^{\mathrm{Ae}}\right)-\mathrm{X}_{\mathrm{O}_{2}}^{\mathrm{Ae}}\left(1-\mathrm{X}_{\mathrm{CO}_{2}}^{\mathrm{A}^{\mathrm{O}}}\right)}{\left(1-\mathrm{X}_{\mathrm{O}_{2}}^{\mathrm{Ae}}-\mathrm{X}_{\mathrm{CO}_{2}}^{\mathrm{Ae}}-\mathrm{X}_{\mathrm{CO}}^{\mathrm{Ae}}\right) \mathrm{X}_{\mathrm{O}_{2}}^{\mathrm{A}^{\mathrm{O}}}}$ & Eq 14 \\
\hline $\mathrm{X}_{\mathrm{H}_{2} \mathrm{O}}^{\circ}=\frac{\mathrm{RH} \times \mathrm{p}_{\mathrm{s}}\left(\mathrm{T}_{\mathrm{a} 0}\right)}{\mathrm{p}_{\mathrm{a}}}=\frac{R H}{p_{a}} E X P\left(23.2-\frac{3816}{-46+T_{0}}\right) \approx \frac{0.5 \times 2.5 \mathrm{kPa}}{101.5 \mathrm{kPa}}=0.0123$ & Eq 21 \\
\hline $\mathrm{M}_{\mathrm{a}}=\mathrm{M}_{\mathrm{dry}}\left(1-\mathrm{X}_{\mathrm{H}_{2} \mathrm{O}}^{\mathrm{O}}\right)+\mathrm{M}_{\mathrm{H}_{2} \mathrm{O}} \mathrm{X}_{\mathrm{H}_{2} \mathrm{O}}^{\mathrm{o}}=28.95 \frac{\mathrm{g}}{\mathrm{mol}}(1-0.0123)+18 \frac{\mathrm{g}}{\mathrm{mol}} \times 0.0123=28.815$ & Eq 22 \\
\hline $\begin{array}{l}\dot{\mathrm{Q}}=\left[\mathrm{E}-\left(\mathrm{E}_{\mathrm{CO}}-\mathrm{E}\right) \frac{(1-\emptyset)}{2 \emptyset} \frac{\mathrm{X}_{\mathrm{CO}}^{\mathrm{Ae}}}{\mathrm{X}_{\mathrm{O}_{2}}^{\mathrm{Ae}}}\right] \emptyset \frac{\dot{\mathrm{m}}_{\mathrm{e}}}{1+\emptyset(\alpha-1)} \frac{\mathrm{M}_{\mathrm{O}_{2}}}{\mathrm{M}_{\mathrm{a}}}\left(1-\mathrm{X}_{\mathrm{H}_{2} \mathrm{O}}^{\mathrm{O}}\right) \mathrm{X}_{\mathrm{O}_{2}}^{\mathrm{A}^{\mathrm{o}}} \\
=\left[13.1-(17.6-13.1) \mathrm{MJ} / \mathrm{kg} \frac{(1-\emptyset)}{2 \emptyset} \frac{\mathrm{X}_{\mathrm{CO}}^{\mathrm{Ae}}}{\mathrm{X}_{\mathrm{O}_{2}}^{\mathrm{Ae}}}\right] \times \emptyset \frac{\dot{\mathrm{m}}_{\mathrm{e}}}{1+\emptyset(1.105-1)} \frac{32.0 \frac{\mathrm{g}}{\mathrm{mol}}}{28.815}(1-0.012) \mathrm{X}_{\mathrm{O}_{2}}^{\mathrm{A}_{2}^{\mathrm{o}}}\end{array}$ & Eq 20 \\
\hline
\end{tabular}

\subsubsection{Data processing and HRR calculations}

A time step greater than $1 \mathrm{~s}$ was required for the computer to process the large amount of data (i.e. every 0.2 seconds taking 400 samples at $2000 \mathrm{~Hz}$ ). Thus, a time step of $1.5 \mathrm{~s}$ was set in the program to process data and log calculations so that it matches with the delay time of $45 \mathrm{~s}$ (i.e. 30 time steps to match the 45 seconds).

To calculate the mass flow rate to be used in the HRR calculation, temperature and velocity data are processed as shown in Figure 3-16. Temperatures from six thermocouples are averaged. Velocities are calculated by Eq 26 using $\Delta p$ measured from 
the four bi-directional probes. The four velocity values are averaged and then timeaveraged again over $15 \mathrm{~s}$ to filter oscillations. The mass flow rate calculated by Eq 23 is set to hold-up for $45 \mathrm{~s}$ to synchronize with the delayed gas concentration data before entering into the HRR calculation algorithm. The oxygen depletion factor is calculated using gas concentration data. In Eq 14, $X_{O_{2}}^{A^{o}}$ and $X_{\mathrm{CO}_{2}}^{A^{o}}$ were set as user inputs so that a user reads and defines these initial values before running a test. Eq 21 and Eq 22 were set-up in the program, which are only valid for normal operations. Finally, the HRR is calculated by Eq 20 assuming that $\mathrm{E}_{\mathrm{O} 2}$ (heat release per unit mass of $\mathrm{O}_{2}$ consumed in the reaction), Eco (net heat release per unit mass of $\mathrm{O}_{2}$ consumed for combustion of $\mathrm{CO}$ to $\mathrm{CO}_{2}$ ) and $\alpha$ (expansion factor) are constant. The constant values can be changed if required as the measurement system is programmed such that a user can easily change these values on the front panel of Labview.

\subsection{Summary}

A measurement system has been developed for Carleton University's laboratory tunnel to be used for measuring HRR of various types of tunnel fires. The system uses oxygen calorimetry for accurate and reliable measurements under different ventilation conditions, as well as with a suppression system operating. The HRR measurement system collects data at the end of the upper middle chamber directing all combustion products through this design area by the exhaust fan system. The oxygen calorimetry requires accurate measurements of the mass flow rate, $\mathrm{CO}_{2}, \mathrm{CO}$ and $\mathrm{O}_{2}$ concentrations.

Accurate measurements of mass flow rate of gases were challenging due to the variation of the flow velocity inside the large chamber of the facility. To obtain good 
representation of the flow velocity and other parameters across the entire cross-section of the chamber, the instrumentation in the fan chamber was designed based upon extensive analysis of various CFD simulations as well as manual velocity measurements. This study found the least amount of instrumentation and their locations of measurements that ensure reasonable accuracy. Four bi-directional probes and six thermocouples as well as a steel gas sampling grid covering the measurement area of the fan chamber were installed.

Signals from thermocouples, pressure transducers, and the gas analyzers are transmitted via the data acquisition system (DAS) to the real-time HRR calculation and display system, which was programmed using Labview (version 8.6). The schematics of programming are presented, which includes synchronizing gas concentration measurements due to the delay in gas sampling/ analysing system in the calculations of HRR. 


\section{CHAPTER 4. CALIBRATION OF THE HRR MEASUREMENT SYSTEM}

The calculation of the HRR involves a large number of parameters. Among these, the mass flow rate is one of the most important parameters along with the oxygen concentration. As discussed in Section 3.2.1, the calculations of mass flow rate in a duct generally need to be corrected, and the correction factor is dependent on the variation of temperature and velocity over the measurement area of the duct.

In this study, the correction factor for mass flow rates due to the nature of the flow inside the large chamber of the facility was found experimentally by examining flows under various conditions. However, it is difficult to obtain the correction factor directly from the flow characteristics because of the uncertain velocity profile over the measurement area in the fan chamber. Thus, the correction factor was sought for the HRR measurement system as the overestimated mass flow rates without corrections must be reflected consistently in the HRR calculations. A series of calibration tests was conducted to find the correction factor in the case of tunnel tests to adjust the HRR measurements. Calibration tests for the atrium were also conducted by Michels [92].

\subsection{Calibration test arrangement}

In the calibration tests for the tunnel, the measured HRR by the system using data collected in the fan chamber was compared with the known HRR of the source fire. The correction factor was calculated by comparing a time integrated HRR ( $\mathrm{Q}$ ) with the energy content $(\mathrm{E})$ of the fuel used in each test. Propane fires and heptane pool fires were 
used with different fire sizes and fan capacities. Table 4-1 shows a list of tests and conditions used.

\subsubsection{Propane burner calibration system}

The propane burner calibration system (see Figure 3-15), which consists of a propane flow meter, propane calorimeter, and burners, are used to produce a range of HRR up to $10 \mathrm{MW}$. The burners were placed $10 \mathrm{~m}$ from the east end of the tunnel. The flow rate of propane was measured by a flow meter (a Sierra Steel-Mass Model 640S with measurement range $0-30 \mathrm{~kg} / \mathrm{min}$ ) and the energy content of the propane employed was calculated in the propane calorimeter using the effective heat of combustion $\left(\mathrm{H}_{\mathrm{ch}}\right)$ of 44 $\mathrm{MJ} / \mathrm{kg}$. The source HRR from the propane burner is registered in the real-time HRR measurement system via the DAS. The source value is then used as a reference to determine the correction factor of the HRR measurement system. For the propane experiments, the $\mathrm{HRR}$ per unit mass of $\mathrm{O}_{2}, \mathrm{E}_{\mathrm{O} 2}$, was set to $12.9 \mathrm{MJ} / \mathrm{kg}$ and the expansion factor, $\alpha$, was set to 1.084 .

\subsubsection{Propane test arrangement}

Three different types of propane calibration tests were carried out. Type A propane test used a constant HRR for a duration that was enough for the system to produce steadystate responses. Type $\mathrm{P}$ test produced a short pulse of energy release from the propane burners to observe the system response. In Type B tests, in order to capture the system transient response, the HRR started with a high HRR and decreased step by step at a regular time interval. 


\subsubsection{Heptane test arrangement}

Three calibration tests were also carried out burning known amounts of heptane. Two tests were carried out using a $1.2 \mathrm{~m}$ pan with two different amounts of heptane. To test the capability of the HRR measurement system, a calibration test was also conducted using both heptane and propane (see Figure 4-1). In the test, a $1.8 \mathrm{~m}$ pan with heptane produced about $13 \mathrm{MW}$ and the propane burner produced $10 \mathrm{MW}$. In the measurement system, the HRR per unit mass of $\mathrm{O}_{2}, \mathrm{E}_{\mathrm{O} 2}$, was set to $13.1 \mathrm{MJ} / \mathrm{kg}$ (suggested by Huggett [51]) and the expansion factor, $\alpha$, was set to 1.10 (suggested by Parker [52]) for the heptane and propane fire. These values were suggested for most fires where the composition of the fuel is unknown.

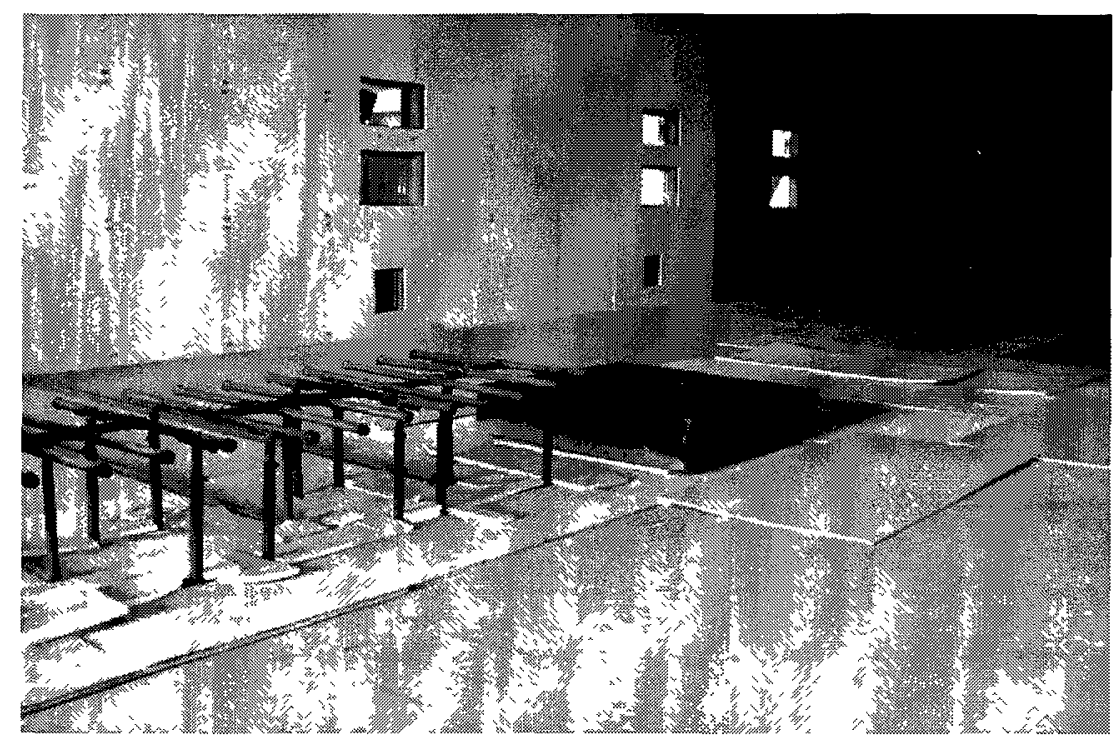

Figure 4-1 Test arrangement for Heptane and propane fire 


\subsection{Results}

4.2.1. Overall results for the HRR, flow rates and gas concentrations

Figure 4-2 shows a screenshot of the measurement system panel for Test A5. The measured temperature over time of six thermocouples showed uniform results at any given time during the calibration tests, as observed also in the CFD simulations. The HRR calculations followed the same trend as the flow temperature in the fan chamber. Finally, the time variation of the gas concentrations was very similar to that of the temperature.

The HRR measurement system showed reasonable estimates of the HRR after some delay, as shown in Figure 4-2. The first response of temperature change was detected at 20 seconds in this test at $50 \%$ fan speed. This is the travel time for smoke to reach the measurement area in the chamber, and it ranges from approximately 10 seconds at $100 \%$ fan speed to about 20 seconds at $50 \%$ and 30 seconds at $25 \%$ fan speed. The measured HRR is delayed by an additional 45 seconds due to the delay time for the gas analysis system. Since no correction had been made in the program yet, the HRR results were consistently overestimated.

To show a better visual comparison of the measured HRR with the propane HRR, all results are time-shifted when presented in this thesis. Figure 4-3 shows HRR results from Test A5, which also shows the HRR adjusted by a factor of 0.83 . This factor was found by comparing (see Figure 4-4) the time integrated HRR (system calculations), JQ [MJ], to the total energy content of the propane fire, E [MJ]. 


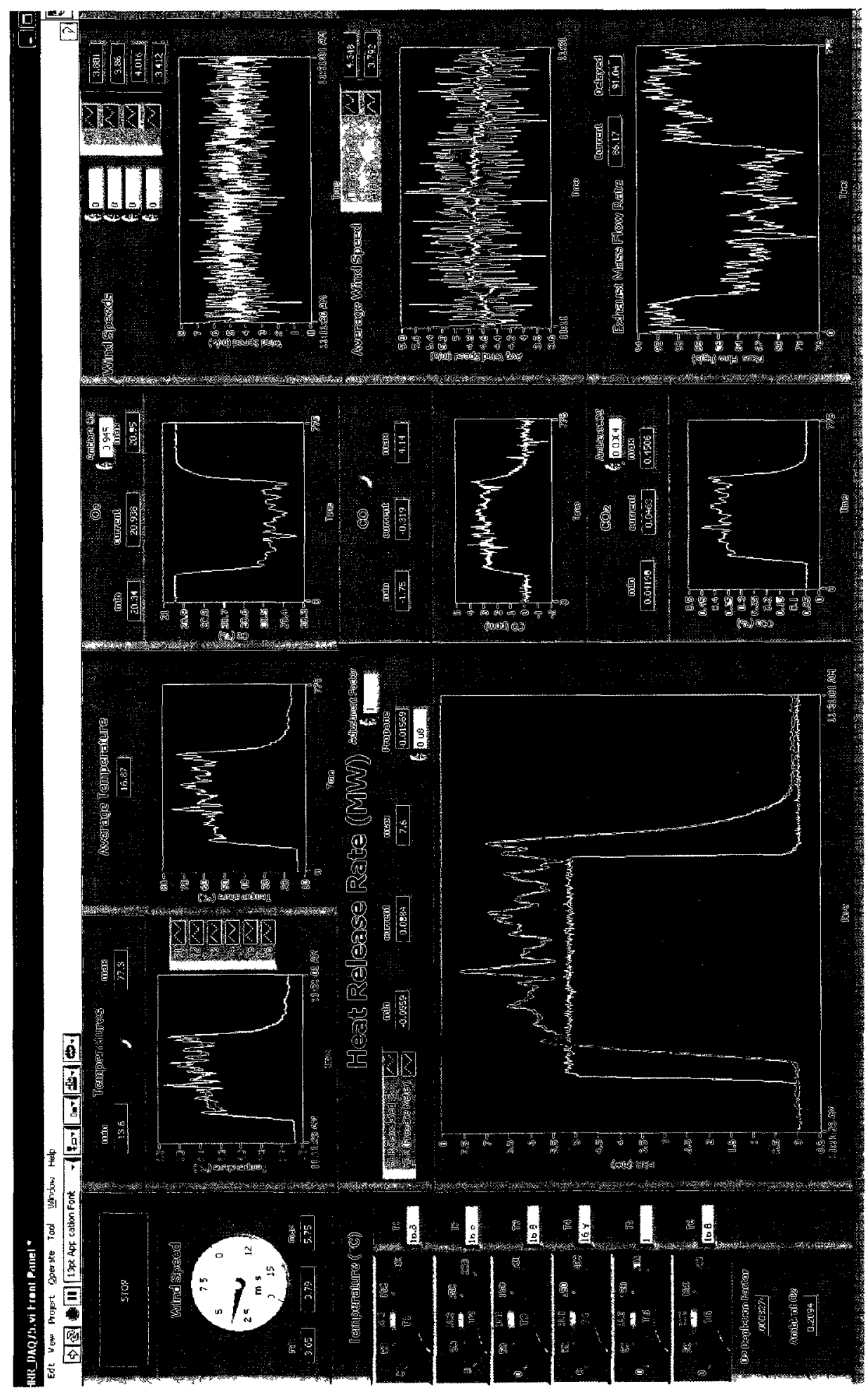

Figure 4-2 The front panel of the real time HRR measurement calculation and display system

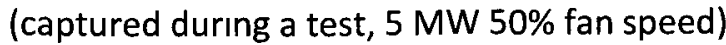


The adjusted HRR compares well with the HRR from the calibration burners but shows some variations over time although the propane fire provided a steady constant HRR of 5 MW during the test (for $700 \mathrm{~s}$ ). The variation in the HRR calculations is mainly influenced by the time variation of temperature and oxygen concentrations measured during the test.

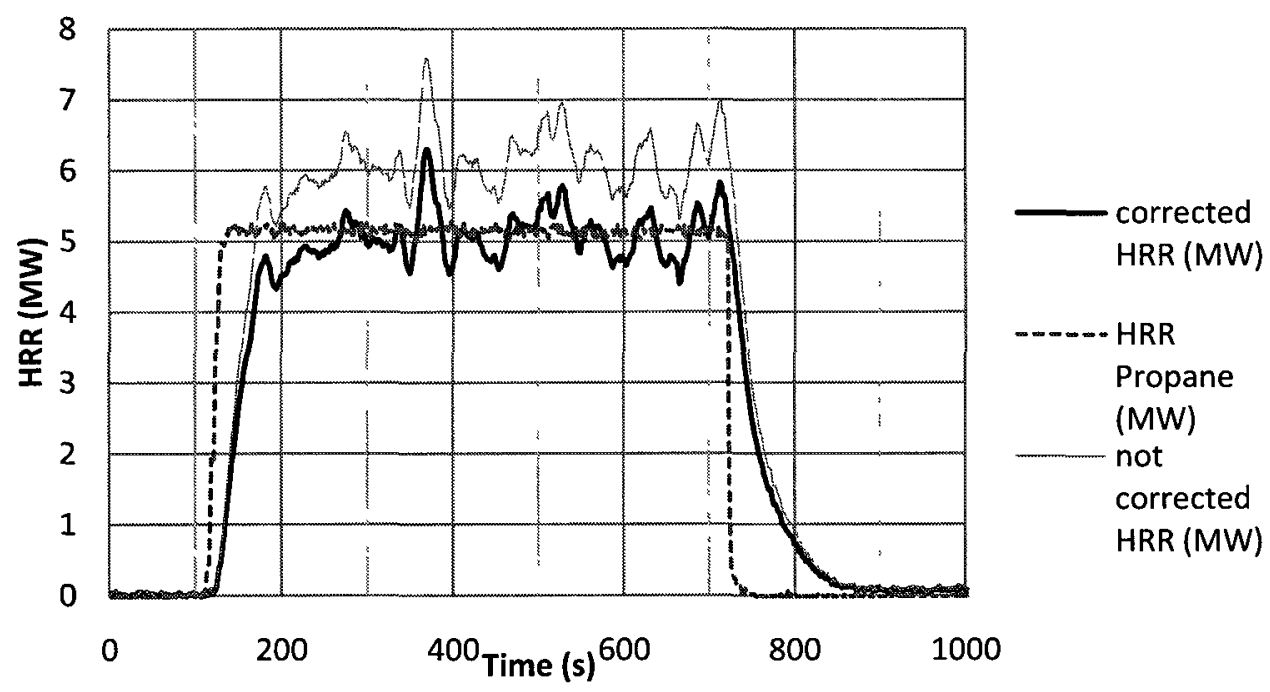

Figure 4-3 HRR results from a calibration test A5 of the HRR measurement system using propane burners ( $50 \%$ fan speed, $5 \mathrm{MW}$ )

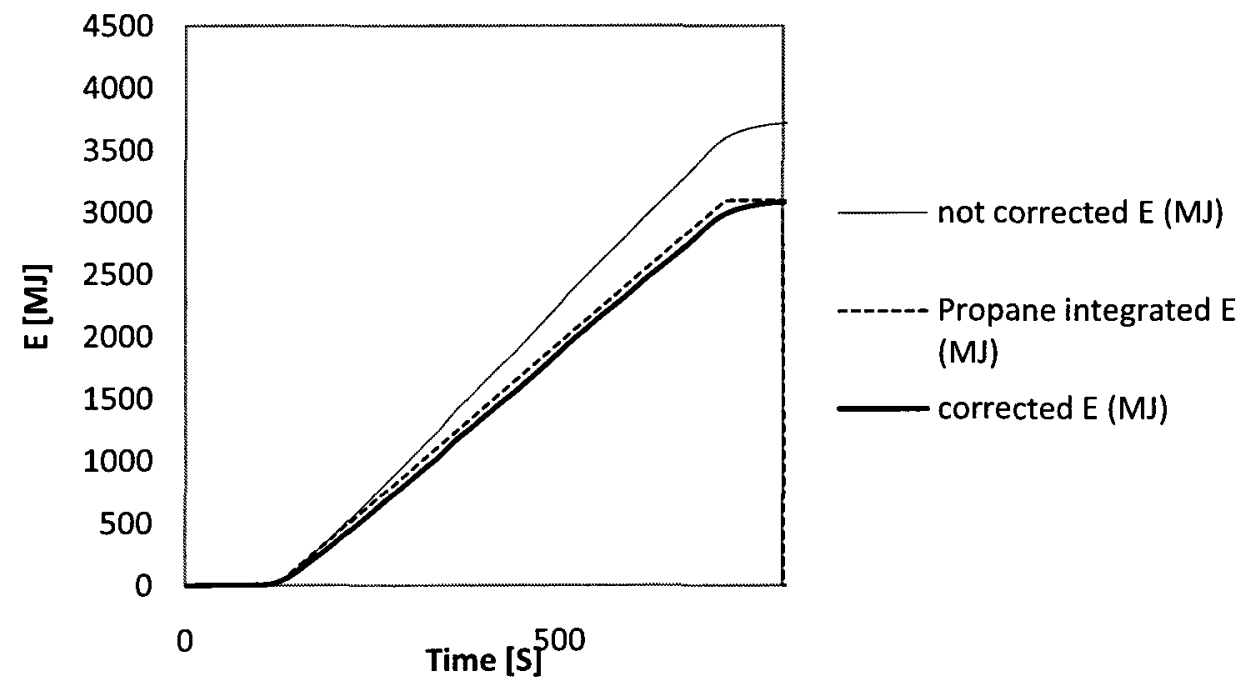

Figure 4-4 The correction factor matching JQ to E from a calibration test A5 (50\% fan speed, 5 $\mathrm{MW}$ ) 


\subsubsection{HRR measurement system response}

For each calibration test, the correction factor that matches $\int \mathrm{Q}$ to $\mathrm{E}$ was found, and the measured (corrected) HRR was time-shifted to make a comparison to the input HRR by propane burners or heptane pool fires. It was observed in all calibration tests that, after the first response, the measurement system requires a significant extra time to reach steady state. This transport lag time is caused by the dilution and accumulation of smoke in various locations along the path. This delay caused the system to smooth out the HRR calculation at the beginning of the test and to smear the HRR data after the end of the test (see Figure 4-3).

Figure 4-5 compares the system responses to $5 \mathrm{MW}$ propane calibration fire at different fan speeds. The system response time to the sudden increase of the propane HRR is approximately 60 seconds at all fan speeds, within which the system shows measurement change of about $90 \%$ of the actual heat being released. However, it took more time to achieve the ultimate measurement ( $100 \%$ of the actual HRR) at all fan speeds. 


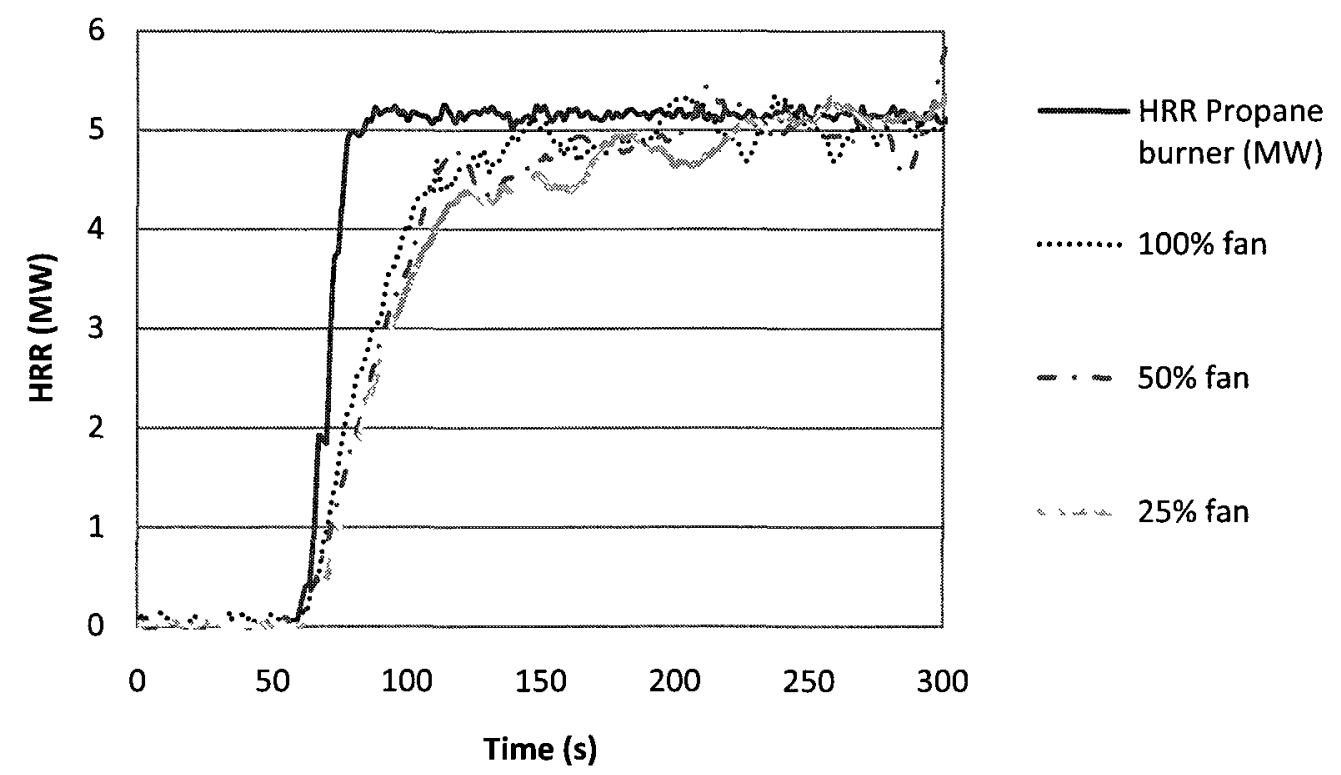

Figure 4-5 Comparisons of the system response to $5 \mathrm{MW}$ calibration fire for different fan speeds

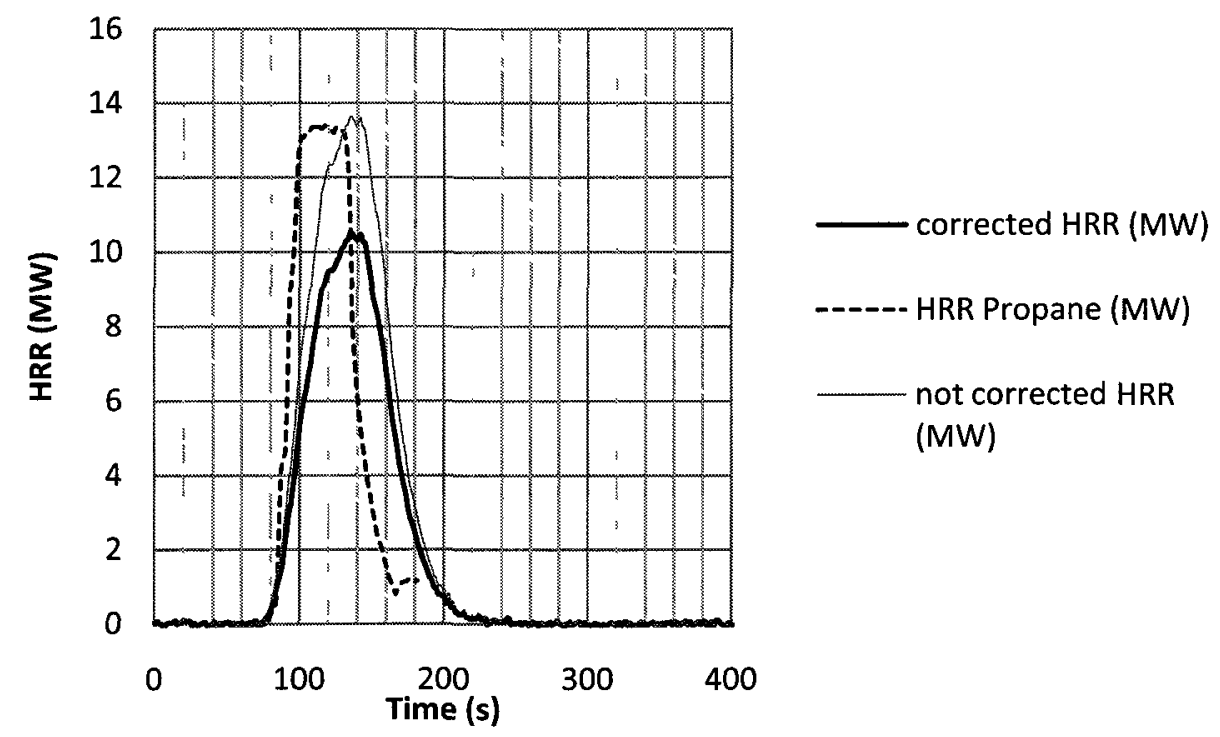

Figure 4-6 Results from a calibration test P13 of the HRR measurement system using propane burners (100\% fan speed, $13 \mathrm{MW}$, for 40 seconds)

The issue of this system response time is highlighted in Test P13, where the propane calibration burners produced a short pulse (for 40 seconds) of $13 \mathrm{MW}$ to examine the system response at $100 \%$ fan speed. Figure 4-6 shows the HRR results from Test P13, which is adjusted by a factor of 0.77 . The factor 0.77 was found by comparing the time 
integrated HRR (the area under the uncorrected HRR curve), $\mathrm{Q}$, to the total energy content of the propane fire, E. The system estimated incorrect peak time and peak value.

\subsubsection{Range of operation}

A series of tests was carried out to calibrate the experimental tunnel for HRR measurements using propane. The experiments used fan speeds of 25,50 , and $100 \%$ and propane fires between $2.5 \mathrm{MW}$ and $10 \mathrm{MW}$. As the measurement system requires collecting all combustion products, a suitable fan capacity must be used for a specific size of fire. This means that the longitudinal air velocity in the laboratory tunnel must be able to direct all smoke into the fan chamber. Results showed that a $25 \%$ fan speed was able to handle fires as large as $8 \mathrm{MW}$ with no loss of smoke products. However, a longer system response delay was experienced at $25 \%$ fan speed than at the larger fan speeds. A $25 \%$ fan speed must be the minimum fan speed to ensure a reasonable estimate of HRR for this HRR measurement system.

The calibration test results showed that the system is responsive to various fires sizes, as small as $2.5 \mathrm{MW}$. However, due to the scale of the facility, the measurement system is more suited to large fires that last a long time. A calibration test was conducted to test the capacity of the measurement system and the ability to handle large amounts of smoke that can result in significant smoke build-ups and a measurement system response delay.

As the system is meant to measure various types of tunnel fires and sizes, up to low severity of HGV about $20 \mathrm{MW}$, a test was conducted using both a heptane pool fire and propane burners that can produce more than 20 MW. Figure 4-7 shows HRR results from 
this test. In the test, a pan fire $(1.6 \mathrm{~m} \mathrm{x} 1.6 \mathrm{~m})$ with $123 \mathrm{~kg}$ of heptane and propane burners of $10 \mathrm{MW}$ were ignited at the same time. The fans operated at full-speed, which generated about $3 \mathrm{~m} / \mathrm{s}$ of longitudinal air flow in the tunnel. The propane burners were turned off about 6 min after ignition, and the heptane pool burned off about 7 min after ignition. The effective heat of combustions $\left(\mathrm{H}_{\mathrm{ch}}\right)$ of $44 \mathrm{MJ} / \mathrm{kg}$ and $41.2 \mathrm{MJ} / \mathrm{kg}$ were used for propane and heptane, respectively. An estimation of steady-state burning rate of heptane was made, which was found to be significantly affected by the airflow conditions in the tunnel. The total energy content of the fuel, E [MJ] was compared with the time integrated HRR (system calculations), JQ [MJ], and 0.91 was found for the correction factor.

The heptane pool produced a HRR of about $13 \mathrm{MW}$, which was determined based on the total energy content of heptane and the time span of the fire. The fire size is much greater than the theoretical HRR of $9 \mathrm{MW}$, which can be realized by the same size of a pool fire in a wind free environment, as suggested by Babrauskas [97]. The longitudinal air flow caused intense and fast burning of the heptane fire. The HRR measurement system was successful in measuring a $23 \mathrm{MW}$ fire in real-time. 


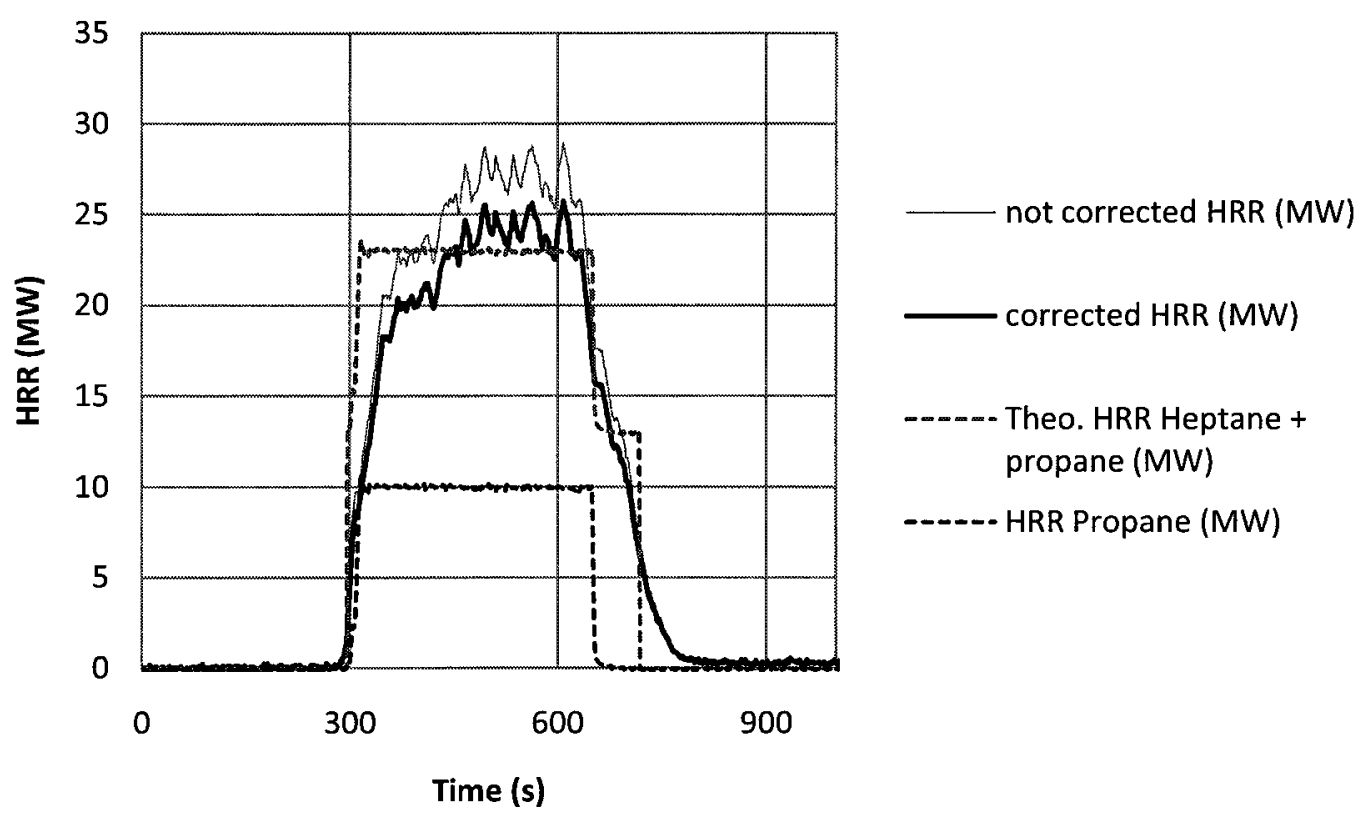

Figure 4-7 Results from a calibration test of the HRR measurement system using propane burners and heptane pool fire (100\% fan speed, $23 \mathrm{MW})$

The correction factor of 0.91 found in Test HP16 is about 10\% higher than the expected value of about 0.83 (average value found from propane tests). This may be due to the fact that theoretical values of the effective heat of combustions are used in the calculation of energy content of heptane and propane. The heat of combustion varies depending on temperature and availability of oxygen (equivalence ratio). It appears that the combustion was incomplete (the combustion efficiency was about 0.9 ) as a large amount of smoke was generated from the large fire of $23 \mathrm{MW}$. Note that the combustion efficiency could be calculated by measuring the yield of $\mathrm{CO}$, soot and any unburned hydrocarbon fuel. This HRR measurement results indicate that the system can handle incomplete combustion as the method, oxygen calorimetry, accounts for the difference $\left(E_{C O}\right)$ of heat released of $\mathrm{CO}$ and $\mathrm{CO}_{2}(283 \mathrm{~kJ} / \mathrm{mol}$ of oxygen consumed $)$. 


\subsubsection{Calibration test results}

Table 4-1 summarizes the results of the calibration tests including the measured average velocity and $\mathrm{O}_{2}$ concentration in the fan chamber. Results of $\int \mathrm{Q}$ and $\mathrm{E}$ are shown in the table. The factor that matches $\int \mathrm{Q}$ to $\mathrm{E}$ was found to be $0.80 \sim 0.86$ from propane tests. The results from Type $\mathrm{P}$ tests were outside of this range because of their extremely short fire durations. From the heptane tests, the factor was found to be 0.84 and 0.86 . Overall, it is found that the factor varies depending on fan speed.

In Figure 4-8, correction factors are plotted with respect to $\mathrm{O}_{2}$ concentrations. Overall, the correction factor slightly increases with a decrease of $\mathrm{O}_{2}$ concentrations. A value of 0.85 was applied to the result from Test B1 1 to see if it is appropriate for the various sizes of fire. In test $\mathrm{B} 11$, the propane calibration burners started with $8 \mathrm{MW}$ and decreased step by step at a regular time interval. The fans were running at $25 \%$ capacity, generating about $1-2 \mathrm{~m} / \mathrm{s}$ of air velocity in the tunnel. Figure 4-9 shows the adjusted HRR measurement results from Test B11. Although there is some system response delay at every transition of fire size, the system results compares well with the propane HRR. Therefore, a constant factor of 0.85 is suggested for the calibration factor for the system, and this has been incorporated in the Labview program to be used for all tunnel tests. 


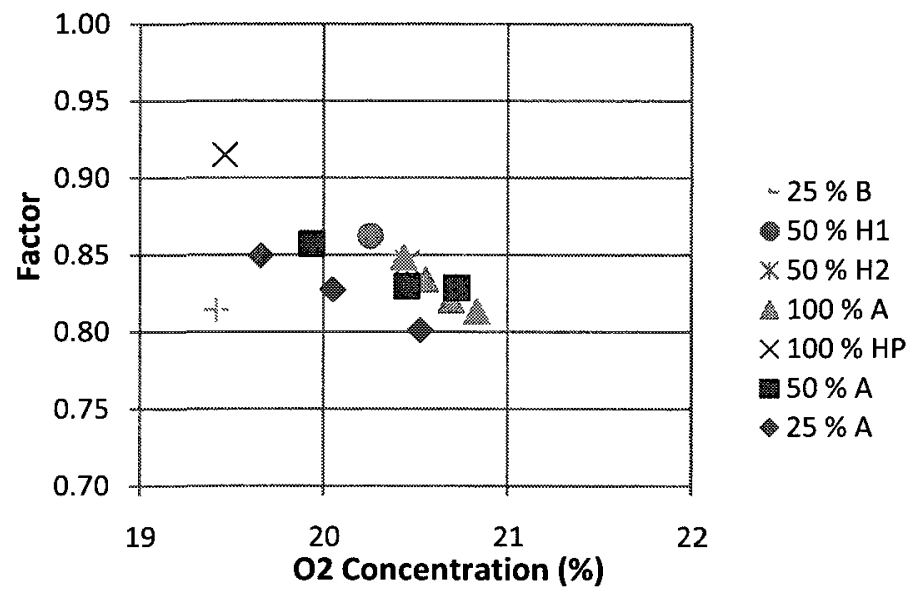

Figure 4-8 Correction factors with respect to $\mathrm{O} 2$ concentration

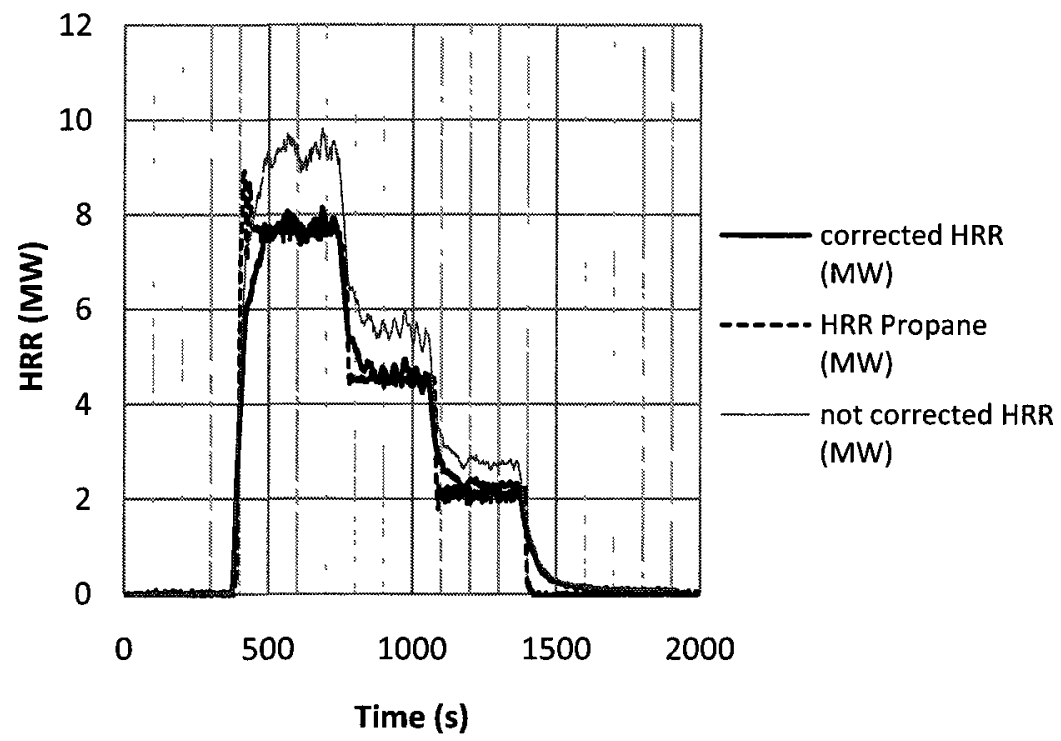

Figure 4-9 Corrected HRR calculation for Test B11 (25\%, 8-2 MW Type B propane test, correction factor $=0.83$ ) 
Table 4-1 A list of calibration tests and summary of results

\begin{tabular}{|c|c|c|c|c|c|c|c|c|c|c|c|c|c|c|c|}
\hline \multirow{3}{*}{ Type } & \multirow{3}{*}{ ID } & \multirow{3}{*}{ Fire } & \multirow{3}{*}{\begin{tabular}{|c|} 
Duration \\
$s$ \\
\end{tabular}} & \multirow{3}{*}{$\begin{array}{c}\text { Fan } \\
\text { Capacity } \\
\%\end{array}$} & \multirow{3}{*}{$\begin{array}{c}\text { Velocity } \\
\mathrm{m} / \mathrm{s}\end{array}$} & \multirow{3}{*}{$\begin{array}{l}02 \\
\% \\
\end{array}$} & \multicolumn{2}{|l|}{ Input } & \multicolumn{2}{|l|}{ Output } & \multicolumn{4}{|c|}{ Corrected } & \multirow{3}{*}{$\begin{array}{c}\begin{array}{c}\text { Transport } \\
\text { time }\end{array} \\
s \\
\end{array}$} \\
\hline & & & & & & & HRR & $\mathrm{E}$ & HRR & $\mathrm{sQ}$ & \multicolumn{2}{|c|}{ HRR } & \multicolumn{2}{|c|}{ sQ } & \\
\hline & & & & & & & $\mathrm{MW}$ & $\mathrm{MJ}$ & $\mathrm{MW}$ & $\mathrm{MJ}$ & Factor & $\mathrm{MW}$ & Factor & $\mathrm{MJ}$ & \\
\hline A & 1 & 2.5MW Propane & 395 & 25 & 2.59 & 20.52 & 2.6 & 1010 & 3.1 & 1261 & 0.83 & 2.4 & 0.80 & 1010 & 35 \\
\hline A & 2 & 5MW Propane & 370 & 25 & 2.66 & 20.05 & 5.3 & 1958 & 6.2 & 2366 & 0.85 & 5.1 & 0.83 & 1958 & 30 \\
\hline A & 3 & 7.5MW Propane & 350 & 25 & 2.79 & 19.66 & 7.5 & 2630 & 8.7 & 3096 & 0.86 & 7.3 & 0.85 & 2630 & 25 \\
\hline A & 4 & 2.5MW Propane & 350 & 50 & 4.61 & 20.72 & 2.6 & 882 & 3.0 & 1065 & 0.85 & 2.5 & 0.83 & 882 & 20 \\
\hline A & 5 & 5MW Propane & 600 & 50 & 4.69 & 20.45 & 5.1 & 3093 & 6.1 & 3728 & 0.84 & 5.1 & 0.83 & 3093 & 20 \\
\hline A & 6 & $10 \mathrm{MW}$ Propane & 320 & 50 & 4.73 & 19.94 & 10.0 & 3214 & 11.5 & 3749 & 0.88 & 9.7 & 0.86 & 3214 & 15 \\
\hline A & 7 & 2.5MW Propane & 280 & 100 & 8.17 & 20.83 & 2.5 & 691 & 3.0 & 850 & 0.83 & 2.4 & 0.81 & 691 & 10 \\
\hline A & 8 & 5MW Propane & 270 & 100 & 8.21 & 20.69 & 5.1 & 1387 & 6.1 & 1690 & 0.84 & 5.0 & 0.82 & 1387 & 10 \\
\hline A & 9 & 7.5MW Propane & 285 & 100 & 8.24 & 20.55 & 7.6 & 2150 & 9.0 & 2578 & 0.84 & 7.5 & 0.83 & 2150 & 10 \\
\hline A & 10 & 10MW Propane & 170 & 100 & 7.78 & 20.43 & 10.0 & 1731 & 11.5 & 2039 & 0.87 & 9.7 & 0.85 & 1731 & 10 \\
\hline B & 11 & 8 2MW Propane & 1070 & 25 & 2.68 & 19.41 & 7.9 & 4925 & 9.8 & 6048 & 0.81 & 7.9 & 0.81 & 4925 & 30 \\
\hline $\mathbf{P}$ & 12 & 16MW Propane & 85 & 100 & 8.36 & 20.18 & 16.3 & 746 & 16.5 & 966 & 0.99 & 12.7 & 0.77 & 746 & 10 \\
\hline $\mathbf{P}$ & 13 & 13MW Propane & 110 & 100 & 8.37 & 20.33 & 13.5 & 701 & 13.6 & 915 & 0.99 & 10.5 & 0.77 & 701 & 5 \\
\hline $\mathrm{H1}$ & 14 & $\begin{array}{r}5 \mathrm{MW} \text { Heptane } \\
46.94 \mathrm{~kg}\end{array}$ & 420 & 50 & 4.66 & 20.25 & 6.0 & 1934 & 8.5 & 2243 & 0.86 & 7.3 & 0.86 & 1934 & 20 \\
\hline $\mathrm{H} 2$ & 15 & $\begin{array}{r}5 \mathrm{MW} \text { Heptane } \\
20.43 \mathrm{~kg} \\
\end{array}$ & 360 & 50 & 4.69 & 20.45 & 5.0 & 842 & 6.6 & 996 & 0.84 & 5.6 & 0.84 & 842 & 20 \\
\hline \multirow[t]{2}{*}{ HP } & \multirow[t]{2}{*}{16} & $10 \mathrm{MW}$ Propane & 340 & \multirow[t]{2}{*}{100} & \multirow[t]{2}{*}{8.38} & \multirow[t]{2}{*}{19.46} & \multirow[t]{2}{*}{22.9} & 3414 & \multirow[t]{2}{*}{27.1} & \multirow[t]{2}{*}{9271} & \multirow[t]{2}{*}{0.85} & \multirow[t]{2}{*}{24.1} & \multirow[t]{2}{*}{0.91} & \multirow[t]{2}{*}{8482} & \multirow[t]{2}{*}{10} \\
\hline & & $\begin{array}{r}\text { and } 10 \mathrm{MW} \text { Heptane } \\
123 \mathrm{~kg}\end{array}$ & 420 & & & & & 5068 & & & & & & & \\
\hline
\end{tabular}

note :

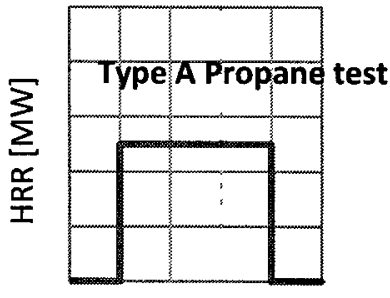

Time (s)

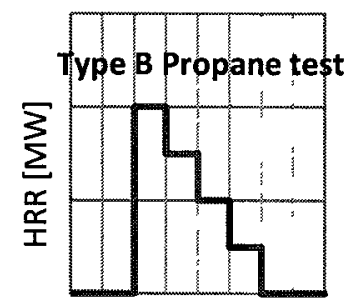

Time (s) 


\subsection{Summary}

A series of calibration tests was conducted. From the test results, a calibration factor of 0.85 for the HRR measurement system was found which adjusts the overestimated flow rates due to flow deflection near the walls.

There is response delay due to the large-scale of the facility, and this causes noise and apparent peaks in the HRR measurements. Thus, the system's ability to handle a sudden increase or decrease of HRR is limited. As the measurement system requires collecting all combustion products, a suitable fan capacity must be used for a specific size of fire. This means that the longitudinal air velocity in the laboratory tunnel must be able to direct all smoke into the fan chamber. Results showed that a $25 \%$ fan speed was able to handle fires as large as $8 \mathrm{MW}$ with no loss of smoke products. However, a longer system response delay was experienced at $25 \%$ fan speed than the larger fan speeds. A $25 \%$ fan speed must be the minimum fan speed to ensure a reasonable estimate of HRR for this HRR measurement system.

The calibration test results showed that the system is responsive to various fires sizes, as small as $2.5 \mathrm{MW}$. However, due to the scale of the facility, the measurement system is more suited for large fires that last a long time. The result from the calibration test of 24 MW shows that the developed HRR measurement system has the ability to handle large amounts of smoke generated from large fires with no significant smoke build-up. 


\section{CHAPTER 5. UNCERTAINTY ANALYSIS OF HRR MEASUREMENTS}

Measurements always have errors because physical phenomena are inherently random in nature. In addition to the random errors, systematic errors can be associated with the measurements resulting in low accuracy [98]. As direct measurements of HRR are not possible, HRR is calculated as a function of many other variables. It is important to know the combined possible error resulting from the uncertainty of each variable in the calculations of HRR. Uncertainty analysis was conducted with data obtained from the calibration test program.

This chapter introduces a method of uncertainty analysis used in the present study and presents the combined uncertainty in the HRR estimations, as well as the uncertainty associated with each measurement variable. The results of the analysis assess the effect of each variable in the output results and identify the major sources of uncertainty, which in turn help improve the system design.

\subsection{Method}

The law of uncertainty propagation is often used to calculate the resultant uncertainty associated with a function of several independent measurements.

\subsubsection{Uncertainty propagation}

The principle of the law of uncertainty propagation comes from the concept that the probability distribution function of a dependent variable can be derived from the 
probability distributions of component variables. For single random variable $\mathrm{X}$ and estimate $\mathrm{Y}$, the density functions for $f_{X}$ and $f_{Y}$ are correlated as following;

$$
\begin{gathered}
Y=g(X) \\
f_{Y}(Y) d y=f_{X}(X) d x
\end{gathered}
$$

We can derive the mean $(\mathbb{E})$ and variance $($ Var $)$ of the unknown density function of $f_{Y}$ based on the known $f_{X}$ and the given function, $Y=g(X)$.

$$
\begin{gathered}
\mathbb{E}[Y]=\int Y f_{Y}(Y) d y=\int g(X) f_{X}(X) d x \\
\operatorname{Var}[Y]=\int\left(Y-\mu_{Y}\right)^{2} f_{Y}(Y) d y=\int(g(X)-\mathbb{E}(Y))^{2} f_{X}(X) d x
\end{gathered}
$$

Often, it is difficult to integrate the above equations, so we use a numerical method to expand $g(X)$ in a Taylor series.

$$
Y=g\left(\mu_{X}\right)+\left.\left(X-\mu_{X}\right) \frac{\partial g}{\partial X}\right|_{X=\mu_{X}}+\left.\frac{1}{2}\left(X-\mu_{X}\right)^{2} \frac{\partial^{2} g}{\partial X^{2}}\right|_{X=\mu_{X}}+\cdots
$$

Using 1st order second moment approximation [98] of the random variable $\mathrm{X}$, we can approximately calculate the mean and variance of .

$$
\begin{gathered}
\mathbb{E}[Y] \simeq g\left(\mu_{X}\right) \\
\operatorname{Var}[Y] \simeq \operatorname{Var}[X]\left(\frac{\partial g}{\partial X}\right)^{2}
\end{gathered}
$$

Applying the principle to the problem of HRR measurements that are function of many random variables,

$$
Q=g\left(X_{1}, X_{2}, \cdots, X_{n}\right)
$$


We obtain the first-order approximate mean and variance of $Y$ as follows:

$$
\mathbb{E}(Q) \simeq g\left(\mu_{X 1}, \mu_{X 2}, \cdots, \mu_{X n}\right)
$$

The mean of the function is approximately equal to the function of the means.

$$
\operatorname{Var}(Q) \simeq \sum_{i=1}^{n} \operatorname{Var}\left(X_{i}\right)\left(\frac{\partial g}{\partial X_{i}}\right)^{2}+\sum_{i}^{n} \sum_{\neq j}^{n} \frac{\partial g}{\partial X_{i}} \frac{\partial g}{\partial X_{j}} \operatorname{COV}\left(X_{i}, X_{j}\right)
$$

The partial derivatives are evaluated at $\mu_{X i}$. If each variable is statistically independent or uncorrelated, $\operatorname{COV}\left(X_{i}, X_{j}\right)=0$, then the Eq becomes

$$
\operatorname{Var}(Q) \simeq \sum_{i=1}^{n} \operatorname{Var}\left(X_{i}\right)\left(\frac{\partial g}{\partial X_{i}}\right)^{2}
$$

To use the above method,

- First, break down the HRR equation into several components so that each variable is mutually independent and uncorrelated with any other.

- Second, find the uncertainty $(u)$ of each component. $u_{X_{1}}=\sqrt{\operatorname{Var}\left(X_{i}\right)}=\sigma_{X_{1}}$

- Third, find the partial derivatives of the HRR equation with respect to each component, $\frac{\partial g}{\partial x_{i}}$.

Therefore, the combined uncertainty of HRR estimation can be expressed as a sum of uncertainty contributions of each component.

$$
\mathrm{u}(Q)=\sqrt{\left(u_{X_{1}} \frac{\partial g}{\partial X_{1}}\right)^{2}+\left(u_{X_{2}} \frac{\partial g}{\partial X_{2}}\right)^{2}+\cdots}
$$

And, the relative uncertainty can be expressed as below $[85,86,99]$; 


$$
\frac{u(Q)}{Q}=\sqrt{\left(\frac{X_{1}}{Q} \frac{u_{X_{1}}}{X_{1}} \frac{\partial g}{\partial X_{1}}\right)^{2}+\left(\frac{X_{2}}{Q} \frac{u_{X_{2}}}{X_{2}} \frac{\partial g}{\partial X_{2}}\right)^{2}+\cdots}
$$

As the above method can be valid when each variable is mutually independent, each parameter used in the equation of HRR calculation should be tracked. In particular, the method requires partial derivatives of each variable. In fact, tracking $\mathrm{n}$ different parameters and getting $\mathrm{n}$ partial derivatives is not simple. Some previous studies $[85,86$, 99] simplified the original equation of HRR and used the partial derivatives of the equation only for selected components. However, it was still very complex and time consuming.

\subsubsection{Kragten spreadsheet}

Kragten [100] suggested a simple way to execute the method of uncertainty propagation by using a spreadsheet program and approximately getting the partial derivatives $\left(\frac{\partial g}{\partial X_{i}}\right)$ numerically. A recent study [101] used Kragten spreadsheet to calculate the uncertainty in HRR estimation. The concept of the approximate partial derivates used in the Kragten worksheet can be expressed as below. As the partial derivatives are evaluated at $\mu_{X i}$,

$$
\begin{aligned}
& \frac{\partial g}{\partial X_{i}} u_{X_{i}}=\left[Q+\frac{\partial g}{\partial X_{i}} u_{X_{i}}\right]-Q \Rightarrow \Delta Q \\
& \quad=g\left(\mu_{X 1}, \mu_{X 2}, \cdots, \mu_{X i}+u_{X_{i}}, \cdots, \mu_{X n}\right)-g\left(\mu_{X 1}, \mu_{X 2}, \cdots \mu_{X i}, \cdots, \mu_{X n}\right)
\end{aligned}
$$

The general scheme of the Kragten worksheet is shown in Table 5-1. The procedure is as follows: arrange the $\mathrm{n}$ component variables, and make an $(\mathrm{n} \times \mathrm{n})$ matrix in the worksheet. Use the base value (mean) of each variable, calculate the dependent variable, $Q$, using the equation $g\left(X_{1}, X_{2}, \cdots, X_{n}\right)$ in the first column. Repeat the calculation in the next column 
using the same base values except $\mathrm{i}^{\text {th }}$ value that must be $\mu_{X i}+u_{X_{i}}$. In the next row, calculate $\Delta Q$ as explained above. Then, calculate $\frac{\partial g}{\partial X_{\mathrm{i}}} \frac{X_{\mathrm{i}}}{Q}$ that are the relative sensitivity coefficients $\left(C_{i}\right)$ [101]. Finally, calculate the relative combined uncertainty as shown in Eq 45 .

Table 5-1 The general scheme of Kragten spreadsheet [100]

\begin{tabular}{|c|c|c|c|c|c|}
\hline & & $\mathrm{X}_{1}$ & $x_{2}$ & $\cdots$ & $x_{n}$ \\
\hline $\mathrm{X}_{1}$ & $\mu_{\mathrm{X} 1}$ & $\mu_{\mathrm{X} 1}+u_{\mathrm{X}_{1}}$ & $\mu_{\mathrm{X} 1}$ & $\cdots$ & $\mu_{\mathrm{X} 1}$ \\
\hline $\mathrm{X}_{2}$ & $\mu_{\mathrm{X} 2}$ & $\mu_{\mathrm{X} 2}$ & $\mu_{\mathrm{X} 2}+u_{x_{2}}$ & $\ldots$ & $\mu_{\mathrm{X} 2}$ \\
\hline$\ldots$ & $\ldots$ & $\ldots$ & $\ldots$ & $\ldots$ & $\ldots$ \\
\hline $\mathrm{X}_{\mathrm{n}}$ & $\mu_{\mathrm{Xn}}$ & $\mu_{\mathrm{Xn}}$ & $\mu_{\mathrm{Xn}}$ & $\cdots$ & $\mu_{X_{n}}+u_{X_{n}}$ \\
\hline & $Q$ & $Q+\frac{\partial \mathrm{g}}{\partial \mathrm{X}_{1}} \mathbf{u}_{\mathrm{X} 1}$ & $Q+\frac{\partial \mathrm{g}}{\partial \mathrm{X}_{2}} \mathrm{u}_{\mathrm{x}_{2}}$ & $\ldots$ & $Q+\frac{\partial \mathrm{g}}{\partial \mathrm{X}_{\mathrm{n}}} \mathbf{u}_{\mathrm{X}_{\mathrm{n}}}$ \\
\hline & $\Delta Q$ & $\frac{\partial g}{\partial X_{1}} u_{X_{1}}$ & $\frac{\partial \mathrm{g}}{\partial \mathrm{X}_{2}} \mathbf{u}_{\mathrm{x}_{2}}$ & $\ldots$ & $\frac{\partial g}{\partial X_{n}} u_{X_{n}}$ \\
\hline & $\mathrm{C}_{\mathrm{i}}$ & $\frac{\partial \mathrm{g}}{\partial \mathrm{X}_{1}} \frac{\mathrm{X}_{1}}{\mathrm{Q}}$ & $\frac{\partial \mathrm{g}}{\partial \mathrm{X}_{2}} \frac{\mathrm{X}_{2}}{\mathrm{Q}}$ & $\cdots$ & $\frac{\partial \mathrm{g}}{\partial \mathrm{X}_{\mathrm{n}}} \frac{\mathrm{X}_{\mathrm{n}}}{\mathrm{Q}}$ \\
\hline
\end{tabular}

\subsection{Uncertainty Analysis}

To apply the method described above in the uncertainty analysis of HRR measurements, 28 individual variables used in the calculation of HRR were identified. Each variable is mutually independent and uncorrelated with each other. Table 5-2 lists the 28 parameters. Among these, 8 parameters are assumed to be constant with zero uncertainty. For instance, the cross sectional area of the exhaust fan chamber (A), which 
is used in the calculation of mass flow rate of exhaust gas $\left(\dot{m}_{e}\right)$, is assumed to have zero uncertainty. Technically, there must be an error in the measurement of the area, but it is negligible due to the large scale of the fan chamber. We also assumed that the heat release per unit mass of $\mathrm{O}_{2}$ consumed in the reaction $(\mathrm{E})$ is constant. Actually, $\mathrm{E}$ is one of the most important parameters in the calculation of HRR, and its uncertainty must be addressed because the value varies depending on chemical compositions of a fuel. However, we assume $\mathrm{E}$ is constant in this analysis because sample data used in this uncertainty analysis are mostly obtained from the same fuel, propane.

20 variables are selected to be analysed since they are most likely to affect the uncertainty of the HRR estimation. To find the mean and dispersion of each measurement variable, enough observational data are necessary. A large amount of sample data was obtained from the calibration test program (See Chapter 4). The HRR measurement system collected a large number of data sets of four differential pressures, six temperatures, $\mathrm{O}_{2}$, $\mathrm{CO}_{2}$ and $\mathrm{CO}$ concentrations every $1.5 \mathrm{sec}$ while the calibration propane burners were generating a constant heat for about 5 min. For example, in the test of $10 \mathrm{MW}$ propane fire with $50 \%$ fan speed, we obtained about 150 sample data sets that were transmitted during the steady-state condition. The data were used to determine the mean and standard deviation of each variable. These uncertainties that are determined experimentally are classified as Type A [86].

In the case that we cannot determine the uncertainty based on observational data, the uncertainty can be determined based on engineering judgement, experience or the specification of a measurement device provided by its manufacturer. This is called Type 
B uncertainty. In this study, there are 6 type B uncertainties determined. For instance, the mean and dispersion of the mass flow rate correction factor $(\zeta)$ were determined based on calibration test results.

Table 5-2 A list of parameters and measurement variables; the mean and the relative sensitivity coefficient are obtained for the test of $10 \mathrm{MW}$ with $50 \%$ fan speed.

\begin{tabular}{|c|c|c|c|c|c|c|}
\hline & $\begin{array}{l}\text { Parameter } \\
\mathrm{X}_{1} \\
\end{array}$ & $\mu_{1}$ & $\frac{\mathrm{u}_{\mathrm{X}_{1}}}{\mathrm{X}_{1}}$ & $C_{1}=\frac{X_{1}}{Q} \frac{\partial g}{\partial X_{1}}$ & $\begin{array}{l}\text { Uncertainty } \\
\text { contribution }\end{array}$ & $\begin{array}{l}\text { Type } \\
\text { uncertainty }\end{array}$ \\
\hline 1 & $\mathrm{X}_{\mathrm{O} 2}^{\mathrm{AO}}$ & 20.95 & $0.01 \%$ & 24.071 & $0.01 \%$ & 1 \\
\hline 2 & $\mathrm{X}_{02}^{\mathrm{Ae}}$ & $\ldots \quad 19.94$ & $0.15 \%$ & -22.829 & $9.15 \%$ & 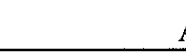 \\
\hline 3 & $\mathrm{X}_{\mathrm{CO}}^{\mathrm{Ae}}$ & 6.99 & $19.21 \%$ & 0.000 & $0.00 \%$ & $\underline{-2}$ \\
\hline 4 & $\mathrm{X}_{\mathrm{CO} 2}^{\mathrm{AO}}$ & 0.04 ; & $3.78 \%$ & 0.011 & $0.00 \%$ & I \\
\hline 5 & $\mathrm{X}_{\mathrm{CO} 2}^{\mathrm{Ae}}$ & 0.7209 & $2.80 \%$ & -0.166 & $0.17 \%$ & $I$ \\
\hline 6 & $\mathrm{~T}_{1}^{\mathrm{e}}$ & _ 102.85 & $3.76 \%$ & -0.023 & $0.01 \%$ & $\underline{t}$ \\
\hline 7 & $\mathrm{~T}_{2}^{\mathrm{e}}$ & -103.20 & $3.66 \%$ & -0.023 & $0.01 \%$ & 1 \\
\hline 8 & $\mathrm{~T}_{3}^{\mathrm{e}}$ & _ & $3.98 \%$ & -0.023 & $0.01 \%$ & 1 \\
\hline 9 & $\mathrm{~T}_{4}^{\mathrm{e}}$ & _ 100.05 & $4.17 \%$ & -0.022 & $0.01 \%$ & 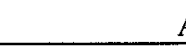 \\
\hline 10 & $\mathrm{~T}_{5}^{e}$ & _ 99.39 & $4.26 \%$ & -0.022 & $0.01 \%$ & $\underline{I}$ \\
\hline 11 & $\mathrm{~T}_{6}^{\mathrm{e}}$ & , _ _ _ & $4.05 \%$ & -0.022 & $0.01 \%$ & 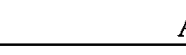 \\
\hline 12 & $\mathrm{k}_{\mathrm{p}}$ & {$[\ldots 1.10]$} & $5.00 \%$ & -0.952 & $17.96 \%$ & 1 \\
\hline 13 & $\Delta \mathrm{p}_{1}$ & 14.46 & $29.93 \%$ & 0.129 & $11.89 \%$ & 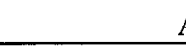 \\
\hline 14 & $\Delta \mathrm{p}_{2}$ & $\ldots 14.68$ & $31.67 \%$ & 0.131 & $13.69 \%$ & $I$ \\
\hline 15 & $\Delta \mathrm{p}_{3}$ & --12.72 & $36.76 \%$ & 0.114 & $13.85 \%$ & $\underline{I}$ \\
\hline 16 & $\Delta \mathrm{p}_{4}$ & -12.90 & $35.33 \%$ & 0.115 & $13.18 \%$ & $\underline{t}$ \\
\hline 17 & $\alpha$ & $\ldots-1.08^{\prime}$ & $4.43 \%$ & -0.001 & $0.00 \%$ & 1 \\
\hline 18 & $\zeta$ & 0.85 & $5.00 \%$ & 1.000 & $19.80 \%$ & I \\
\hline 19 & $\mathrm{~T}_{\mathrm{a}}^{\mathrm{o}}$ & -15 & $6.59 \%$ & -0.005 & $0.00 \%$ & $t$ \\
\hline 20 & $\mathrm{RH}$ & 0.50 & $60.00 \%$ & -0.005 & $0.08 \%$ & I \\
\hline \multicolumn{5}{|c|}{ The relative combined uncertainty } & \multicolumn{2}{|c|}{$11.2 \%$} \\
\hline 21 & $\mathrm{E}$ & \multicolumn{3}{|c|}{$12.9 \ldots \ldots$} & \\
\hline 22 & $\mathrm{E}_{\mathrm{CO}}$ & \multicolumn{3}{|c|}{17.9} & \\
\hline 23 & A & \multicolumn{3}{|l|}{16.3} & \\
\hline 24 & $\rho_{0} T_{0}$ & \multicolumn{3}{|l|}{$1.203 \times 293$} & & \\
\hline 25 & $\mathrm{p}_{\mathrm{a}}$ & \multicolumn{3}{|l|}{101.5} & & \\
\hline 26 & $\mathrm{M}_{\mathrm{O} 2}$ & \multicolumn{3}{|l|}{32} & & \\
\hline 27 & $M_{\text {dry }}$ & \multicolumn{2}{|l|}{28.95} & & & \\
\hline 28 & $\mathrm{M}_{\mathrm{H}_{2} \mathrm{O}}$ & \multicolumn{3}{|l|}{18} & & \\
\hline
\end{tabular}


Using the mean and dispersion found for each measurement variable, the uncertainty analyses were carried out following the Kragten worksheet scheme. A sample worksheet for the test of $10 \mathrm{MW}$ with $50 \%$ fan speed is attached in Appendix C. In the case of 10 MW with $50 \%$ fan speed, the relative combined uncertainty was found to be about $11.2 \%$. The calculated relative sensitivity coefficients $\left(C_{i}\right)$ show that the HRR estimation is most sensitive to oxygen mole fraction measured by the gas analyser. The mass flow rate correction factor $(\zeta)$ and bi-directional probe constant $\left(k_{p}\right)$ show relatively high values of their sensitivity coefficients. Consequently, the analysis shows that most significant error contributors are $X_{02}^{A_{e}}$ and the variables used in the calculation of the mass flow rate of exhaust gas.

\subsection{Results and Conclusions}

Table 5-3 show a summary of the results from the uncertainty analysis carried out for the 11 calibration tests. The analysis shows that, in general, about $25 \%$ of the error comes from oxygen concentration measurements, and the rest comes from the mass flow rate measurements of exhaust gas. Figure 5-1 shows the uncertainty contribution by each variable that is averaged from 11 calibration tests.

The relative combined uncertainty found for all tests are in the range of $10 \%$ to $15 \%$. In Figure 5-2, the ratio of the measured HRR by the system to the input HRR ( $Q_{\text {measured }}$ $\left./ Q_{\text {nput }}\right)$ is plotted with respect to $Q_{\text {nnput. }}$ The figure shows the performance of the system for various fire sizes under different fan speeds of 25,50 and $100 \%$. As the fire size becomes large, the system tends to slightly underestimate HRR. This systematic error is 
mainly due to $\zeta$ whose average value was used in the calculation of HRR regardless of fire sizes.

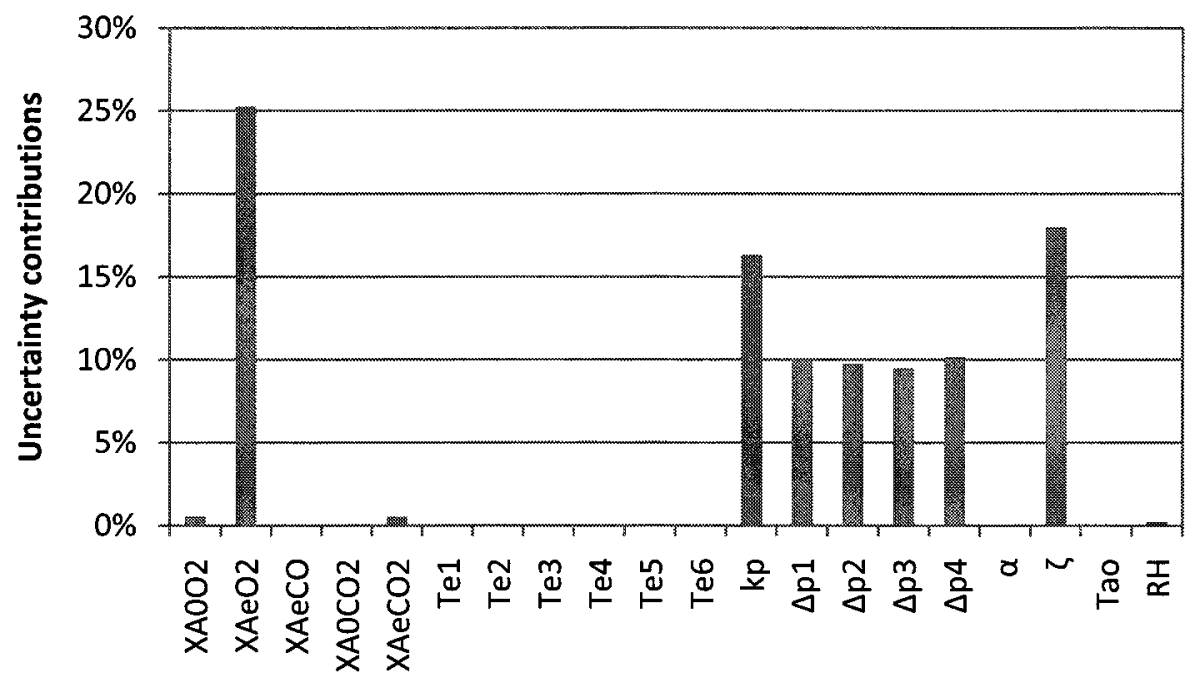

Figure 5-1 Uncertainty contributions by each component (averaged results from 11 tests)

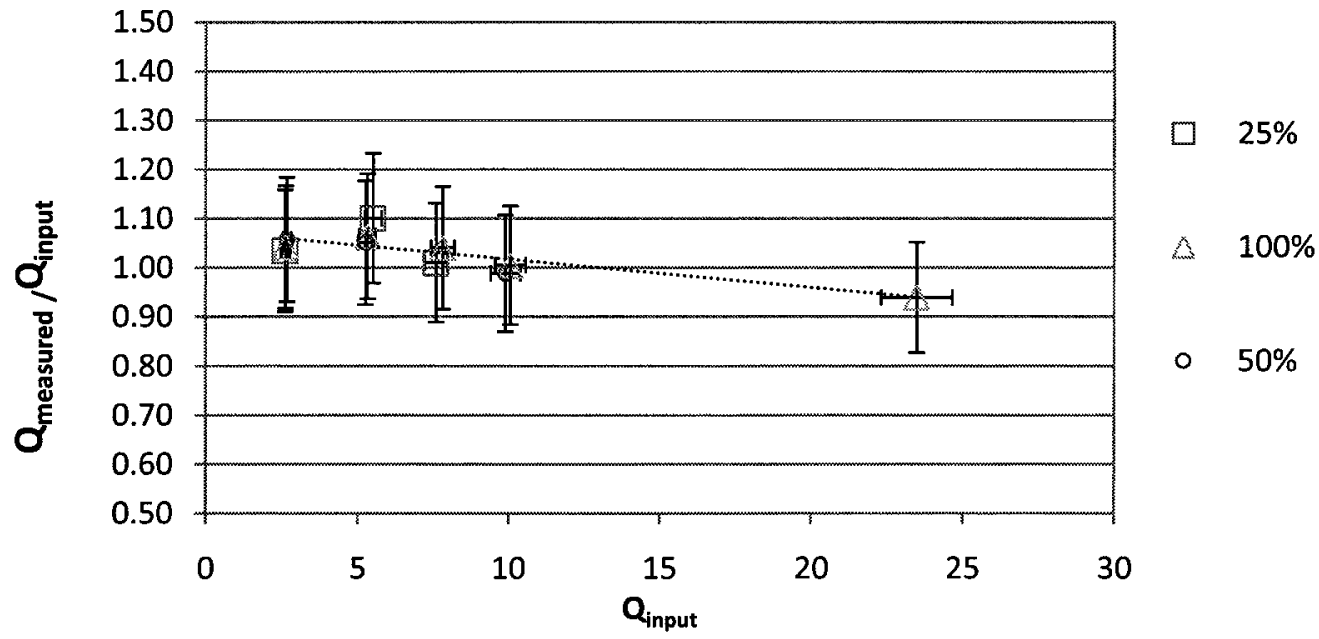

Figure 5-2 Performance of the HRR measurement system

It is concluded that the analysis gives insight into the measurement system, and the results can be used to improve the system design. It is important to regularly assess the system measurements and control the system devices, particularly the pressure transducers and the gas analyser. 
Table 5-3 Results of uncertainty analysis for two different sample data sets obtained from different test conditions

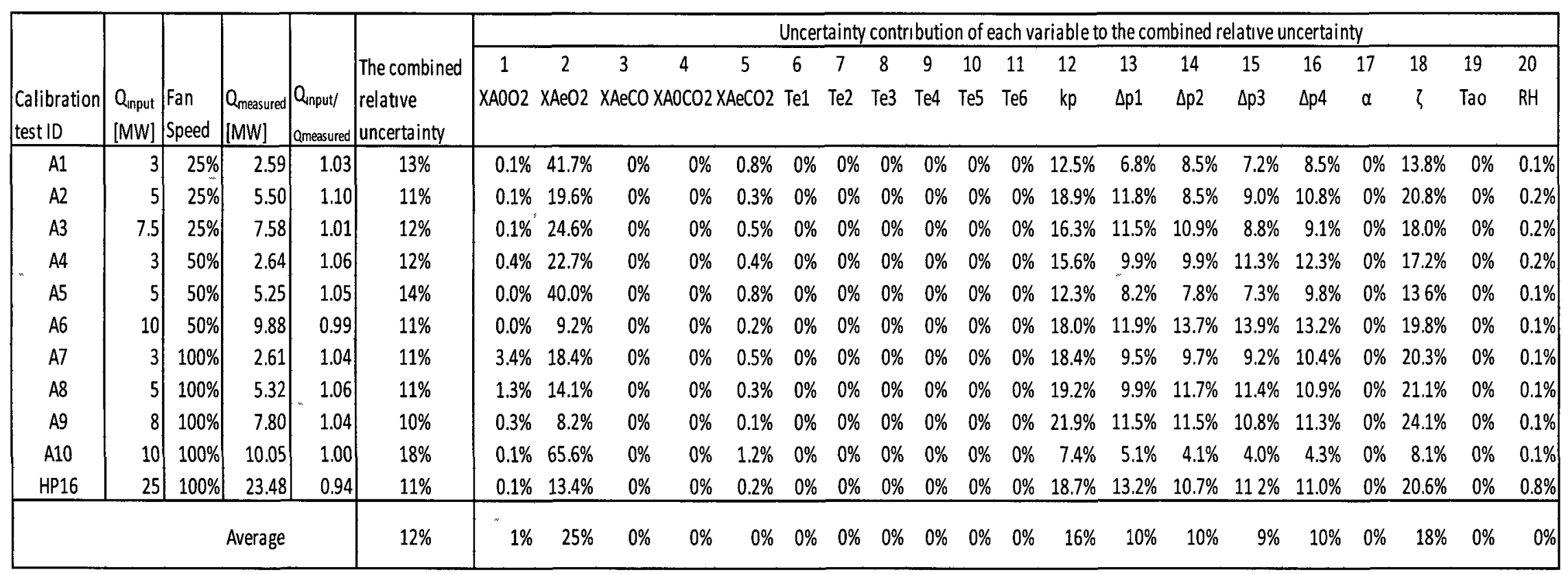




\subsection{Summary}

It is necessary to know how the accuracy of the HRR measurement using the new system as the system will be used in much research in tunnel fire safety engineering. Although many different random variables are used in the calculation of HRR, the possible error in the measurement of HRR can be easily analysed by the law of uncertainty propagation that is approximated by the $1^{\text {st }}$ order $2^{\text {nd }}$ moment method. By expanding the equation of HRR into the basic measurements (temperatures, differential pressures and gas concentrations), mutually independent components were identified. Then, the mean and dispersion of each component were determined based on sample measurements. Using the Kragten worksheet, the propagation of the uncertainty of each component was calculated. The relative combined uncertainty of the system measurements is about 10 $15 \%$ for the fire sizes tested in the calibration tests. The measurements of mass flow rate and oxygen concentration are the two most significant error contributors. The uncertainty analysis described in this study can be used for periodic calibration tests and a maintenance program to assess the performance of the system. 


\section{CHAPTER 6. SUPPRESSION TESTS}

This chapter describes the full-scale suppression test program conducted using a sprinkler system in the laboratory tunnel at Carleton University.

The scope of this test program included the following;

- Bucket tests to investigate the influence of longitudinal air flows on the spray pattern of the sprinkler system.

- Fire tests with suppression operating to investigate the mitigation effect of the sprinkler system along with the longitudinal ventilation system and to examine the impact of the sprinkler system on the efficiency of the longitudinal ventilation system.

- Evaluation of the HRR measurement system to determine its accuracy during suppression.

In this chapter, details of the test facility, test arrangement and test procedure are presented. Test results are also briefly presented in this chapter. Further discussion and analysis of results are revisited in Chapter 7 and Chapter 9.

\subsection{Tunnel facility}

The laboratory tunnel, which is $10 \mathrm{~m}$ wide, $5.5 \mathrm{~m}$ high and $37.5 \mathrm{~m}$ long, was used for the full-scale fire tests. Figure 6-1 shows the test set-up in the tunnel. A sprinkler system was installed under the tunnel ceiling. The tunnel ceiling is insulated, and walls are also insulated and lined with corrugated metal sheets to protect the insulation from water damage. 
The temperature profiles and the propagation of heat depend strongly on the cross section of the tunnel. Proper investigations of the convective flows and thermal radiation are possible in the laboratory tunnel because the cross section, $10 \mathrm{~m}$ wide and $5.6 \mathrm{~m}$ high, is typical of tunnels with two traffic lanes. Test results obtained in Carleton's laboratory tunnel were found to be reasonably extrapolated to longer tunnels in a previous study [91]. In that study, it was concluded that the length of the tunnel does not significantly impact on the temperature development close to the fire location.

\subsubsection{Ventilation}

The exhaust fan system was controlled at $25 \%, 50 \%$, and $100 \%$ of its capacity, which created longitudinal air flows in the tunnel of $0.5-0.7 \mathrm{~m} / \mathrm{s}, 1.3-1.5 \mathrm{~m} / \mathrm{s}$ and $2.8-3.0 \mathrm{~m} / \mathrm{s}$ (calculated based on the exhaust fan capacity), respectively. The main opening of the tunnel and the two side louver openings at the east end were open during the tests. At the main opening, flow straitening vanes (see Figure 6-2) were installed to maintain uniform air flows over the cross-section of the tunnel, from the inlet. Smoke was extracted by the fan system through the ceiling openings, which are located at the west end of the tunnel and connected to the fan chamber. 


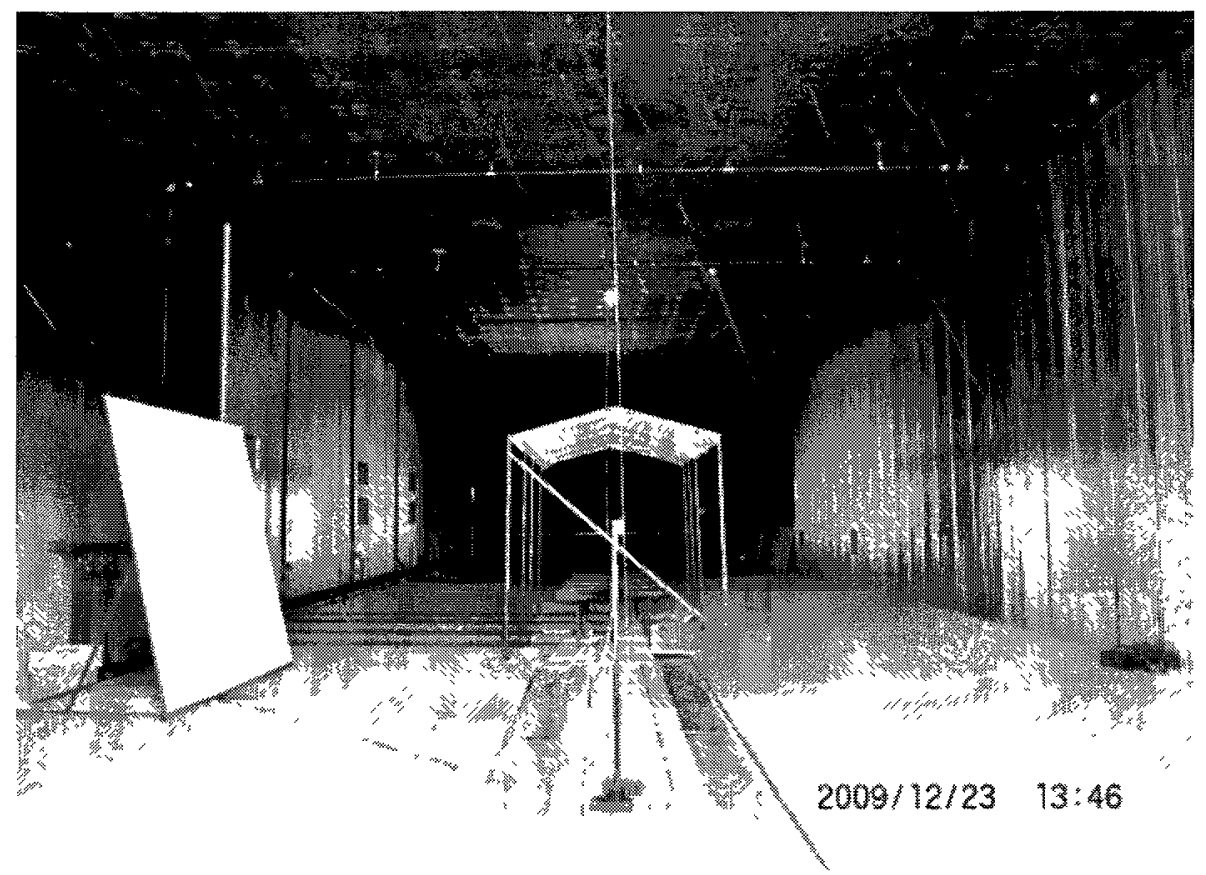

Figure 6-1 Test set-up in the tunnel

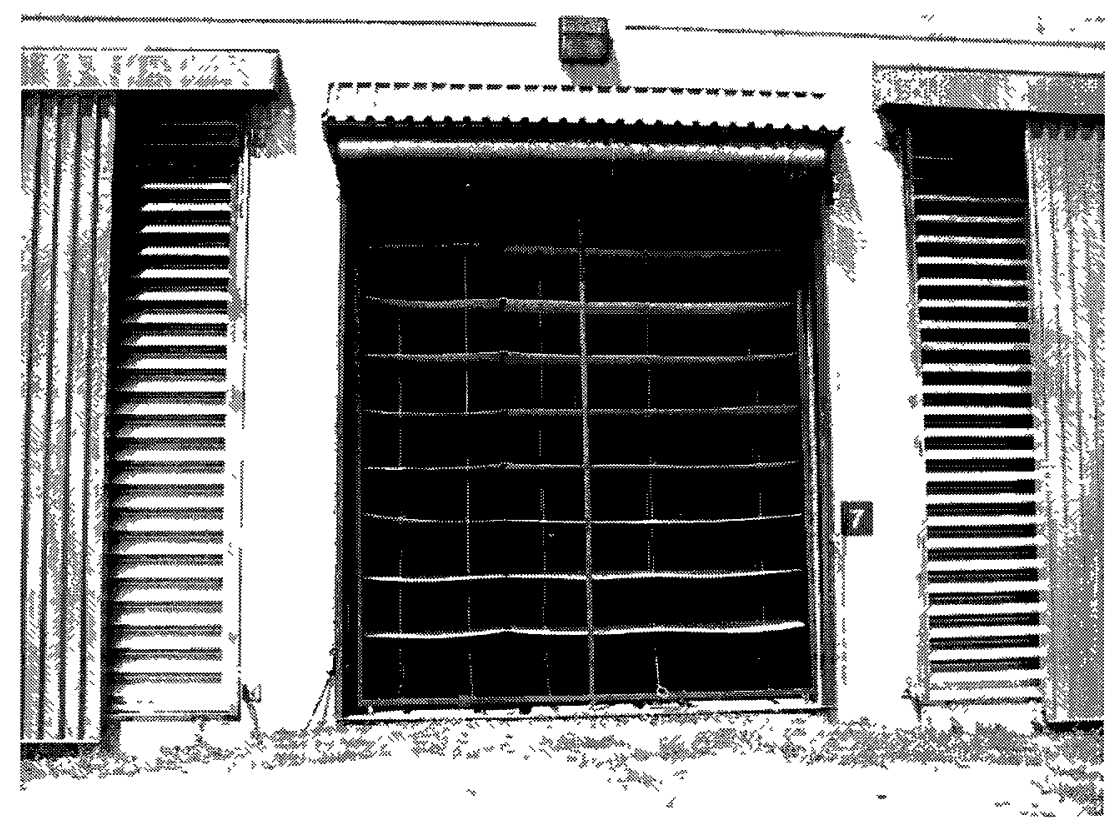

Figure 6-2 Flow straightening vanes at the main opening 


\subsubsection{Sprinkler system}

An open deluge sprinkler system using large droplets was used. The system was manually operated during the tests. Water spray rates of $3,6,9$ and $141 / \mathrm{min} / \mathrm{m}^{2}$ were examined. These water spray rates were determined based on the following information.

- There are no guidelines specifying design criteria and performance objectives, and the current guidance for WFFFS in tunnels is performance-based [14, 25, 26]. However, in the Japanese guidelines [24]; the standard water density is $6 \mathrm{l} / \mathrm{min} / \mathrm{m}^{2}$ with a minimum discharge pressure of $0.34 \mathrm{MPa}$.

- Water spray rates from $21 / \mathrm{min} / \mathrm{m}^{2}$ to about $12 \mathrm{1} / \mathrm{min} / \mathrm{m}^{2}$ were tested in the previous tests. From the literature review, it was found that the HRR of HGV fires decreased by about $80 \%$ [39].

- Applying NFPA 13 [102], the design standard for automatic sprinkler systems in industrial buildings, the minimum application rate for light hazard occupancies is $4 \mathrm{l} / \mathrm{min} / \mathrm{m}^{2}$ with a minimum design area of $140 \mathrm{~m}^{2}$. The maximum application rate suggested is $12.2 \mathrm{l} / \mathrm{min} / \mathrm{m}^{2}$ for extra hazard occupancy with a minimum design area of $230 \mathrm{~m}^{2}$

A sprinkler system was installed under the ceiling above the fire area (See Figure 6-3(a)). The water spray system consists of 5 parallel, $9 \mathrm{~m}$-long branches spaced at a distance of $3.7 \mathrm{~m}$, which are connected to a main pipe. Each branch has four sprinkler heads spaced at $2.5 \mathrm{~m}$. A total of 20 sprinkler heads were fitted in an upright position.

The type of sprinkler nozzles has a thread size of $15 \mathrm{~mm}$ and a K-factor of 161.3 $1 / \mathrm{min} / \mathrm{bar}^{0.5}\left(11.2 \mathrm{gpm} / \mathrm{psi}^{0.5}\right)$ which generates large droplets. The maximum capacity of the system is $12 \mathrm{1} / \mathrm{min} / \mathrm{m}^{2}$ with an application area of $185 \mathrm{~m}^{2}$, which is designed based on NFPA 13. The water flow rate and application area can be adjusted to test variable water flow rates and operating areas. For most tests, three branches $(\# 1, \# 2, \# 3)$ over the fire 
area were open for a spray area of $111 \mathrm{~m}^{2}$ to test water spray rates of 3, 6 and $91 / \mathrm{min} / \mathrm{m}^{2}$. In two tests, two branches $(\# 2, \# 3)$ were open for a spray area of $74 \mathrm{~m}^{2}$ to test a water application density of $14 \mathrm{1} / \mathrm{min} / \mathrm{m}^{2}$. Water flow rates and pressures of the sprinkler system were measured for each test. Table 6-1 shows operating pressures for each water application rate tested.

Table 6-1 Tested sprinkler water spray rates

\begin{tabular}{|c|c|c|c|c|c|}
\hline \multicolumn{3}{|c|}{ Water flow rate } & \multicolumn{2}{c|}{ Pressure } & $\begin{array}{c}\text { Spray } \\
\text { area }\end{array}$ \\
\hline $\mathrm{gpm}$ & $1 / \mathrm{min}$ & $1 / \mathrm{min} / \mathrm{m}^{2}$ & $\mathrm{kPa}$ & $\mathrm{psi}$ & $\mathrm{m}^{2}$ \\
\hline 85 & 322 & 2.9 & 55 & 8 & 111 \\
\hline 170 & 643 & 5.8 & 117 & 17 & 111 \\
\hline 290 & 1098 & 9.9 & 248 & 36 & 111 \\
\hline 290 & 1098 & 14.8 & 345 & 50 & 74 \\
\hline
\end{tabular}

\subsection{Fire tests}

To analyze the effectiveness of the longitudinal ventilation system and evaluate the effects of the sprinkler system, shielded propane fires with a constant HRR were used under the sprinkler system. This condition simulates the situation when the suppression system successfully controls the growth of the fire and keeps the HRR to its value at the time of activation. The fire was placed $12 \mathrm{~m}$ from the tunnel opening. Figure 6-3(b) shows the test arrangement and the sprinkler system in the tunnel. Table 6-2 shows a list of the tests carried out.

In each test, the fire started without the sprinkler system operating. After steady-state data were acquired for about 5 min without suppression, the sprinkler system was opened for another $5 \mathrm{~min}$ in most tests or $10 \mathrm{~min}$ in some cases where two different water application rates were tested in a row. A constant supply rate of propane was maintained 
during the test. This test procedure allowed a comparison of the HRR measurements without and with the sprinkler system operating. It also enables a comparison of the condition in the tunnel without and with the suppression system operating. After closing the sprinkler system, the fire was maintained if possible for another $5 \mathrm{~min}$ in order to evaluate the effect of water spray on the performance of the HRR measurement system and heat flux meters after suppression.

Table 6-2 List of tests

\begin{tabular}{|c|c|c|c|c|c|c|c|}
\hline & ID & Water spray rate & $\begin{array}{c}\text { Heat } \\
\text { release }\end{array}$ & $\begin{array}{c}\text { Critical } \\
\text { Velocity }\end{array}$ & $\begin{array}{c}\text { Air } \\
\text { velocity }\end{array}$ & $\begin{array}{c}\text { Fan } \\
\text { speed }\end{array}$ & $\begin{array}{c}\text { Spray } \\
\text { area }\end{array}$ \\
\hline & & $\mathrm{l} / \mathrm{min} / \mathrm{m}^{2}$ & MW & $\mathrm{m} / \mathrm{s}$ & $\mathrm{m} / \mathrm{s}$ & $\%$ & $\mathrm{~m}^{2}$ \\
\hline 1 & T5M25\%3_9 & 3 and 9 & 5 & 1.85 & 0.7 & 25 & 111 \\
\hline 2 & T5M25\%6 & 6 & 5 & 1.85 & 0.7 & 25 & 111 \\
\hline 3. & T5M50\%3_9 & 3 and 9 & 5 & 1.85 & 1.3 & 50 & 111 \\
\hline 4 & T5M50\%6 & 6 & 5 & 1.85 & 1.3 & 50 & 111 \\
\hline 5 & T5M100\%3 & 3 & 5 & 1.85 & 2.8 & 100 & 111 \\
\hline 6 & T5M100\% 6 & 6 & 5 & 1.85 & 2.8 & 100 & 111 \\
\hline 7 & T5M100\%9 & 9 & 5 & 1.85 & 2.8 & 100 & 111 \\
\hline 8 & T10M25\%3 & 3 & 10 & 2.33 & 0.7 & 25 & 111 \\
\hline 9 & T10M25\%6 & 6 & 10 & 2.33 & 0.7 & 25 & 111 \\
\hline 10 & T10M25\%9 & 9 & 10 & 2.33 & 0.7 & 25 & 111 \\
\hline 11 & T10M50\%3_9 & 3 and 9 & 10 & 2.33 & 1.3 & 50 & 111 \\
\hline 12 & T10M50\%6 & 6 & 10 & 2.33 & 1.3 & 50 & 111 \\
\hline 13 & T10M50\%14 & 14 & 10 & 2.33 & 2.8 & 100 & 74 \\
\hline 14 & T10M100\%3_9 & 3 & 10 & 2.33 & 2.8 & 100 & 111 \\
\hline 15 & T10M100\%6 & 6 & 10 & 2.33 & 2.8 & 100 & 111 \\
\hline 16 & T10M100\%14 & 14 & 10 & 2.33 & 2.8 & 100 & 74 \\
\hline 17 & H15M50\%6 & 6 & 15 & 2.66 & 1.3 & 50 & 111 \\
\hline 18 & H15M50\%9 & 9 & 15 & 2.66 & 1.3 & 50 & 111 \\
\hline 19 & H15M100\%6 & 6 & 15 & 2.66 & 2.8 & 100 & 111 \\
\hline 20 & H15M100\%9 & 9 & 15 & 2.66 & 2.8 & 100 & 111 \\
\hline
\end{tabular}




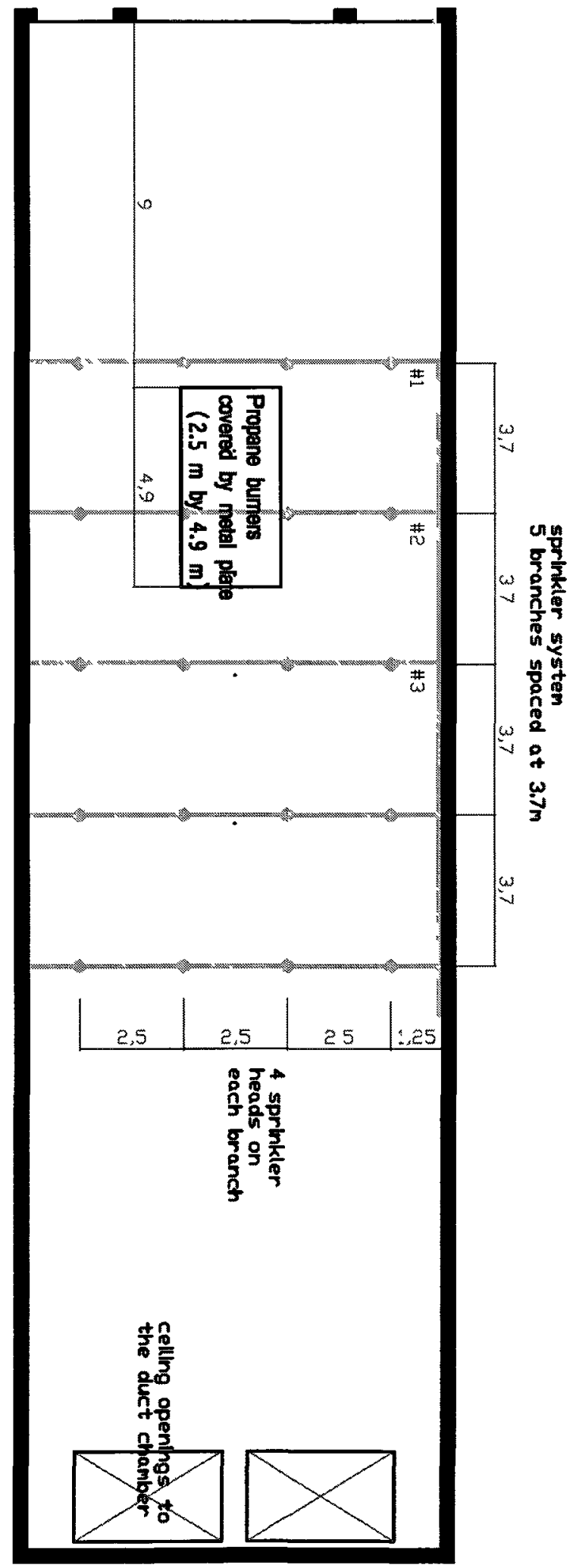

(a) Sprinkler system (Plan view)

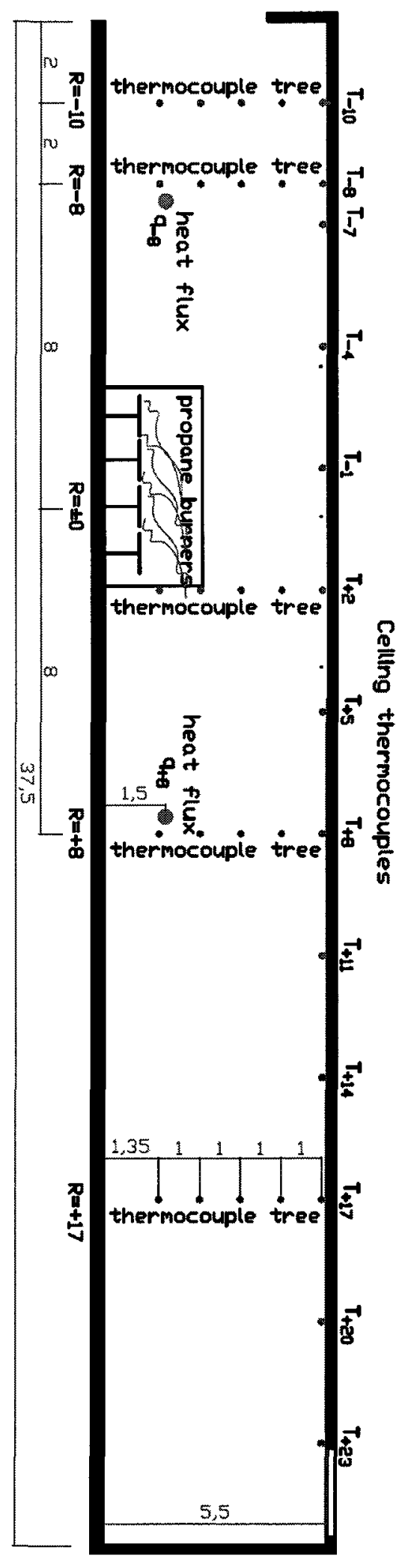

(b) Instrumentation (Section view)

Figure 6-3 Sprinkler system and instrumentation in the tunnel 


\subsubsection{Fire}

Propane fires were used and controlled to generate a constant HRR in the test program. Fire sizes of 5, 10 and $15 \mathrm{MW}$ were selected based on the following considerations.

- Based on the literature review, expected mitigation for the test fires is about $40 \%$ $\sim 70 \%$ for 10 to $20 \mathrm{MW}$ fire.

- A fire always starts as a small fire, and the suppression system is expected to activate when the fire is still small.

- The ideal performance of WFFFS is at least to keep a constant level of HRR after the activation of the system, not more than $20 \mathrm{MW}$ [25].

The top of the fire was shielded by a metal plate $(2.9 \mathrm{~m} \times 4.9 \mathrm{~m})$ that was built over the fire area at the height of $2.8 \mathrm{~m}$ (see Figure 6-2). This is to simulate tunnel fires shielded within a vehicle or in a cargo area.

Propane burners were used to ensure a steady HRR required by the test. The HRR was controlled using a propane flow meter. Since the propane burners were capable of generating a HRR up to $10 \mathrm{MW}$, a heptane pan fire was also used together with propane burners to achieve a higher HRR. The size of the rectangular pan was $1.5 \mathrm{~m}$ by $0.76 \mathrm{~m}$. The pan was about $0.3-0.4 \mathrm{~m}$ deep, which was deep enough to ensure a constant pyrolysis rate over the surface of the pan. The pan was placed next to the propane burners, under the metal shield as shown in Figure 6-4. 


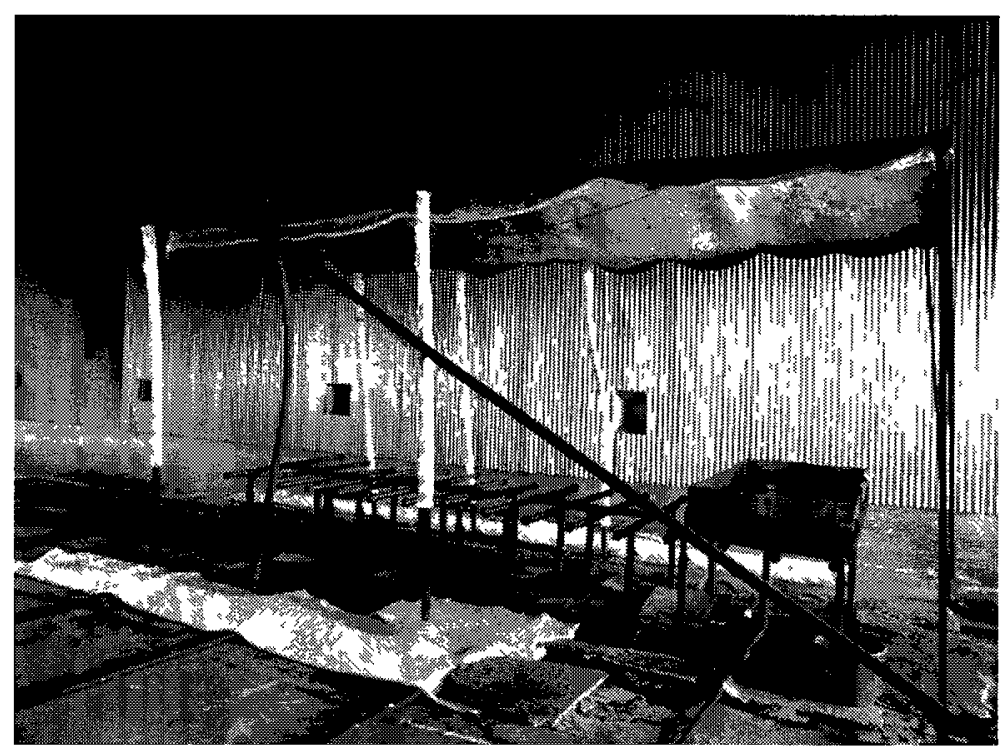

Figure 6-4 The propane burners and heptane pool for the fire test of $15 \mathrm{MW}$

\subsubsection{HRR measurement system}

During these tests, the HRR measurement system was tested to evaluate the system accuracy during suppression. The large quantities of water vapour generated by the suppression system may affect the calculation of the HRR by oxygen calorimetry since the system does not measure the water vapour content of the exhaust gases [11]. Gas concentrations $\left(\mathrm{O}_{2}, \mathrm{CO}_{2}\right.$ and $\left.\mathrm{CO}\right)$ and mass flow rates of the exhaust gases are measured at the instrumentation station in the fan chamber, and the data were analysed to evaluate HRR measurements with the suppression system operating.

\subsubsection{Thermocouples}

Figure 6-3(b) shows instrumentation in the laboratory tunnel. The ceiling temperatures $0.16 \mathrm{~m}$ below the ceiling were measured along the centre line of the tunnel. The locations of the thermocouples are shown in Figure 6-3(b). Four thermocouple trees were placed along the centre line of the tunnel, two downstream of the fire, one near the fire, 
and two upstream of the fire. The thermocouple trees measure temperatures at the height of $1.35,2.35,3.35$ and $4.35 \mathrm{~m}$.

\subsubsection{Gardon gauge}

Heat fluxes were measured at a height of $1.5 \mathrm{~m}$ at two locations $8 \mathrm{~m}$ downstream of the fire and $8 \mathrm{~m}$ upstream of the fire. Water-cooled sensor, Garden gauges (Model number 64-20-18, Medtherm Corporation) were used. The manufacturer-specified sensing surface emissivity was 0.92 , and the cooling water temperature was set at about $5-10^{\circ} \mathrm{C}$ higher than the ambient temperature to minimize convection heat transfer, and to avoid condensation on the sensor surface. The top of the gauge was covered by metal sheet to prevent direct falling of water droplet on the sensor surface. The measurements with and without the cover were examined without the sprinkler system operating, and no measurable effect was found.

\subsubsection{Plate thermometer}

A plate thermometer measures adiabatic surface temperature, based on which the incident heat flux can be calculated. Two plate thermometers (Model PL1001) manufactured from Thermal-Elecra® were used to measure heat flux, and the measurements were compared with the Gardon gauge measurements. A schematic drawing of the plate thermometer is shown in Figure 6-5. 


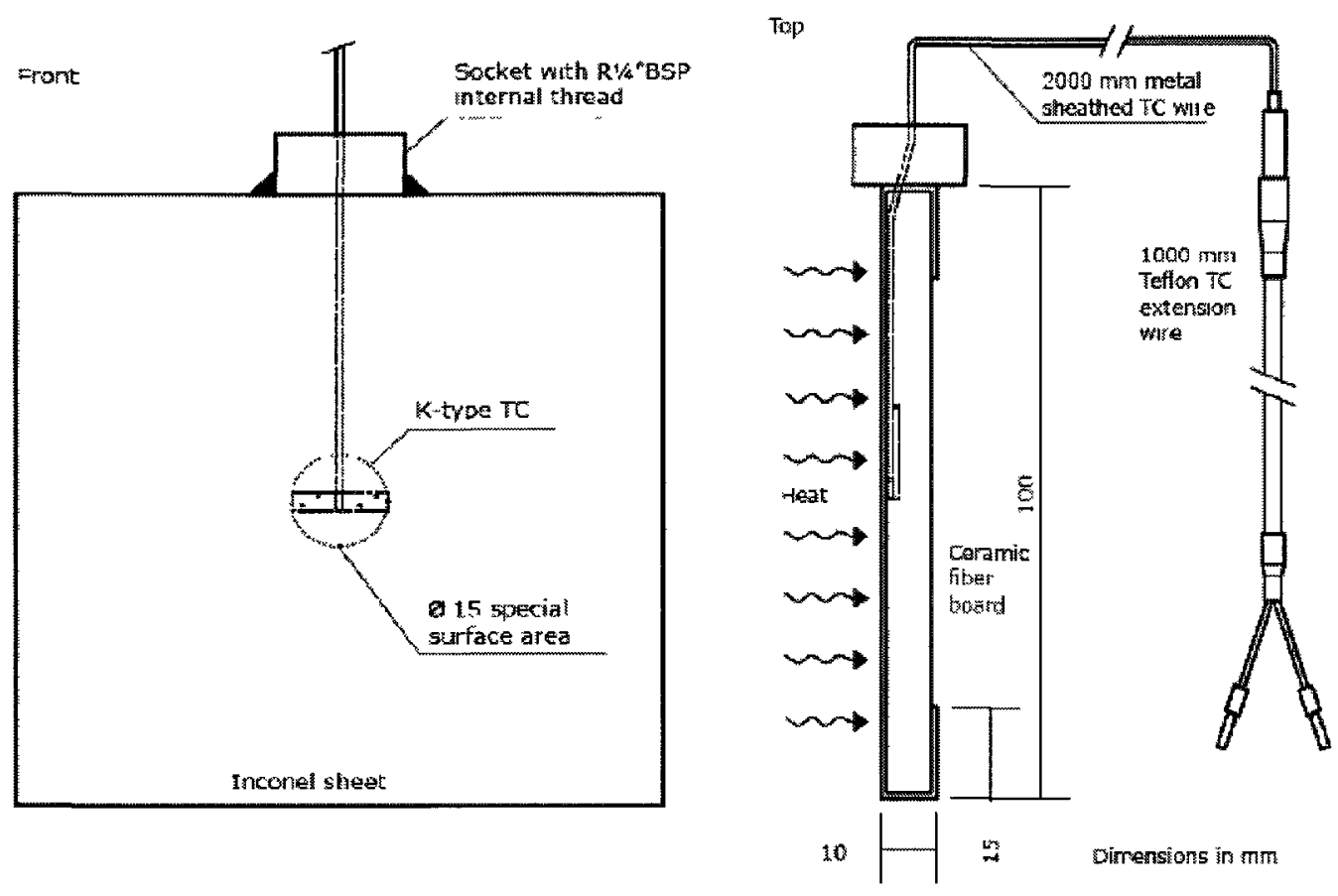

Figure 6-5 Plate thermometer (the manufacture provided)

The plate thermometers constructed in accordance with ISO 834-1 (1999) and EN1363-1 (1999) are sheathed with a $0.7 \mathrm{~mm}$ thick nickel alloy (INCONEL®600) sheet. The following material properties were assumed to be constant and were used in the heat flux calculations;

$\rho_{\mathrm{st}}$ density of Inconel metal plate $850 \mathrm{~kg} / \mathrm{m} 3$

$\mathrm{C}_{\mathrm{pst}}$ the specific heat capacity $440 \mathrm{~J} / \mathrm{kg} \mathrm{K}$

$\delta_{\text {st }}$ the thickness of the steel plate $0.7 \mathrm{~mm}$

\subsection{Bucket test description}

In order to find how the spray characteristics are influenced by the applied air velocities, bucket tests were conducted. A total of 66 buckets having a diameter of $0.28 \mathrm{~m}$ were distributed over the spray area to examine the spray pattern on the floor. The arrangement of the buckets is shown in Figure 6-6 and Figure 6-7. 
Table 6-3 show the list of bucket tests. Tests were conducted first without the fan system running. Water discharged for 5 min through 12 nozzles was collected in 66 buckets. The collected water at each bucket was measured for different water spray rates of 320 , 640 and $1090 \mathrm{l} / \mathrm{min}$.

The influence of longitudinal air flows at a fan speed of $50 \%(1.3-1.5 \mathrm{~m} / \mathrm{s})$ and $100 \%$ $(2.8 \mathrm{~m} / \mathrm{s}-3.0 \mathrm{~m} / \mathrm{s})$ was examined by comparing the spray pattern on the floor.

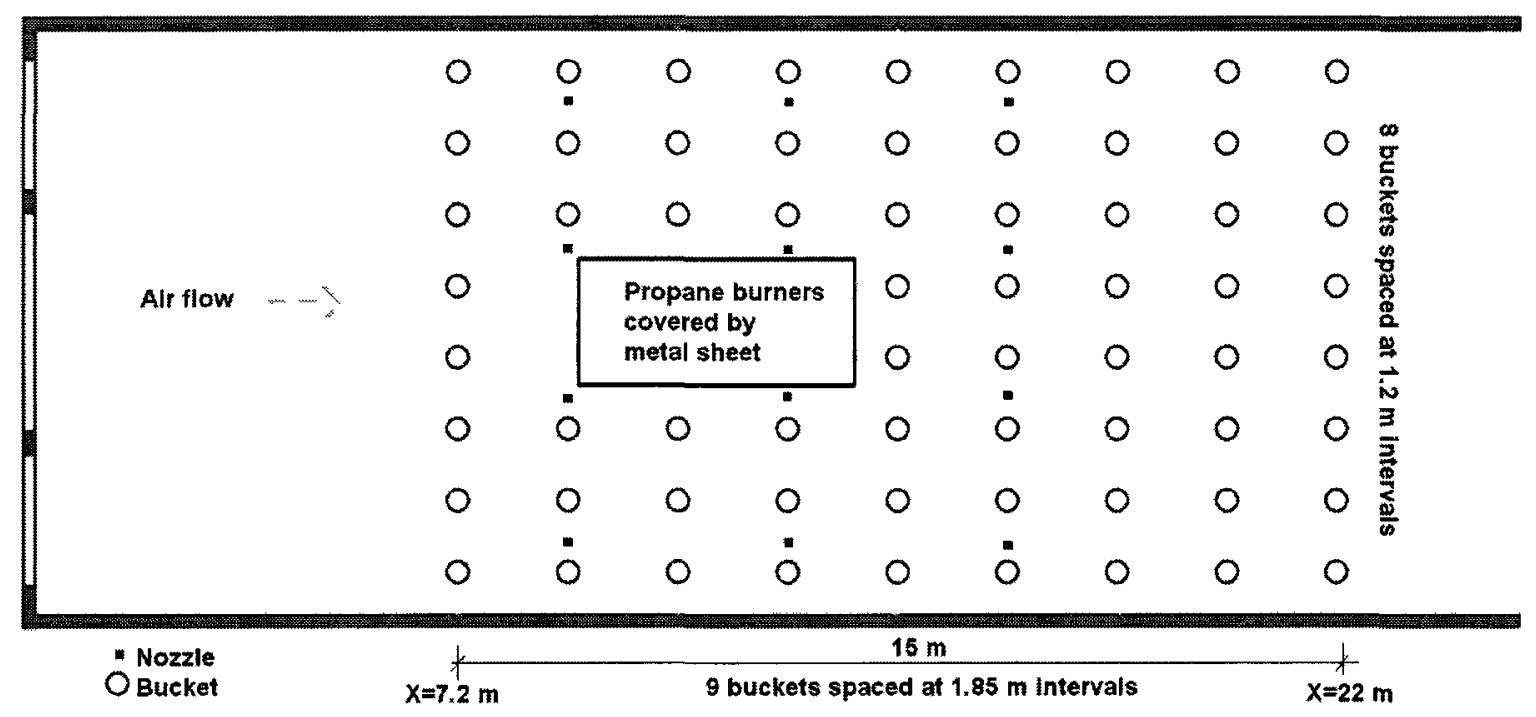

Figure 6-6 Arrangement of buckets 


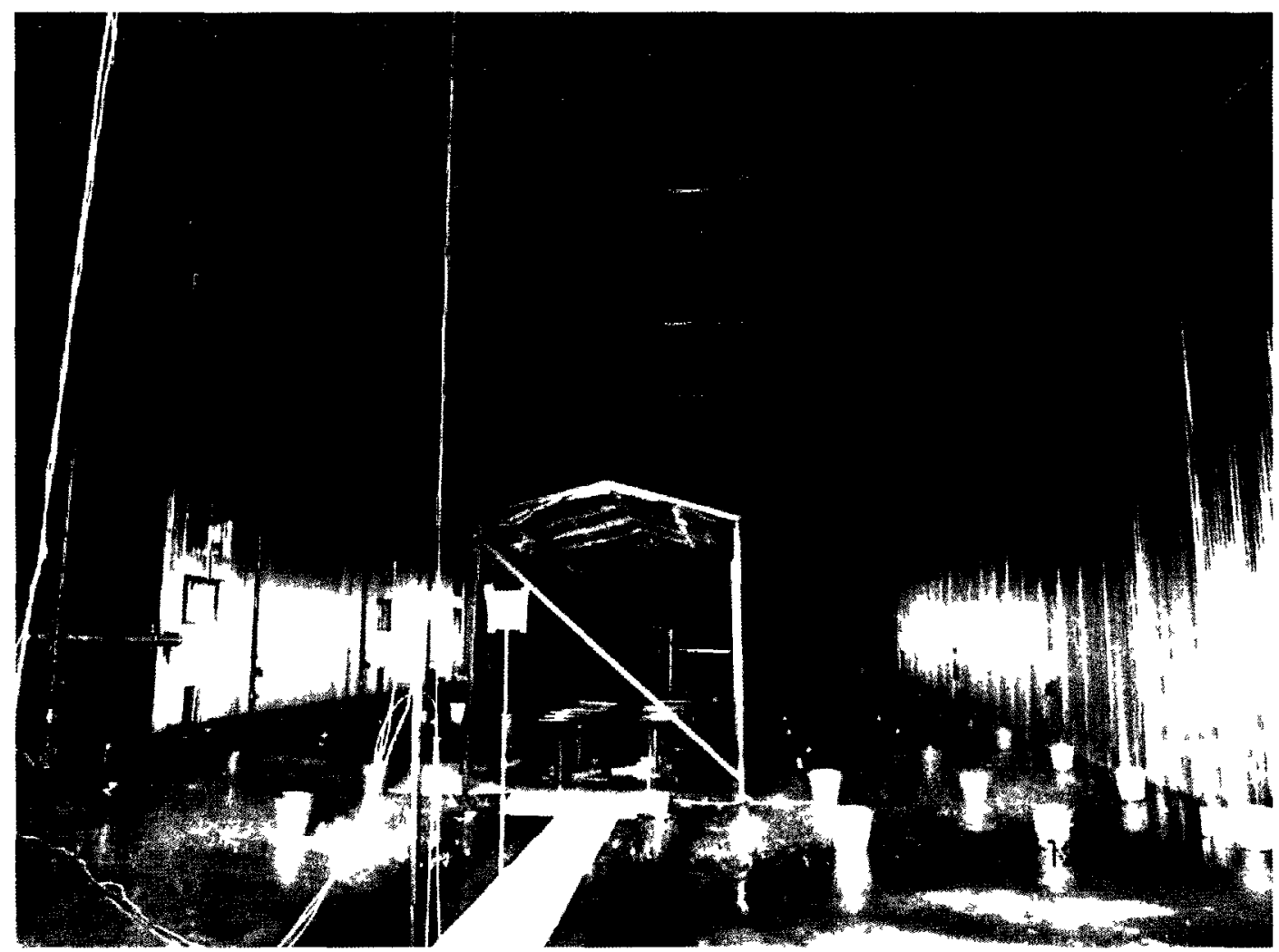

Figure 6-7 Bucket test

Table 6-3 List of bucket tests

\begin{tabular}{|r|l|l|c|r|r|r|r|}
\hline & ID & $\begin{array}{l}\text { Total water } \\
\text { flow rate }\end{array}$ & $\begin{array}{c}\text { Nominal Water } \\
\text { spray density }\end{array}$ & \multicolumn{2}{|c|}{ Pressure } & \multicolumn{1}{c|}{$\begin{array}{c}\text { Air } \\
\text { velocity }\end{array}$} & $\begin{array}{c}\text { Fan } \\
\text { speed }\end{array}$ \\
\hline & & $1 / \mathrm{min}$ & $1 / \mathrm{min} / \mathrm{m}^{2}$ & \multicolumn{1}{c|}{$\mathrm{kpa}$} & $\mathrm{psi}$ & $\mathrm{m} / \mathrm{s}$ & \multicolumn{1}{c|}{$\%$} \\
\hline 1 & $\mathrm{~B} 0 \% 3$ & 320 & 3 & 55 & 8 & 0 & 0 \\
\hline 2 & $\mathrm{~B} 50 \% 3$ & 320 & 3 & 55 & 8 & 1.7 & 50 \\
\hline 3 & $\mathrm{~B} 100 \% 3$ & 320 & 3 & 55 & 8 & 2.7 & 100 \\
\hline 4 & $\mathrm{~B} 0 \% 6$ & 640 & 6 & 117 & 17 & 0 & 0 \\
\hline 5 & $\mathrm{~B} 50 \% 6$ & 640 & 6 & 117 & 17 & 1.7 & 50 \\
\hline 6 & $\mathrm{~B} 100 \% 6$ & 640 & 6 & 117 & 17 & 2.7 & 100 \\
\hline 7 & $\mathrm{~B} 0 \% 9$ & 1090 & 9 & 248 & 36 & 0 & 0 \\
\hline 8 & $\mathrm{~B} 50 \% 9$ & 1090 & 9 & 248 & 36 & 1.7 & 50 \\
\hline 9 & $\mathrm{~B} 100 \% 9$ & 1090 & 9 & 248 & 36 & 2.7 & 100 \\
\hline
\end{tabular}




\subsection{Bucket test results}

The water collection rate at each bucket was calculated, and the rate normalised to the nominal water spray density has been plotted to see the spray pattern on the floor. Figure 6-8 shows results from the test of water spray density of $31 / \mathrm{min} / \mathrm{m}^{2}$ under an air flow of 0 $\mathrm{m} / \mathrm{s}$. At the spray boundary between nozzles, higher water spray rates than the nominal rate were measured because the water sprays from neighbouring nozzles overlapped.

When a longitudinal air flow of $2.8-3.0 \mathrm{~m} / \mathrm{s}$ was induced by the exhaust fan system, water sprays became dispersed toward the air flow direction, as shown in Figure 6-9. The water spray rates measured in the buckets are between 0.75 and 1.25 of the nominal water spray rate.

A similar result was found for the water spray rate of $91 / \mathrm{min} / \mathrm{m}^{2}$. The spray pattern without a longitudinal air flow in Figure 6-10 shows that the water droplets are more distributed over the floor area mainly because of the wider spray angle than the water spray density of $31 / \mathrm{min} / \mathrm{m}^{2}$. As shown in Figure 6-11, under a longitudinal air flow of $2.8-3.0 \mathrm{~m} / \mathrm{s}$, water droplets were pushed downstream of the nozzle locations, and water was more evenly distributed over the longer section of the tunnel than the water spray density of $31 / \mathrm{min} / \mathrm{m}^{2}$.

The influence of longitudinal air flows is greater in the case of the water spray density of $9 \mathrm{l} / \mathrm{min} / \mathrm{m}^{2}$ than $31 / \mathrm{min} / \mathrm{m}^{2}$ although the discharge velocity of water droplets could be larger in the case of water spray density of $91 / \mathrm{min} / \mathrm{m}^{2}$ due to the high operating pressure. This is because the downward thrust of a droplet generated from the water spray rate of 9 $1 / \mathrm{min} / \mathrm{m}^{2}$ is lower due to the smaller size of the droplets. 


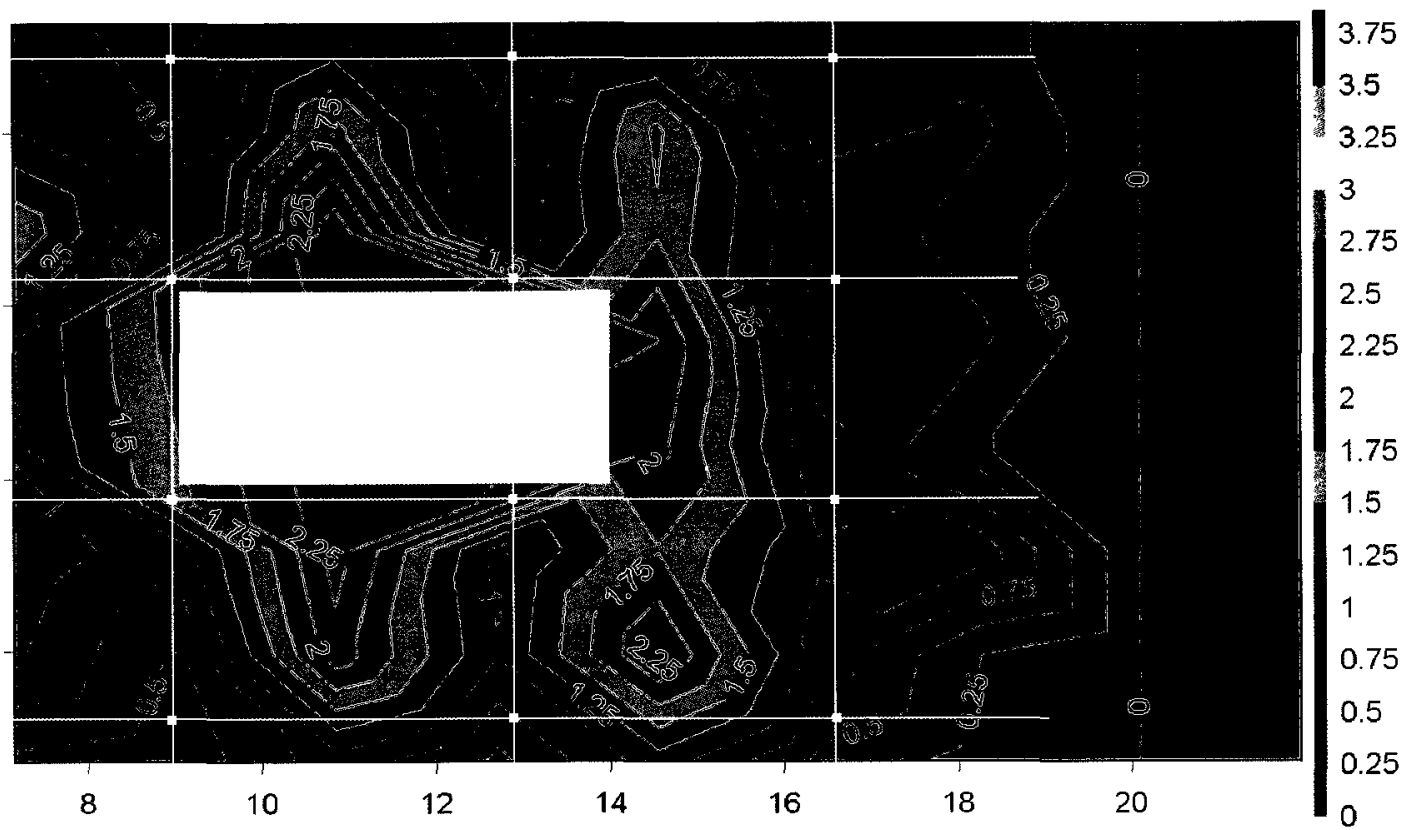

Figure 6-8 The collected water spray rate normalised to the nominal water spray rate of $3 \mathrm{l} / \mathrm{min} / \mathrm{m}^{2}$ under an air flow of $0 \mathrm{~m} / \mathrm{s}$

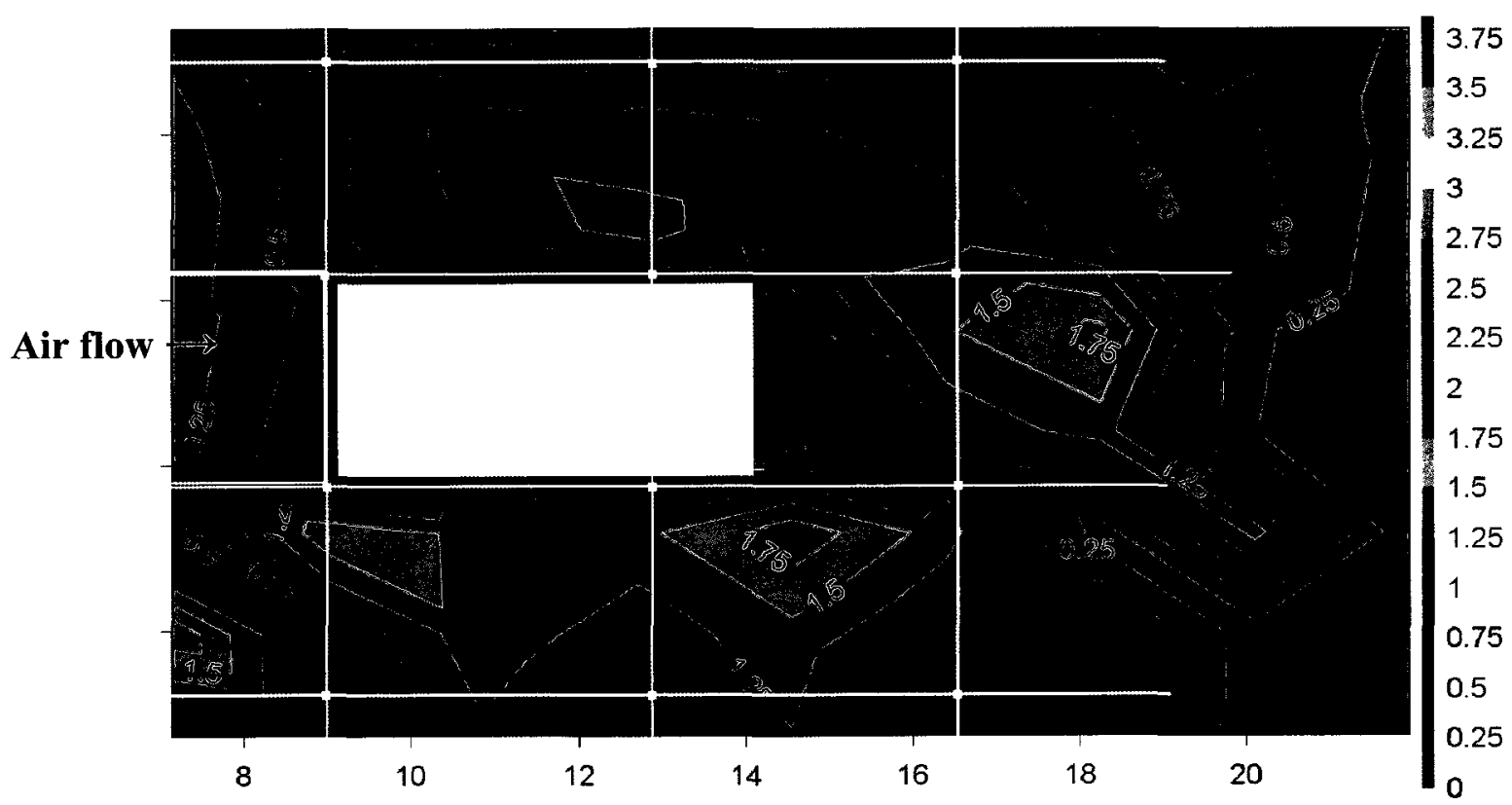

Figure 6-9 The collected water spray rate normalised to the nominal water spray rate of $3 \mathrm{l} / \mathrm{min} / \mathrm{m}^{2}$ under an air flow of $2.7 \mathrm{~m} / \mathrm{s}$ (Fan speed 100\%) 


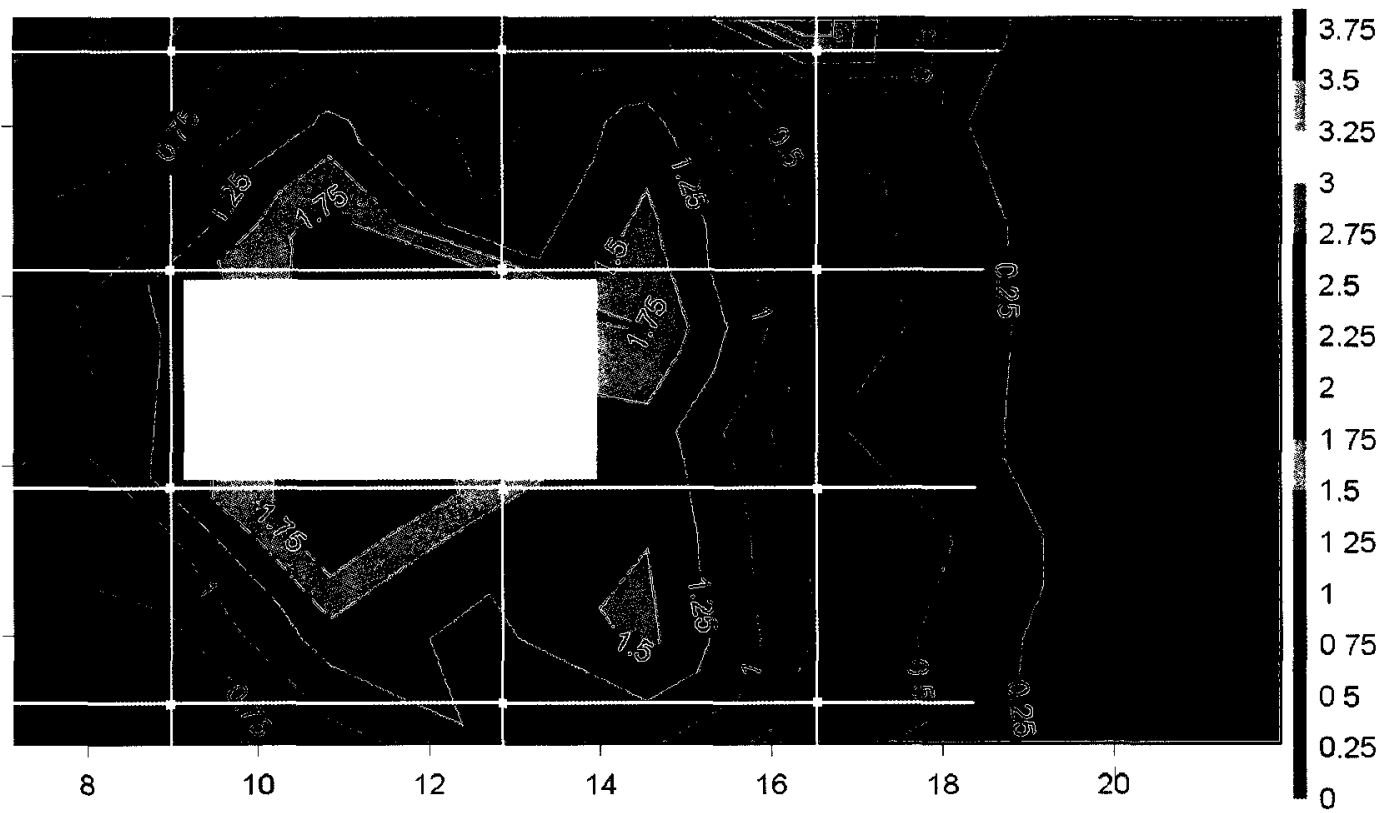

Figure 6-10 The collected water spray rate normalised to the nominal water spray rate of $91 / \mathrm{min} / \mathrm{m}^{2}$ under an air flow of $0 \mathrm{~m} / \mathrm{s}$

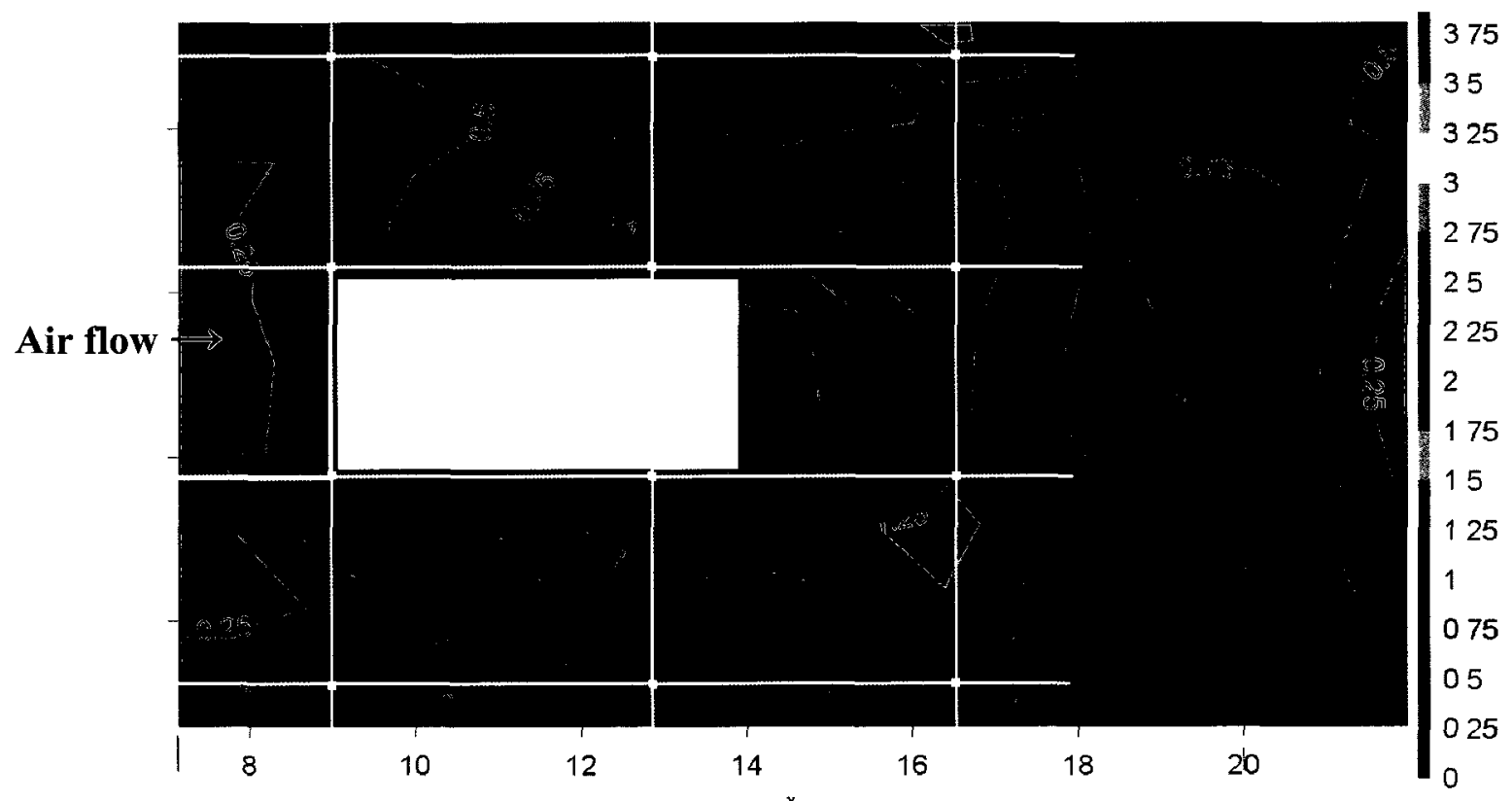

Figure 6-11 The collected water spray rate normalised to the nominal water spray rate of $91 / \mathrm{min} / \mathrm{m}^{2}$ under an air flow of $2.7 \mathrm{~m} / \mathrm{s}$ (Fan speed 100\%) 


\subsection{Fire test results}

This section briefly describes HRR measurements, temperature and heat flux measurements during the suppression tests. Figure 6-12 shows a photo taken during a suppression test. (Some of these results are published in 'An experimental study of the impact of tunnel suppression on tunnel ventilation' presented at Fourth International Symposium on Tunnel Safety and Security 2010 [103].)

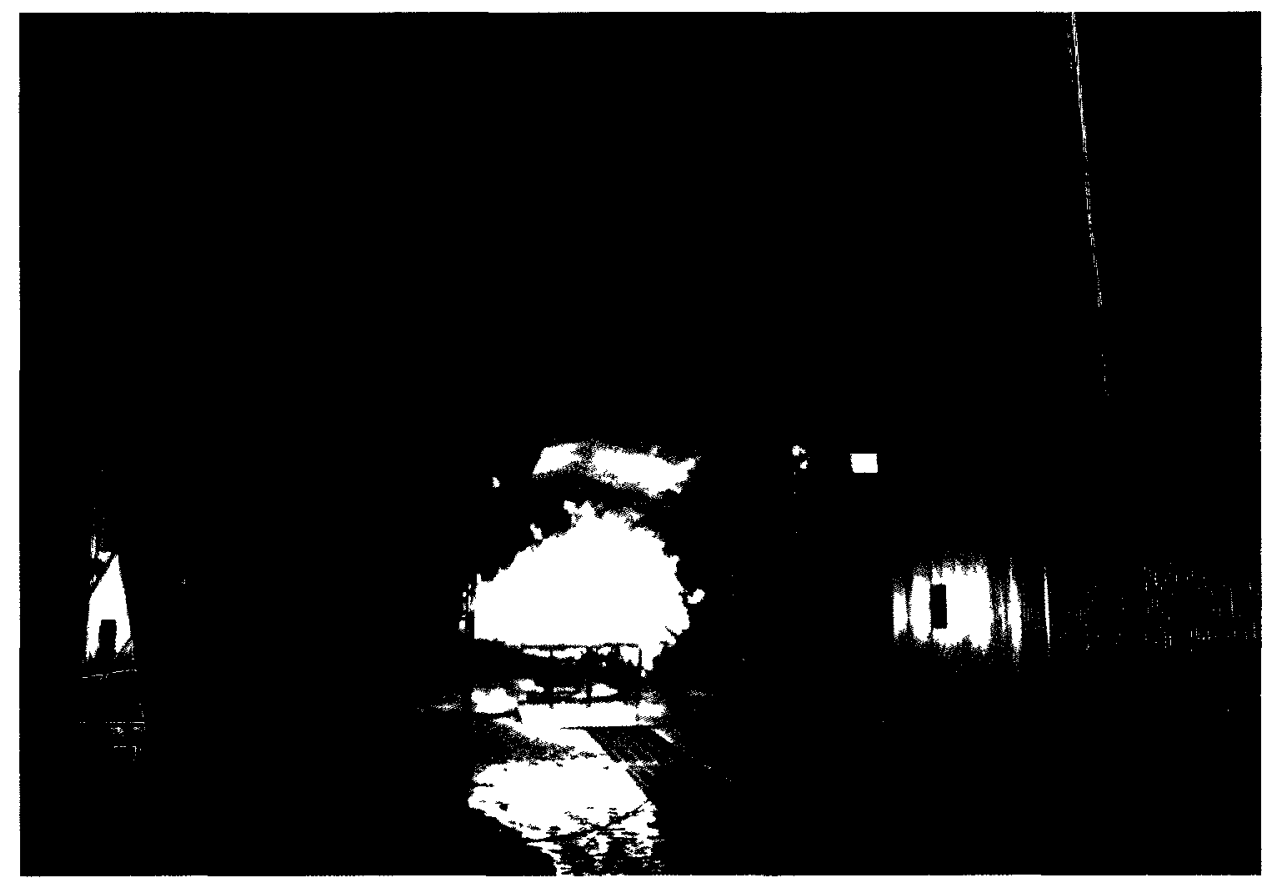

Figure 6-12 A photo taken during the suppression test

6.5.1. HRR measurements and gas concentrations in the fan chamber

In this experimental program, propane burners were used in most tests to generate a constant HRR throughout the test, and the HRR was measured to ensure a consistent HRR during suppression. In most tests, HRR measurements were pretty consistent regardless of the presence of water sprays. Figure 6-13 shows results from a $10 \mathrm{MW}$ propane fire test under $100 \%$ fan speed. In the middle of the test, the sprinkler system 
discharged a water flow density of $31 / \mathrm{min} / \mathrm{m}^{2}$ for $5 \mathrm{~min}$ and $9 \mathrm{1} / \mathrm{min} / \mathrm{m}^{2}$ for another $8 \mathrm{~min}$. The consistent HRR of $10 \mathrm{MW}$ was measured by the system. The measured oxygen concentrations were also consistent, confirming that the propane burning was constant throughout the test.

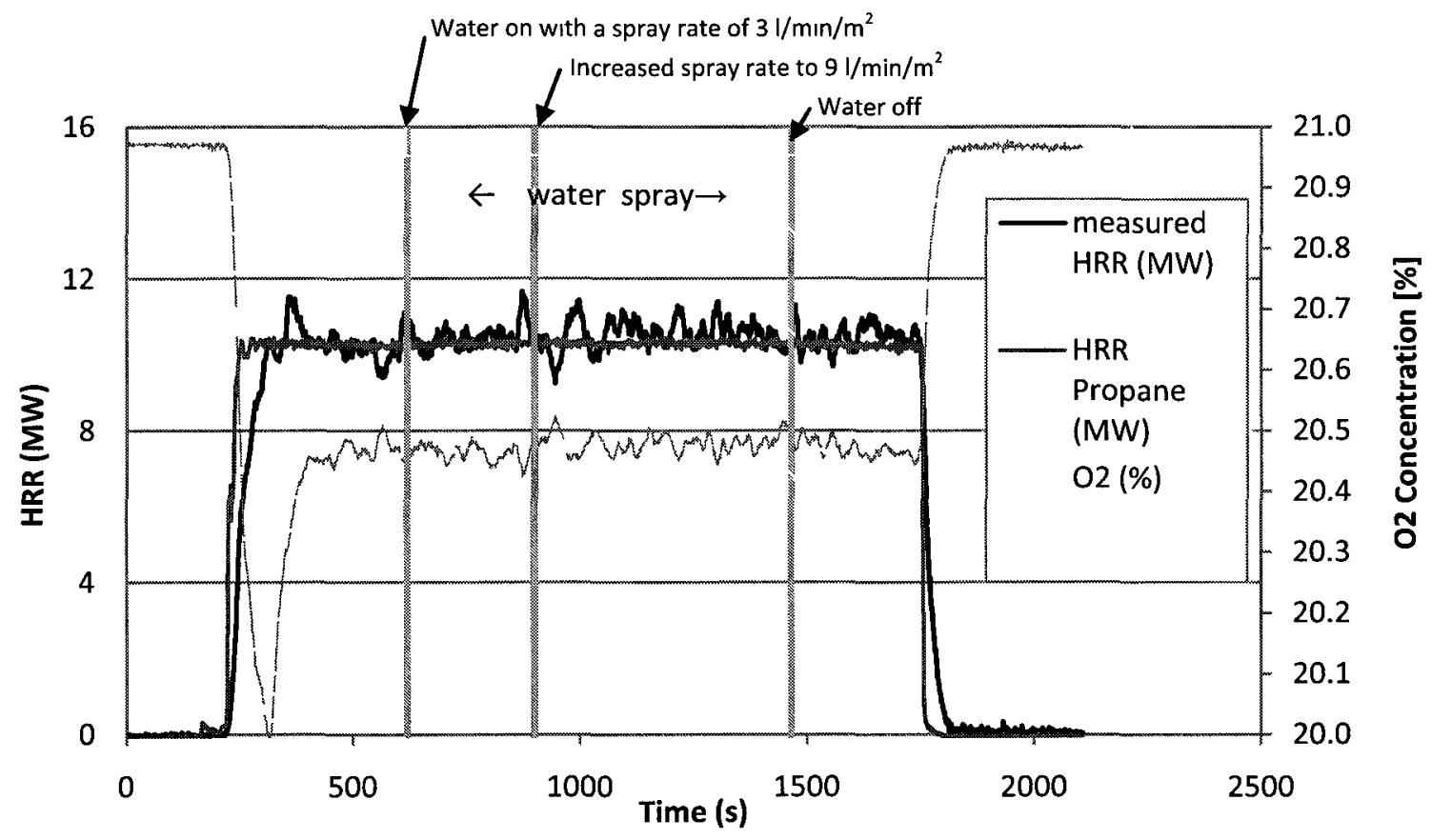

Figure 6-13 The measured HRR and $\mathrm{O}_{2}$ concentration over time for $10 \mathrm{MW}$ fire with a $100 \%$ fan speed and water spray densities of $31 / \mathrm{min} / \mathrm{m}^{2}$ and $9 \mathrm{l} / \mathrm{min} / \mathrm{m}^{2}$ (Note: the fan speed was gradually increased from $50 \%$ to $100 \%$, and at $400 \mathrm{~s}$ the fan speed reached $100 \%$ ) 


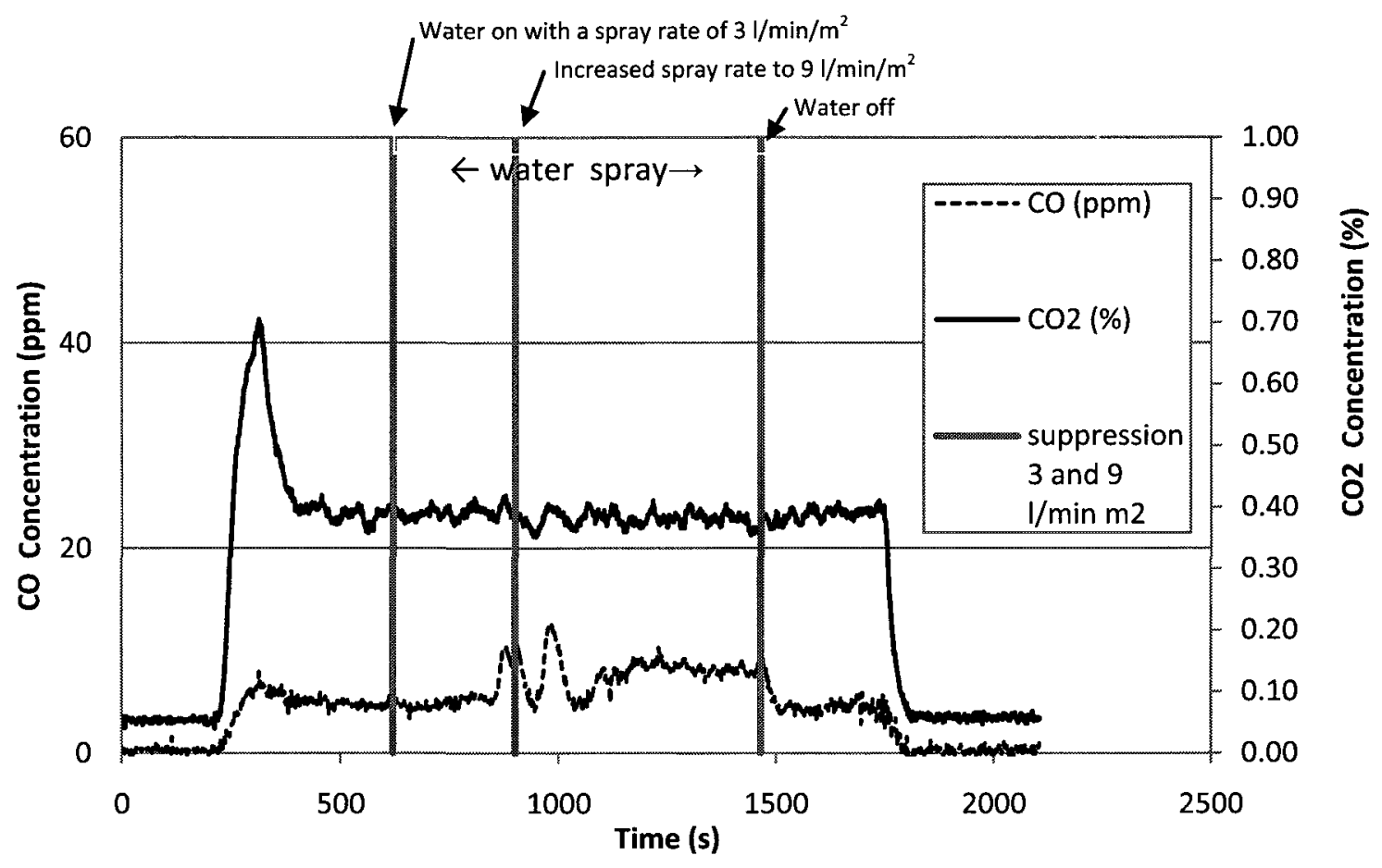

Figure 6-14 The measured $\mathrm{CO}$ and $\mathrm{CO}_{2}$ concentration over time for $10 \mathrm{MW}$ fire with a $100 \%$ fan speed and water spray densities of $3 \mathrm{l} / \mathrm{min} / \mathrm{m}^{2}$ and $9 \mathrm{l} / \mathrm{min} / \mathrm{m}^{2}$ (Note: the fan speed was gradually increased from $50 \%$ to $100 \%$, and at 400 s the fan speed reached $100 \%$ )

However, in some tests in which large water flow densities were tested with a fan speed of $25 \%$, considerable measurement errors in HRR were found. Figure 6-15 shows results from the $10 \mathrm{MW}$ fire test with a $25 \%$ fan speed. A large water flow density of $91 / \mathrm{min} / \mathrm{m}^{2}$ was discharged in the middle of the test for about $5 \mathrm{~min}$. The measured $\mathrm{HRR}$ and $\mathrm{O}_{2}$ concentration were unstable for a short time after the opening of the sprinkler system as well as after the closing of the system. Nevertheless, the mean $\mathrm{O}_{2}$ concentrations during suppression are comparable to the measurement prior to the suppression activation. In contrast, the measured HRR during suppression is considerably higher than without suppression. The more the temperature in the fan chamber dropped, the more apparent the overestimation of the HRR was. 
In most tests, $\mathrm{CO}$ from the incomplete combustion increased during suppression as shown in Figure 6-14 and Figure 6-16. In the case of the $10 \mathrm{MW}$ test with $100 \%$ fan speed and varying water spray rates (Figure 6-14), CO slightly increased with the increase of water discharge rate. Presumably, this is because the large amount of water vapour generated during suppression with a water spray rate of $91 / \mathrm{min} / \mathrm{m}^{2}$ displaces oxygen and suffocates the combustion reactions. However, the rate of the incomplete combustion is small so that the measured HRR is consistent throughout the test (see Figure 6-13).

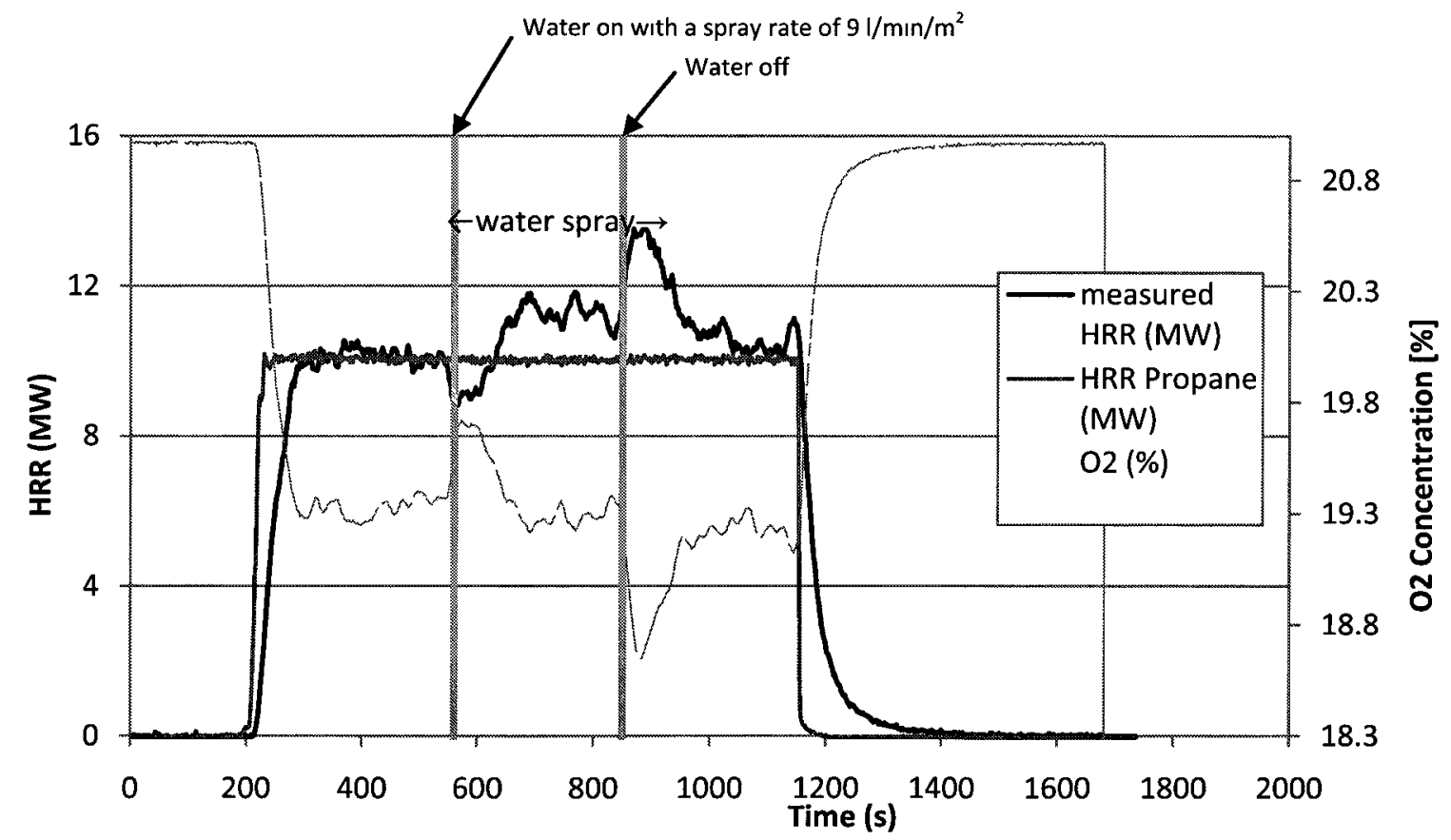

Figure 6-15 The measured HRR and $\mathrm{O}_{2}$ concentration over time for $10 \mathrm{MW}$ fire with a $25 \%$ fan speed and a water spray density of $9 \mathrm{l} / \mathrm{min} / \mathrm{m}^{2}$ 


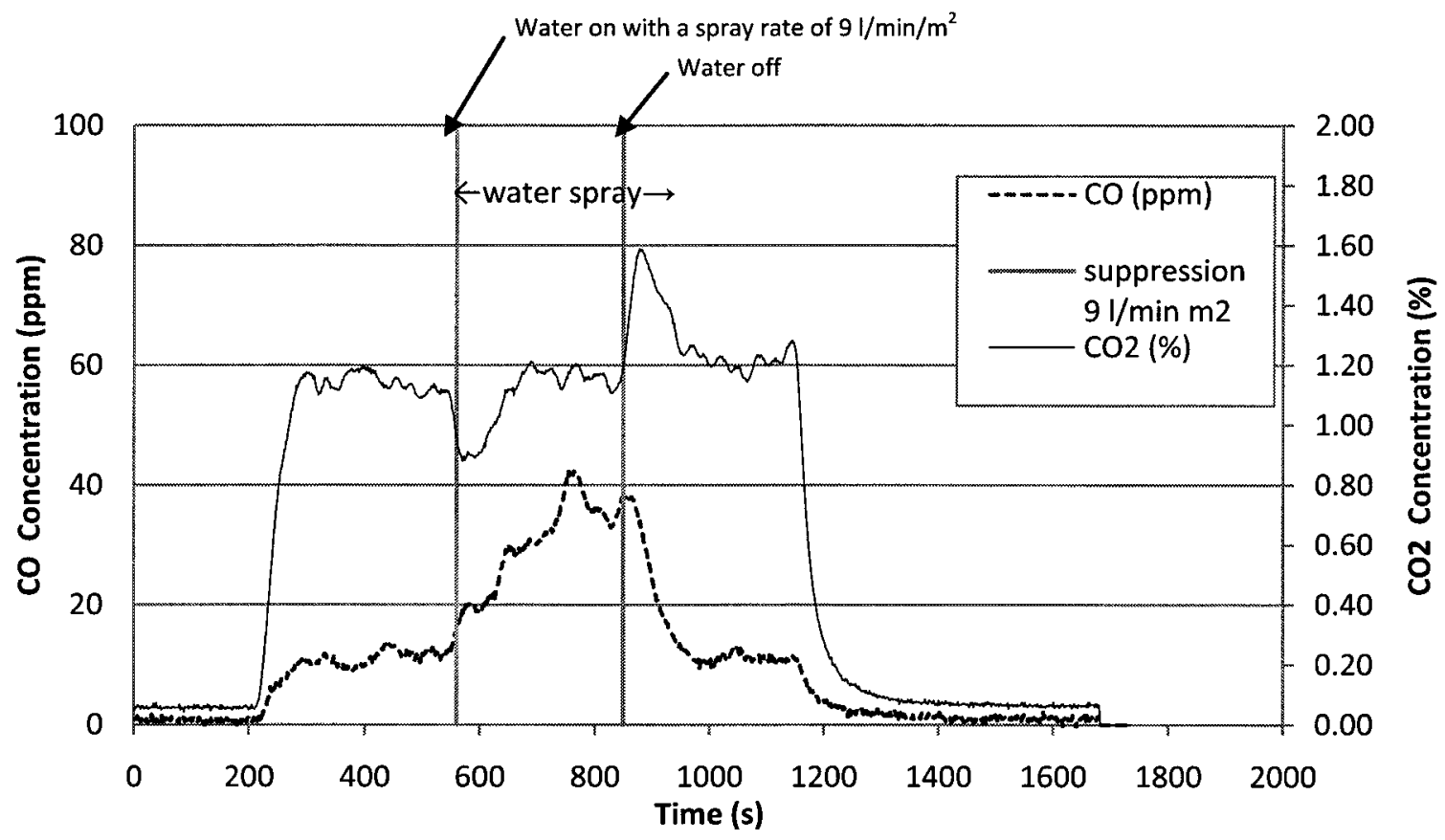

Figure 6-16 The measured $\mathrm{CO}$ and $\mathrm{CO}_{2}$ concentration over time for $10 \mathrm{MW}$ fire with a $25 \%$ fan speed and a water spray rate of $9 \mathrm{l} / \mathrm{min} / \mathrm{m}^{2}$

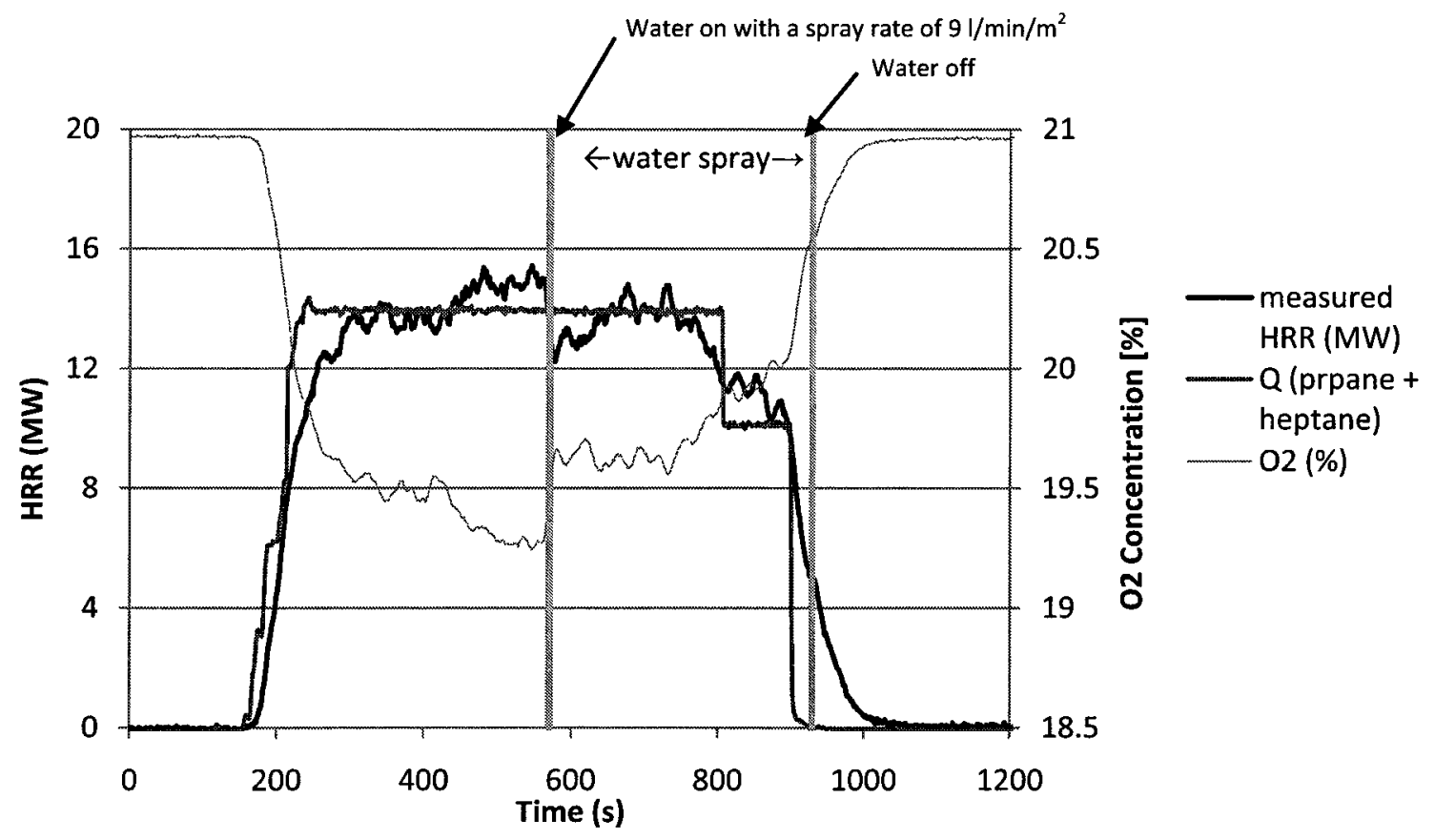

Figure 6-17 The measured HRR and $\mathrm{O}_{2}$ concentration over time for $15 \mathrm{MW}$ fire with a $25 \%$ fan speed and a water spray density of $91 / \mathrm{min} / \mathrm{m}^{2}$

In the case of heptane and propane tests, although the heptane pool was placed under the metal shield, the water spray affected the burning of heptane and decreased the HRR. 
Among 4 tests of $15 \mathrm{MW}$ using heptane and propane, the effect of water spray on reducing the HRR was measurable only in the suppression test of $91 / \mathrm{min} / \mathrm{m}^{2}$ with $50 \%$ fan speed (see Figure 6-17). During suppression, the measured oxygen concentration was increased, which means the suppression system slowed the combustion process by cooling the surrounding.

\subsubsection{Longitudinal ceiling temperature profile}

Time-averaged temperatures during the steady-state condition were obtained in each test without and with the sprinkler system operating. In Figure 6-18, the longitudinal ceiling temperature $(\Delta \mathrm{T})$ profiles during the $10 \mathrm{MW}$ fire without the sprinkler system operating are compared for different fan speeds. The results show that the profile from the $25 \%$ and $50 \%$ fan speeds are similar, but the profile from the $100 \%$ fan speed shows lower temperatures due to dilution. The location of the peak temperature also shifted downstream as the fan speed increases.

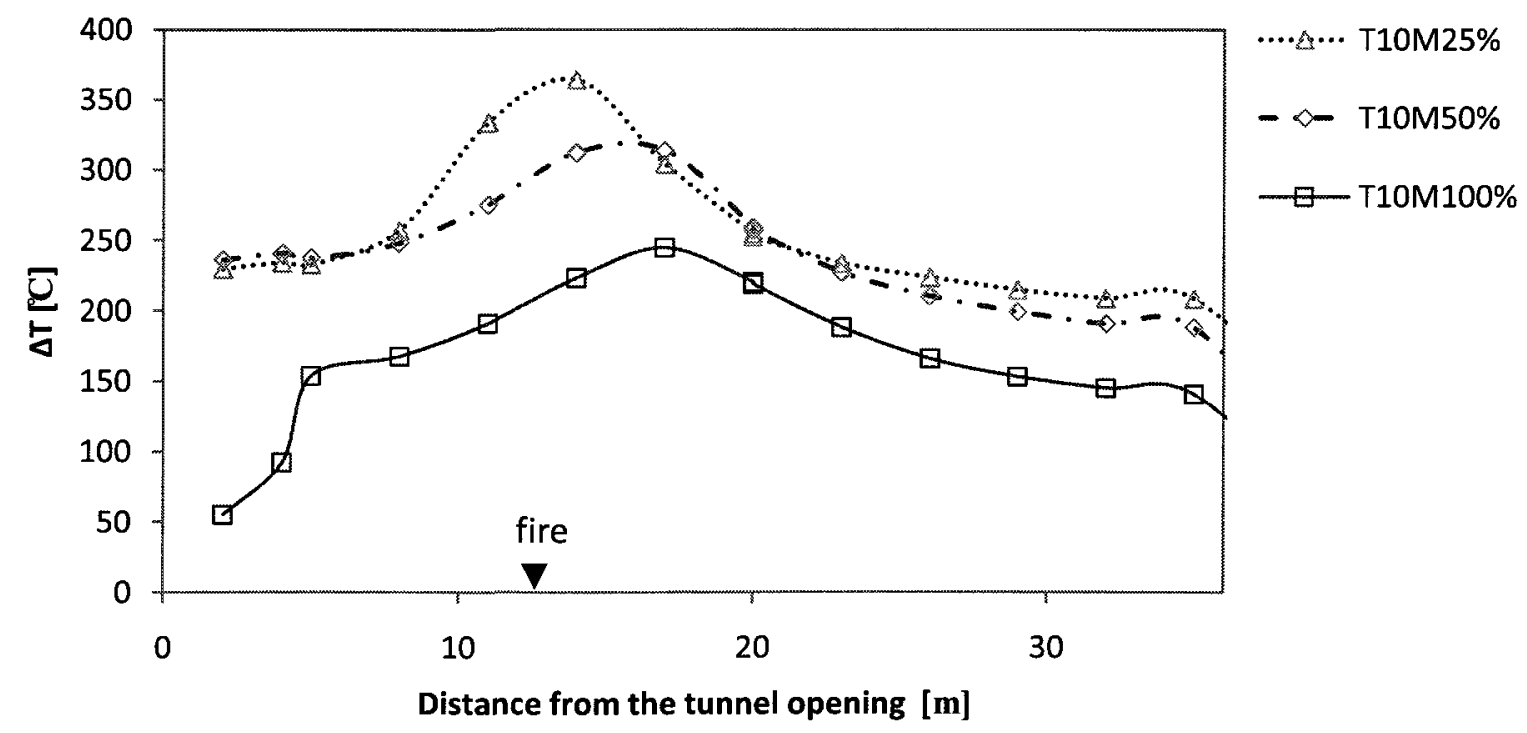

Figure 6-18 Longitudinal ceiling temperature profiles $(\Delta T)$ from the $10 \mathrm{MW}$ fire for different fan speeds without the sprinkler system operating 


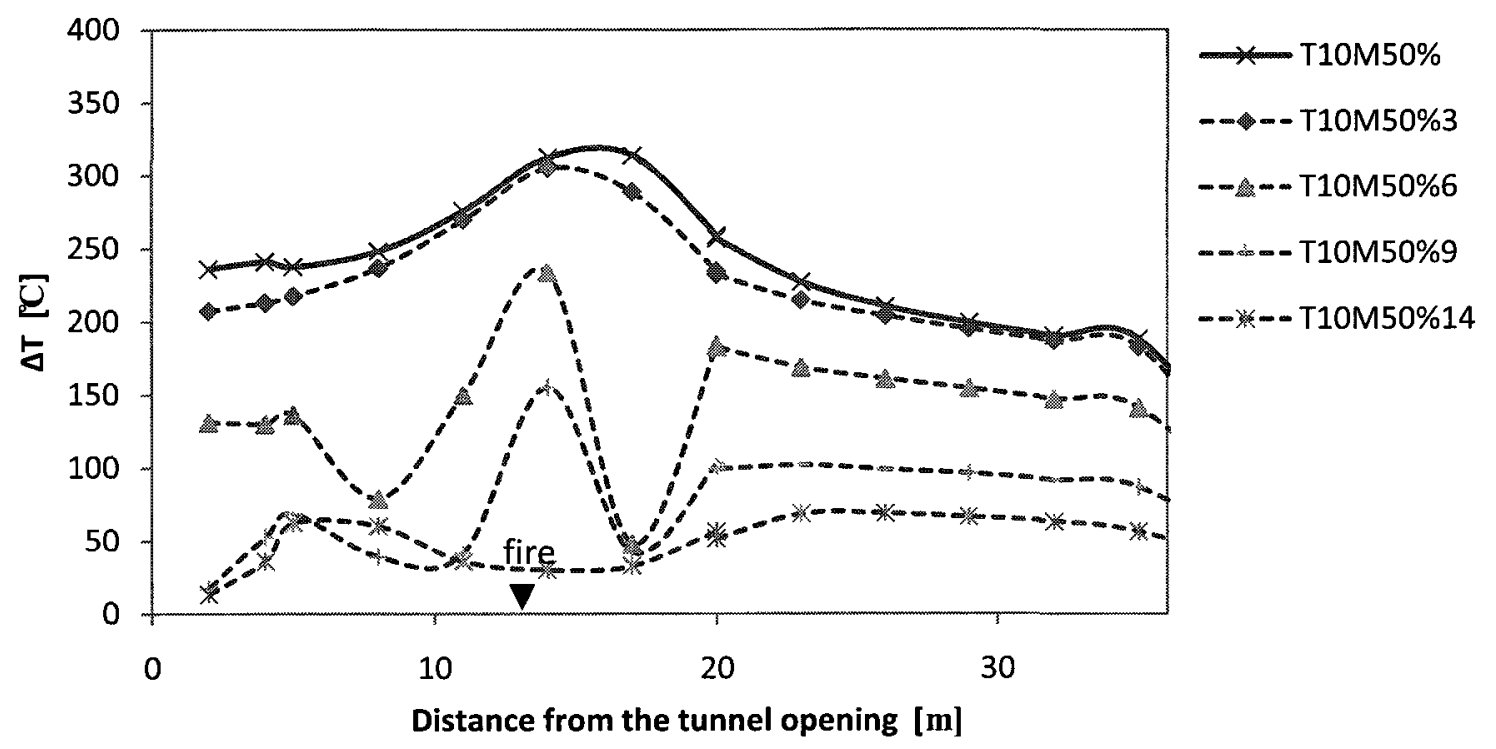

Figure 6-19 Longitudinal ceiling temperature profiles $(\Delta T)$ from the $10 \mathrm{MW}$ fire at $50 \%$ fan speed with the sprinkler system operating

With the sprinkler system operating, all ceiling temperatures along the length of the tunnel dropped, in particular, in the area upstream of the fire and the spray section. Test results show that the combination of a large longitudinal air velocity and water spray rate effectively cool hot gases. Figure 6-19 compares the temperature $(\Delta \mathrm{T})$ results from different water spray rates. When a water flow density of $91 / \mathrm{min} / \mathrm{m}^{2}$ was used, the ceiling temperature during the $10 \mathrm{MW}$ fire dropped by about $100^{\circ} \mathrm{C}$ downstream of the fire. The use of water flow density of $31 / \mathrm{min} / \mathrm{m}^{2}$ decreased the ceiling temperatures downstream of the fire slightly, about $10^{\circ} \mathrm{C}$. 


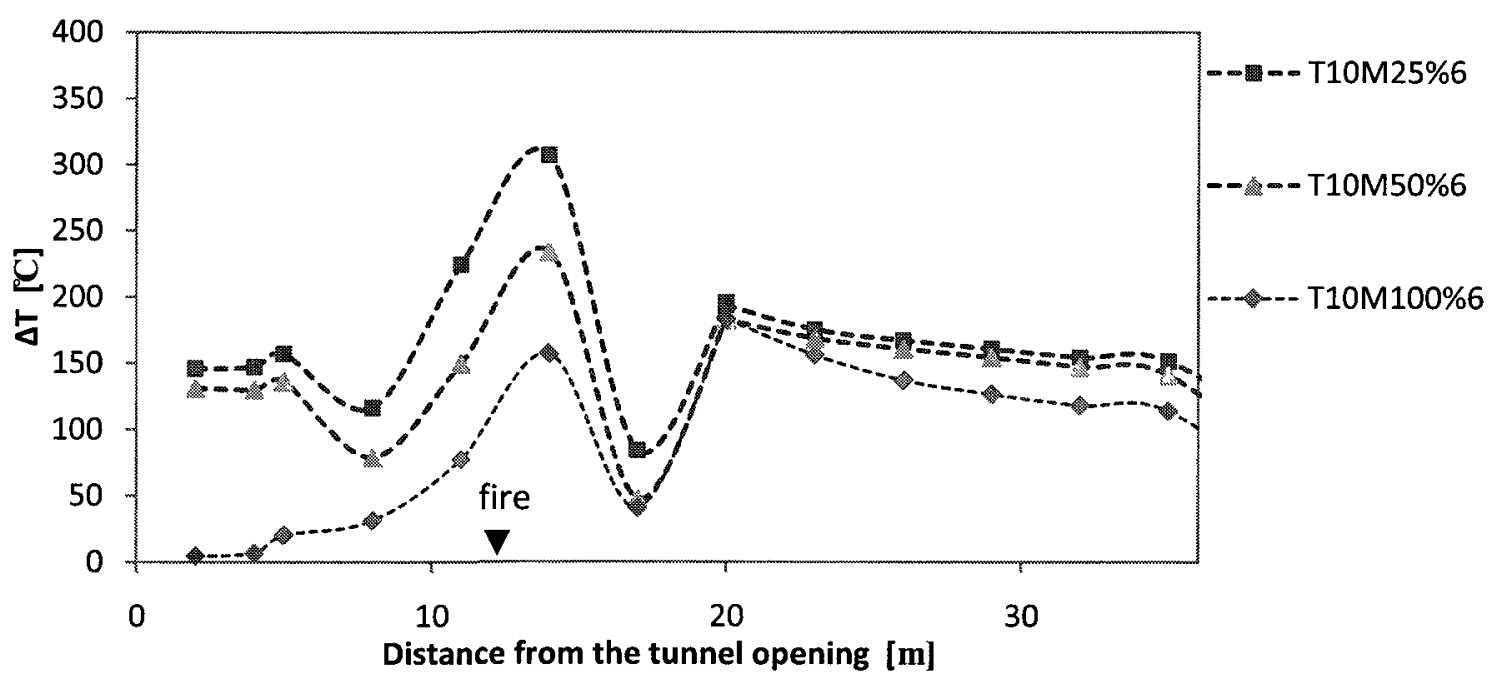

Figure 6-20 A comparison of longitudinal ceiling temperature profiles $(\Delta T)$ for different fan speeds (10 MW fire during suppression with a water spray rate of $6 \mathrm{l} / \mathrm{min} / \mathrm{m}^{2}$ )

Figure 6-20 compares the effect of different air flow velocities on the ceiling temperature $(\Delta \mathrm{T})$ profile resulted from the same water spray density of $61 / \mathrm{min} / \mathrm{m}^{2}$. Results show similar temperature profiles downstream of the fire regardless of air flow velocities; however, the maximum temperature in the vicinity of the fire as well as temperature upstream of the fire decreases with increasing air flow velocity.

\subsubsection{Vertical temperature profile - Upstream}

Figure 6-21 shows the vertical temperature $(\Delta \mathrm{T})$ profiles $10 \mathrm{~m}$ upstream for the $10 \mathrm{MW}$ fire. The effectiveness of the longitudinal ventilation system in resisting smoke upstream of the fires was significantly improved when accompanied by the sprinkler system. The backlayering was reduced with the use of the sprinkler system and the effect was more significant with larger water flow densities. 
With a water spray density of $9 \mathrm{l} / \mathrm{min} / \mathrm{m}^{2}$ the backlayering completely disappeared even though the air flow of $1.7 \mathrm{~m} / \mathrm{s}$ generated by the fan speed of $50 \%$, was less than the critical velocity of $2.3 \mathrm{~m} / \mathrm{s}$ required for the $10 \mathrm{MW}$ fire.

Figure 6-22 compares the effect of different air flow velocities on the vertical temperature $(\Delta \mathrm{T})$ profile $10 \mathrm{~m}$ upstream of the fire that was during suppression with a water spray density of $6 \mathrm{1} / \mathrm{min} / \mathrm{m}^{2}$. The results show that the sprinkler system alone cannot achieve successful smoke control, and the ventilation system needs to be properly designed to work in conjunction with the sprinkler system.

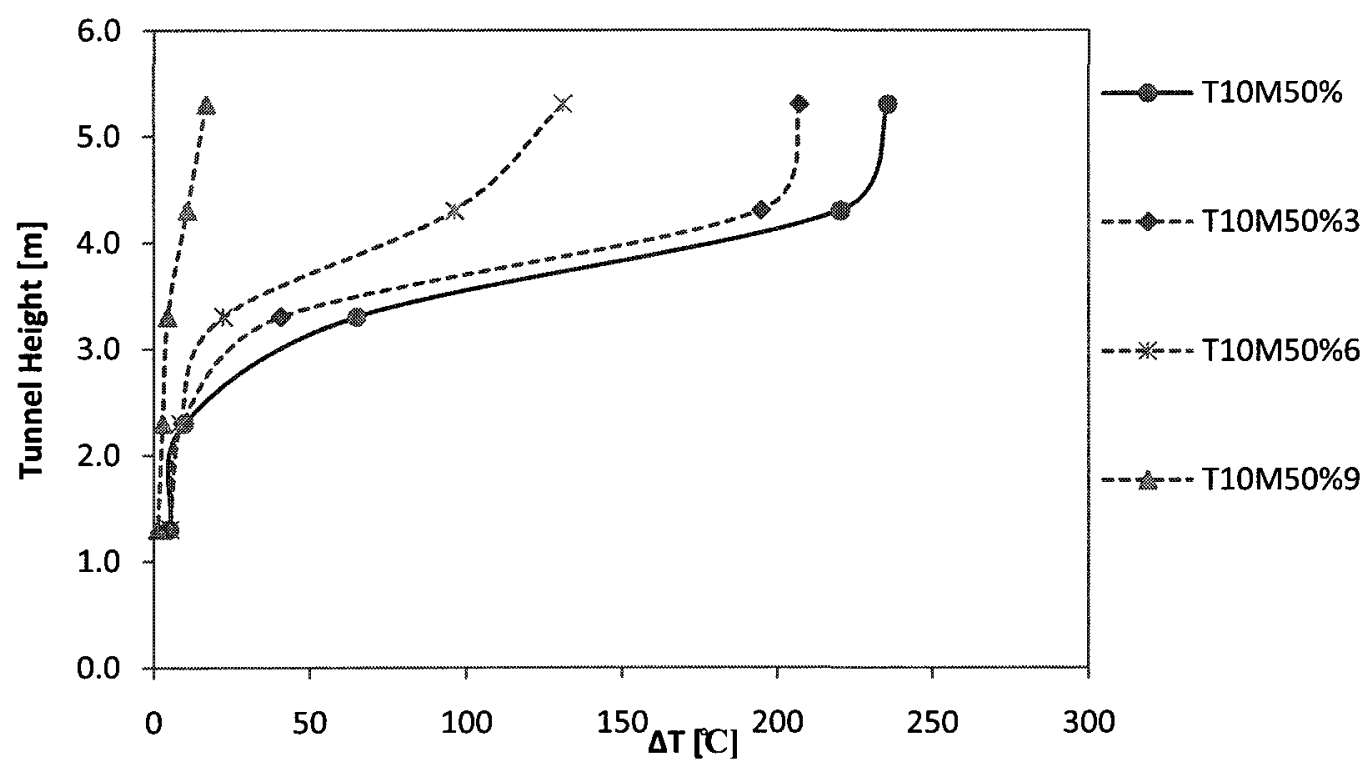

Figure 6-21 A comparison of vertical temperature $(\Delta \mathrm{T})$ profiles $10 \mathrm{~m}$ upstream of the $10 \mathrm{MW}$ fire with and without the sprinkler system operating ( $50 \%$ fan speed) 


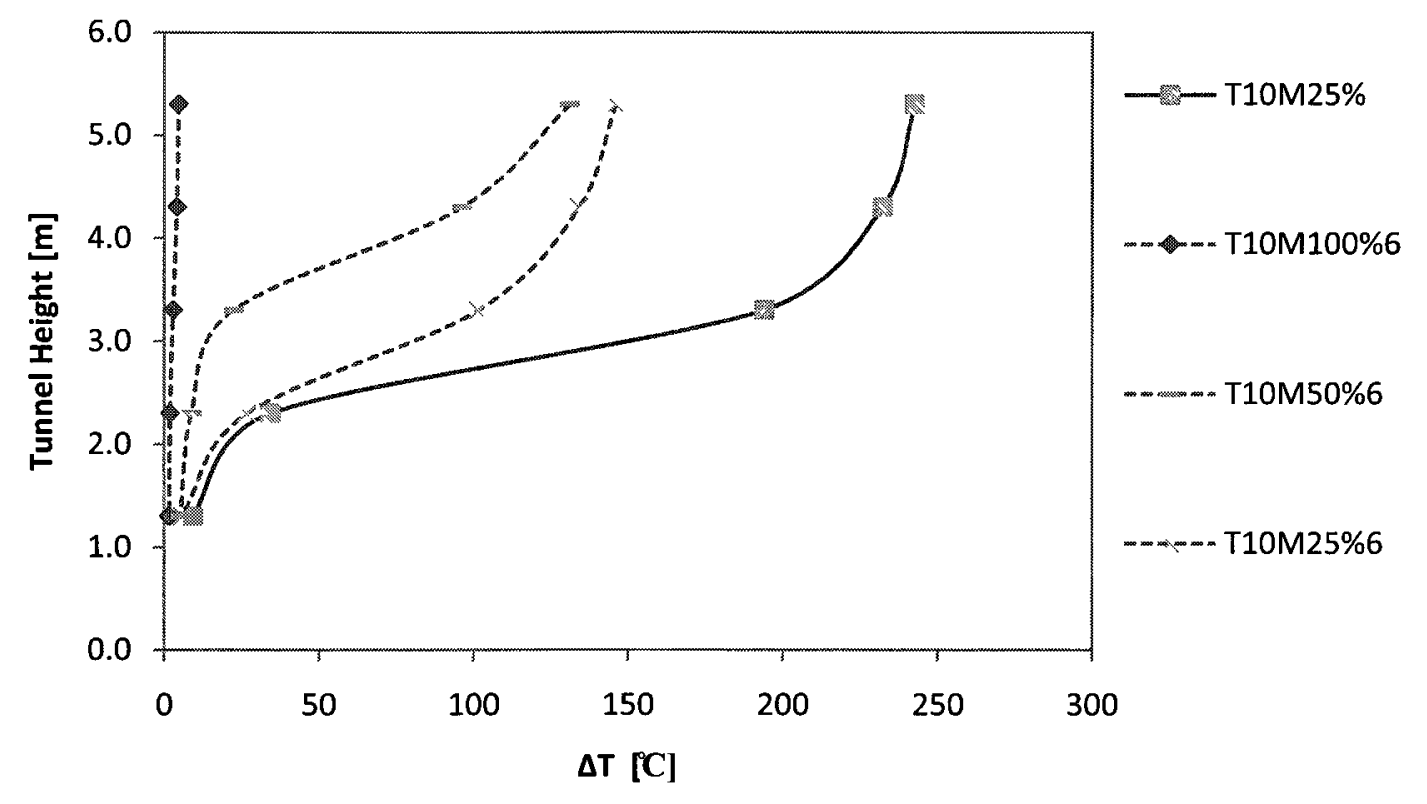

Figure 6-22 A comparison of vertical temperature $(\Delta \mathrm{T})$ profile $10 \mathrm{~m}$ upstream of the $10 \mathrm{MW}$ fire with different fan speeds ( with a water spray density of $61 / \mathrm{min} / \mathrm{m}^{2}$ )

\subsubsection{Vertical temperature profile - Downstream}

Error! Reference source not found. compares the vertical temperature $(\Delta T)$ profiles at $\mathrm{R}=+17 \mathrm{~m}$ (17 $\mathrm{m}$ downstream of the fire). The sprinkler system together with the longitudinal air flow cooled the gases. The cooling was more significant with the larger water flow density; however, up to a height of $2.3 \mathrm{~m}$ the gas temperatures are similar regardless of water spray rates. 


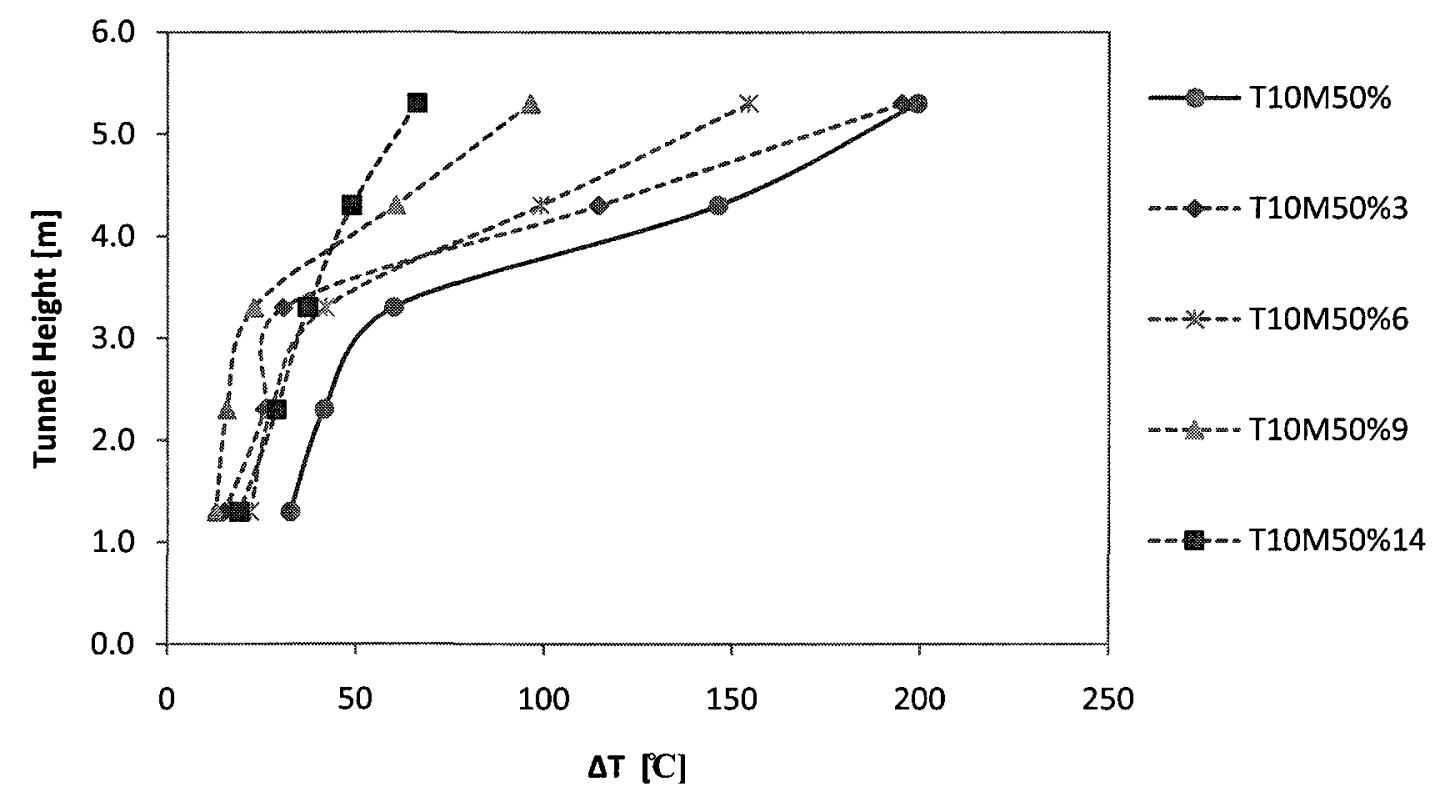

Figure 6-23 Vertical temperature $(\Delta \mathrm{T})$ profile $17 \mathrm{~m}$ downstream of a $10 \mathrm{MW}$ fire for different water spray rates

\subsubsection{Heat flux measurements}

Figure 6-24 compares heat fluxes measured $8 \mathrm{~m}$ downstream $\left(\mathrm{q}_{+8}\right)$ and $8 \mathrm{~m}$ upstream( $\left(\mathrm{q}_{-8}\right)$ over time for the $10 \mathrm{MW}$ fire with $25 \%$ fan speed and water spray density of $61 / \mathrm{min} / \mathrm{m}^{2}$. Before the sprinkler system was activated, heat fluxes measured at both locations were about $6-8 \mathrm{~kW} / \mathrm{m}^{2}$, which are high enough to be lethal [104]. After the sprinkler was activated, heat fluxes at both locations decreased to $3-4 \mathrm{~kW} / \mathrm{m}^{2}$. This decrease in heat flux is mainly from radiation absorption and scattering by the water droplets. The measured heat fluxes, however, were affected by some direct cooling by droplets on the gauge surface, since it was not possible to completely prevent water droplets from falling on the sensor despite the fact that the top of the gauge was covered by a metal sheet. Particularly in the tests with the large water spray densities, a great deal of small water droplets due to the high operating pressure were generated and drifted in the air. 


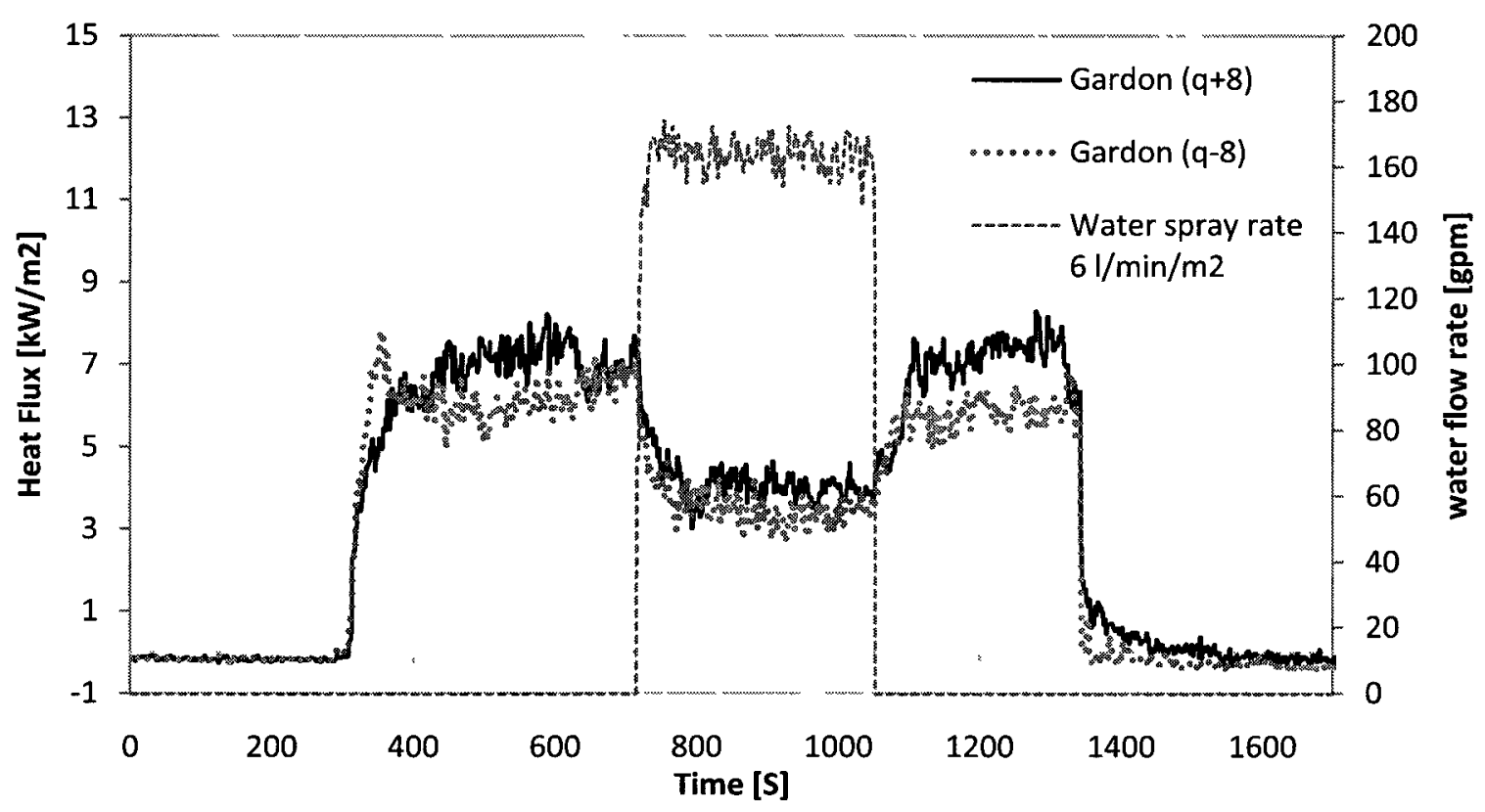

Figure 6-24 A comparison of heat flux $\left(\mathrm{q}_{+8}\right)$ measured $8 \mathrm{~m}$ downstream and heat flux $\left(\mathrm{q}_{-8}\right)$ measured $8 \mathrm{~m}$ upstream of the $10 \mathrm{MW}$ fire (Fan $25 \%$, water spray density $6 \mathrm{l} / \mathrm{min} / \mathrm{m}^{2}$ )

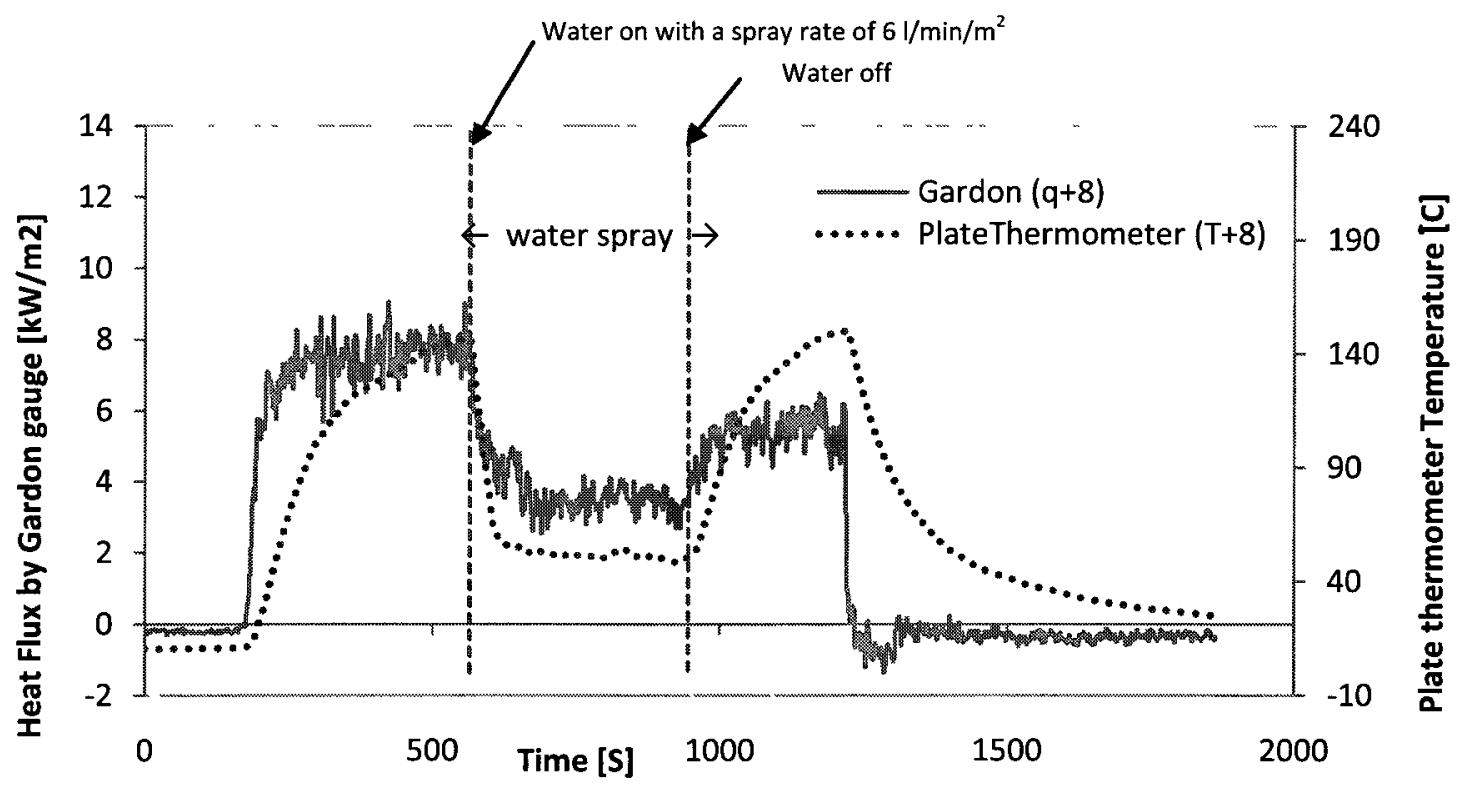

Figure 6-25 A comparison of Gardon gauge heat flux measurements and temperature measurements by a plate thermometer at the same location, $8 \mathrm{~m}$ downstream of a 10-MW fire with a $50 \%$ fan speed and water spray density of $6 \mathrm{l} / \mathrm{min} / \mathrm{m}^{2}$

In some tests, the Gardon gauge measured lower heat fluxes than the actual values after closing the water spray because water droplets had wetted the surface of the gauge 
downstream of the fire. This measurement problem is demonstrated in Figure 6-25, in which the measured heat flux does not increase to its expected value after closing the water spray. On the other hand, the temperature measured by the plate thermometer at the same location does increase to its pre-sprinkler activation value. To screen out this kind of errors, the measurements in each test were compared with the heat flux obtained from the temperature measurement by plate thermometers. Detailed calculations and comparisons with Gardon gauge measurements are discussed in Chapter 9.3.4.

\subsection{Summary}

The full-scale suppression test program was conducted using the sprinkler system in the laboratory tunnel of Carleton University.

Bucket tests were carried out first to examine the influence of longitudinal air flows on the spray pattern of the sprinkler system. Results show that the longitudinal air flow pushed the water spray in the direction of the air flow, and water droplets became more evenly distributed over the longer section of the tunnel.

In suppression tests, a constant HRR of 5,10 or $15 \mathrm{MW}$ fire was established in the laboratory tunnel without and with the sprinkler system operating to examine the effect of the suppression system with various longitudinal air flows in the tunnel.

The HRR measurement system was also tested during the suppression tests to examine the measurement accuracy during suppression. Results show that the more the temperature dropped by the sprinkler system, the more apparent the measurement error was. 
20 tests were conducted with various water spray densities of $3-141 / \mathrm{min} / \mathrm{m}^{2}$ and with longitudinal air flows of $0.7-3.0 \mathrm{~m} / \mathrm{s}$. The ceiling temperatures along the length of the tunnel and vertical temperature profiles upstream and downstream of the fire were monitored. Further analyses of the data obtained from the test program were conducted, and the results are presented in Chapter 9. 


\section{CHAPTER 7. HRR MEASUREMENTS DURING SUPPRESSION}

During the suppression test program, 20 experiments were conducted, and HRR measurements by the system were evaluated to determine the performance of the system in measuring the HRR of fires during water suppression. In Chapter 6, the description of suppression tests and brief results of HRR measurements are presented. For some tests in which large quantities of water vapour were generated by the suppression system, it was found that the system overestimated the HRR.

This chapter discusses what caused the measurement problems during suppression, and suggests a simple method to correct the HRR measurement.

\subsection{Analysis of HRR measurements during suppression}

A simple method to correct the HRR measurement during suppression was developed based on the relation between temperature and oxygen depletion factors. The corrected HRR measurements are presented and also compared with the measurement by the original method.

\subsubsection{Methodology}

The original method to calculate HRR using the oxygen calorimetry was developed considering an unsuppressed fire. A detailed description of oxygen calorimetry is presented in Chapter 3.2. The important parameters in the calculation of the HRR are mass flow rates of incoming air and the oxygen depletion factor that is calculated based on the gas concentrations measured by a gas analyser. 


$$
\mathrm{Q}=\left[E_{O 2}-\left(E_{C O}-E_{O 2}\right) f\right] \varnothing \dot{m}_{a}^{o} \frac{M_{O_{2}}}{M_{a}} X_{O_{2}}^{o}
$$

When the suppression system is activated adding water to the combustion process, water vapour is generated due to heat transfer between water droplets and the plume/flames. The hood system draws both smoke (the mixture of combustion products and air) and water vapour produced by suppression.

Although water vapour generated enters into the combustion gas sampling system, the water vapour does not affect measurements of gas concentration. The reason is that in the sampling line water vapour is removed, and gas concentrations are measured relative to the flow rate of dry air. Also, the calculation of the oxygen depletion factor $(\varnothing)$ and the incomplete combustion factor $(f)$ are not affected by water vapour because they are derived from the nitrogen balance.

A significant error can come from the calculation of the mass flow rate of incoming air ( $\dot{m}_{a}^{o}$ ) since in the method of oxygen calorimetry $\dot{m}_{a}^{o}$ is calculated indirectly from the mass flow rate of the exhaust smoke ( $\dot{m}_{a}^{e}$ ) using the chemical relation (Eq 16) that is only valid for unsuppressed fires. Therefore, the calculation of the mass flow rate of the incoming air should be corrected.

$\mathrm{Eq} 16$ is rewritten considering the molar flow rate of water vapour $\left(\dot{n}_{v}\right)$ that is evaporated from the suppression system. $\dot{n}_{a}^{e v}$ is the molar flow rate of the exhaust gas collected in the hood system when the suppression system is active.

$$
\dot{n}_{a}^{e}=\dot{n}_{a}^{o}-\emptyset \dot{n}_{a}^{o}+\alpha \emptyset \dot{n}_{a}^{o}
$$




$$
\begin{gathered}
\dot{n}_{a}^{e v}=\dot{n}_{a}^{e}+\dot{n}_{v}=\dot{n}_{a}^{o}-\emptyset \dot{n}_{a}^{o}+\alpha \emptyset \dot{n}_{a}^{o}+\dot{n}_{v}=\{1+\emptyset(\alpha-1)\} \dot{n}_{a}^{o}+\dot{n}_{v} \\
\dot{m}_{a}^{o}=\frac{M_{a}^{0}}{\{1+\emptyset(\alpha-1)\}}\left[\frac{\dot{m}_{a}^{e v}}{M_{a}^{e v}}-\frac{\dot{m}_{v}}{M_{H 2 o}}\right]=\frac{\dot{m}_{a}^{e v}}{\{1+\emptyset(\alpha-1)\}}\left[\frac{M_{a}^{0}}{M_{a}^{e v}}-\frac{M_{a}^{0}}{M_{a}^{e v}} X_{e v}^{v}\right] \\
X_{e v}^{v}=\frac{M_{a}^{e v} \dot{m}_{v}}{M_{H 2 o} \dot{m}_{a}^{e v}}
\end{gathered}
$$

$\dot{m}_{a}^{e v}$ is the mass flow rate of the exhaust gas collected in the hood system when the suppression system is active, and $\dot{m}_{v}$ is mass flow rate of water vapour that is evaporated from the suppression system. $X_{e v}^{v}$ is the volumetric fraction of water vapour that is evaporated from the suppression system in the exhaust gas collected in the hood system with the suppression system operating.

Thus, substituting Eq 48 into the base equation $\mathrm{Eq}$ 10, HRR equation for suppressed fires can be simplified using the volumetric fraction of water vapour that is introduced into the sampling line due to the suppression system in the duct system. $M_{a}^{e v}$ is the molecular weight of exhaust air that includes water vapour introduced by the suppression system, and $M_{a}^{0}$ is the molecular weight of incoming air.

$$
\begin{array}{cc}
\mathrm{Q}_{\mathrm{new}}=\left[E_{O 2}-\left(E_{C O}-E_{O 2}\right) f\right] \varnothing \frac{M_{O_{2}}}{M_{a}^{o} X_{O_{2}}^{o} \frac{\dot{m}_{a}^{e v}}{\{1+\emptyset(\alpha-1)\}}\left[\frac{M_{a}^{o}}{M_{a}^{e v}}\left(1-X_{e v}^{v}\right)\right]} & \text { Eq } 50 \\
\mathrm{Q}_{\text {new }}=\mathrm{Q}\left[\frac{M_{a}^{0}}{M_{a}^{e v}}\left(1-X_{e v}^{v}\right)\right] & \text { Eq } 51
\end{array}
$$

Measurements of the volumetric fraction of water vapour are expensive and not available for most calorimeters that use the original equation (Eq 10). In addition, separate measurements of $X_{e v}^{v}$ is not possible because water vapour in the incoming air, the combustion products and evaporation from a suppression system are all mixed in the duct system. Also finding an expression for the volumetric fraction of water vapour $X_{e v}^{v}$ is not 
simple because $X_{e v}^{v}$ depends on the amount of water discharge rate, fire size, as well as ventilation conditions. The best way is quantifying $X_{e v}^{v}$ based on the measurements from the existing devices of the HRR measurement system, such as temperature measurements.

To determine $X_{e v}^{v}$, it is assumed that the evaporation of water droplets is proportional to the cooling occurred during suppression. Defining $Q_{C}$ as the convective heat flow of smoke and air mixture carried by the longitudinal air flow $\left(\mathrm{Q}_{\mathrm{c}}=C_{p} \dot{\mathrm{m}}_{e} \Delta T_{e}\right)$, and $\mathrm{Q}_{\mathrm{C}_{-} \mathrm{S}}$ as the convective heat flow with the suppression system operating $\left(\mathrm{Q}_{\mathrm{c}_{-} s}=C_{p} \dot{\mathrm{m}}_{\mathrm{ev}} \Delta T_{e v}\right)$, then,

$$
X_{e v}^{v} \cong \frac{\mathrm{Q}_{\text {cooling }}}{\mathrm{Q}_{\mathrm{c}}}=\frac{\mathrm{Q}_{\mathrm{c}}-\mathrm{Q}_{\mathrm{c} \_\mathrm{s}}}{\mathrm{Q}_{\mathrm{c}}} \cong 1-\frac{\Delta T_{e v}}{\Delta T_{e}}
$$

In the experiments, $\dot{\mathrm{m}}_{\mathrm{e}}$ was very close to $\dot{\mathrm{m}}_{\mathrm{ev}}$, therefore, $X_{e v}^{v}$ is approximately equal to $\left(1-\frac{\Delta T_{e v}}{\Delta T_{e}}\right)$

$T_{e}$ is the exhaust gas temperature that could have been achieved in the duct, had water spray not been introduced. $T_{\mathbf{e}}$ is proportional to the heat generated by the fire, and this means that $T_{e}$ is directly proportional to the oxygen consumed during the combustion, more precisely, the oxygen depletion factor. Therefore, $\Delta T_{e}$ can be obtained as a function of the oxygen depletion factor $(\varnothing)$. Finally, the method to calculate HRR for suppressed fires $Q_{\text {new }}$ becomes

$$
\begin{gathered}
\mathrm{Q}_{\text {new }}=\mathrm{Q}\left[\frac{M_{a}^{0}}{M_{a}^{e v}}\left(1-X_{e v}^{v}\right)\right] \\
X_{e v}^{v} \cong 1-\frac{\Delta T_{e v}}{\Delta T_{e}(\varnothing)}
\end{gathered}
$$




$$
M_{a}^{e v}=M_{a}^{e}\left(1-X_{e v}^{v}\right)+M_{H_{2} O}\left(X_{e v}^{v}\right)
$$

Eq 54

\subsection{Analysis of temperature vs. the oxygen depletion factor}

Figure 7-1 compares the temperature rise $\left(\Delta \mathrm{T}_{\mathrm{e}}\right)$ of the exhaust gas and the oxygen depletion factor $(\emptyset)$, which resulted from the calibration test HP16 (24 MW fire combined of propane burners and heptane, $100 \%$ fan speed, see Chapter 4.2 .3 for details). $\Delta \mathrm{T}_{\mathrm{e}}$ shows a very similar pattern (a dotted line) to the oxygen depletion factor, yet $\Delta \mathrm{T}_{\mathrm{e}}$ exists long after the fire was fully extinguished. This is mainly due to the radiation and convection heat transfer from the walls that were heated over time.

Assuming that the temperature alteration has occurred linearly over the duration of the fire, $\Delta T_{e}$ is corrected by subtracting the value calculated from the linear function at each time. In turn, the corrected $\Delta T_{e}$ is found to perfectly follow the footsteps of the oxygen depletion factor over time. This comparison proves that the actual $\Delta \mathrm{T}_{\mathrm{e}}$ is directly proportional to the oxygen depletion factor.

In order to find the relation between the actual $\Delta \mathrm{T}_{e}$ and $\Phi, \Phi$ and the actual $\Delta \mathrm{T}_{\mathrm{e}}$ are computed in each test conducted in the calibration test program and the suppression test program. In Figure 7-2, the averaged $\Phi$ and actual $\Delta \mathrm{T}_{\mathrm{e}}$ that are obtained during the steady-state are plotted. A linear relation is found between the actual $\Delta \mathrm{T}_{\mathrm{e}}$ and $\Phi$.

$$
\Delta T_{e}(\varnothing)=f(\varnothing)=1340 \emptyset+8
$$

This function is only valid for this measurement facility, yet a similar function can be found in a different facility and measurement system. 


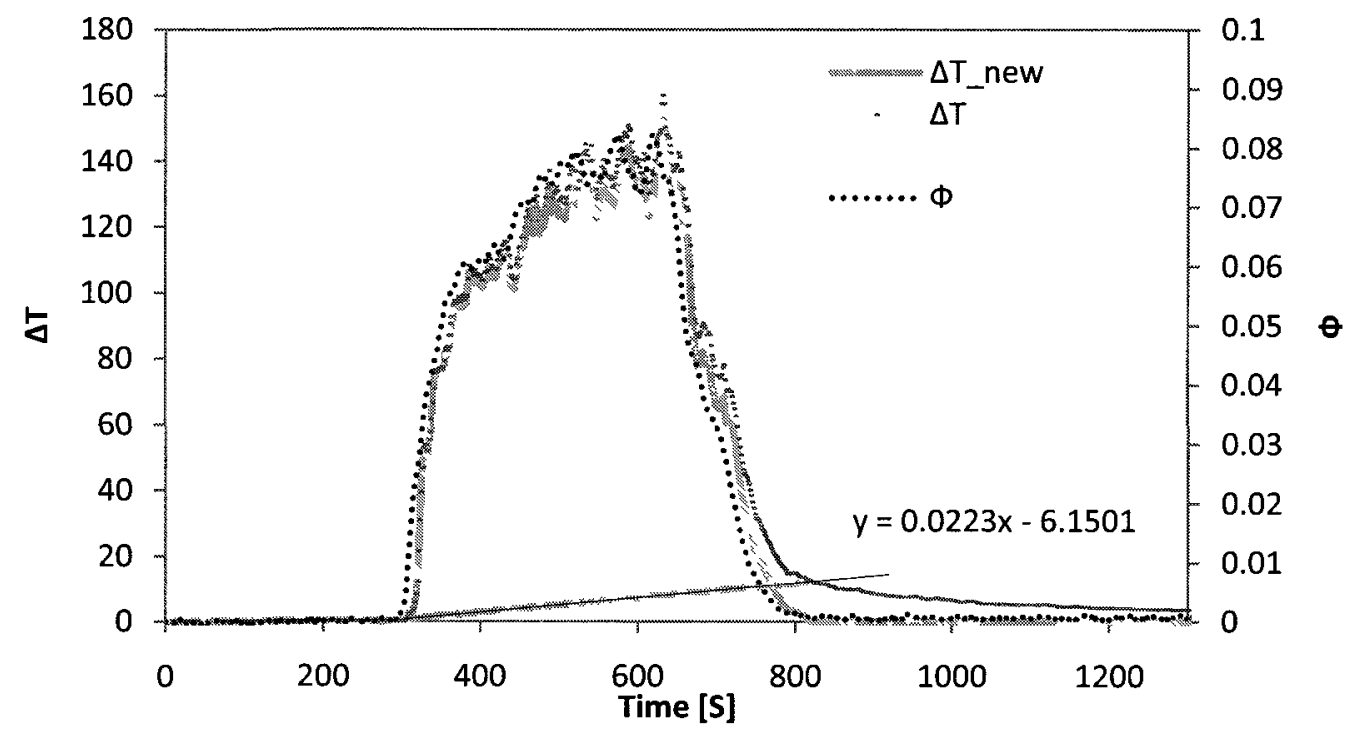

Figure 7-1 A comparison between the temperature rise $(\Delta T)$ of exhaust gas and the oxygen depletion factor $(\Phi)$ ( Test results from a calibration test $\# 16$, a $24 \mathrm{MW}$ fire combined of propane burners and a heptane pool, $100 \%$ fan speed)

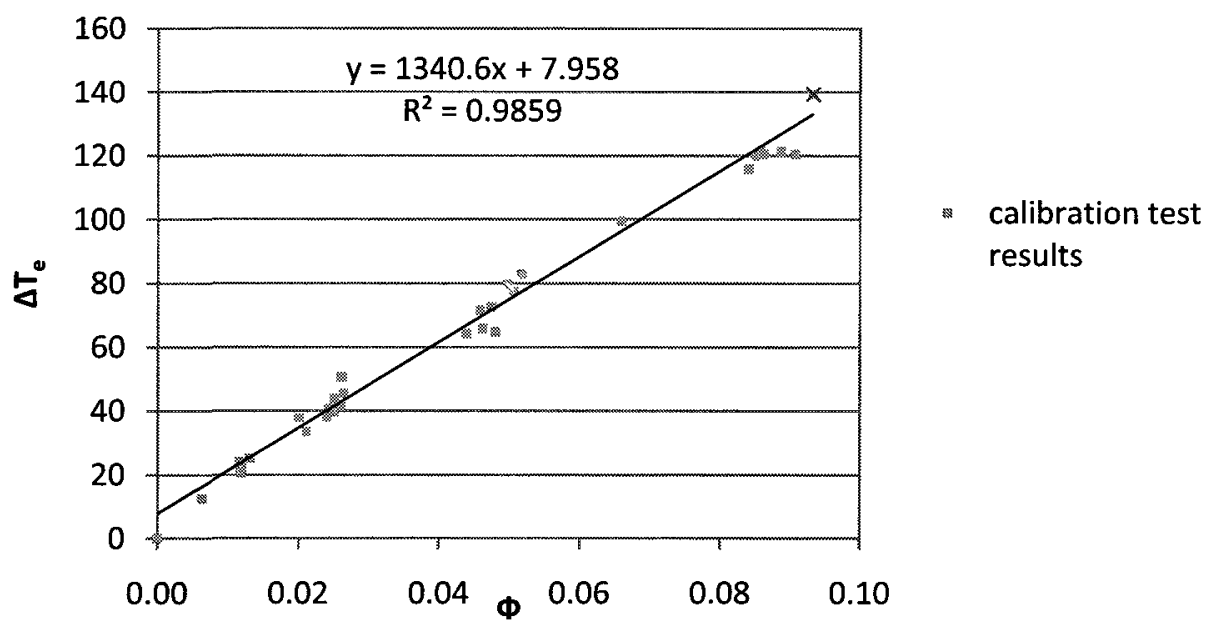

Figure $7-2 \Delta T_{e}$ as a function of $\Phi$

\subsection{Correction of the HRR during suppression}

Figure 7-3 compares the measured oxygen depletion factor with the actual $\Delta \mathrm{T}_{\mathrm{ev}}$ that resulted from the $10 \mathrm{MW}$ fire test with a $50 \%$ fan speed. $\Delta \mathrm{T}_{\mathrm{ev}}$ in the fan chamber dropped when the sprinkler system was active, and the temperature drop is more significant under the large water spray rate of $91 / \mathrm{min} / \mathrm{m}^{2}$. On the other hand, the oxygen depletion factor decreased by less than $10 \%$ during suppression. This causes the 
measurement error in the HRR; the original equation overestimate HRR as plotted in Figure $7-4$ due to the temperature measurements that were altered by water vapour intrusion.

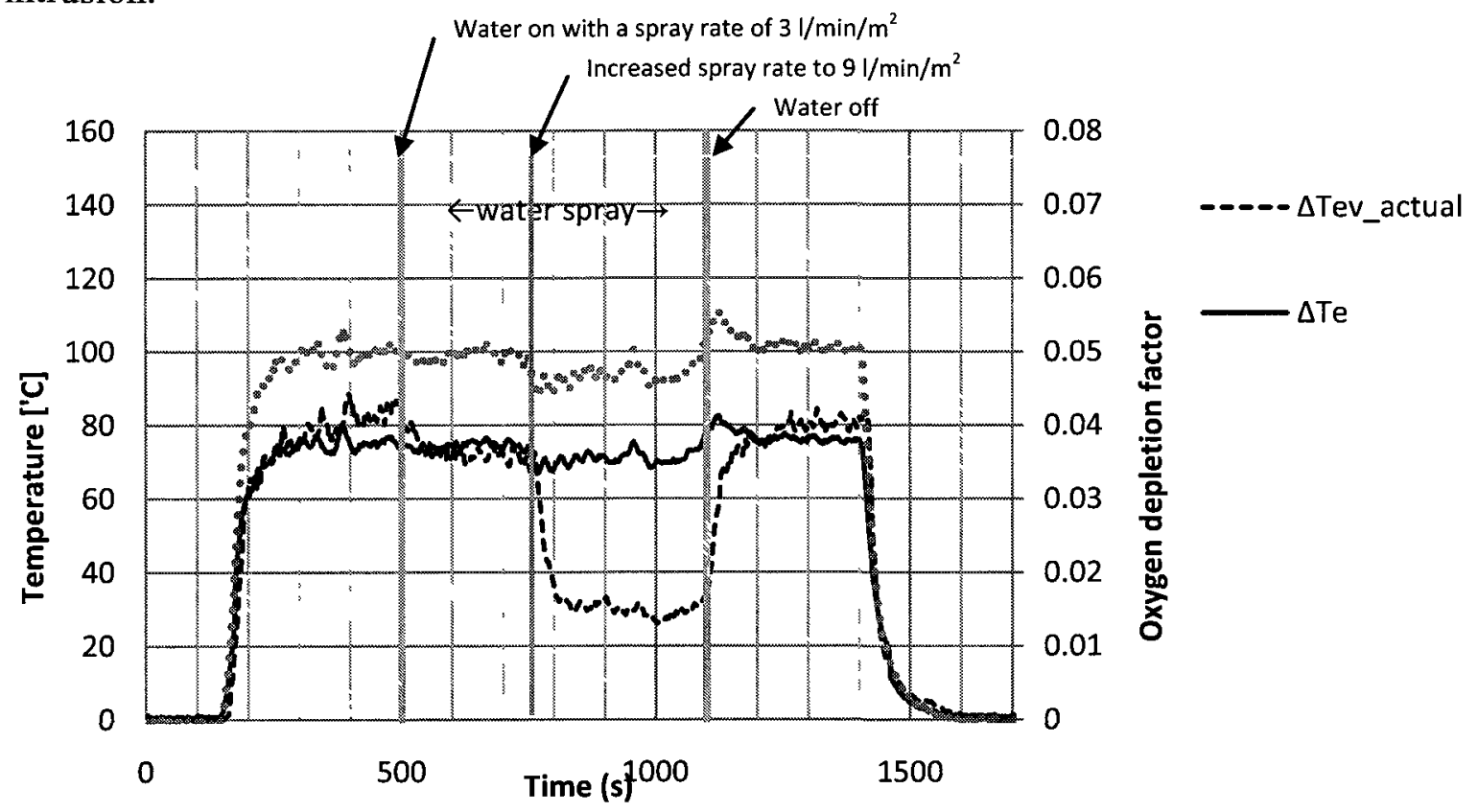

Figure 7-3 A comparison of oxygen depletion factor with the actual $\Delta \mathrm{T}_{\mathrm{ev}}$ and $\Delta \mathrm{T}_{\mathrm{e}}$ resulted from the $10 \mathrm{MW}$ fire test under $50 \%$ fan speed and water spray rate of 3 and $9 \mathrm{l} / \mathrm{min} / \mathrm{m}^{2}$

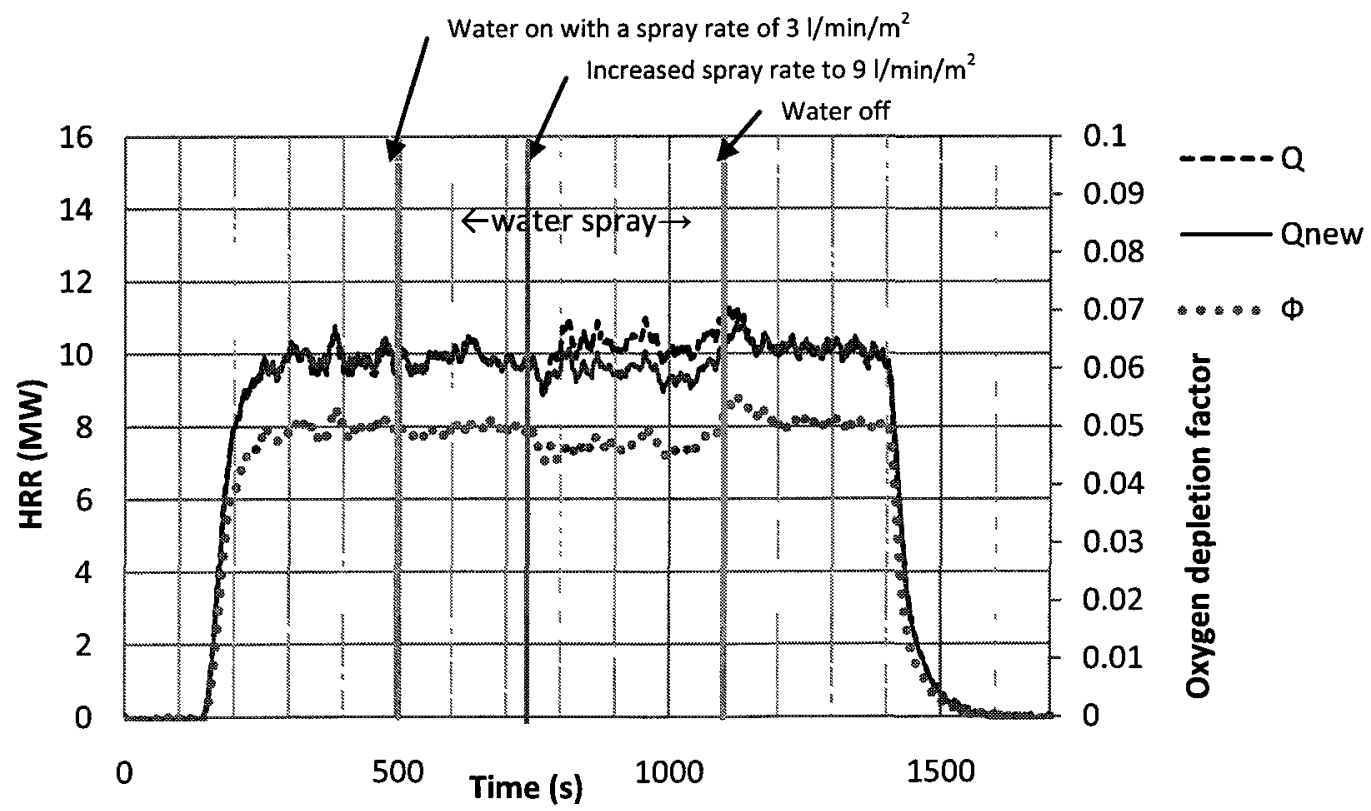

Figure 7-4 Corrected HRR, $Q_{\text {new, }}$ compared with $Q$ (a $10 \mathrm{MW}$ fire under $50 \%$ fan speed with a water spray rate of 3 and $91 / \mathrm{min} / \mathrm{m}^{2}$ ) 
The calculation of $\Delta \mathrm{T}_{\mathrm{e}}$, using the relation found between the actual $\Delta \mathrm{T}_{\mathrm{e}}$ and $\Phi$, was demonstrated in Figure 7-3. The ratio of $\Delta \mathrm{T}_{\mathrm{ev}} / \Delta \mathrm{T}_{\mathrm{e}}$ gives an estimate of the evaporation that occurred during suppression. Using the simple method (Eq 51) to correct HRR during suppression, $\mathrm{Q}_{\text {new }}$ was calculated and compared with the $\mathrm{Q}$ obtained by the original method in Figure 7-4. The correction is minimal for a water spray rate of 3 $\mathrm{l} / \mathrm{min} / \mathrm{m}^{2}$, but the simple method corrects the overestimation by the original method for a water spray rate of $9 \mathrm{1} / \mathrm{min} / \mathrm{m}^{2}$. This result shows that the method can be used for different water flow rates as it effectively predicts the content of water vapour that is variable for different water flow rates.

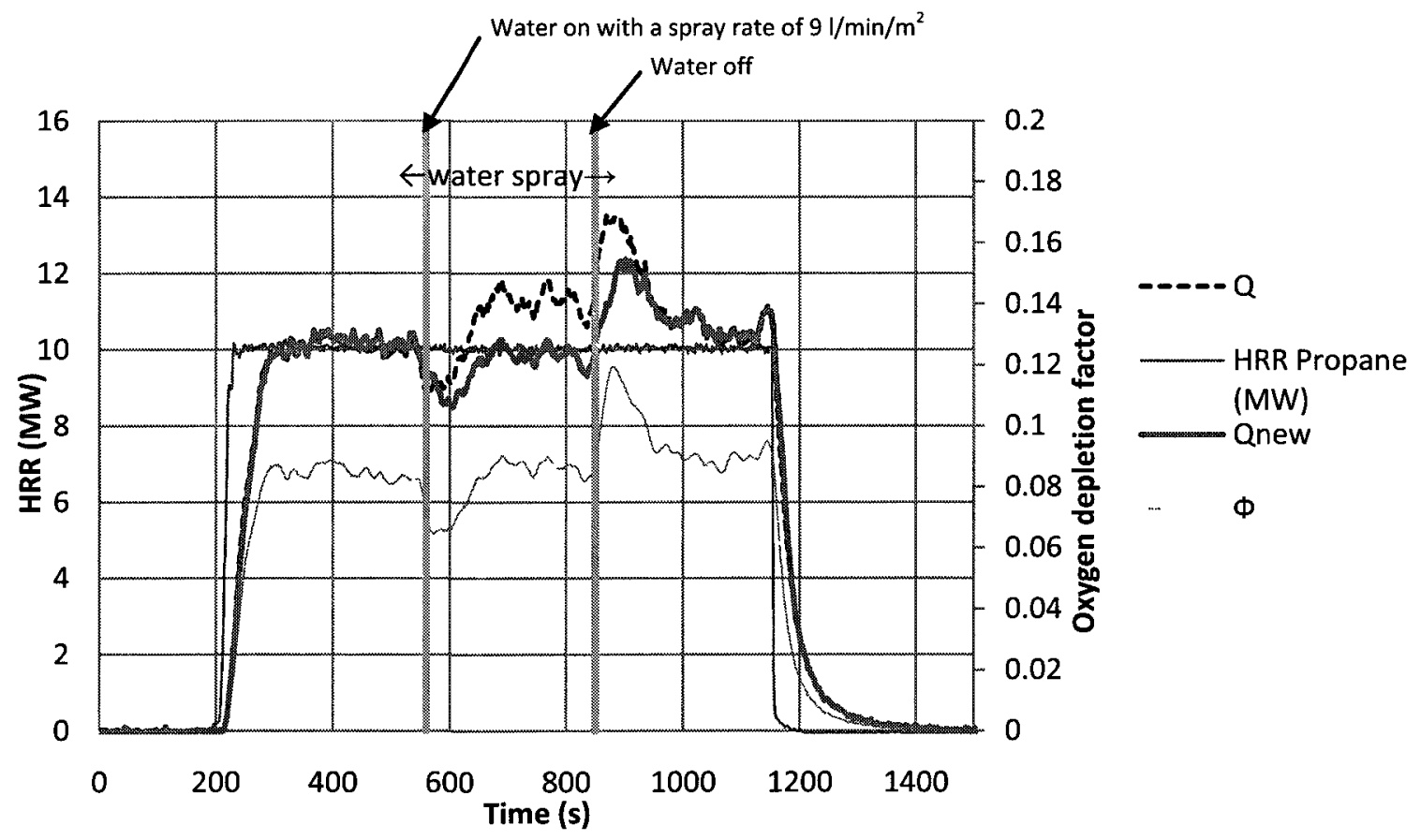

Figure 7-5 Corrected HRR, $Q_{\text {new, }}$ compared with Q (a $10 \mathrm{MW}$ fire under $25 \%$ fan speed with a water spray rate of $9 \mathrm{l} / \mathrm{min} /{ }^{2}$ )

Figure 7-5 compares $\mathrm{Q}$ and $\mathrm{Q}_{\text {new }}$ resulted from the test in which the largest $X_{e v}^{v}$ was found (a propane fire test of $10 \mathrm{MW}$ under $25 \%$ fan speed, with a water spray rate of $91 / \mathrm{min}^{2}$ ). Although a large amount of water vapour was generated, it can be seen from the 
measurements of $\emptyset$ that the burning of the propane fire was consistent even during suppression. Comparing with measurements of $\emptyset$, the estimation by the new method, $\mathrm{Q}_{\text {new }}$, is found to be reasonable while $\mathrm{Q}$ by the original method is overestimated by about $10-15 \%$ during suppression.

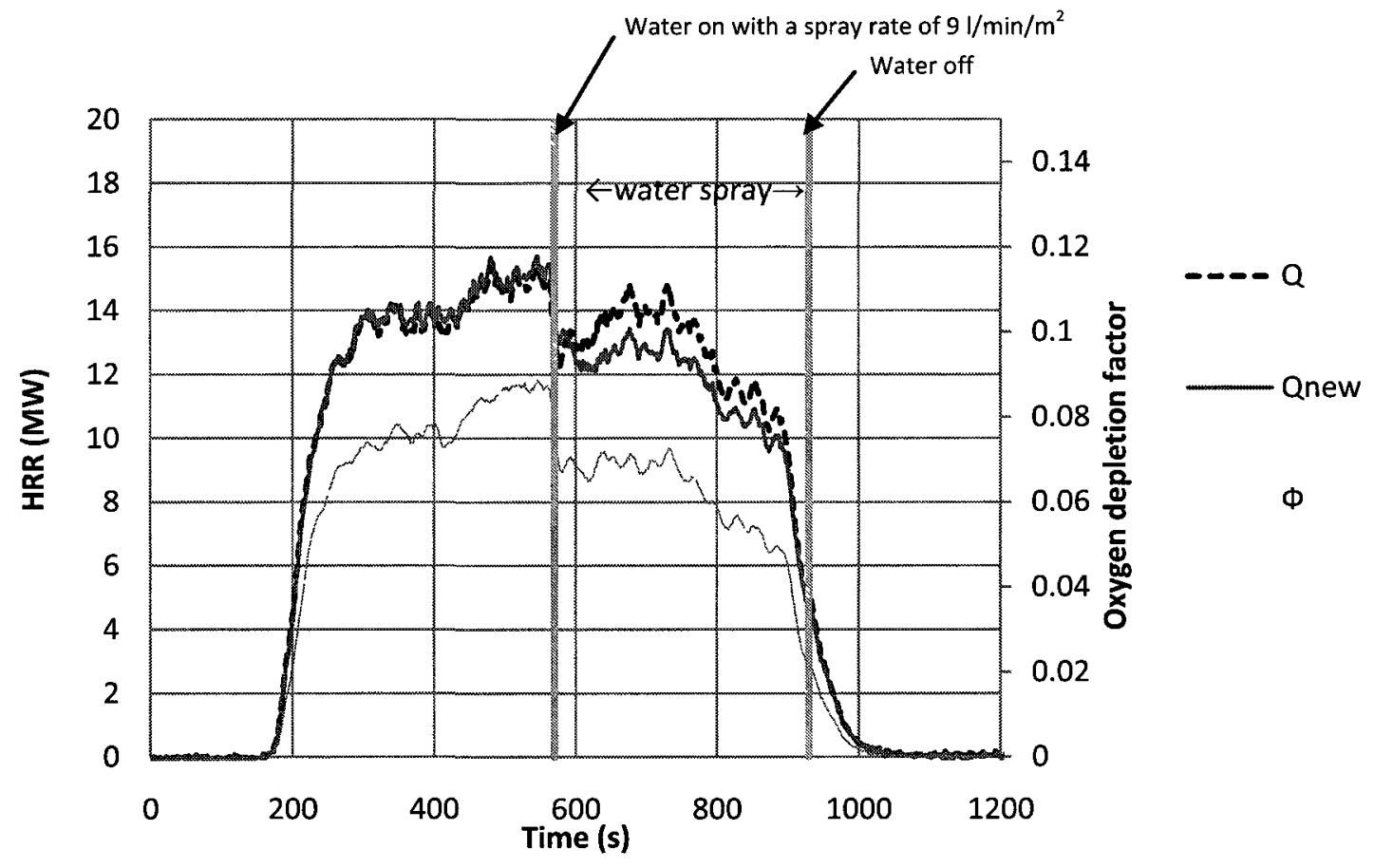

Figure 7-6 A comparison of $Q$ and $Q_{\text {new }}$ for the test of $15 \mathrm{MW}$ fire (heptane and propane fire) under $50 \%$ fan speed and water spray rate of $9 \mathrm{l} / \mathrm{min} / \mathrm{m}^{2}$

In the case of heptane and propane tests, the new method also calculates the HRR successfully, returning the decreased HRR of the fire via the correlation of temperature and $\emptyset$ used in the method. Figure 7-6 compares $\mathrm{Q}$ and $\mathrm{Q}_{\text {new }}$ resulted from the test $\mathrm{H} 15 \mathrm{M}$ $50 \% 9$. 


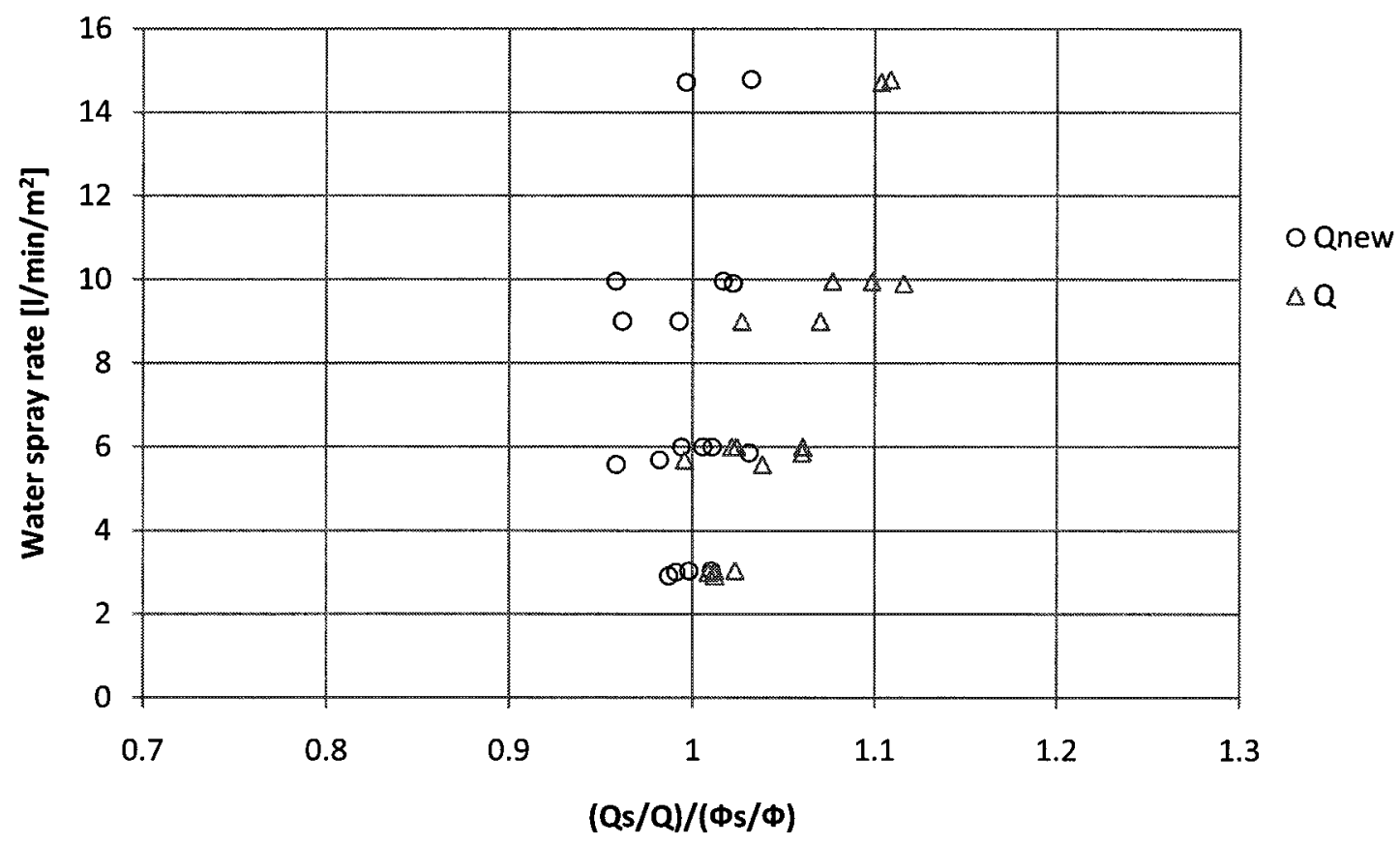

Figure 7-7 A comparison of performance of $Q_{\text {new }}$ and $Q$

The performance of two methods $Q$ and $Q_{\text {new }}$ in estimating the HRR can be examined only when the input $H R R$ is known. Thus, the estimates of $\left(Q_{s} / Q\right)$ by both methods are compared with $\left(\emptyset_{s} / \varnothing\right)$ rather than the nominal input HRR or the total energy content of the fuel since complete combustion of the fuel cannot be sure. In Figure 7-7, to compare the performance of two methods, $\left(\mathrm{Q}_{\mathrm{s}} / \mathrm{Q}\right) /\left(\emptyset_{\mathrm{s}} / \emptyset\right)$ are plotted with respect to water spray rates. The figure shows that the HRR (Q) is overestimated during suppression, and the errors are systematically increasing with the increase of water spray rates. On the other hand, the influence of water spray rates on the performance of the method $Q_{\text {new }}$ is small.

As discussed, the systematic error was estimated using the relation between the actual $\Delta \mathrm{T}_{\mathrm{e}}$ and $\emptyset$, and HRR measurements by the original method were corrected. Residual uncertainties in the estimates by the $Q_{\text {new }}$ are evaluated by the method of uncertainty propagation using Kragten spreadsheet discussed in Chapter 5. The relative combined 
uncertainty of estimation by $\mathrm{Q}_{\text {new }}$ is in the range of $10-15 \%$, which is similar to the uncertainty found for the original method.

\subsection{Summary}

The HRR measurement system was evaluated for its accuracy during suppression. In order to investigate the impact of the water vapour on the measurement of HRR, propane fire tests were conducted with the sprinkler system operating while maintaining a constant flow rate of propane.

The analysis of the test results showed that the HRR measurements by the original method of oxygen calorimetry, when suppression is active, yielded HRR overestimation by up to $10 \%$. The error mainly comes from the large quantities of water vapour generated by the suppression system. Measurements of the volumetric fraction of water vapour are not available for most calorimeters that use the oxygen calorimetry. In addition, separate measurements of water vapour introduced by the sprinkler system are not possible. Thus, the water vapour introduced by the sprinkler system was estimated based on the temperature measurements of the exhaust gases. Based on the temperature measurement and the relation of temperature and oxygen depletion factor, the present study proposed a simple method to correct the HRR measurement during suppression. The corrected HRR by the simple method were presented and also compared with the measurement by the original method. 


\section{CHAPTER 8. CFD SIMULATIONS OF SUPPRESSION TESTS}

The objectives of the simulation program are to extend the experimental data, to visualize the conditions inside the tunnel, and to observe the interactions between the sprinkler system and hot gas flows in the tunnel. Using a CFD model, the Fire Dynamics Simulator (FDS) [90], selected full-scale suppression tests were simulated first to compare with the experimental data to verify the use of FDS in tunnel applications. The comparison study was then followed by numerical simulations to examine smoke dispersion from large fires along a longer section of a tunnel than the laboratory tunnel. This chapter describes the CFD simulations and presents comparisons of predicted results with experimental results. (Some of these results are published in 'Modelling the interaction between suppression and ventilation systems in tunnel fires' presented at Interflame 2010 [105].)

\subsection{Description of CFD SIMULATIONS}

The current research employed the Fire Dynamics Simulator (FDS) version 5.4.1, developed by the National Institute for Standards and Technology. FDS [90] is a Large Eddy Simulation (LES) model and solves a form of high-speed filtered Navier-Stokes equations, valid for low-speed buoyancy driven flow. The LES simulates the large eddies that are evolved from the fire plume but uses a sub grid scale model using Smagorinsky treatment to model small-scale turbulent viscosity. Turbulence parameter used in the present study was 0.2 for Smagorinsky constant. For combustion, FDS uses a mixture fraction method based on equilibrium chemistry. 
In FDS, the interactions of the discrete water droplets with the continuous air flow are modelled by adopting a 'Lagrangian model'. The water droplets are represented by the Lagrangian particles, and the model tracks the transport of sample droplets in the air and calculates heat transfer between the droplets and the hot gas.

\subsubsection{Model tunnels}

First, the tunnel test facility including the fan chamber and the tunnel, which is $10 \mathrm{~m}$ wide, $5.5 \mathrm{~m}$ high and $37.5 \mathrm{~m}$ long, were modelled as illustrated in Figure 8-1(a). A uniform grid with dimensions of $0.25 \mathrm{~m}(\mathrm{D}) \times 0.25 \mathrm{~m}(\mathrm{~W}) \times 0.25 \mathrm{~m}(\mathrm{H})$ was used since this grid size was found to yield reasonable values in grid convergence tests. In addition, this resolution is in accordance with values that are suggested by the FDS guidelines [90] Boundary conditions are concrete for walls and insulation board for the tunnel ceiling; walls around the fire area are insulated and sheathed with corrugated metal sheet.

Second, a $53 \mathrm{~m}$ long tunnel $10 \mathrm{~m}$ wide and $5.5 \mathrm{~m}$ high was also modelled to examine more closely the smoke backlayering upstream of the fire. This was done by extending the inlet of the tunnel as shown in Figure 8-1(b). Therefore, other conditions remained the same with the model laboratory tunnel. Grid sizes and boundary conditions are the same with the model laboratory tunnel.

\subsubsection{Ventilation}

For the model laboratory tunnel, the main opening was open with dimensions of $3.8 \mathrm{~m}$ wide and $4.3 \mathrm{~m}$ high, and two louver openings were also open with dimensions of $1.2 \mathrm{~m}$ wide and $4.8 \mathrm{~m}$ high at the east end. At the main opening, the flow straightening vanes 
were also modelled as used in the experiments. For the $53 \mathrm{~m}$ long tunnel, the free open boundary condition was used at the tunnel opening.

For both the model laboratory tunnel and the $53 \mathrm{~m}$ long tunnel, the mechanical exhaust system on top of the tunnel was modelled. The exhaust system was set to exhaust 66 and $33 \mathrm{~m}^{3} / \mathrm{s}$ of gas, to simulate fan capacities of $50 \%$ and $25 \%$, respectively. A longitudinal air flow was created inside both model tunnels by the system since the system draws smoke from two ceiling openings connected to the fan chamber.

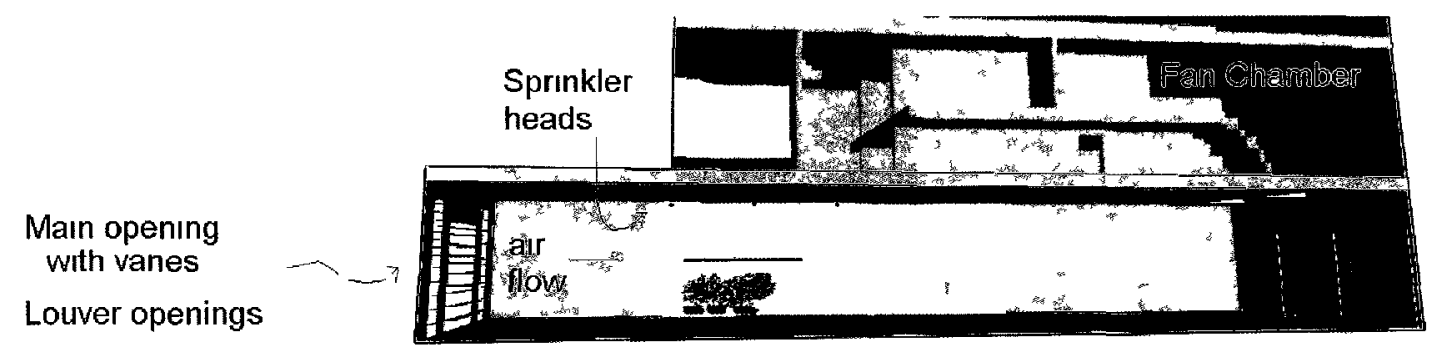

(a) Model laboratory tunnel

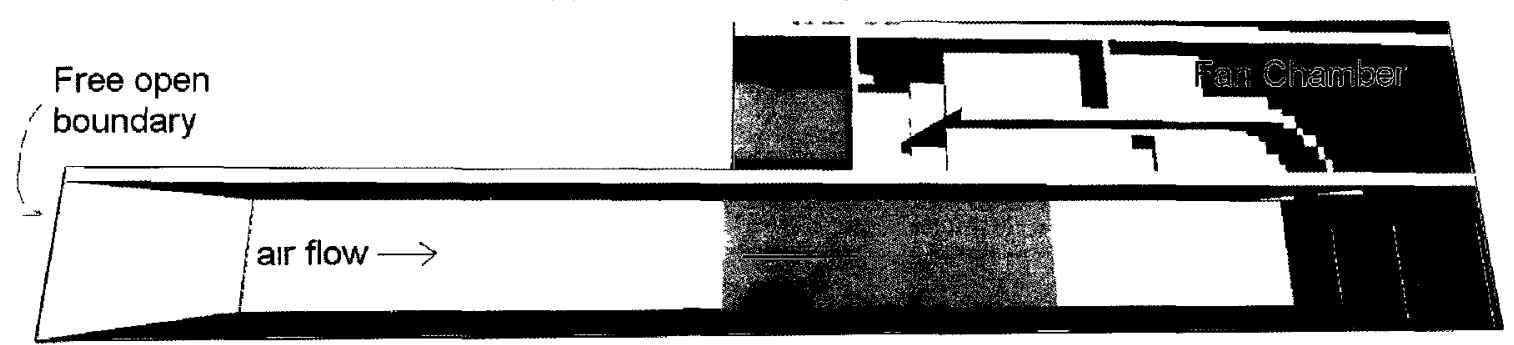

(b) $53 \mathrm{~m}$ long model tunnel

Figure 8-1 (a) Model laboratory tunnel and (b) $53 \mathrm{~m}$ long model tunnel

\subsubsection{Fire simulations}

To compare with the suppression experiments, fire sizes of 5 and $10 \mathrm{MW}$ were selected and modelled in the model laboratory tunnel under the same conditions used in the experiments. The fire was placed $12 \mathrm{~m}$ from the east end along the centre of the model laboratory tunnel. The fire was covered by a metal sheet insulated at the fire side. 
Under the cover, three propane burners $1.3 \mathrm{~m}$ by $0.9 \mathrm{~m}$ ( the same size as used in the experiments) were placed with a prescribed total Heat Release Rate (HRR) of 5 or 10 MW.

Fire sizes of 10, 25 and $40 \mathrm{MW}$ were simulated in the $53 \mathrm{~m}$ long tunnel. The fire was placed at $27 \mathrm{~m}$ from the east end of the model tunnel.

Gas temperatures were monitored along the central cross section of both model tunnels. After reaching steady-state, the mean temperature data were obtained for 5 min without the sprinkler system operating, and then after the sprinkler system was activated, the mean temperature data during suppression were also obtained for another $5 \mathrm{~min}$.

\subsubsection{Sprinkler system}

In both model tunnels, sprinkler heads were distributed over the fire area as in the test tunnel. FDS requires water droplet characteristics to calculate the effect of water spray that are introduced into the model tunnels. Water droplet distribution is defined using the Rosin-Rammler and log normal distribution functions, which are commonly used for normal sprinkler systems [106]. Equation (1) shows the Cumulative Volume Fraction (CVF) of the distributed droplet diameters $(d)$.

$$
F(\mathrm{~d})=\left\{\begin{array}{cc}
\frac{1}{\sqrt{2 \pi}} \int_{0}^{d} \frac{1}{\bar{\sigma} d} e^{\frac{-\left[\ln \left(d / d_{m}\right)\right]^{2}}{2 \bar{\sigma}^{2}}} d d \quad\left(d \leq d_{m}\right) \text { Log normal } \\
1-e^{-0.693\left(\frac{d}{d_{m}}\right)^{r}} \quad\left(d_{m}<d\right) \text { Rosin-Rammler }
\end{array}\right.
$$

Where $d_{m}$ is the median droplet diameter, and $\gamma$ and $\bar{\sigma}$ are parameters for the RosinRammler and log normal distribution, respectively. Sheppard [107] measured the 
sprinkler spray characteristics of various types of sprinkler heads. For the sprinkler heads used in the present study, values of 2.04 and 0.58 were used for $\gamma$ and $\bar{\sigma}$, respectively, as they were measured by Sheppard for a upright sprinkler head with orifice diameter of 16 $\mathrm{mm}$. While $\gamma$ and $\bar{\sigma}$ are constant, $d_{m}$ is a function of the operating pressure and orifice diameter and design of the head. For the test with an operating pressure of $250 \mathrm{kPa}$, we used $700 \mu \mathrm{m}$ that was measured by Sheppard for similar type of sprinkler heads with operating pressure of $232 \mathrm{kPa}$. For the other two tests with lower operating pressures, a slightly larger droplet size of $750 \mu \mathrm{m}$ was used. The spray angle was set from 30 to 80 degrees. For comparison, a mean diameter of $900 \mu \mathrm{m}$ was simulated for the case with water flow density of $31 / \mathrm{min} / \mathrm{m}^{2}$. In the trial simulation, slightly narrow spray stream angles of $20-70$ degrees were set. Table $8-1$ shows a list of simulations and the conditions used.

Table 8-1 List of simulations

\begin{tabular}{|c|c|c|c|c|c|c|c|c|c|c|}
\hline \multirow[t]{2}{*}{ ID } & \multicolumn{2}{|c|}{ Water flow rate } & \multirow{2}{*}{\begin{tabular}{|c|} 
Pressure \\
$\mathrm{kPa}$ \\
\end{tabular}} & \multicolumn{4}{|c|}{ Droplet characteristics } & \multirow{2}{*}{$\begin{array}{l}\text { HRR } \\
\text { MW }\end{array}$} & \multirow{2}{*}{$\frac{\text { Fan }}{\mathrm{m}^{3} / \mathrm{s}}$} & \multirow{2}{*}{$\begin{array}{l}\text { Spray } \\
\text { area } \\
\mathrm{m}^{2}\end{array}$} \\
\hline & $1 / \mathrm{min}$ & $1 / \mathrm{min} / \mathrm{m}^{2}$ & & $d_{m}$ & $\gamma$ & $\sigma^{-}$ & $\theta$ & & & \\
\hline \begin{tabular}{l|l}
1 & $\mathrm{~S} 5 \mathrm{M} 50 \% 3$ \\
\end{tabular} & 322 & 2.9 & 55 & 900 & 2.04 & 0.58 & $20-70$ & 5 & 66 & 111 \\
\hline S5M50\%3 & 322 & 2.9 & 55 & 750 & 2.04 & 0.58 & $30-80$ & 5 & 66 & 111 \\
\hline 2 S5M50\%6 & 643 & 5.8 & 117 & 750 & 2.04 & 0.58 & $30-80$ & 5 & 66 & 111 \\
\hline 3 S5M50\%9 & 1098 & 9.9 & 248 & 700 & 2.04 & 0.58 & $30-80$ & 5 & 66 & 111 \\
\hline 4 S10M50\%6 & 643 & 5.8 & 117 & 750 & 2.04 & 0.58 & $30-80$ & 10 & 66 & 111 \\
\hline 5 S10M50\%6-long & 643 & 5.8 & 117 & 750 & 2.04 & 0.58 & $30-80$ & 10 & 66 & 111 \\
\hline 6 S25M50\%9 & 1098 & 9.9 & 248 & 700 & 2.04 & 0.58 & $30-80$ & 25 & 66 & 111 \\
\hline 7 S25M50\%9-long & 1098 & 9.9 & 248 & 700 & 2.04 & 0.58 & $30-80$ & 25 & 66 & 111 \\
\hline 8 S40M $25 \% 6$ & 643 & 5.8 & 117 & 750 & 2.04 & 0.58 & $30-80$ & 40 & 33 & 111 \\
\hline 9 S40M25\%6-long & 643 & 5.8 & 117 & 750 & 2.04 & 0.58 & $30-80$ & 40 & 33 & 111 \\
\hline
\end{tabular}




\subsection{Simulation results}

8.2.1. Comparison of simulated results with experimental results without the sprinkler system operating

From the simulations and experiments, the time-averaged temperatures obtained during steady-state are compared before the suppression system was activated. In Figure 8-2, the simulated ceiling temperatures resulted from the model laboratory tunnel as well as from the $53 \mathrm{~m}$ long tunnel are plotted with respect to the distance (R) from the fire. In the figure, comparisons with test data, which were also averaged after steady-state, are made.

The simulated ceiling temperature results from two different model tunnels are very similar, and these simulated ceiling temperatures from both model tunnels compare well with the measured temperatures. The maximum ceiling temperatures in the vicinity of the fire predicted by the simulations are about $10 \%$ higher than the measured temperature. While the simulated ceiling temperature results show good agreement with the experimental data in the area upstream of the fire, the simulated results downstream of the fire are about $10 \%$ lower than the test results.

Figure 8-3 and Figure 8-4 compare the simulated vertical temperature profiles from both model tunnels with the temperatures measured at thermocouple trees at $\mathrm{R}=-10 \mathrm{~m}$ and $\mathrm{R}=+17 \mathrm{~m}$, respectively. The simulated ceiling temperature results for the two different model tunnels are very similar to each other, particularly in the vertical temperature profiles $17 \mathrm{~m}$ downstream of the fire. The simulated results are also in good agreement with the measured temperature data. 
Good agreement between the simulated results and the measured data was also obtained for the temperature profile $10 \mathrm{~m}$ upstream of the fire (Figure 8-3). However, the simulated results from the $53 \mathrm{~m}$ long tunnel show different results due to the longer inlet passage. The extended tunnel inlet let smoke mix with air, which resulted in a less distinct upper layer than the laboratory tunnel. Nonetheless, the maximum temperature predictions from the both model tunnels show a very good agreement with the experimental data.

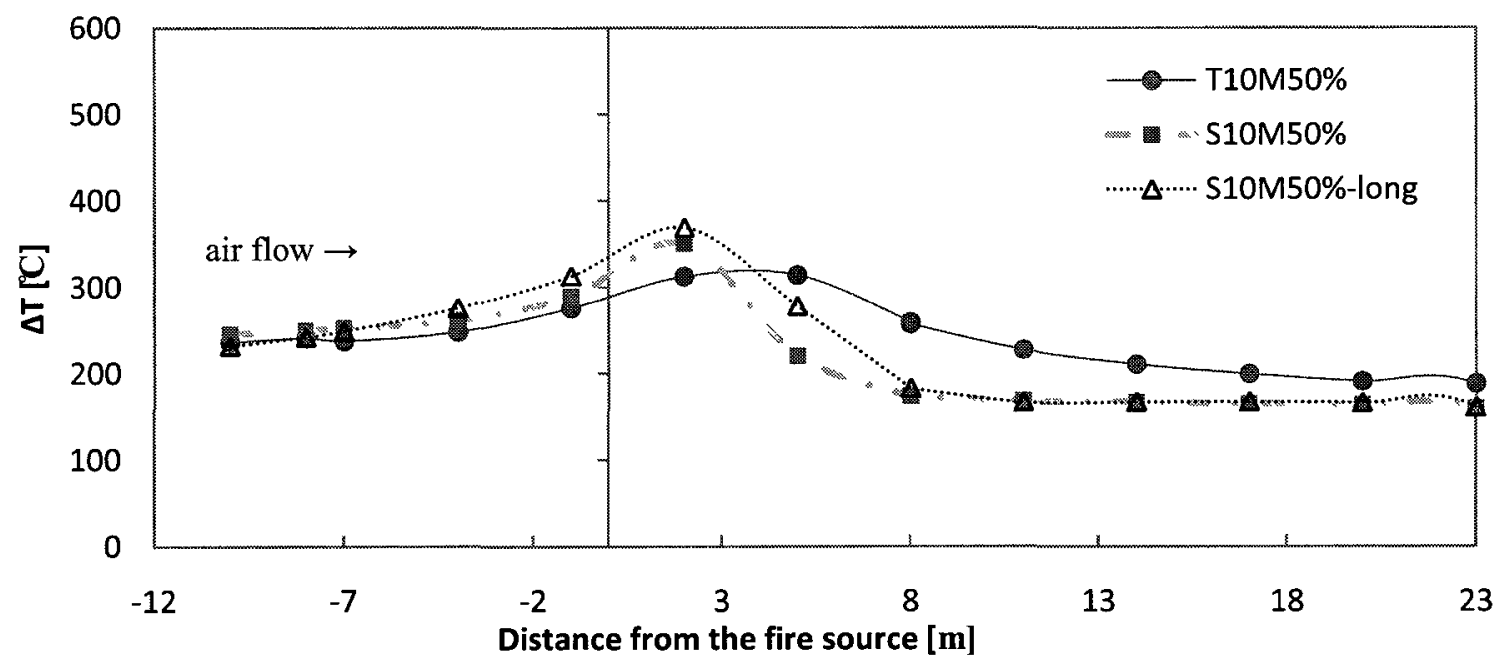

Figure 8-2 Comparisons of the temperature profile along the tunnel without the sprinkler system operating ( $10 \mathrm{MW}$ fire, $50 \%$ fan speed) 


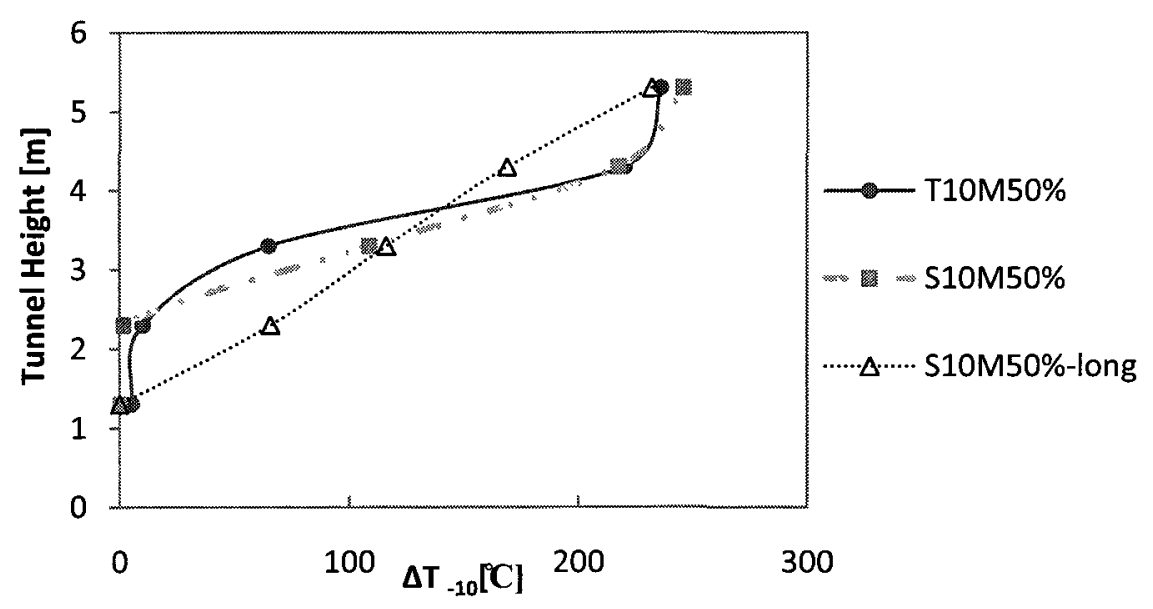

Figure 8-3 Comparison of vertical temperature profiles $10 \mathrm{~m}$ upstream of the $10 \mathrm{MW}$ fire without the sprinkler system operating

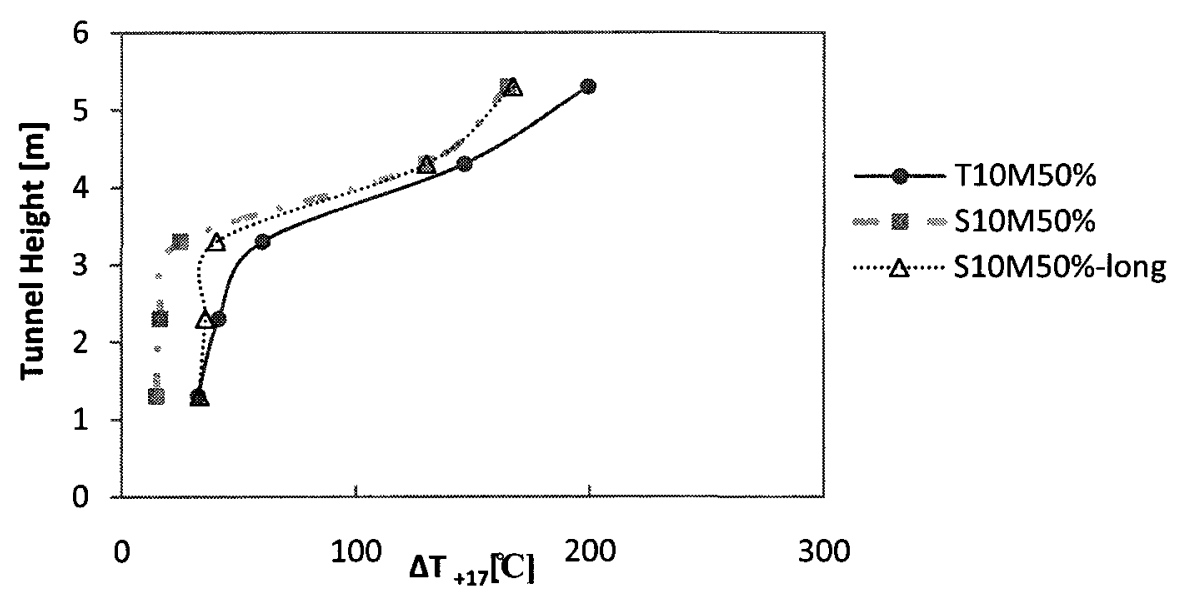

Figure 8-4 Comparison of vertical temperature profiles $17 \mathrm{~m}$ downstream of the $10 \mathrm{MW}$ fire without the sprinkler system operating

\subsubsection{Comparison of the spray pattern}

As the conditions inside the tunnel during suppression depend greatly on the water spray characteristics, it is necessary to examine the simulated water spray pattern. Figure 8-5(a) demonstrates how the water droplets discharged from the sprinkler heads interacts with the gas flow. Figure 8-5(b) show the simulated spray pattern on the floor, and Figure 8-5(c) show the spray pattern obtained from the bucket test of B50\%6. 


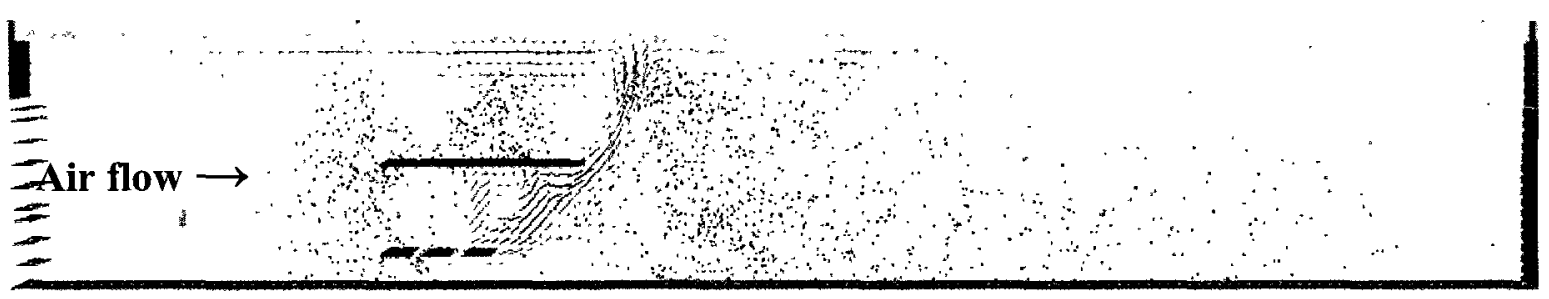

(a) Water droplets discharged in the tunnel (S10M50\%6)

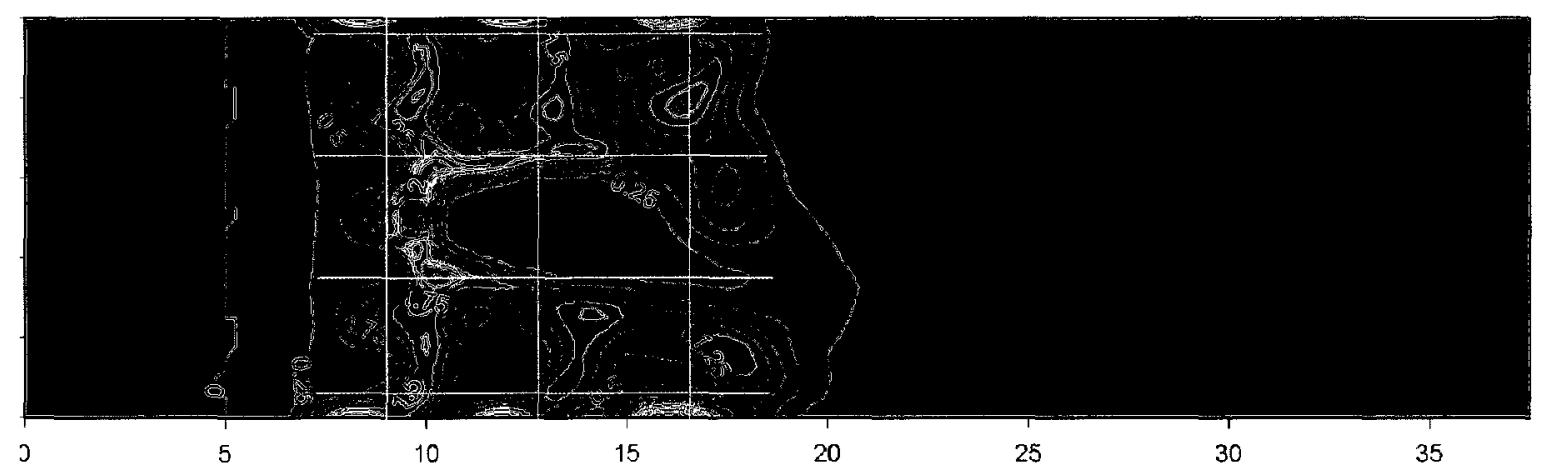

(b) The simulated water spray pattern (S10M50\%6)

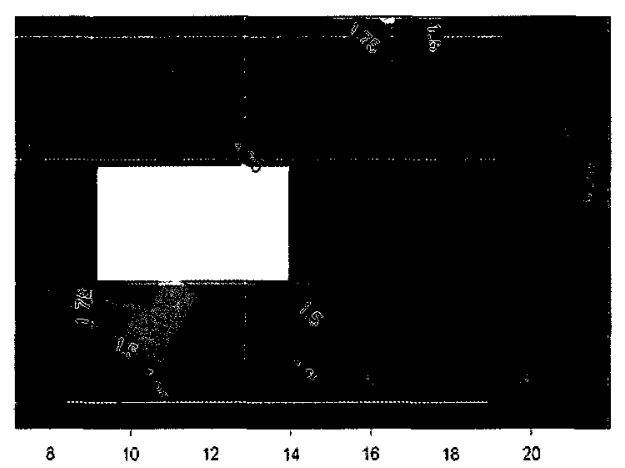

(c) The water spray pattern from the bucket test, $B 50 \% 6$

Figure 8-5 The influence of the longitudinal air flow on the water spray pattern in the case of water spray density of $6 \mathrm{l} / \mathrm{min} / \mathrm{m}^{2}$ under an air flow of $1.4 \mathrm{~m} / \mathrm{s}$ (Fan speed $50 \%$ )

The simulated water spray pattern is found to be different from the measured spray pattern from the bucket tests. The test results show a more uniform water distribution over the floor than the simulation results. 
8.2.3.Comparison between the simulated results and the experimental results with the sprinkler system operating

In Figure $8-6$, the gas temperature drop due to the sprinkler system measured in the experiments (the $5 \mathrm{MW}$ fire with $50 \%$ fan speed) is compared with the temperature drop predicted by the simulations. Both the simulated and experimental results show that the cooling effect depends on the water spray rate.

The simulated results are in good agreement with test results. In the test with a water flow density of $61 / \mathrm{min} / \mathrm{m}^{2}$, the measured temperature drop in the spray section was irregular. The measured temperature drop downstream of the sprinkler system was similar to the simulated temperature drops.

In the simulations of water spray rate of $31 / \mathrm{min} / \mathrm{m}^{2}$, the simulated results with the mean droplet diameter of $900 \mu \mathrm{m}$ were slightly better than with the $750 \mu \mathrm{m}$ simulated results.

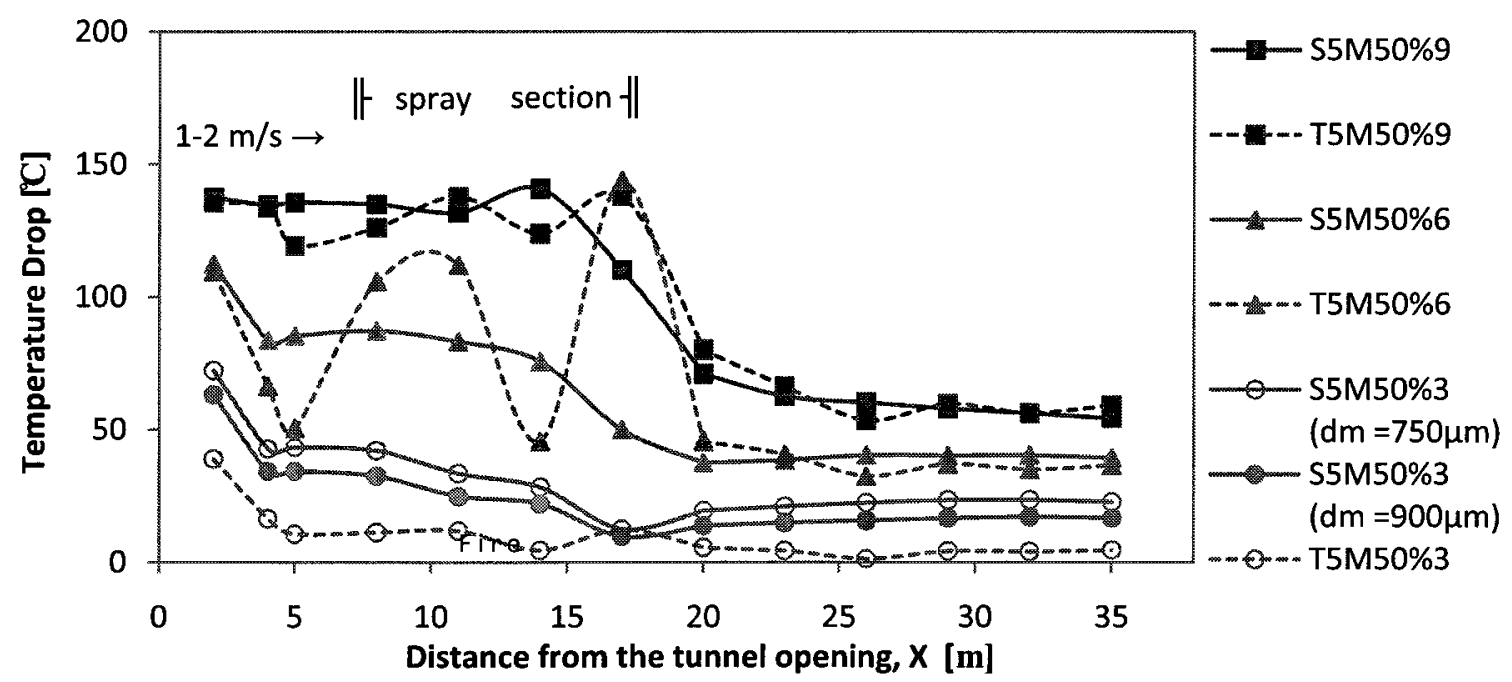

Figure 8-6 Ceiling temperature drops by the sprinkler system with different water flow densities The simulated vertical temperature profiles are compared with the temperatures measured at thermocouple trees $10 \mathrm{~m}$ upstream of the fire $(X=2 \mathrm{~m})$. The simulated results with 
water flow densities of 3 and $6 \mathrm{1} / \mathrm{min} / \mathrm{m}^{2}$ show good agreement with the test data (see Figure 8-7), but the simulated results with water flow density of $31 / \mathrm{min} / \mathrm{m}^{2}$ are lower than the test results.

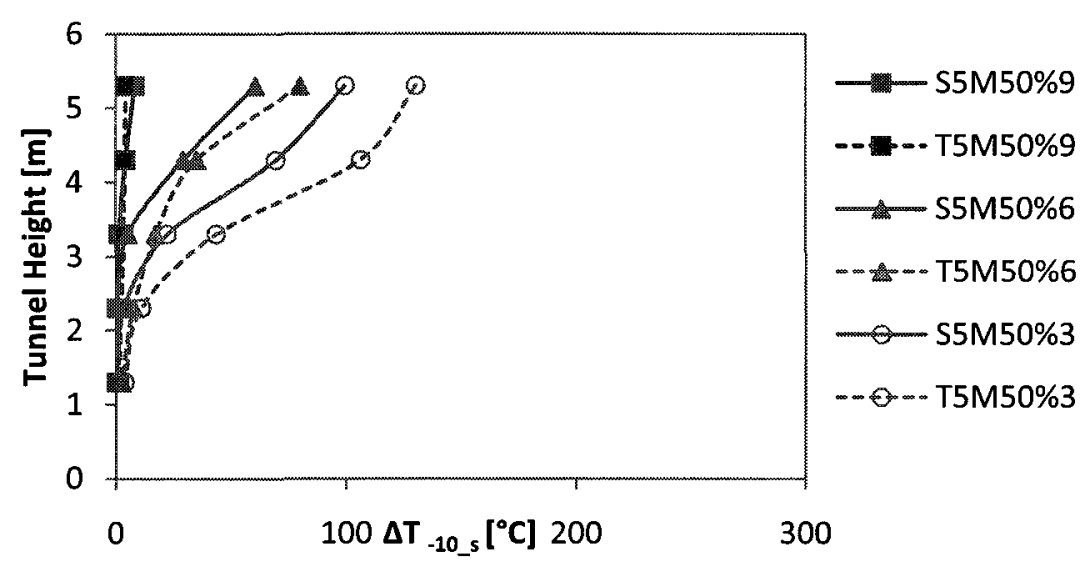

Figure 8-7 Vertical temperature profiles $10 \mathrm{~m}$ upstream with the suppression system operating with various water spray densities ( $5 \mathrm{MW}$ fire with $50 \%$ fan speed)

Figure 8-8 compares the simulated temperature results from both the model laboratory tunnel and the $53 \mathrm{~m}$ long tunnel with the measured data with the sprinkler system operating. The simulated temperature profiles $10 \mathrm{~m}$ upstream of the $10 \mathrm{MW}$ fire agree very well with the measurements. However, for large fires, the simulated temperature results from the $53 \mathrm{~m}$ long tunnel are found to be about $10-20 \%$ lower than the results from the model laboratory tunnel. This is because the air flow conditions in the tunnel affect the cooling effectiveness of the sprinkler system, and this influence is more apparent with the larger HRR. The simulation results from the large fire sizes of $25 \mathrm{MW}$ and $40 \mathrm{MW}$ from both the $53 \mathrm{~m}$ long tunnel and the model laboratory tunnel are included in the data analysis of the effect of the sprinkler system under longitudinal air flows discussed in Chapter 9. 


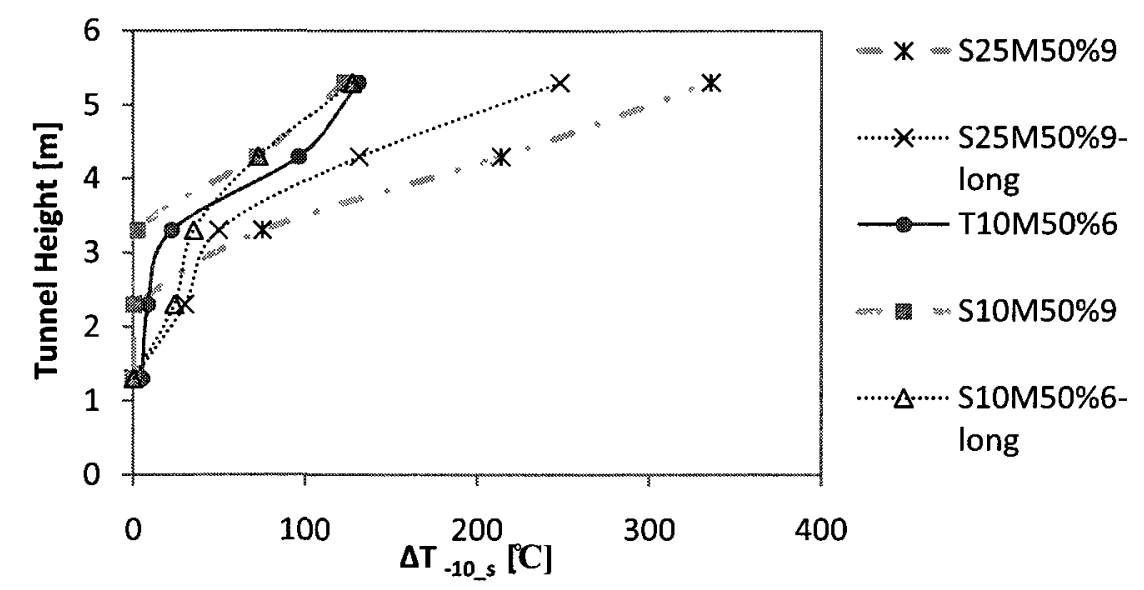

Figure 8-8 Vertical temperature profiles $10 \mathrm{~m}$ upstream with the suppression system operating with a water spray density of $6 \mathrm{l} / \mathrm{min} / \mathrm{m}^{2}$ (10 MW fire with $50 \%$ fan speed)

\subsection{Summary}

Using a CFD tool, the Fire Dynamics Simulator (FDS), selected full-scale suppression tests were simulated first to compare with the experimental data to verify the use of FDS in tunnel applications. Without the sprinkler system operating, there is good agreement between the simulated results and the measured data. The simulated results show the impact of the length of the inlet passage is minimal over the longitudinal temperature profile in the tunnel. In particular, the predicted maximum temperature agrees very well with the measured data. Thus, the results including the smoke backlayering found in the laboratory tunnel can be reasonably extrapolated to longer tunnels.

With suppression active, the simulations allowed us to visualize the conditions inside the tunnel and to observe the interaction of water droplets and the smoke flow in the tunnel. The air flows affected the spray distribution in the spray zone. Simulations of the complex interaction of water droplets and smoke flow were affected by many factors, such as water flow rates, spray characteristics, water droplet sizes and distributions. 
However, there is not enough information available to determine these spray characteristics for most of WFFFS.

As the fire scenario used in this study did not require the modelling of the suppression effect of the sprinkler system, the simulated temperature results showed a relatively good agreement with test data. Therefore, FDS can be used with some level of confidence to calculate the conditions in a tunnel in case of fires with defined HRR with both ventilation and suppression system operating [90]. 


\section{CHAPTER 9. THE EFFECT OF THE USE OF WFFFS AND LONGITUDINAL VENTILATION SYSTEMS IN TUNNELS}

The suppression test program of the current study was carried out to investigate how the ventilation and suppression systems affect the temperature distribution and the heat and smoke spread in the tunnel. The absolute cooling effect and radiation attenuation were examined by activating the sprinkler system over a propane fire which generated a constant HRR. The conditions generated by the test represent the situation when the suppression system successfully arrests the development of a fire and limits the HRR to that at the time of activation. As briefly discussed in Chapter 6.5, the sprinkler system reduced the degree of backlayering, and significant cooling and radiation attenuation were observed. Analyses were carried out to find methods to estimate these effects by both the sprinkler system and the longitudinal ventilating system. Data obtained from the suppression test program and CFD simulation program were analysed. Experimental data available from previous tunnel tests were also used in the analyses.

This chapter discusses the following;

- Analysis of the cooling effect of both sprinkler and ventilation systems

- Analysis of the impact of the sprinkler system on the effectiveness of the longitudinal ventilation system

- Analysis of radiation attenuation by the sprinkler system 


\subsection{Analysis of the cooling effect of the sprinkler system under longitudinal airflows}

The maximum gas temperature near the tunnel ceiling was analyzed to identify the thermal intensity that the tunnel structure would experience from tunnel fires. The cooling effect of the sprinkler system along with longitudinal air flows was correlated with the water spray densities and longitudinal air velocities.

\subsubsection{Temperature and fire}

The test data from the previous research that include large fire tests in the Runehamar tunnel and the small-scale study by SP are plotted in Figure 9-1. Details of each test conditions are summarised in Table 9-1, and Chapter 2.2 describes these projects in detail. Note that the maximum temperatures obtained during suppression in the SP small-scale tests are also included in the figure. The maximum gas temperatures near the tunnel ceiling (without the sprinkler system operating) obtained from the test program of the present study are also plotted in the figure.

Although the data are obtained from various tests with different cross-sectional areas and different air flows in the tunnel, the maximum temperature without the suppression system operating can be approximately correlated with HRR (see the dotted line in Figure 9-1). Some data appear to be scattered about the graph. The data obtained from tests that used a high air velocity $(4-6 \mathrm{~m} / \mathrm{s})$ in the tunnel showed low temperature values. The tunnel cross-sectional area also affects the temperature results (e.g. Repparfjord tunnel with a cross-section area of $25 \mathrm{~m}^{2}$ ). In addition, whether the fire is shielded or not also affects the temperature. 
The temperature increases with the increase of $\mathrm{HRR}$ and levels off at about $1300^{\circ} \mathrm{C}$ (flame temperature) when the HRR is greater than about $100 \mathrm{MW}$. This indicates that for large fires the flame touches the ceiling as the combustion takes up a large volume in the tunnel. The limiting HRR is actually variable depending on the fuel type, arrangement and cross sectional area of the tunnel. One can see that this pattern is similar to the correlation of critical velocity with respect to Q (see Figure 2-3). This is because the velocity required to prevent the backlayering of the smoke is directly related to the temperature that is driving the smoke to propagate.

If the flame does not reach the tunnel ceiling, the maximum ceiling temperature $\left(T_{\max }\right)$ for the same size of fire varies depending on the ceiling height and ventilation conditions as well as the cooling effect by WFFFS if the fire is during suppression. Thus, to accurately estimate $T_{\max }$, it is necessary to develop a method that considers the effects of various ventilation conditions as well as cooling by water sprays. 


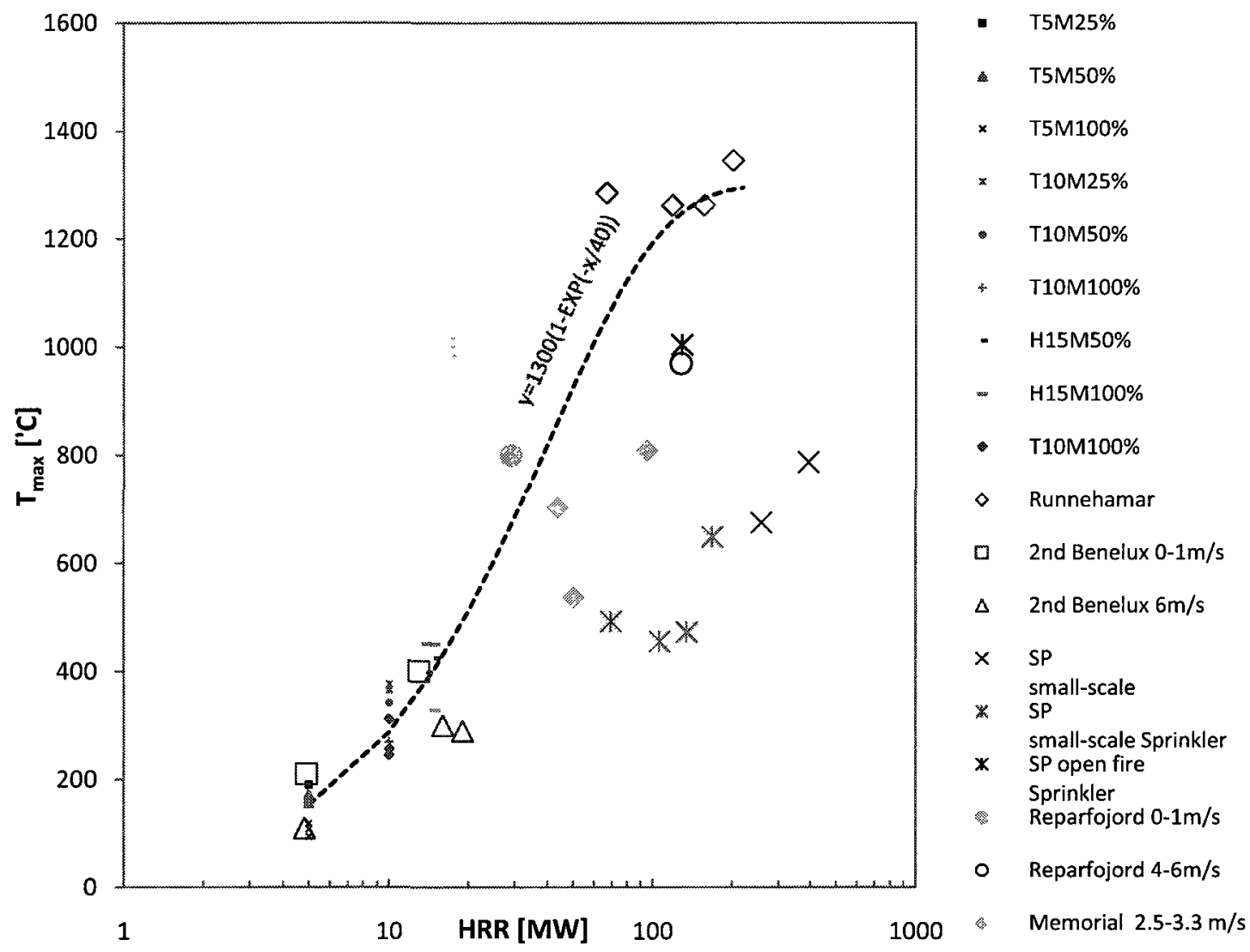

Figure 9-1 Temperature with respect to HRR 
Table 9-1 Summary of previous tunnel fire tests

\begin{tabular}{|c|c|c|c|c|c|c|c|}
\hline & $\begin{array}{l}\text { Area } \\
{\left[\mathrm{m}^{2}\right]} \\
\end{array}$ & $\begin{array}{l}\text { Hydraulic } \\
\text { height }[\mathrm{m}]\end{array}$ & Test ID & Fire scenario & $\begin{array}{c}\text { Peak } \\
\text { HRR } \\
\text { [MW] }\end{array}$ & $\begin{array}{c}\text { Air velocity } \\
{[\mathrm{m} / \mathrm{s}]}\end{array}$ & $T_{\max }$ \\
\hline \multirow{3}{*}{$\begin{array}{l}\text { Reparfojord } \\
{[32,33,34]}\end{array}$} & 25.0 & 5.0 & & Bus & 29 & 0.3 & $800^{*}$ \\
\hline & 25.0 & 5.0 & & simulated HGV, shielded & 17 & 0.5 & $1000^{*}$ \\
\hline & 25.0 & 5.0 & & Real trailer and furniture & 128 & 3.6 & $970^{*}$ \\
\hline \multirow{4}{*}{$\begin{array}{l}\text { Runnehamar } \\
\text { [38] }\end{array}$} & 54.0 & 7.2 & T4 & shielded, Cartons and PXcups & 67 & 3 & 1285 \\
\hline & 54.0 & 7.2 & T3 & shielded, furniture and fixture & 119 & 3 & 1262 \\
\hline & 54.0 & 7.2 & $\mathrm{~T} 2$ & mattresses & 157 & 3 & 1262 \\
\hline & 54.0 & & $\mathrm{~T} 1$ & $\begin{array}{l}\text { shielded, wood and plastic } \\
\text { pallets }\end{array}$ & 202 & 3 & \\
\hline \multirow{5}{*}{$\begin{array}{l}\text { 2nd Benelux } \\
{[35,37]}\end{array}$} & 50.0 & 6.7 & 6 & Passenger car & 5 & $0-1$ & $210^{*}$ \\
\hline & 50.0 & 6.7 & 7 & Passenger car & 5 & 6 & $110^{*}$ \\
\hline & 50.0 & 6.7 & 8 & shieldedwood pallets & 13 & $0-1$ & $400^{*}$ \\
\hline & 50.0 & 6.7 & 9 & shieldedwood pallets & 19 & 6 & $290^{*}$ \\
\hline & 50.0 & 6.7 & 10 & shieldedwood pallets & 16 & 6 & $300^{*}$ \\
\hline \multirow{3}{*}{$\begin{array}{l}\text { Memorial } \\
{[44,47]}\end{array}$} & 60.2 & 7.7 & $612 B$ & open pool & 44 & 2.4 & $700^{\star}$ \\
\hline & 60.2 & 7.7 & $624 \mathrm{~B}$ & open pool & 50 & 2.9 & $540^{*}$ \\
\hline & 60.2 & 7.7 & $621 \mathrm{~A}$ & open pool & 95 & 3.3 & $810^{*}$ \\
\hline \multirow{2}{*}{$\begin{array}{l}\text { SP } \\
\text { small-scale } \\
{[56]} \\
\end{array}$} & 43.2 & 6.2 & 8 & Shielded wood cribs & 259 & 3.0 & $675^{\star \star}$ \\
\hline & 43.2 & 6.2 & 6 & Shielded wood cribs & 391 & 3.0 & $787^{\star *}$ \\
\hline \multirow{6}{*}{$\begin{array}{l}\text { SP } \\
\text { small-scale } \\
\text { Sprinkler } \\
\\
{[56]}\end{array}$} & 43.2 & 6.2 & 1 & $\begin{array}{l}\text { Shielded wood cribs } \\
\text { water } 5 \mathrm{l} / \mathrm{min} / \mathrm{m} 2\end{array}$ & 135 & 3.0 & $472^{\star \star}$ \\
\hline & & & & Shielded wood cribs & & & \\
\hline & 43.2 & 6.2 & 2 & water $7 \mathrm{l} / \mathrm{m} ı \mathrm{n} / \mathrm{m} 2$ & 106 & 3.0 & $455^{\star \star}$ \\
\hline & 43.2 & 6.2 & 3 & $\begin{array}{l}\text { Shielded wood cribs } \\
\text { water } 3.5 \mathrm{l} / \mathrm{min} / \mathrm{m} 2\end{array}$ & 168 & 3.0 & $648^{\star *}$ \\
\hline & 43.2 & 6.2 & 4 & $\begin{array}{l}\text { Shielded wood cribs } \\
\text { water } 5 \mathrm{l} / \mathrm{min} / \mathrm{m} 2\end{array}$ & 70 & 2.0 & $491^{\star \star}$ \\
\hline & 43.2 & 6.2 & 5 & $\begin{array}{l}\text { Open wood cribs } \\
\text { water } 5 \mathrm{l} / \mathrm{min} / \mathrm{m} 2\end{array}$ & 129 & 3.0 & $1004^{\star \star}$ \\
\hline
\end{tabular}

Note: * Approximate values

$$
\text { ** } \Delta T_{\max }
$$

\subsubsection{Theoretical consideration}

Under longitudinal ventilation, the flame becomes tilted toward the direction of air flow, so is the hot gas rising from the flame impinging the ceiling. This pattern of the plume affected by the ventilation flow can be characterized by the Richardson number (Ri) of 
the plume and the longitudinal air flow that pushes the plume. The Ri calculated using Eq 57 [108], characterizes the ratio of the buoyancy of the hot flow to the momentum of the flow with a layer depth D. $\rho_{0}$ is density of ambient air, and $\rho$ is density of the hot flow.

$$
\mathrm{Ri}=\frac{g\left(\rho_{0}-\rho\right) D}{\rho V^{2}}=\frac{\Delta T g D}{T_{o} V_{p}^{2}}
$$

When there is no suppression system operating, the local smoke velocity $\left(V_{p}\right)$ is mainly governed by $\mathrm{Q}$ as well as the geometry of the tunnel since the driving force of the hot flow is the buoyancy of the plume. Thomas [109] correlated the horizontal velocity of the smoke flow as a function of $\mathrm{Q}^{1 / 3}$. If the flame reaches the ceiling, the velocity of the smoke flow becomes independent of $\mathrm{Q}$ because the ceiling temperature is the flame temperature. From a critical velocity study done by $\mathrm{Wu}$ and Baker [18], this happens when the dimensionless $\frac{\mathrm{Q}}{\mathrm{P}_{\mathrm{o}} \mathrm{C}_{\mathrm{p}} \mathrm{T}_{\mathrm{o}} \mathrm{g}^{1 / 2} \overline{\mathrm{H}}^{5 / 2}}$ is greater than 0.2 . Thus, $\mathrm{Ri}^{*}$ can be correlated with the ventilation condition since $\mathrm{Ri}^{*}$ of the tilted plume is a result of the longitudinal air flow $\left(\mathrm{V}^{*}\right)$. Ultimately, $\frac{\Delta T_{\max }}{T_{\mathrm{o}}}$ can be obtained as a function of $\mathrm{Q}^{* 2 / 3}$ and $\mathrm{V}^{*}$.

$$
\begin{gathered}
\qquad \mathrm{Ri}^{*} \Rightarrow \frac{\Delta T_{\max }}{T_{\mathrm{o}} Q^{* 2 / 3}} \text { VS. } \mathrm{V}^{*} \\
\text { where } \mathrm{Q}^{*}=\frac{\mathrm{Q}}{\rho_{\mathrm{o}} \mathrm{C}_{\mathrm{p}} \mathrm{T}_{\mathrm{o}} \mathrm{g}^{1 / 2} \overline{\mathrm{H}}^{5 / 2}} \\
\text { if } \frac{\mathrm{Q}}{\rho_{\mathrm{o}} \mathrm{C}_{\mathrm{p}} \mathrm{T}_{\mathrm{o}} \mathrm{g}^{1 / 2} \overline{\mathrm{H}}^{5 / 2}}>0.2, \mathrm{Q}^{*}=0.2 \\
V^{*}=\mathrm{V} / \sqrt{g \bar{H}}
\end{gathered}
$$


Using a similar approach, Kurioka [110] developed a model to predict $\frac{\Delta T_{\max }}{T_{0}}$ based on $Q^{*}$ and Froude number, Fr. For unsuppressed fires, the following model is proposed, which is empirically found based on small-scale test data obtained from various geometries of model tunnels ( $1 / 10$ and $1 / 2$ scales). Note that the height from the surface of fire source to tunnel ceiling $(\mathrm{H})$ was used instead of the hydraulic height of the tunnel $(\bar{H})$ in the model.

$$
\begin{array}{ll}
\frac{\Delta T_{\max }}{T_{\mathrm{o}}}=1.77\left(Q^{* 2 / 3} / \mathrm{Fr}^{1 / 3}\right)^{6 / 5} & \text { when }\left(Q^{* 2 / 3} / \mathrm{Fr}^{1 / 3}\right)<1.35 \\
\frac{\Delta T_{\max }}{T_{\mathrm{o}}}=2.54 & \text { when }\left(Q^{* 2 / 3} / \mathrm{Fr}^{1 / 3}\right)>1.35 \\
& \text { where } \quad \mathrm{Fr}=\mathrm{V}^{2} / \mathrm{gH}
\end{array}
$$

The intensity of the air flow against the plume buoyancy, however, should be properly treated considering the relative effect on the plume. Therefore, considering the relative velocity to the fire size, $\frac{\mathrm{V}^{*}}{\mathrm{Q}^{*}}$, the following relation can be found.

$$
\frac{\Delta T_{\max }}{T_{o}}=f\left(\mathrm{Q}^{* 2 / 3}, \frac{\mathrm{V}^{*}}{\mathrm{Q}^{*}}\right)
$$

9.1.3. Maximum ceiling temperature without a suppression system operating With the data obtained from the suppression test program and the FDS simulations of the present study, $\frac{\Delta T_{\max }}{T_{\mathrm{o}}}$ without the sprinkler system operating are analysed. A correlation with $Q^{* 2 / 3},\left(\frac{V^{*}}{Q^{*}}\right)^{1 / 3}$ is found as below, based only on the test data, yet the simulated 
results also follow the correlation. Figure 9-2 compares the estimation by the correlation with the data.

$$
\frac{\Delta T_{\max }}{T_{o}}=9.94\left[\frac{Q^{* 2 / 3}}{\left(V^{*} / Q^{*}\right)^{1 / 3}}\right]^{1.04}=10\left[\frac{Q^{*}}{V^{* 1 / 3}}\right]
$$

Then, $T_{\max }$ data available from the previous full-scale tests and small-scale tests are also plotted in the figure to see these data from other studies fit to the correlation. These data came from a wide range fire sizes (5 MW-390 MW) and longitudinal air velocities (up to $6 \mathrm{~m} / \mathrm{s}$ ). For large fires, if the calculated $\frac{\mathrm{Q}}{\mathrm{P}_{\mathrm{o}} \mathrm{C}_{\mathrm{p}} \mathrm{T}_{\mathrm{o}} \mathrm{g}^{1 / 2} \overline{\mathrm{H}}^{5 / 2}}$ is greater than 0.2 , the asymptotic value of $Q^{*}, 0.2$, is used.

Despite the various geometries of the tunnels and test conditions used in the previous studies, the data are well correlated by $\frac{Q^{*}}{V^{* 1 / 3}}$. Full-scale test data from the $2^{\text {nd }}$ Benelux tunnel sit on the correlation line. However, some data deviate considerably, especially at higher values of $\frac{\Delta T_{\max }}{T_{o}}$. This is because $T_{\max }$ is the flame temperature, not the gas temperature in the case when $\frac{Q}{\rho_{0} C_{p} T_{o} g^{1 / 2} \bar{H}^{5 / 2}}$ is greater than 0.2 .

The model by Kurioka was also tested on the data set. As shown in Figure 9-3, it appears that the model predictions are weak, and it overestimates $\Delta T_{\text {max }}$ because open fires were used in Kurioka. In conclusion, the model developed in the present study gives better prediction than earlier models 


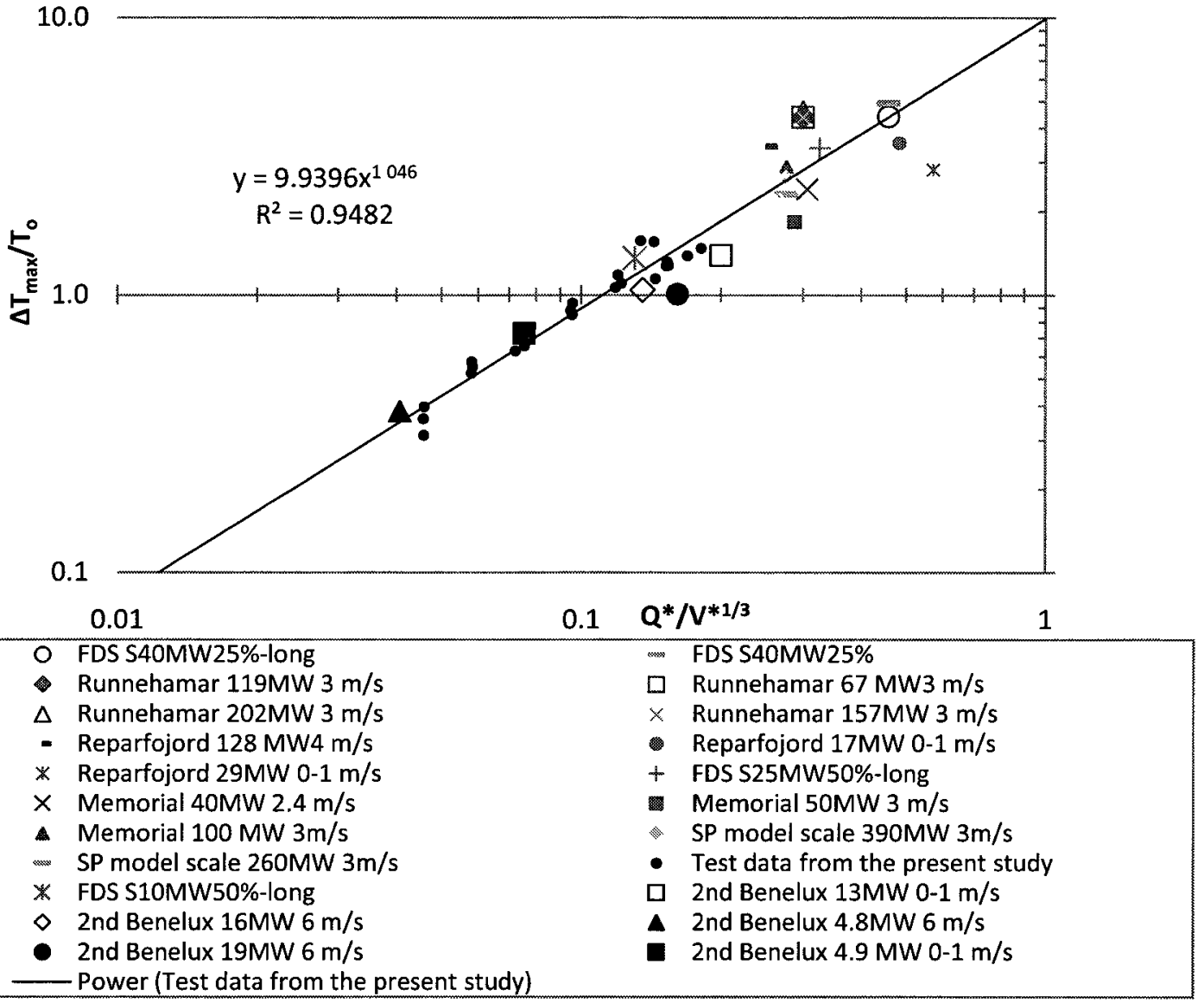

Figure 9-2 Maximum ceiling temperature without water sprays as a function of $Q^{*}, V^{*}$
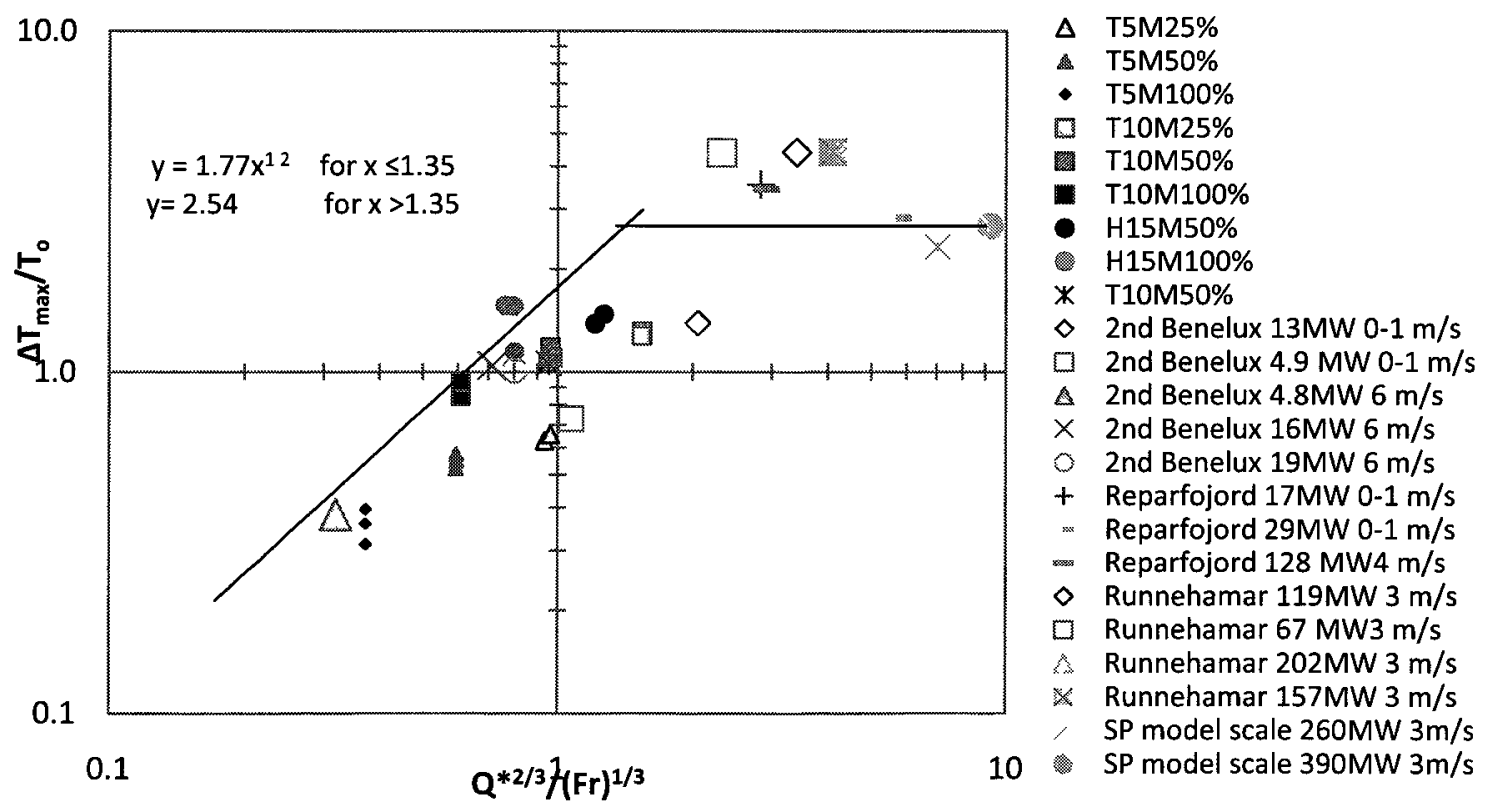

Figure 9-3 A comparison with the model by Kurioka 
9.1.4. The maximum ceiling temperature with a suppression system operating In general, the spray characteristics of WFFFS, such as the water spray rate, the discharge pressure and droplet sizes, mainly govern the cooling effect of the system. As discussed in the bucket test results (Chapter 6.4), the droplet dispersion by the longitudinal air flow also affects the spray characteristics. The effective interaction of water droplets and hot gases can occur when the temperature of the plume is high in a wind-free, enclosed space. It has been observed in Chapter 7 that the rate of evaporation depends on the water spray rate as well as the longitudinal air velocity. When a large water flow rate was tested under a fan speed of $25 \%$, considerable evaporation occurred.

Since taking the factors discussed above into consideration is very complicated, we consider only the main factors that affect the cooling effect of the sprinkler system used in the present study. The factor of $\frac{Q^{*}}{V^{* 1 / 3}}$, which is found from the analysis of the maximum temperature without the suppression system operating, is considered since the factor includes the effect of air velocity on the temperature. The cooling effect of the sprinkler system is proportional to the water spray density $(\omega)$ and the gas temperature. Thus, a factor of $\omega Q^{* 2 / 3}$ is considered in the analysis since the temperature of the horizontal smoke flow can be correlated with $\mathrm{Q}^{2 / 3}[109]$.

Finally, the maximum ceiling temperature in the case with the suppression system operating can be found as a function of $\frac{Q^{*}}{V^{* 1 / 3}}$ and $\omega Q^{* 2 / 3}$. 


$$
\frac{\Delta T_{\max \_s}}{T_{o}}=f\left(\frac{Q^{*}}{V^{* 1 / 3}}, \omega Q^{* 2 / 3}\right)
$$

The maximum ceiling temperature data obtained during suppression from the suppression test program and the FDS simulations are plotted in Figure 9-4, and a correlation is found based on the data from the present study.

$$
\frac{\Delta T_{\max \_s}}{T_{o}}=23.5\left[\frac{Q^{*}}{V^{* 1 / 3}\left(\omega Q^{* 2 / 3}\right)^{1 / 3}}\right]^{1.642}=23.5\left[\frac{Q^{* 7 / 9}}{\left(\omega V^{*}\right)^{1 / 3}}\right]^{8 / 5}
$$

The model was tested using the test data from the SP small-scale experiments. The maximum temperature data measured during suppression sit in the vicinity of the correlation line. However, further validation is necessary. This correlation is only valid within the range of tested fire sizes (5-40 MW), water spray densities (3-9 $\left.1 / \mathrm{min} / \mathrm{m}^{2}\right)$ and air velocities $(0.5-3 \mathrm{~m} / \mathrm{s})$. It can be only applied for a similar type of sprinkler system.

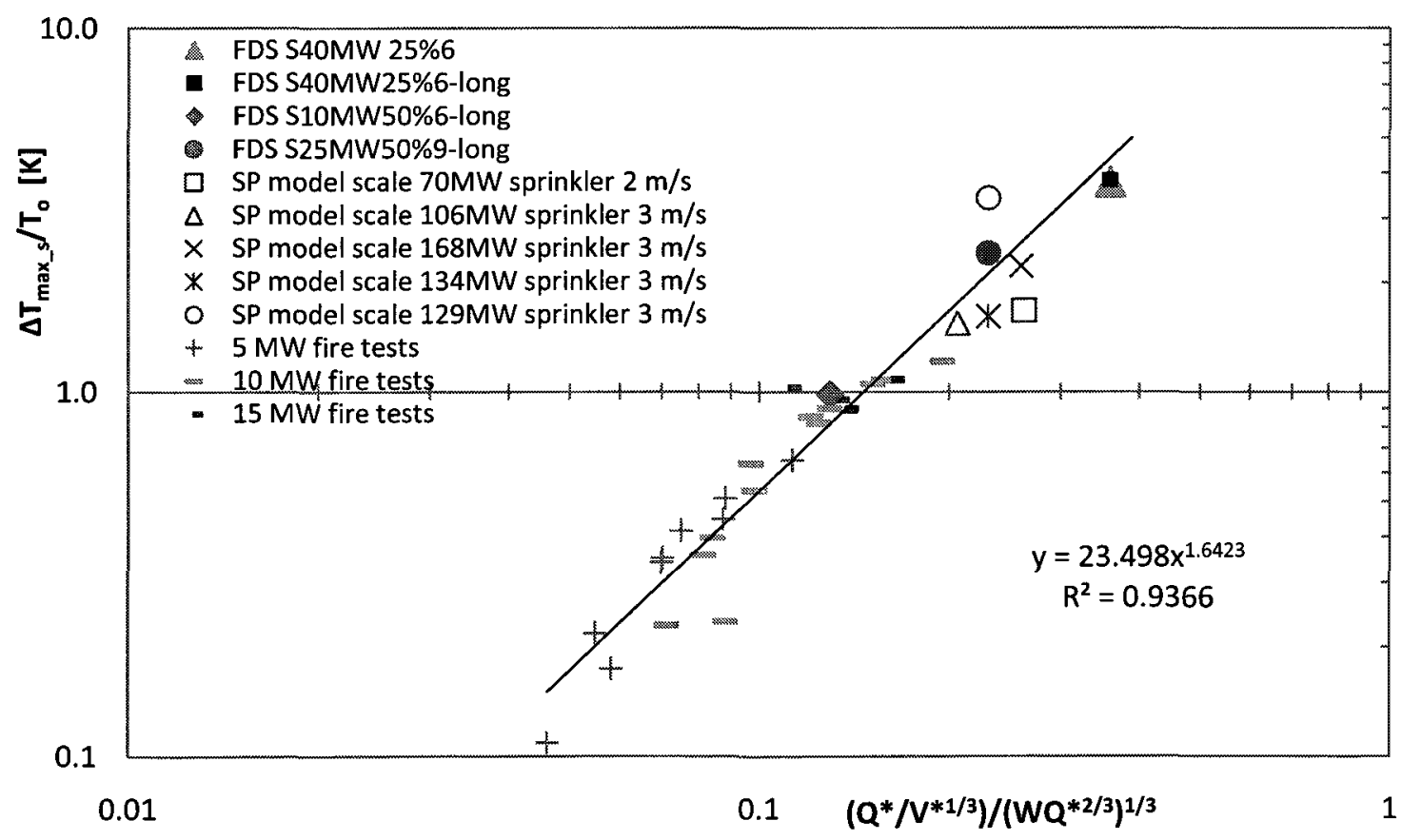

Figure 9-4 Maximum ceiling temperature during suppression 


\subsubsection{Ceiling temperatures downstream of the fire}

As smoke disperses along the length of tunnels, temperature gradually decreases due to some mixing with air and heat losses to the boundary. While longitudinal ventilation systems are effective in cooling gases, the cooling effect is more significant when both systems were used. In Chapter 6.5.2, the results of the ceiling temperature profile have been presented.

The ceiling temperature $21 \mathrm{~m}$ downstream of the fire from the suppression test program is plotted in Figure 9-5. The temperature $21 \mathrm{~m}$ downstream of the large fires obtained from the simulation program are also plotted. The test results of $\frac{\Delta T_{+21} s}{T_{o}}$ are well correlated by the same factors of $\frac{Q^{*}}{V^{* 1 / 3}}$ and $\omega Q^{* 2 / 3}$, which are used in the analysis of the maximum ceiling temperature during suppression. The figure shows that $\frac{\Delta T_{+21 \_} s}{T_{o}}$ increases with the increases of $\frac{Q^{* 7 / 9}}{\left(\omega V^{*}\right)^{1 / 3}}$; however, when $\frac{Q^{* 7 / 9}}{\left(\omega V^{*}\right)^{1 / 3}}$ reaches a certain value, the temperature jumps up. This is because the flame of these large fires extends along the ceiling, toward the direction of the air flow. The values of $\mathrm{Q}^{*}$ are 0.2 in these data set from the FDS simulations and the SP small-scale tests. 


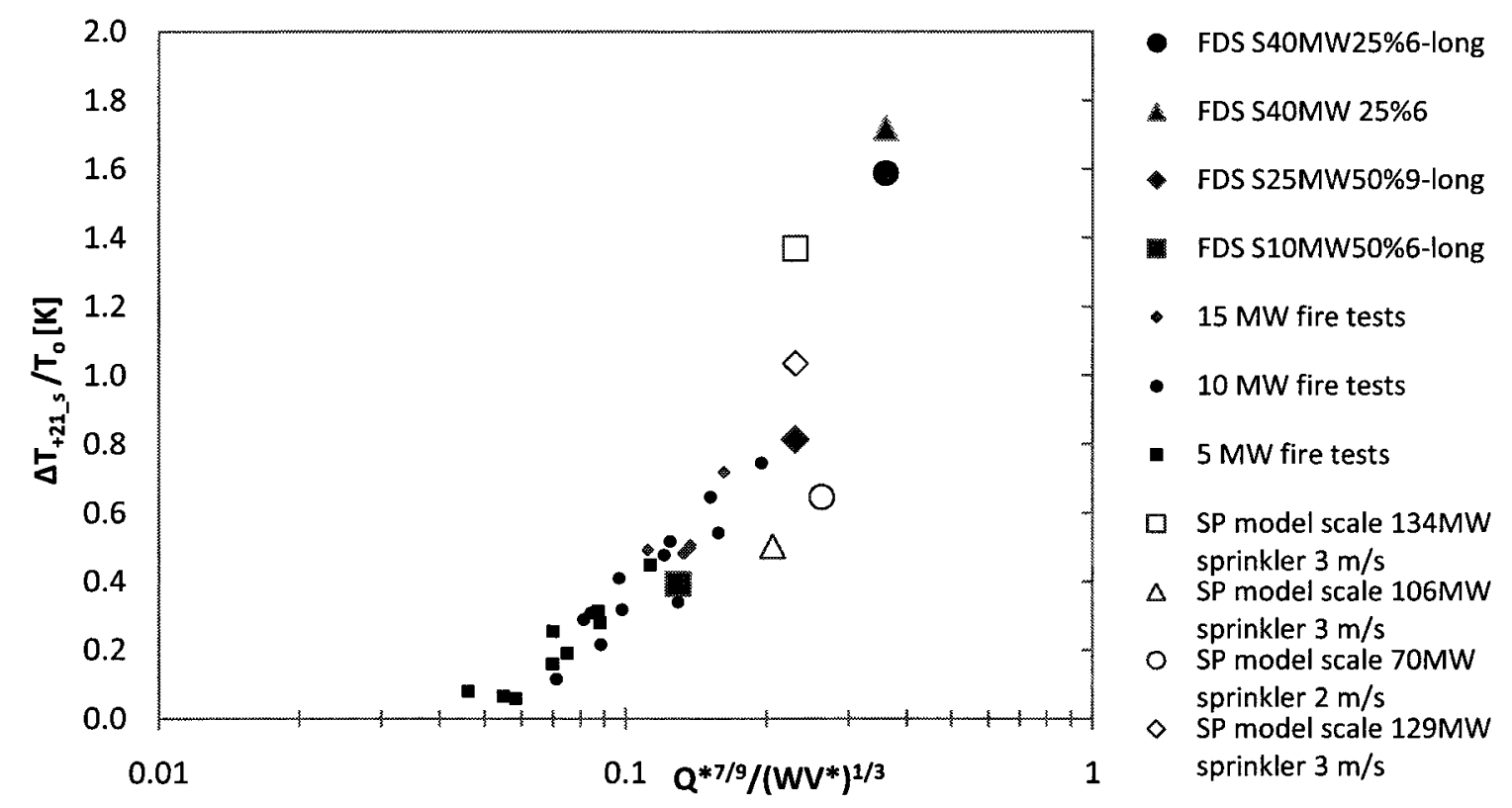

Figure 9-5 Ceiling temperature $21 \mathrm{~m}$ downstream of the fire with the sprinkler system operating

\subsection{Analysis of the impact of sprinkler systems on the effectiveness of the longitudinal ventilation systems}

The temperature results from the suppression test program show that the degree of backlayering diminished with the sprinkler system operating. This means that the wellestablished current method to estimate the critical velocity is not applicable when WFFFS is used. The driving force to propagate smoke is the buoyancy force from the hot plume. As the sprinkler system cools the temperature of the plume, it could be expected that the driving force to propagate smoke decreases, thus enabling the longitudinal ventilation system to prevent backlayering of smoke with a lower velocity than the critical velocity.

In this section, an analysis of temperature data $10 \mathrm{~m}$ upstream of the fire was performed to correlate the degree of backlayering with the given conditions of air velocity, water spray density and fire size. 


\subsubsection{Methodology}

Under natural ventilation, the plume generated from a fire in a tunnel impinges the ceiling and flows underneath the tunnel ceiling. Characteristics of the smoke spreading along the tunnel can be related to the plume running under a horizontal obstruction or through a channelled horizontal passage. The Richardson number of the plume crawling under a horizontal obstruction decreases as the smoke flows away from the fire [111]. This is because the horizontal velocity of the hot flow $\left(V_{p}\right)$ increases as the buoyancy of the plume transforms into horizontal momentum due to the presence of the horizontal obstruction.

When there is a longitudinal air flow against the smoke flow, the movement of hot flow upstream of the fire is resisted by the longitudinal air flow. The degree of backlayering depends on the ratio of the ventilation velocity to the critical air velocity $\left(\frac{\mathrm{v}}{\mathrm{V}_{\mathrm{c}}}\right)$. If the ventilation velocity is greater than the critical velocity, there would be no backlayering. In general, backlayering is determined whether the smoke is contained within $11-12 \mathrm{~m}$ upstream of the fire [50]. Therefore, a correlation can be obtained between the local Ri

of the hot flow about $10 \mathrm{~m}$ upstream of the fire and the ventilation condition $\left(\frac{\mathrm{v}}{\mathrm{V}_{\mathrm{c}}}\right)$. The degree of backlayering can be expressed as the temperature rise, which is measured $10 \mathrm{~m}$ upstream of the fire $\left(\Delta T_{-10}\right)$, normalized to the ambient temperature, $\frac{\Delta T_{-10}}{T_{\mathrm{o}}}$ that can be found from the correlation between $\mathrm{Ri}$ and $\frac{\mathrm{V}}{\mathrm{V}_{\mathrm{c}}}$.

$$
R i^{*} \Rightarrow \frac{\Delta T_{-10}}{\mathrm{~T}_{0} \mathrm{Q}^{* 2 / 3}} \quad \text { VS. } \quad \frac{\mathrm{V}}{\mathrm{V}_{\mathrm{c}}}
$$


A similar approach can be taken when there is a suppression system operating. The resulting $\mathrm{Ri}^{*}$ of the flow, which is induced from the fire and cooled by passing through the suppression section over the fire area, can be also correlated with the ventilation condition. Therefore, the degree of backlayering expressed as the temperature rise normalized to the ambient temperature, $\frac{\Delta T_{-10 s} s}{T_{\mathrm{o}}}$, can be found as a function of $V_{p}$ and ventilation condition, $\mathrm{V} / \mathrm{V}_{\mathrm{c}}$.

However, the local smoke velocity $\left(V_{p}\right)$, during suppression, depends on not only $\mathrm{Q}^{*}$ but also the cooling effect of the suppression system, which is governed by the water spray rate $(\omega)$ and droplet sizes. Ultimately, the degree of backlayering during suppression, $\frac{\Delta T_{-10_{-} s}}{T_{\mathrm{o}}}$, can be found as a function of $\mathrm{Q}^{*}, \omega$ and $\frac{\mathrm{V}}{\mathrm{V}_{\mathrm{c}}}$ since the cooling effect of the suppression system is mainly governed by the water discharge rate. $\Delta T_{-10_{-} s}$ is the temperature rise measured $10 \mathrm{~m}$ upstream of the fire with the sprinkler system operating.

$$
\frac{\Delta T_{-10_{-} s}}{T_{\mathrm{o}}}=\mathrm{f}\left(\mathrm{Q}^{*}, \omega, \frac{\mathrm{V}}{\mathrm{V}_{\mathrm{c}}}\right)
$$

\subsubsection{Backlayering without suppression}

The temperature increase measured at the location $10 \mathrm{~m}$ upstream of the fire without the sprinkler system operating $\left(\Delta T_{-10}\right)$ are collected from the suppression test program, and $\mathrm{Ri}^{*}$ of the plume are calculated using Eq 57 and Eq 2, and plotted with respect to $\mathrm{V} / \mathrm{V}_{\mathrm{c}}$ in Figure 9-6. Additional data obtained from FDS simulations and full-scale data from Runehamar, Reparforjord and Memorial tunnel tests also plotted. Details of these tests are given in Table 9-1. 
The resulting $\mathrm{Ri}^{*}$ of the backlayering smoke about $10 \mathrm{~m}$ upstream of the fire tends to decrease as $\mathrm{V} / \mathrm{Vc}$ increases. This is because of the low temperature rise measured at this location due to the air velocity that is strong enough to resist the smoke flow. For V/Vc greater than 1 , when the backlayering is not present, the calculated $\mathrm{Ri}^{*}$ of the plume at this location is less than about 2.5 .

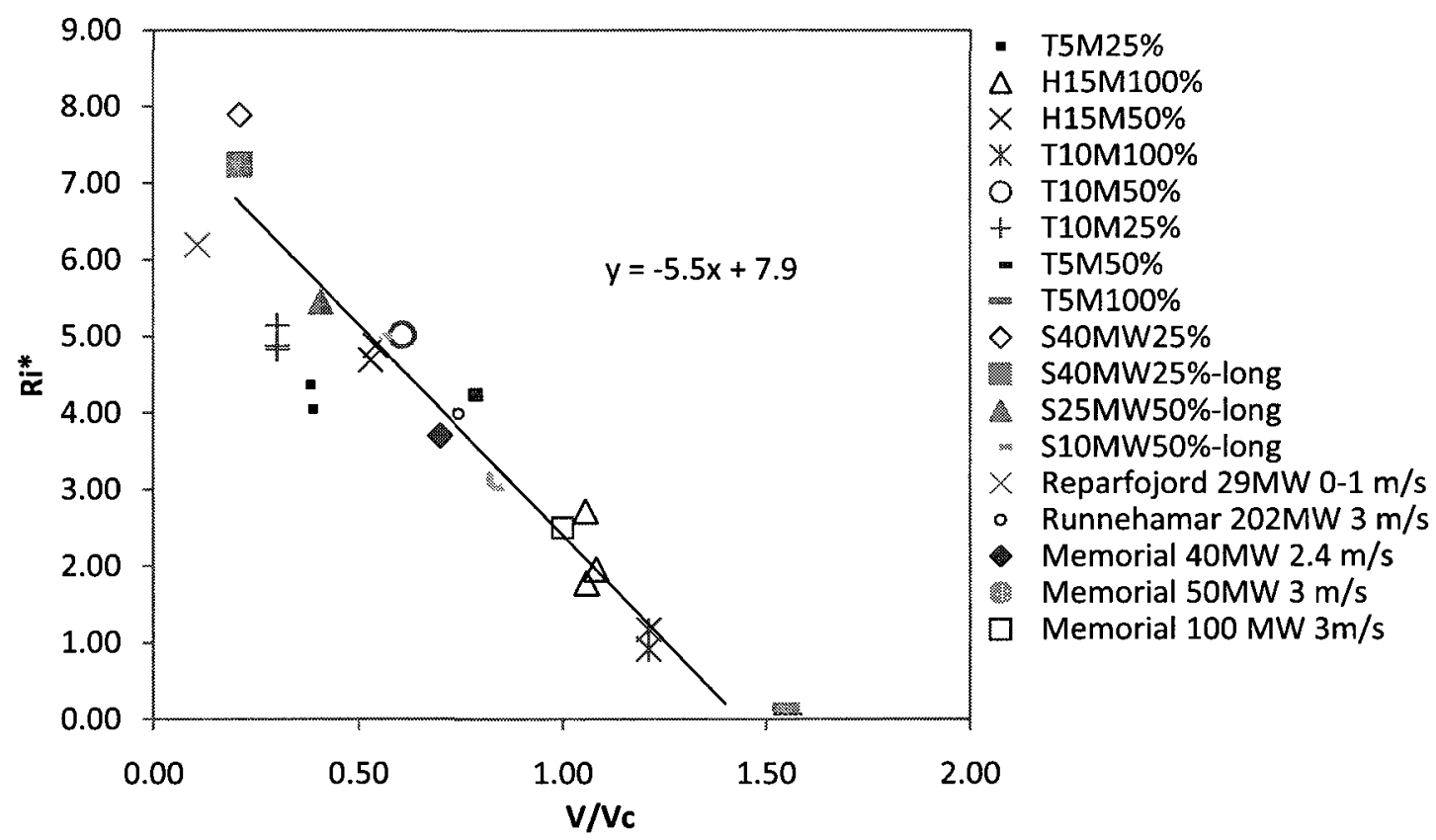

Figure 9-6 Ri* of smoke $10 \mathrm{~m}$ upstream of the fire with respect to $\mathrm{V} / \mathrm{V}_{\mathrm{c}}$

This proves that the local $\mathrm{Ri}^{*}$ of the hot flow about $10 \mathrm{~m}$ upstream of the fire is correlated with the ventilation condition, V/Vc. Therefore, we can further find an expression for the degree of backlayering $\frac{\Delta T_{-10_{-}}}{T_{\mathrm{o}}}$ as a function of $\mathrm{Q}^{*}, \omega$ and $\mathrm{V}^{*}$ during suppression

\subsubsection{Backlayering during suppression}

As it is shown that $\mathrm{Ri}^{*}$ is correlated with $\mathrm{V} / \mathrm{V}_{\mathrm{c}}$, we can similarly find an expression for the degree of backlayering, $\frac{\Delta T_{-10 s}}{T_{0}}$, during suppression. As $\mathrm{Ri}^{*}$ of the flow during 
suppression depends on the source fire and the cooling effect of the spray system, the degree of backlayering during suppression, $\frac{\Delta T_{-10 .}}{T_{\mathrm{o}}}$, would be a function of $\mathrm{Q}^{*}, \omega$ and $\frac{\mathrm{V}}{\mathrm{V}_{\mathrm{c}}}$.

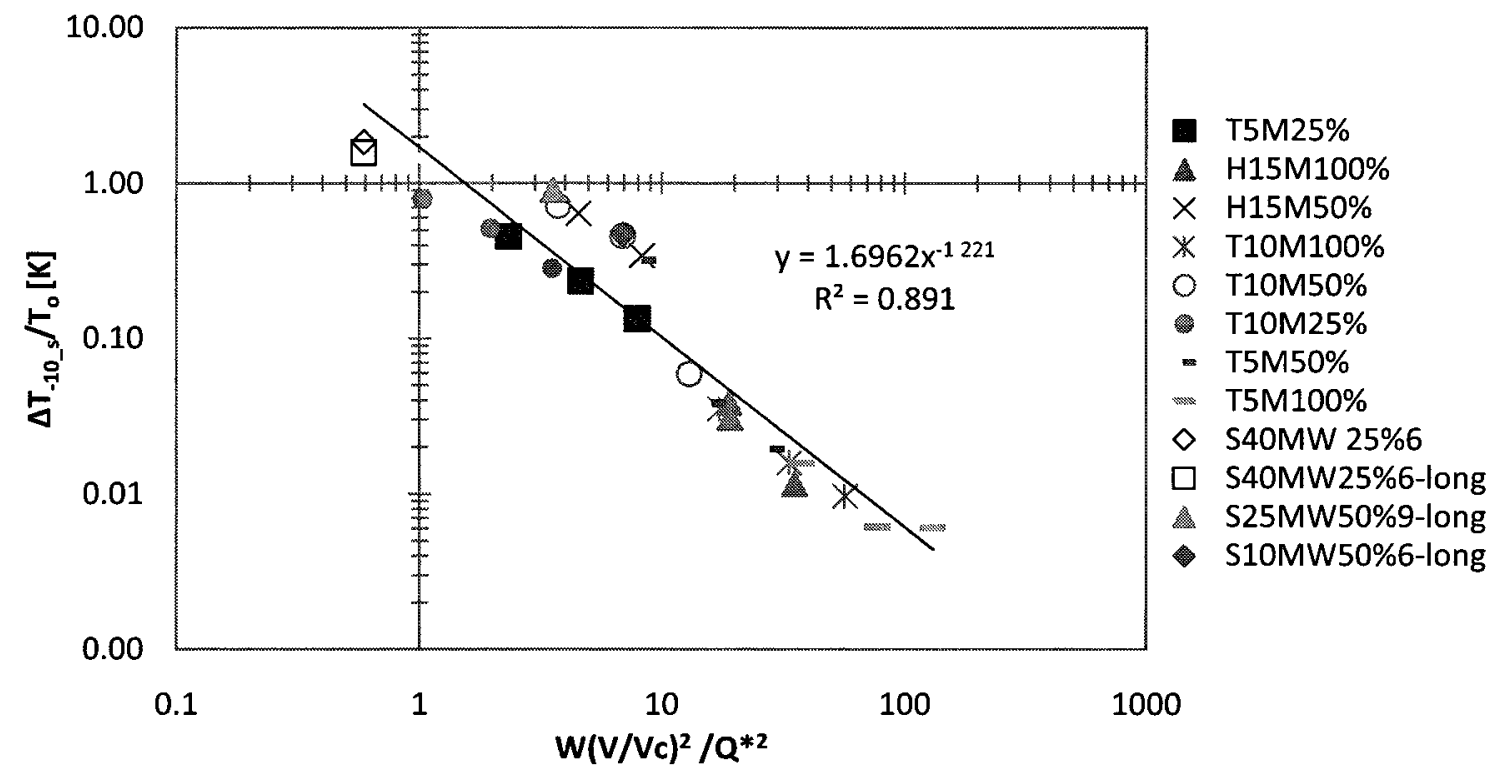

Figure 9-7 Backlayering during suppression as a function of $Q^{*}, \omega, V^{*}$

In Figure 9-7, using test data obtained from the experimental program and from the CFD simulation program of the present study, the degree of backlayering, $\frac{\Delta T_{-10 .}}{T_{0}}$, is correlated with the dimensionless source factor.

$$
\frac{\Delta T_{-10 \_s}}{T_{0}}=1.7\left(\frac{\omega\left(\mathrm{V} / \mathrm{V}_{\mathrm{c}}\right)^{2}}{\mathrm{Q}^{* 2}}\right)^{-1.2}
$$

If $\frac{\Delta T_{-10 s} s}{T_{\mathrm{o}}}>0.1$ is considered as a criterion to determine the presence of backlayering, from Eq 66, the critical source factor comprised of $Q^{*}, \omega$ and $\frac{v}{V_{c}}$ is 9 , which ensures no backlayering. For the source factor greater than the critical value, the cooling effect of spray system combined with the longitudinal air flow wins over the thermal buoyancy source so that the backlayering is minimal upstream area. The correlation can be used to 
determine whether there would be backlayering for a given fire size, water spray rate and wind velocity.

\subsection{Analysis of heat flux}

Assessment of radiative heat flux is important in tunnel fires to prevent fire spread that can result in a catastrophe. The distinguished advantage of WFFFS from ventilation systems is preventing fire spread due to radiation attenuation by the water droplets. Investigation of the effect of radiation attenuation by WFFFS requires accurate measurements of radiation heat flux.

However, the measurement of radiation heat flux is challenging due to the uncertainty associated with the measurement devices and limitations in measurement technologies in the application to the test condition of the present study. This section provides a brief review of radiation heat flux theory, measurements in mixed radiative-convective conditions as well as under water sprays. This section also discusses data analysis of radiation attenuation resulted from the experimental program.

\subsubsection{Methodology}

\section{Incident radiation heat flux ---Estimation of radiation heat flux}

When radiation hits a target (a solid material), the incident radiation is absorbed by the target and reflected on the surface. The incident radiation hitting the target surface from a fire source primarily depends on the emitting power of the radiating heat source, which is known to be proportional to $4^{\text {th }}$ power of the temperature of the radiating source $\left(T_{r}\right)$ and the emissivity of the source $(\varepsilon)$. The incident radiation also depends on the 
configuration of the radiating source (the flame shape) as well as the target's orientation (i.e. view factor or configuration factor, $\mathrm{F}_{\mathrm{f} \rightarrow \mathrm{t}}$ ).

$$
q^{\prime \prime}{ }_{\text {inc }}=\mathrm{F}_{\mathrm{f} \rightarrow \mathrm{T}} \varepsilon \sigma T_{r}^{4}
$$

If the source fire size is known, the radiation heat flux can be estimated assuming the fire is a point source. Radiation heat flux $\left(q^{\prime \prime}\right)$ at the distance $R$ from the point source [112] can be estimated assuming the target faces directly the centre of the flame. $Q_{r}$ is the rate that radiative heat is released from the source.

$$
q^{\prime \prime}{ }_{\text {inc }}=\frac{Q_{r}}{4 \pi R^{2}}
$$

$\underline{\text { Heat transfer in mixed convective and radiative environments }}$

In tunnel fires, the situation is likely to involve both radiation and convection, particularly, when a ventilation system generates air flows in the tunnel. In mixed radiativeconvective conditions, the total heat transfer to a target can be written as below [113].

$$
\dot{q}_{t}=a \dot{q}_{l n c}-\dot{q}_{e m i t}+h\left(T_{o}-T_{T}\right)=\varepsilon \dot{q}_{l n c}-\varepsilon \sigma T_{T}^{4}-h\left(T_{T}-T_{o}\right)
$$

$\dot{q}_{\text {emit }}$ is the radiative heat emitted by the target itself. Heat transfer by convection depends on the temperature gradient between the target surface and the air flow near the surface. The temperature of the air flow induced by the ventilation system is likely to be less than the target surface temperature. Thus, the air flow cools the target, and the cooling would increase with the increase in air velocity since the convective heat transfer coefficient depends on $\mathrm{Re}$ of the flow. 


\section{Radiation attenuation by water droplets}

Water droplets absorb and scatter radiation, and simultaneously, convective heat transfer takes place as water evaporates. Radiation transport through hot air mixed with water droplets and smoke is a complicated phenomenon. The estimation of radiation attenuation by water droplets requires rigorous calculation of the scattering and absorption processes over the spectrum that are functions of the wavelength, the droplet size, and the angle of the ray normal to the surface of the scattering droplet [114].

A simplified model suggested by Ravigururajan and Beltran [115] uses a wavelength averaged attenuation constant ( $\mathrm{K}$ the extinction coefficient) that is a function of droplet radius.

$$
\frac{q^{\prime \prime}}{q_{o}{ }^{\prime \prime}}=e^{-3 \mathrm{KMl} \ell / 4 r_{d} \rho_{w}}
$$

$q "$ and $q_{o} "$ are the outgoing and incoming radiant intensities, $\mathbb{M}$ is the mass of water per unit volume, $\ell$ is the path length, $r_{d}$ is the droplet radius, and $\rho_{w}$ is the water density. $\mathrm{K}$ is the sum of the scattering and absorption coefficients for the droplet.

This model suggests that the effect of radiation attenuation depends on water spray characteristics, such as water droplet size and droplet number density in the unit volume. Previous experiments [116-118] found that the radiation attenuation increased as the water discharge rate increased, and finer drops achieve higher attenuation than large drops. 
Thus, we can correlate the water spray densities with the fraction of radiation transmitted that is the ratio of incident radiation measured without water spray to that measured under spray.

$$
\frac{q_{i n c \_s}}{q_{i n c}} \text { VS. } \omega
$$

Measurements of heat flux

Rearranging Eq 69, the incident heat flux can be calculated based on the temperature of the target surface $\left(T_{\mathrm{T}}\right)$.

$$
q_{i n c}=\frac{\dot{q}_{t}+\varepsilon_{\mathrm{T}} \sigma T_{\mathrm{T}}^{4}+h\left(T_{\mathrm{T}}-T_{o}\right)}{\varepsilon_{\mathrm{T}}}
$$

In the case of a Gardon gauge, $T_{\mathrm{T}}$ is approximately the cooling water temperature. The sensor measures the temperature differences between the centre back of the sensor and water-cooled edge. Since the gauge is calibrated in the radiative environment, convective heat transfer becomes zero. The incident heat flux is directly proportional to the voltage signal generated by the temperature differences.

In the case of a plate thermometer, $T_{\mathrm{T}}$ is the temperature measurement by the plate thermometer. The total heat transfer to the plate is a combination of transient heat stored in the Inconel metal plate and the heat losses that include conduction loss through the plate thermometer [119] .

$$
\dot{q}_{t}=\dot{q}_{\text {cond }}+\dot{q}_{\text {stor }}=K_{\text {cond }}\left(T_{P T}-T_{o}\right)+\rho_{s t} c_{s t} \delta_{s t} \Delta \mathrm{T}_{\mathrm{PT}} \Delta \mathrm{t}
$$


Thus, the incident heat flux hitting the plate thermometer can be calculated if conduction correction factors $K_{\text {cond }}$, the convective heat transfer coefficient h, and given material properties of the metal plate are known.

The conduction correction factor $K_{\text {cond }}$ varies depending upon experimental set-ups since heat transfer occurs through the layer of the Inconel metal plate and the backing insulation as well as by air flow passing over the plate thermometer. While $K_{\text {cond }}$ should be experimentally determined, the convective heat transfer coefficient can be calculated. For a horizontal plate in natural convection, $h$ can be calculated as a function of $\mathrm{T}_{\mathrm{PT}}$ [119]. This applies to the plate thermometer that was placed upstream of the fire.

$$
h=4.0\left(\frac{T_{P T}-T_{o}}{L}\right)^{1 / 4}\left(T_{P T}+T_{o}\right)^{-0.16}
$$

For a horizontal plate in forced convection, $\mathrm{h}$ can be calculated from the Nusselt number [120].

$$
h=\frac{N u k_{g}}{L}
$$

$k_{g}$ is the conductivity of the gas, and $L$ is characteristic length of the surface.

$N u$ Nusselt number was calculated based on Eq 76 that are suggested by $[120,121]$ for a vertical heated plate placed in uniform horizontal air flows. The calculated values from the two equations were very similar.

$$
\begin{aligned}
N u & =0.228 \operatorname{Re}^{0.73} \operatorname{Pr}^{1 / 3} \\
\text { or } \quad N u & =0.57 \operatorname{Re}^{1 / 2} \operatorname{Pr}^{2 / 5}
\end{aligned}
$$

$k_{g}, R e$, and $\operatorname{Pr}$ are evaluated at the film temperature of the gas defined as 


$$
T_{f}=\frac{T_{P L}+T_{o}}{L}
$$

\subsubsection{Measurement of heat flux}

In the suppression test program, Gardon gauges and plate thermometers were used to measure radiative heat fluxes from the fire that was subjected to various longitudinal air velocities in the tunnel.

\section{Gardon gauge measurement}

Radiative heat flux measurements by Gardon gauges in the mixed radiative and convective environments are subjected to errors due to convection effects. In mixed radiative-convective environments, the application of the radiation-based calibration constant becomes less appropriate [122]. Due to the uncertainty of the Gardon gauge performance under convection, Gardon gauge is not intended to be used in mixed radiative-convective condition.

In the tests, to minimize the error due to the convection effect, the cooling water temperature was set to be close to the ambient temperature, yet slightly higher than the ambient to prevent condensation on the sensor surface.

\section{$\underline{\text { PT measurements }}$}

Using the temperature measured by plate thermometers, heat fluxes were calculated by the calculation method explained above. Convective heat transfer coefficients and conduction correction factors necessary for the heat flux calculations were sought for each test condition. 
The $\mathrm{h}$ for the plate thermometer upstream of the fire for all tests was about 9-10, which was calculated by Eq 74 suggested for natural convection. For the plate thermometer downstream of the fire, which is subjected to forced convection, the calculated $h$ values using Eq 75, Eq 76 and Eq 77 were about 10, 13-14, and 17-18, for fan speeds of 25\%, $50 \%$, and $100 \%$ respectively.

Conduction correction factors $\left(K_{\text {cond }}\right)$ were sought by looking up the best-fit value to the heat flux measurements by Gardon gauge. In Figure $9-8, K_{\text {cond }}$ values obtained for each test are plotted with respect to air flow velocities. It appears that the value increases as air flow velocity increases, and upstream values are slightly larger than downstream values. This is because the plate thermometer upstream of the fire loses heat due to air flow through the backside of the plate. In general, a value of 18-24 can be used under an air velocity less than $2 \mathrm{~m} / \mathrm{s}$, and a value of 27 can be used when the air velocity is larger than $2 \mathrm{~m} / \mathrm{s}$. In the open configuration under a large hood, a $K_{\text {cond }}$ value of 22 was obtained by Ingason [119].

Using a value of 20 for $K_{\text {cond }}$, heat flux $8 \mathrm{~m}$ upstream of a $10 \mathrm{MW}$ fire was calculated with temperature measurements by the plate thermometer, and the calculated value is compared with the measurements by Gardon gauge in Figure 9-9. The estimation by the plate thermometer is comparable to the measurements by Gardon gauge, without and with suppression active. 


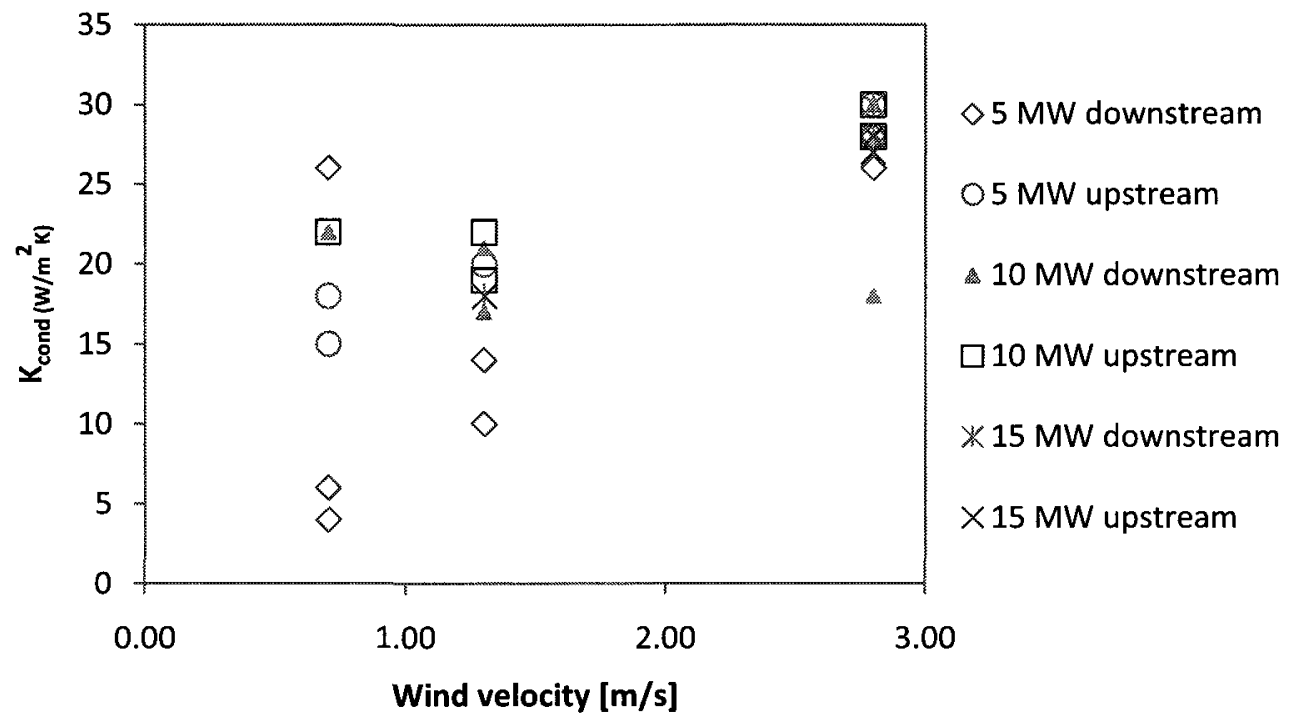

Figure $9-8 \mathrm{k}$ values with respect to air flow velocities

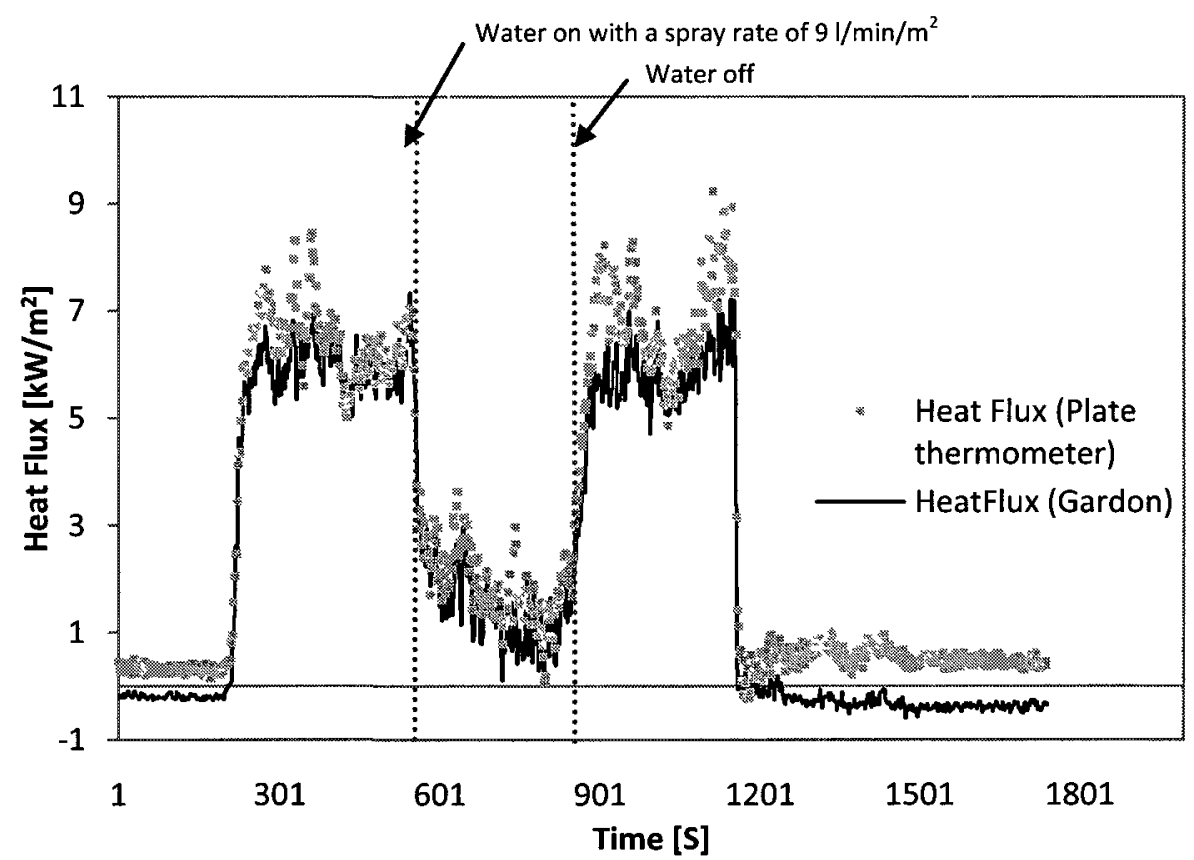

Figure 9-9 A comparison of heat flux measurements between a plate thermometer and Gardon gauge ( heat flux $8 \mathrm{~m}$ upstream of a $10 \mathrm{MW}$ fire under $25 \%$ fan speed and a water spray rate of $91 / \mathrm{min} / \mathrm{m}^{2}$ )

Figure 9-10 compares the measurement by Gardon gauge and the calculated heat flux from plate thermometers for all tests conducted in the test program. Because in some 
cases the Gardon gauges malfunctioned, the calculated values from the plate thermometer were used in the data analysis.

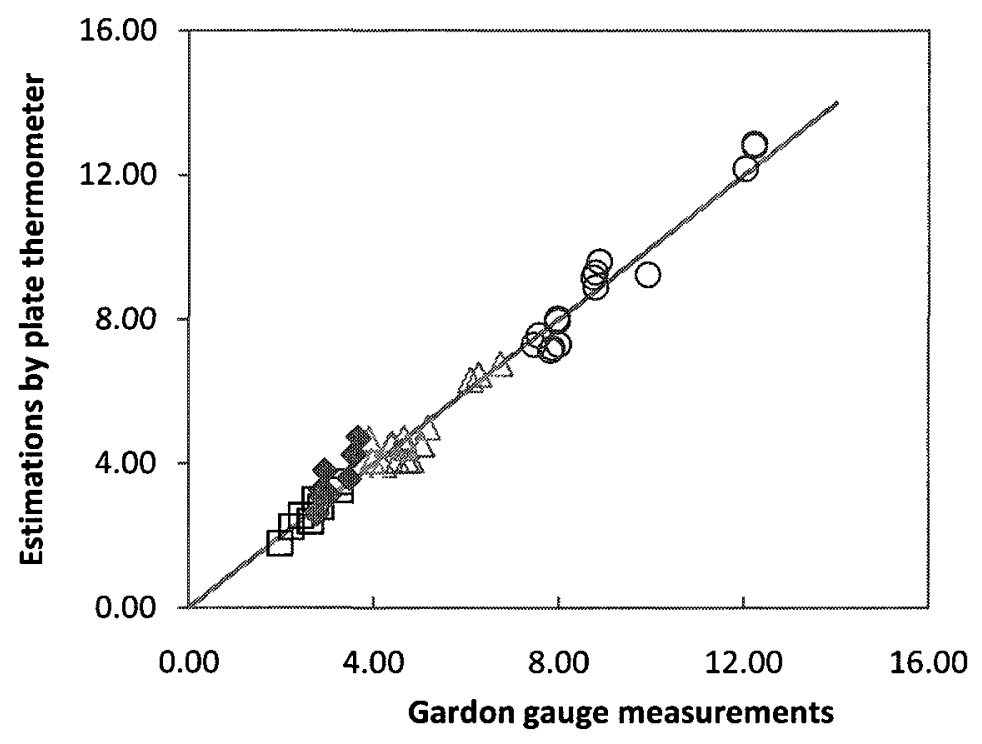

Figure 9-10 A comparison of calculated heat flux with Gardon measurements

\subsubsection{Estimation of heat flux under ventilation}

Figure 9-11 shows the estimation of incident heat flux from various fire sizes, by the point source estimation (Eq 68). $\mathrm{q}_{5}, \mathrm{q}_{8}, \mathrm{q}_{10}$ and $\mathrm{q}_{20}$ are the values at $\mathrm{R}=5,8,10$, and $20 \mathrm{~m}$ from the fire, respectively. Radiation heat $\left(Q_{r}\right)$ is estimated at about 0.35 of the total HRR. Based on this estimation, fire can spread to a vehicle at a distance of $5 \mathrm{~m}$ from a fire of about $12 \mathrm{MW}$ as the critical heat flux for fire spread is about $11-13 \mathrm{~kW} / \mathrm{m}^{2}$ for wood and polystyrene [123]. The largest fire to ensure safe environment for people near the fire (outside $10 \mathrm{~m}$ ) without a mitigation system is about $8 \mathrm{MW}$, as the critical value of $2 \mathrm{~kW} / \mathrm{m}^{2}$ is suggested for people to escape from the tunnel[27]. 
In Figure 9-11, data from the present study as well as previous studies are also plotted for a comparison with estimations. The measured heat fluxes $8 \mathrm{~m}$ downstream $(\mathrm{q}+8)$ and 8 m upstream (q-8), which were obtained by Gardon gauges and plate thermometers, appear reasonable as these data sit within the estimation lines of $\mathrm{q}_{5}$ and $\mathrm{q}_{10}$. For data from experiments with a air velocity of about $0.6 \mathrm{~m} / \mathrm{s}(25 \%$ fan speed $)$, the measured heat fluxes upstream and downstream of the fire are similar because of the least air flow effect. Yet, the measurements tend to be higher than the estimation because the application of the point source method to the relatively long rectangular fire configuration was less appropriate as the flame surface was quite close to the target.

With increase in longitudinal air flows, the heat flux upstream of the fire decreases while the heat flux downstream increases. The heat flux measured at $10 \mathrm{~m}$ upstream $(\mathrm{q}-10)$ of the fire in the Runehamar tunnel (marked with ' $O$ ' in the figure) is significantly lower than the estimation. This is mainly caused by the shifting of the centre of the heat source as the flame is tilted by air flows. 


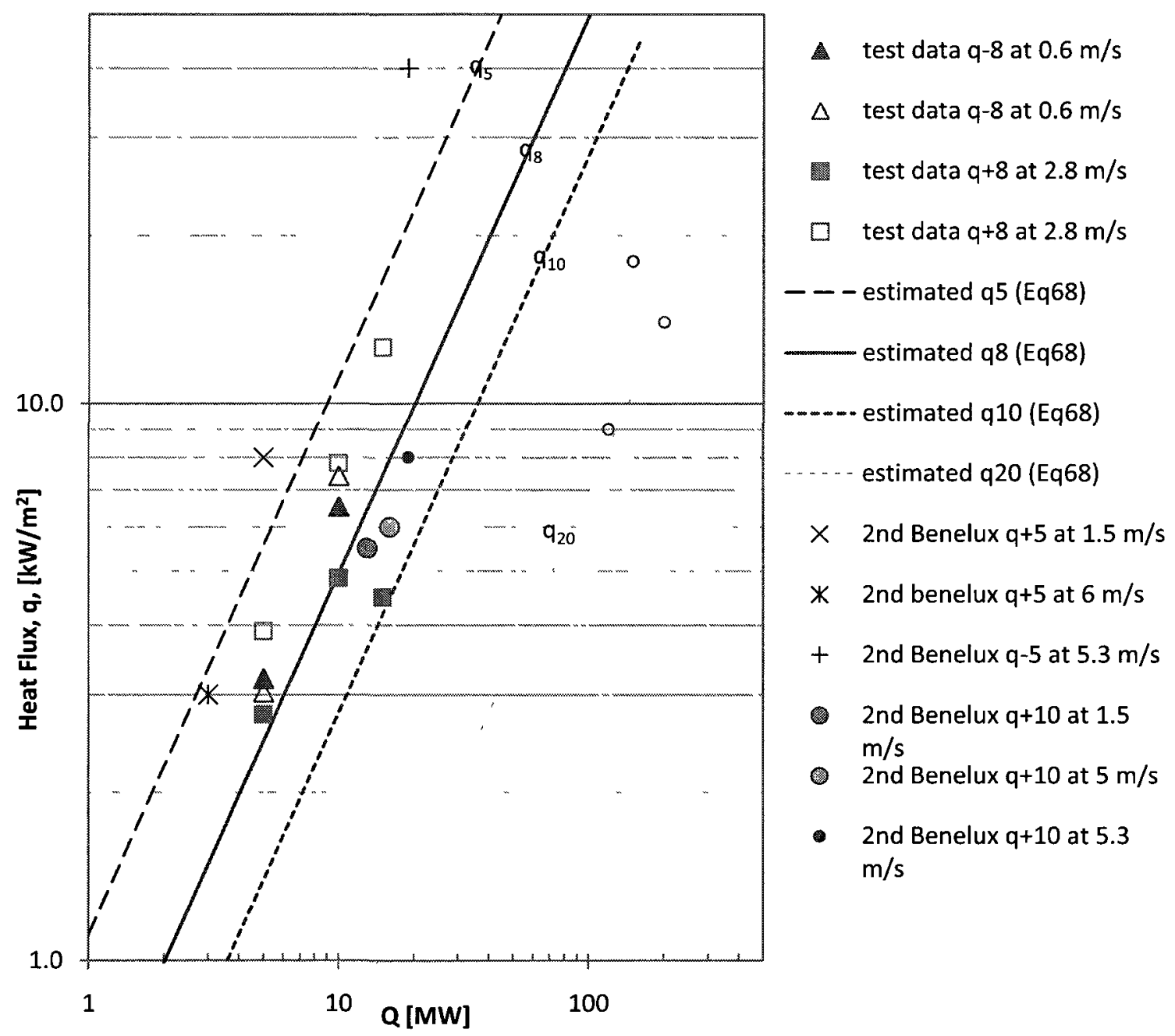

Figure 9-11 Radiation heat flux with respect to $Q$

\subsubsection{Radiation attenuation by water spray}

Fractions of transmitted radiation, $\frac{\dot{q}_{s}}{\dot{q}_{o}}$, are plotted with respect to water spray densities ( $\omega)$ in Figure 9-12 and Figure 9-13 for upstream and downstream, respectively. In Figure 9-12, for the same size of fire and ventilation, transmitted radiations measured upstream of the fire exponentially decrease as the water spray rate increases, and the rate of attenuation is about 0.5 with a water spray rate of $10 \mathrm{l} / \mathrm{min} / \mathrm{m}^{2}$ in most cases. A greater 
degree of radiation attenuation was observed particularly in the tests where significant backlayering was observed (as in $\mathrm{T} 10 \mathrm{M} 25 \%$ and $\mathrm{H} 15 \mathrm{M} 100 \%$ ).

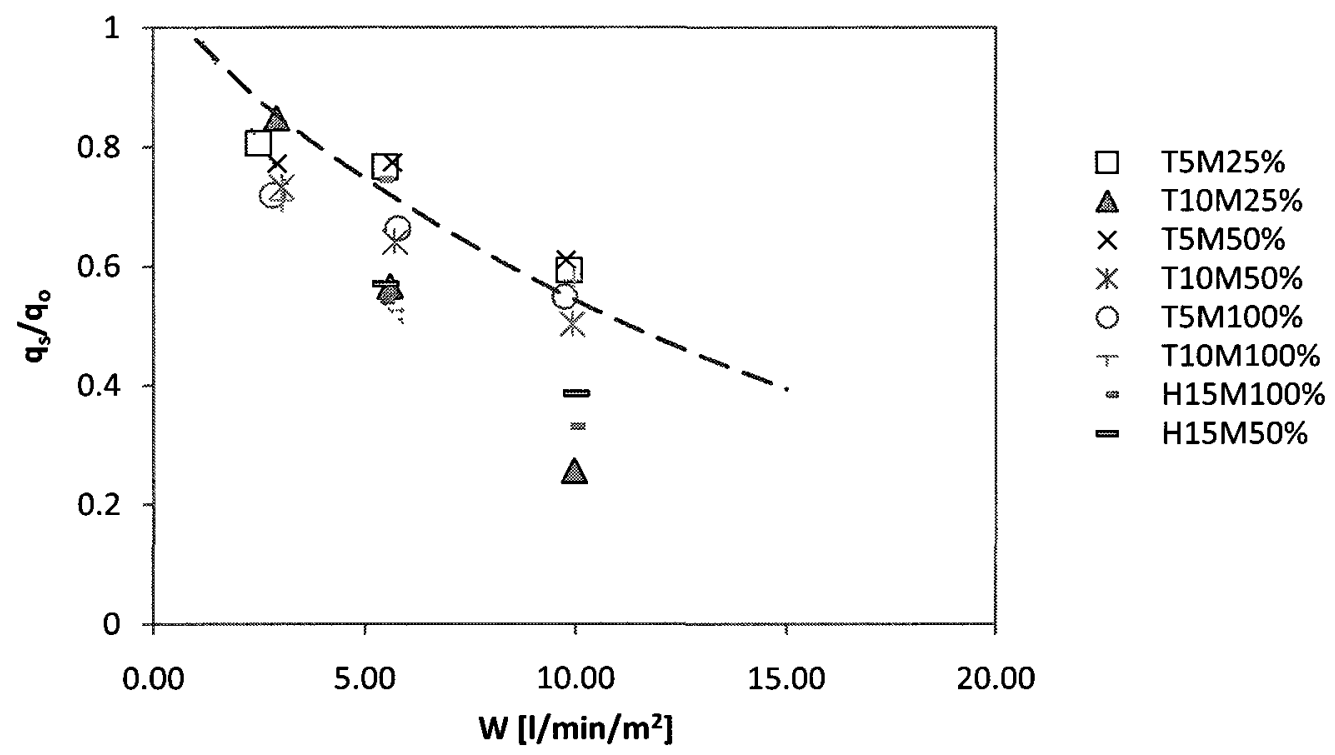

Figure 9-12 Fraction of transmitted radiation for measurement $8 \mathrm{~m}$ upstream of the fire with respect to water spray rates

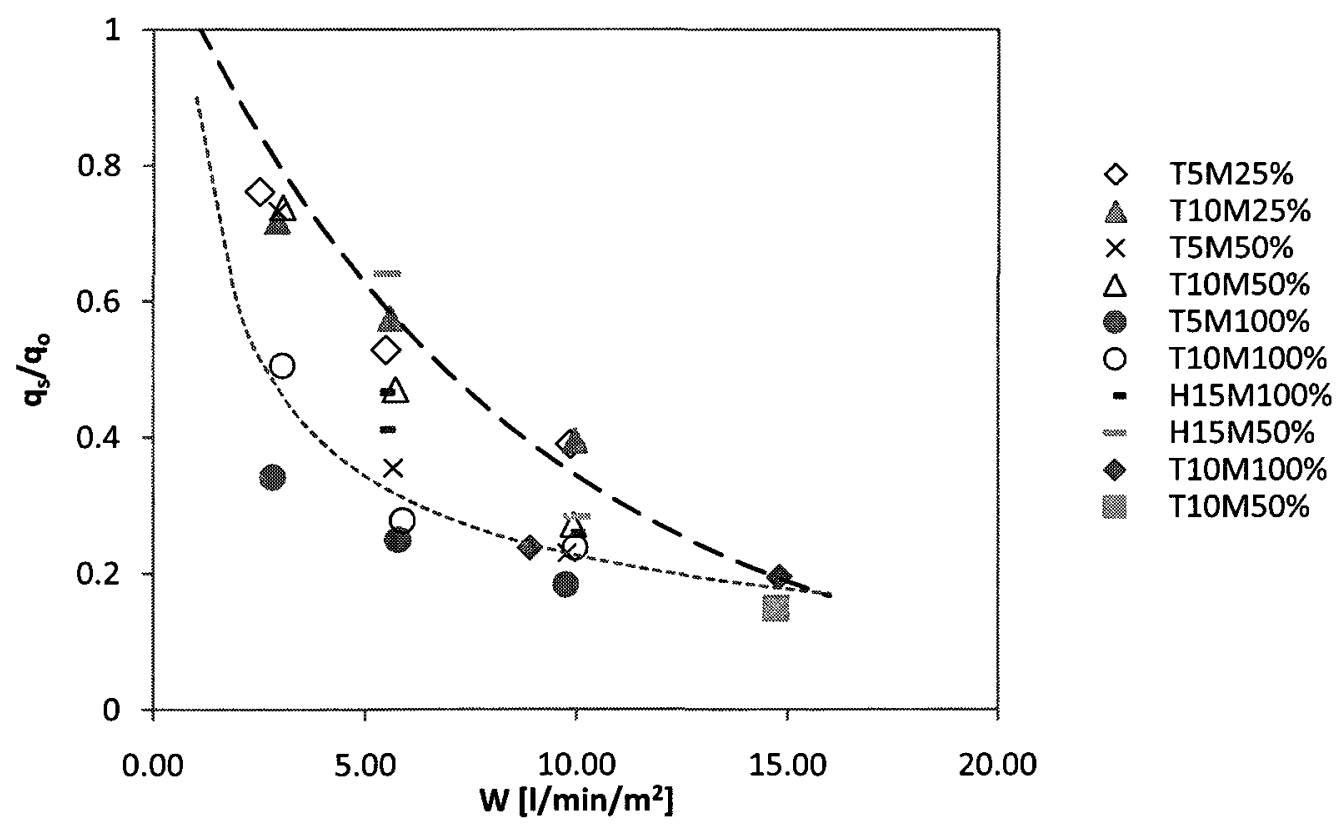

Figure 9-13 Fraction of transmitted radiation for measurement $8 \mathrm{~m}$ downstream of the fire with respect to water spray rates 
The radiation attenuation was more significant in the area downstream than upstream because the radiation transmitted from the fire as well as the hot gas is effectively attenuated by the water spray that acts as a shield. As shown in Figure 9-13, the rate of transmitted radiation exponentially decreases with the increase in water spray densities. When the water spray density was larger than $101 / \mathrm{min} / \mathrm{m}^{2}$, about $60-80 \%$ of the radiation is reduced due to the finer droplets that were distributed more evenly over the spray zone.

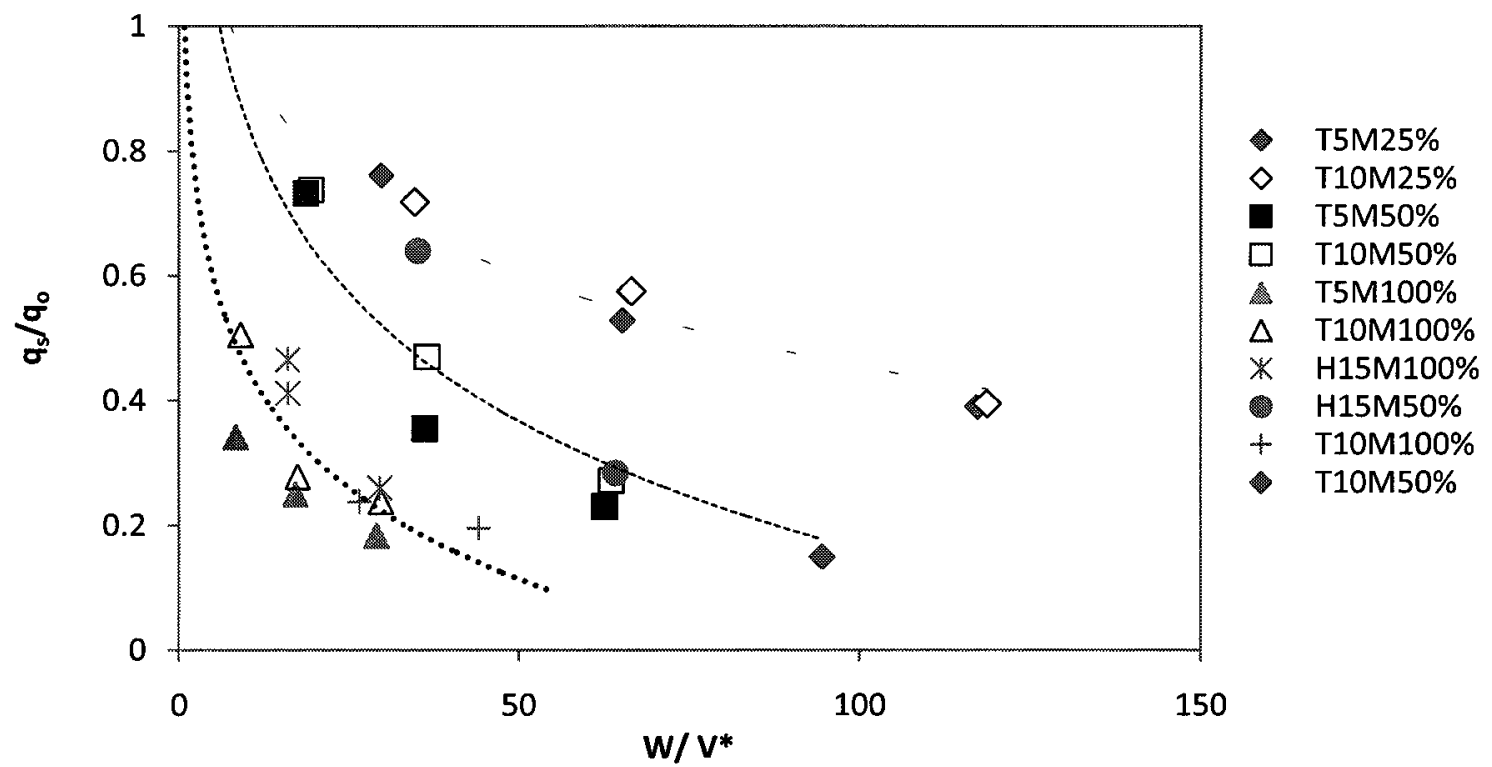

Figure 9-14 Fraction of transmitted radiation for measurements $8 \mathrm{~m}$ downstream of the fire In addition to water spray rates, the air flow velocity also appears to affect the radiation attenuation. The effect of wind speed was more apparent on the measurements downstream. In Figure 9-14, fractions of transmitted radiation measured downstream of the fire are plotted with respect to $\omega / \mathrm{V}^{*}$. It shows that the effect of radiation attenuation increases with increase in the air flow velocity. This is because of the different spray characteristics generated by air flow velocities. From the bucket tests (Chapter 6.4), it was found that the influence of the longitudinal air flow was greater for the larger water spray density, and the water spray was more evenly distributed over a longer section of 
the tunnel with a fan speed of $100 \%$. The elongated path length of the attenuating water spray zone caused a significant reduction in the heat flux.

\subsection{Summary and Conclusions}

9.4.1. The cooling effect of the sprinkler system along with the longitudinal ventilation system

A method to predict the maximum gas temperature near the tunnel ceiling was developed for a fire under longitudinal ventilation. The method gives relatively good predictions over a wide range of fire sizes and velocities.

$$
\frac{\Delta T_{\max }}{T_{o}}=10\left[\frac{Q^{*}}{V^{* 1 / 3}}\right]
$$

In the case of the sprinkler system operating, a method to predict the maximum gas temperature near the ceiling is also proposed which quantifies the relative effect of water sprinkler system to the fire size and ventilation condition. The method is valid within the range of tested fire sizes, water spray rates and air velocities. The method can be applied to a similar type of sprinkler system.

$$
\frac{\Delta T_{\max \_s}}{T_{o}}=23.5\left[\frac{Q^{* 7 / 9}}{\left(\omega V^{*}\right)^{1 / 3}}\right]^{8 / 5}
$$

Based on the methods, Eq 61 and Eq 63, a factor of $\frac{\omega^{1 / 3} V^{* 1 / 3}}{Q^{* 1 / 4}}$ is found which controls the combined cooling effect of the sprinkler system and the longitudinal ventilation system on the maximum ceiling temperature. In Figure 9-15, the results for $\frac{\Delta T_{\max s} s}{\Delta T_{\max }}$ from the suppression test program and the FDS simulations are plotted. 


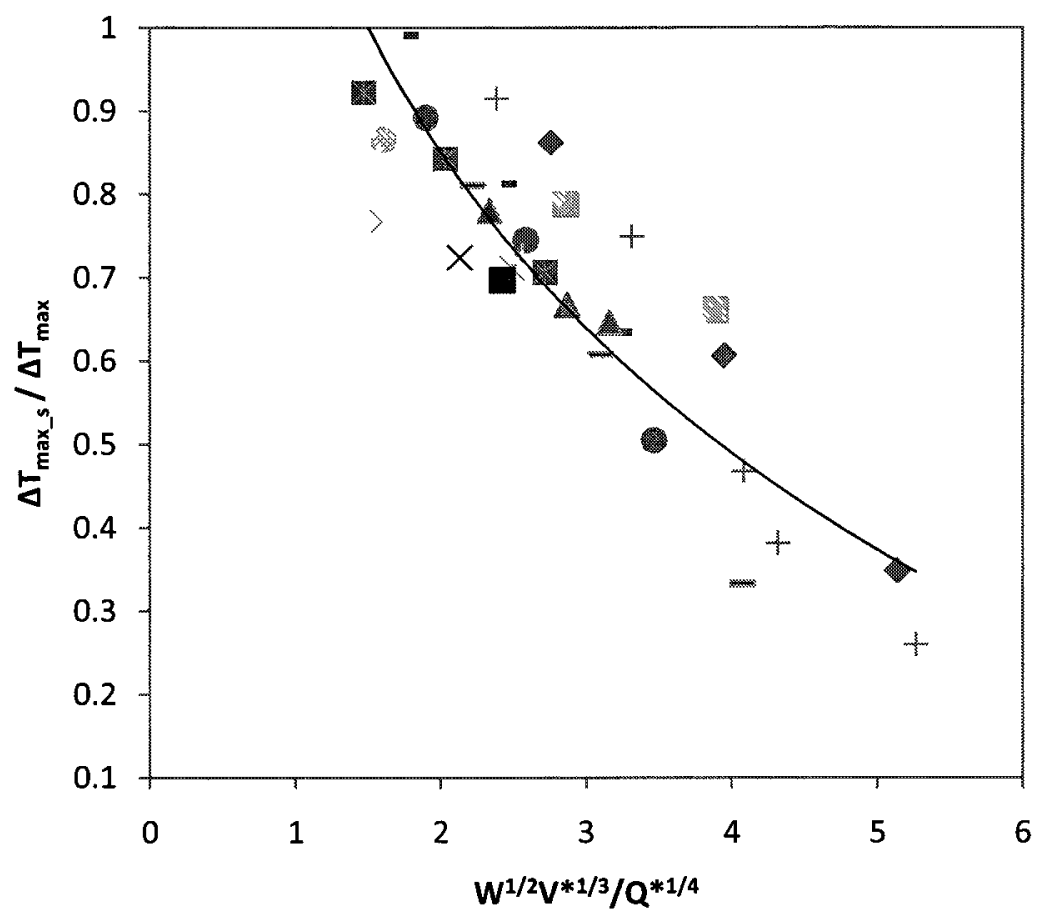

T10M25\%

- $\mathrm{T} 10 \mathrm{M} 50 \%$

$+\quad \mathrm{T} 10 \mathrm{M} 100 \%$

- $15 \mathrm{M} 25 \%$

- T5M50\%

- T5M100\%

(2) $H 15 M 100 \%$

H15M50\%

$\prec \quad$ FDS S40MW 25\%6

$\times \quad$ FDS S25MW50\%9-long

FDS $540 M W 25 \% 6$-long

2. FDS S10MW50\%6-long

- SP model scale 134MW sprınkler $3 \mathrm{~m} / \mathrm{s}$

- SP model scale 106MW sprinkler $3 \mathrm{~m} / \mathrm{s}$

$\times$ SP model scale 70MW sprınkler $2 \mathrm{~m} / \mathrm{s}$

Figure 9-15 $\Delta \mathrm{T}_{\max \_s} / \Delta \mathrm{T}_{\max }$

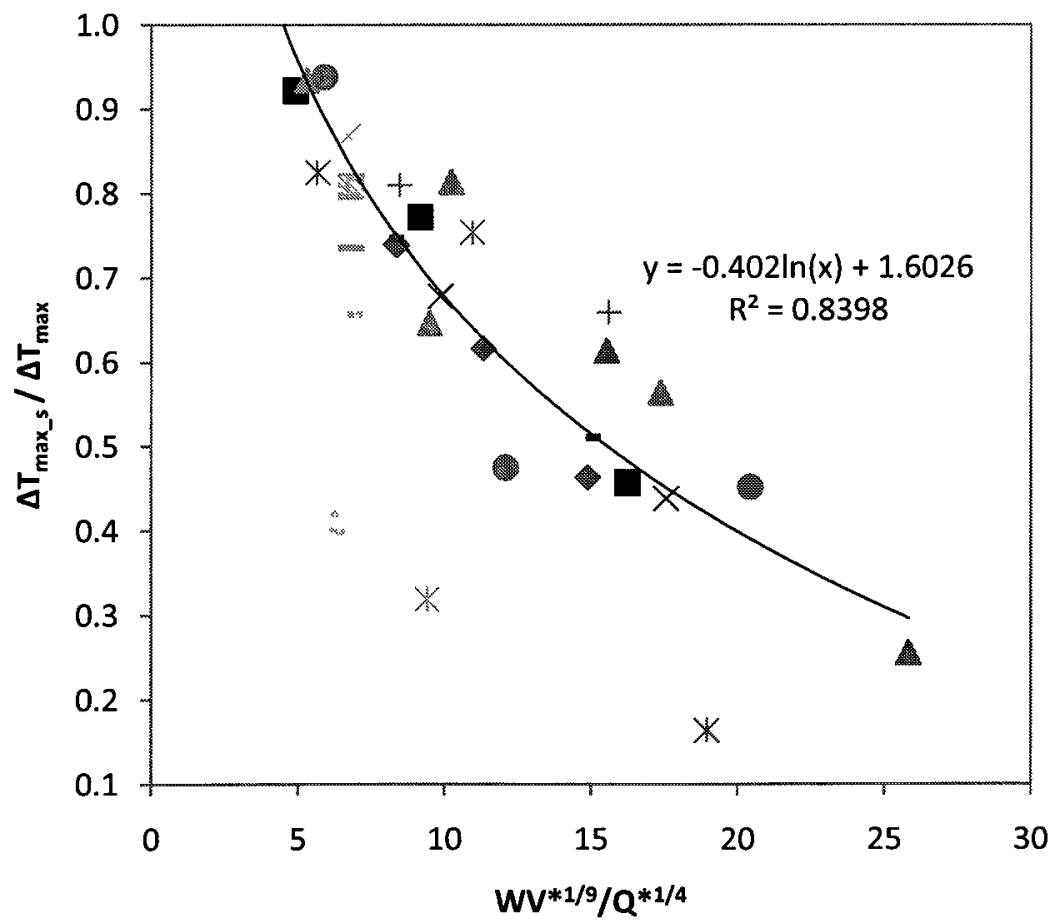

- T10M25\%

- $\mathrm{T} 10 \mathrm{M} 50 \%$

\& $\mathrm{T} 10 \mathrm{M} 100 \%$

$\times \quad$ T5M $25 \%$

× T5M50\%

T5M100\%

$+\mathrm{H} 15 \mathrm{M} 100 \%$

- $\mathrm{H} 15 \mathrm{M} 50 \%$

FDS S40MW 25\%6

- FDS S25MW50\%9-long

FDS S40MW25\%6-long

4. FDS S10MW50\%6-long

$\times \quad$ SP model scale $134 \mathrm{MW}$ sprinkler $3 \mathrm{~m} / \mathrm{s}$

* SP model scale 106MW sprınkler $3 \mathrm{~m} / \mathrm{s}$ $\mathrm{SP}$ model scale 70MW sprınkler $2 \mathrm{~m} / \mathrm{s}$

Figure 9-16 $\Delta \mathrm{T}_{+21 \_s} / \Delta \mathrm{T}_{+21}$ 
The cooling effect of both systems on the temperature about $21 \mathrm{~m}$ downstream of the fire is also plotted in Figure 9-16, and the effect is found to be depending on $\frac{\omega V^{* 1 / 9}}{Q^{* 1 / 4}}$. The temperature downstream of the fire also depends on the flame extension along the tunnel ceiling in the case of large fires as well as on the length of the spray section. As shown in the figure, results from the SP test show larger cooling rate due to the longer spray section, which was about $23 \mathrm{~m}$ long over the fire area.

From these figures, the estimated cooling effect of a water spray rate of $91 / \mathrm{min} / \mathrm{m}^{2}$ is about $0.5-0.6$ for both maximum ceiling temperature and the ceiling temperature $21 \mathrm{~m}$ downstream of a fire size of $15 \mathrm{MW}$, under an air flow of about $1.4 \mathrm{~m} / \mathrm{s}$.

9.4.2. Control of smoke backlayering using the sprinkler system and longitudinal ventilation system

From the data analysis, it is found that the backlayering can be controlled with a velocity lower than the critical velocity when the sprinkler system is used. A method to predict temperature $10 \mathrm{~m}$ upstream of the fire was developed based on the suppression test results from the present study. The method can determine the degree of backlayering, and based on the method (Eq 6), the critical value of the source factor required to prevent backlayering is found as shown below.

$$
\frac{\Delta T_{-10 \_s}}{T_{\mathrm{o}}}<0.1 \quad \text { when } \frac{\omega\left(\mathrm{V} / \mathrm{V}_{\mathrm{c}}\right)^{2}}{\mathrm{Q}^{* 2}} \geq 9
$$

Applying this criterion to a tunnel with a hydraulic diameter of $7.1 \mathrm{~m}, \mathrm{~V} / \mathrm{V}_{\mathrm{c}}$ required to prevent smoke backlayering is plotted in Figure 9-17 for various HRR from 5 to $30 \mathrm{MW}$ 
with respect to water spray densities. For a $15-\mathrm{MW}$ fire, the required velocity is reduced by $50 \%$ when the sprinkler system is applied with a water spray density of $10 \mathrm{1} / \mathrm{min} / \mathrm{m}^{2}$.

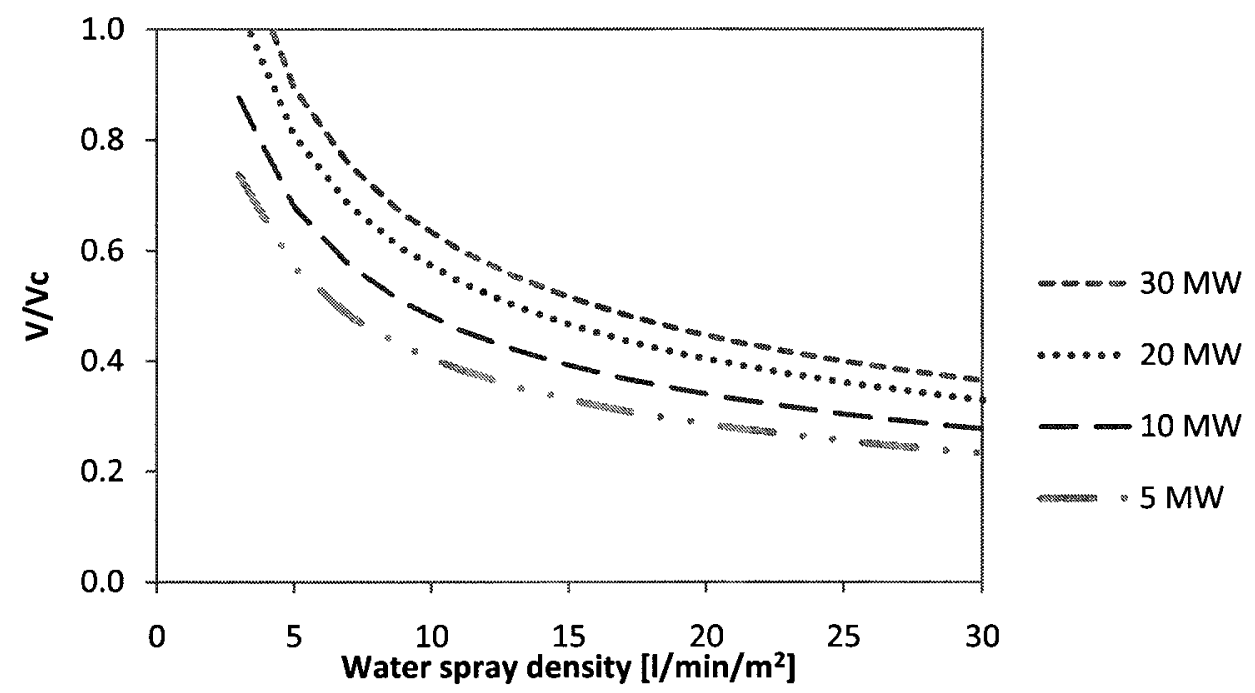

Figure 9-17 The required velocity to prevent the backlayering with the suppression system operating

\subsubsection{Radiation attenuation by the sprinkler system}

The measurements of incident heat flux from tunnel fires were examined to ensure accurate measurements of radiative heat flux in the mixed radiative and convective tunnel environment. Good agreement between the measurements by Gardon gauges and the estimations by plate thermometers were obtained without and with suppression active. The data without suppression active were comparable with the point source estimation by Eq 68. It is recommended that calibration of these devices should be carried out prior to a test in the environment to be tested.

The measurements with the sprinkler system operating show that radiation attenuation by the sprinkler system exponentially increases as the water spray rate increases. The radiation attenuation was significant particularly in the area downstream because the 
radiation transmitted from the fire as well as the hot gas is effectively attenuated by the water spray that acts as a shield. In the case of a $15-\mathrm{MW}$ fire, to achieve significant radiation attenuation more than $50 \%$ at both locations $8 \mathrm{~m}$ downstream and upstream, results shows that water spray density needs to be larger than $6 \mathrm{l} / \mathrm{min} / \mathrm{m}^{2}$.

The air flow velocity also affected the effectiveness of the sprinkler system on radiation attenuation. Since the air flow shifted the water spray downstream, the water spray zone becomes extended toward the air flow direction. Figure 9-18 show the rate of transmitted radiation downstream of the fire with respect to $\omega \mathrm{V}^{*}$.

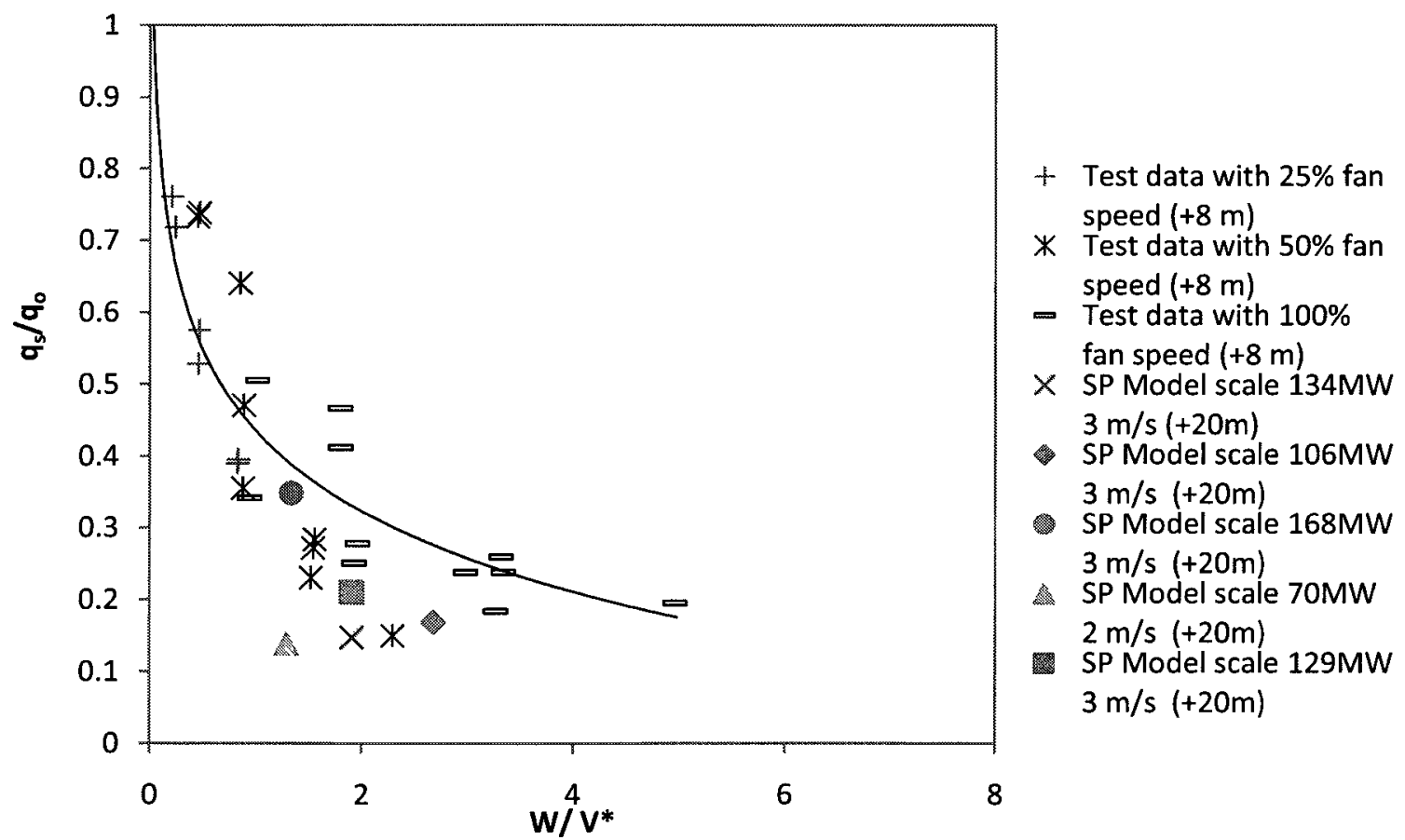

Figure 9-18 Fraction of transmitted radiation downstream of the fire with respect to $\omega \mathrm{V}^{*}$ 


\section{CHAPTER 10. SUMMARY, CONCLUSIONS AND RECOMMENDATIONS}

\subsection{Development of a HRR measurement system}

One of the objectives of the present study was to develop a HRR measurement system which can be used in various tunnel fire safety studies. Using oxygen calorimetry, the HRR measurement system was developed in the full-scale laboratory tunnel of Carleton University. For accurate measurements of HRR, the instrumentation of the HRR measurement system was designed based on extensive analysis of various CFD simulations of the flow pattern in the tunnel facility as well as analysis of manual measurements of the velocity profile in the fan chamber.

The measurement system was programmed using Labview (version 8.6) to calculate and display HRR in real-time. The schematics of programming are presented, which includes synchronizing gas concentration measurements due to the delay (a constant delay of 45 seconds) in gas sampling/ analysing system (Note that a constant sampling rate was kept at approximately $1.5 \mathrm{l} / \mathrm{min}$ ).

A series of calibration tests was carried out to evaluate the performance of the measurement system under various ventilation conditions. Based on the calibration test results, a factor of 0.85 for the HRR measurement system was found which adjusts the overestimated flow rates due to flow deflection near the walls. The calibration test results showed that the system is responsive to various fire sizes, as small as $2.5 \mathrm{MW}$. However, due to the scale of the facility, the measurement system is more suited to large fires that 
last a long time. The result from the calibration test at $24 \mathrm{MW}$ shows that the developed HRR measurement system has the ability to handle large amounts of smoke generated from large fires with no significant response delay or smoke build-up.

Due to the large-scale of the facility, there is system response delay. Therefore, the system's ability to handle a sudden increase or decrease of HRR is limited. A longer system response delay was experienced at $25 \%$ fan speed than the larger fan speeds. A $25 \%$ fan speed must be the minimum fan speed to ensure a reasonable estimate of HRR for this HRR measurement system.

Uncertainty analysis was carried out to evaluate the measurement of HRR by the new system as the system will be used in many studies in tunnel fire safety engineering. The relative combined uncertainty of the system measurements is about $10-15 \%$ for the fire sizes tested in the calibration tests. Measurements of mass flow rate and oxygen concentration are the two most significant error contributors.

The HRR measurement system was also evaluated for its accuracy during suppression. The analysis of the suppression test results showed that the HRR measurement by the original method of oxygen calorimetry yielded a HRR overestimation of up to $10 \%$. The error mainly comes from the large quantities of water vapour generated by the suppression system. Measurements of the volumetric fraction of water vapour are not available for most oxygen calorimeters. The present study proposed a simple method to correct the HRR measurement during suppression, based on the temperature measurement and the relation of temperature and oxygen depletion factor. 
Recommendations: In the future, this system will be used for realistic fire scenarios, such as vehicle fires and HGV fires loaded with different types of materials, yielding various fire growth rates and peak HRR. It is recommended that a suitable fan capacity must be used based on an estimated size and growth rate of fire. The three exhaust fans should be running at the same speed, and the fan speed should be high enough to collect all combustion products. A fan speed of $100 \%$ is recommended for large fires and fast growing fires in order to prevent the loss of smoke and to reduce system response delay.

When minimal air flow is required to limit the effect of air flow on the fire, a minimum fan speed of $25 \%$ can be used. Calibration results showed that with a fan speed of $25 \%$, the system can handle fires as large as $8 \mathrm{MW}$ with no loss of smoke products and with no significant measurement errors.

The calibration factor of 0.85 , which is found from the calibration tests considering different scenarios including different fire sizes and fan speeds, is recommended for tunnel fire tests. However, some judgment must be used in the use of the factor, particularly when a test set-up can result in significantly different velocity profile at the measurement station in the fan chamber. For instance, the gas flow induced from a fire placed near the tunnel side wall or a fire placed very close to the tunnel ceiling openings connected to the fan chamber can results in different velocity profile in the fan chamber. For such a test, a calibration test is recommended prior to the test to examine the effect of the fire set-up. 
Periodic calibration tests are recommended to assess the performance of the system, and the pressure transducers should be calibrated regularly. Before each test, the gas analyser should be calibrated and tested for any measurement error or drift. The uncertainty analysis described in this study can be used for a maintenance program to assess the performance of the system.

The findings of this study suggest that the water vapour generated by the suppression system can produce a considerable error in the HRR measurements. For accurate measurements of HRR, it is recommended to measure actual water vapour for future suppression tests.

\subsection{Investigation of the effect of the use of WFFFS under longitudinal air flows on tunnel fires}

The present study showed that the use of both suppression and longitudinal ventilation systems offers significant advantages over controlling smoke, preventing fire spread and mitigating hazards in the case of tunnel fires. The present study also proposed a method to quantify the effect of both systems on smoke cooling and a method to calculate the velocity required to resist backlayering in the case when the suppression system is active.

The full-scale suppression test program was conducted using a sprinkler system in the laboratory tunnel to investigate the interaction of the sprinkler system and the longitudinal air flows in tunnels. Bucket tests were first conducted to examine the effect of the air flow on the spray pattern. Results showed that the air flow shifted the water spray downstream, and the water spray zone was extended in the air flow direction. This 
in fact affected the effectiveness of the sprinkler system on temperature cooling and radiation attenuation downstream.

The absolute cooling effect and radiation attenuation were examined by activating the sprinkler system over a propane fire which generated a constant HRR. The cooling effect of the sprinkler system and the longitudinal ventilation system was examined by observing the temperature distribution in the tunnel. A method to estimate the maximum gas temperature near the tunnel ceiling was proposed, which can be used to predict the thermal intensity that the tunnel structure would experience during the fire. The method gives relatively good predictions over a wide range of fire sizes and velocities, as well as water spray densities of the sprinkler system.

By cooling smoke temperatures, the suppression system enabled the longitudinal ventilation system to prevent backlayering of smoke at a lower velocity than the critical velocity. An analysis of temperature data upstream of the fire was performed to correlate the degree of backlayering with the given conditions of air velocity, water spray density and fire size. From the data analysis, a method to predict the degree of backlayering upstream of the fire was developed.

Assessment of radiative heat flux is important in tunnel fires; however, care must be taken for accurate measurement of the radiative heat flux in the mixed radiative and convective tunnel environment. It is recommended that calibration of measurement devices should be carried out prior to a test in the environment to be tested. 
The heat flux measurements with the sprinkler system operating show that radiation attenuation by the sprinkler system increases as the water spray rate increases. The radiation attenuation was significant particularly in the area downstream because the radiation transmitted from the fire as well as the hot gas is effectively attenuated by the water spray that acts as a shield.

Recommendations: The methods proposed by the present study succeed in predicting the effect of the both systems on smoke cooling and estimating the velocity required to resist backlayering in the case when the sprinkler system is active. However, the methods should be further validated for various tunnel fire scenarios in actual tunnel environments.

In order to have a complete calculation method and an engineering guide for WFFFS in the design of tunnel fire safety systems, it is recommended that further research be undertaken in the following areas:

- The effect of water mist systems: The cooling effect and radiation attenuation by water mist system can be examined using the controlling factors found in the present study to compare with the sprinkler system.

- The interaction between WFFFS and detection systems: Detecting the location of fire quickly and accurately is critical to operate an open deluge system. The performance of current detectors used in tunnels should be evaluated with a suppression system operating.

- Interaction between WFFFS and transverse ventilation systems: A further research could investigate how WFFFS interacts with transverse ventilation systems.

- The effect of WFFFS on HRR: It is necessary to develop a model to estimate the effect of WFFFS in reducing HRR and controlling fire growth. 
- The effect of system design: A future study exploring different spray patterns and different nozzle designs to optimize the effectiveness of WFFFS in tunnels would also be interesting. 


\section{REFERENCES}

[1] UPTUN, 2008.Fire Development and Mitigation Measures: Fire Scenarios and Accidents in the Past, Workpackage 2 D211.

[2] Los Angeles Times. , Oct. 14, 2007, Crash severs a vital state artery, available: http://articles.latimes.com/2007/oct/14/local/me-freeway14.

[3] Babrauskas, V. and Peacock, R. D., 1992. Heat release rate: The single most important variable in fire hazard, Fire Safety Journal, 18, pp. 255-272.

[4] Grant, G., Brenton, J. and Drysdale, D., 2000. Fire suppression by water sprays, Progress in Energy and Combustion Science, 26, pp. 79-130.

[5] Haack, A., 2005.Technical Report - Part 1, Design Fire Scenarios, FIT - Fire in Tunnels.

[6] Brinson, A., 2010. Active fire protection in tunnels, Fourth International Symposium on Tunnel Safety and Security, Frankfurt am Main, Germany, pp. 47-58.

[7] Almand, K. H., 2008.Safety \& Security in Roadway Tunnels: Final Report, Fire Protection Research Foundation, Quincy, Massachusetts.

[8] Carvel, R. O., Beard, A. N., Jowitt, P. W. and Drysdale, D. D., 2004. The Influence of Tunnel Geometry and Ventilation on the Heat Release Rate of a Fire, Fire Technology, 40, pp. 5-26.

[9] Beard, A. N., Carvel, R. O. and Jowitt, P. W., 2002. Factors affecting tunnel fire size, Journal of Applied Fire Science, 11, pp. 41-52.

[10] Carvel, R. O., Beard, A. N. and Jowitt, P. W., 2001. A method for making realistic estimates of the heat release rate of a fire in a tunnel, 3rd International Conference on Tunnel Fires and Escape from Tunnels, pp. 137-144.

[11] Carvel, R. O., Beard, A. N. and Jowitt, P. W., 2001. A Bayesian estimation of the effect of forced ventilation on a pool fire in a tunnel, Civil Engineering and Environmental Systems, 18, pp. 279-302.

[12] Carvel, R. O., Beard, A. N., Jowitt, P. W. and Drysdale, D. D., 2001. Variation of heat release rate with forced longitudinal ventilation for vehicle fires in tunnels, Fire Safety Journal, 36, pp. 569-596. 
[13] Ingason, H., 2005. "Fire Dynamics in Tunnels", The Handbook of Tunnel Fire Safety, pp. 231-266.

[14] National Fire protection Association, 2008. NFPA 502 "Road Tunnels, Bridges, and Other Limited Access Highways".

[15] World Road Association (PIARC), 1999. Fire and smoke control in road tunnels, PIARC Committee on Road Tunnels (C5), Report 05.05.B.

[16] European Union Directive, 2004. The European Parliament and of the Council on Minimum Safety Requirements for Tunnels in the Trans-European Road Network.

[17] Oka, Y. and Atkinson, G. T., 1995. Control of smoke flow in tunnel fires, Fire Safety Journal, 25, pp. 305-322.

[18] Wu, Y. and Bakar, M. Z. A., 2000. Control of smoke flow in tunnel fires using longitudinal ventilation systems - a study of the critical velocity, Fire Safety Journal, 35, pp. 363-390.

[19] Hwang, C. C. and Edwards, J. C., 2005. The critical ventilation velocity in tunnel fires-a computer simulation, Fire Safety Journal, 40, pp. 213-244.

[20] Hu, L. H., Huo, R. and Chow, W. K., 2008. Studies on buoyancy-driven backlayering flow in tunnel fires, Experimental Thermal and Fluid Science, 32, pp. 14681483.

[21] National Fire Protection Association, 2001.

NFPA 502 "Standard for Road Tunnels, Bridges and Other Limited Access Highways".

[22] National Fire protection Association, 2011. NFPA 502 "Road Tunnels, Bridges, and Other Limited Access Highways".

[23] World Road Association (PIARC), 2008. Road tunnels: An assessment of fixed fire fighting systems, $2008 \mathrm{R} 07$.

[24] Stroeks, R., 2001.Sprinklers in Japanese Road Tunnels, Chiyoda Engineering Consultants Co., Ltd., Project Report BFA-10012.

[25] UPTUN, 2008.Engineering Guidance for Water Based Fire Fighting Systems for the Protection of Tunnels and Subsurface Facilities, Workpackage D251.

[26] World Road Association (PIARC), 2007. PIARC Report: Systems and Equipment for Fire and Smoke Control in Road Tunnels. 
[27] UPTUN, 2008.Development and Mitigation Measures: Target Criteria, Workpackage 2 D221Fire.

[28] 'Purser, D. A., c2002, "Toxicity Assessment of Combustion Products", in SFPE Handbook of Fire Protection Engineering, 3rd., Quincy, Mass. : Bethesda, Md. :, National Fire Protection Association; Society of Fire Protection Engineers,.

[29] Mangs, J. and Keski-Rahkonen, O., 1994. Characterization of the fire behaviour of a burning passenger car. Part I: Car fire experiments, Fire Safety Journal, 23, pp. 1735 .

[30] Mangs, J. and Keski-Rahkonen, O., 1994. Characterization of the fire behaviour of a burning passenger car. Part II: Parametrization of measured rate of heat release curves, Fire Safety Journal, 23, pp. 37-49.

[31] Joyeux, D., 1997.Natural Fires in Closed Car Parks: Car Fire Tests, CTICM, Metz , France, CTICM Report No. INC-96/294d-DJ/NB.

[32] Joyeux, D., 1996.Development of Design Rules for Steel Structures Subjected to Natural Fires in Closed Car Parks, European Commission, RPS Report n ${ }^{\circ} 26$.

[33] Steinert, C., 1997. Parameter study of car fires in parking garages using a mathematical fire simulation model, Bautechnik, 74, pp. 241-249.

[34] Steinert, C., 1994. Smoke and heat production in tunnel fires, Proceedings of the International Conference on Fires in Tunnels, pp. 123-137.

[35] French, S. E., 1994. Eureka 499-HGV fire test (Nov. 1992), Proceedings of the International Conference on Fires in Tunnels, pp. 63-85.

[36] Grant, G. B. and Drysdale, D. D., 1997. Estimating heat release rates from large scale tunnel fires, Proceedings of 5th International Symposium on Fire Safety Science, pp. 1213-1224.

[37] Lemaire, T. and Kenyon, Y., 2006. Large scale fire tests in the Second Benelux Tunnel, Fire Technology, 42, pp. 329-350.

[38] Huijben, I. J. W., 2002. Tests on fire detection systems and sprinkler in a tunnel, ITC Conference Basel.

[39] Ministry of Transport, Public Works and Water Management of the Netherlands, 2002.Project "Safety Test" Report on Fire Tests.

[40] Ingason, H. and Lönnermark, A., 2005. Heat release rates from heavy goods vehicle trailer fires in tunnels, Fire Safety Journal, 40, pp. 646-668. 
[41] Ingason, H. and Lönnermark, A., 2004. Recent achievements regarding measuring of time-heat and time-temperature development in tunnels, lst International Symposium Safe and Reliable Tunnels Innovative European Achievements , Prague, Czech Republic, pp. 87-96.

[42] Carvel, R., Beard, A. and Jowitt, P., 2001. Sensible ventilation control during tunnel fire incidents: The influence of longitudinal ventilation on heat release rate, Fire Engineers Journal, 61, pp. 10-12.

[43] Huijben, J., 2002. "Tests on Fire Detection Systems and Sprinkler in a Tunnel", Tunnel Fires and Escape from Tunnels, Fourth Int.Conference, pp. 73-82.

[44] Carvel, R., Rein, G. and Torero, J. L., 2009. Ventilation and suppression systems in road tunnels: Some issues regarding their appropriate use in a fire emergency, Proceedings of the 2nd International Tunnel Safety Forum for Road and Rail , pp. 375-382.

[45] Phan, L. T., 2007. Spalling and mechanical properties of high strength concrete at high temperature, Concrete Under Severe Conditions: Environment and Loading (CONSECA '07). Proceedings of the Fifth International Conference, Tours, France, pp. 1595-1608.

[46] Ing, R., 1994. Propagation and development of temperatures from tests with railway and road vehicles-comparison between test data and temperature time curves of regulations, Proceedings of the International Conference on Fires in Tunnels, Boras, Sweden.

[47] Bechtel/Parsons Brinckerhoff, 1995.Memorial Tunnel Fire Ventilation Test Program-Comprehensive Test Report.

[48] Metsch, W. W., 1997. Memorial tunnel fire ventilation test program: the full transverse tests, ASHRAE Transactions, 103, pp. 595-605.

[49] Murphy, J. A., 1997. Memorial tunnel fire ventilation test program: the partial transverse tests, ASHRAE Transactions, 103, pp. 606-617.

[50] Kile, G. W. and Gonzalez, J. A., 1997. Memorial tunnel fire ventilation test program: the longitudinal and natural tests, ASHRAE Transactions, 103, pp. 701-713.

[51] Huggett, C., 1980. Estimation of Rate of Heat Release by Means of Oxygen Consumption Measurements, Heyden \& Son Ltd.

[52] Parker, W., 1984. Calculations of the Heat Release Rate by Oxygen Consumption for Various Applications, Journal of Fire Sciences, 2, pp. 380-395. 
[53] Babrauskas, V., 1984. Development of the cone calorimeter - A bench scale heat release rate apparatus based on oxygen consumption, Fire and Materials, 8, pp. 8195.

[54] Babrauskas, V., 1986. Cone calorimeter- A versatile bench-scale tool for the evaluation of fire properties, New Technology to Reduce Fire Losses \& Costs., pp. 78-87.

[55] Bryant, R. A., Ohlemiller, T. J., Johnsson, E. L., Hamins, A., Grove, B. S., Guthrie, W. F., Maranghides, A. and Mulholland, G. W., 2003. The NIST 3 megawatt quantitative heat release rate facility, NIST Spec.Publ, 1007, pp. 1-75.

[56] Stroup, D. W., DeLauter, L., Lee, J. and Roadarmel, G., 2000.Large Fire Research Facility (Building 205) Exhaust Hood Heat Release Rate Measurement System, National Institute of Standards and Technology, NISTIR 6509.

[57] Ingason, H., 1994. Heat release rate measurements in tunnel fires, International Conference on Fires in Tunnels, Borås, Sweden, pp. 86-103.

[58] Tewarson, A., 1982. Experimental Evaluation of Flammability Parameters of Polymeric Materials.

[59] Ingason, H., 2008. Model scale tunnel tests with water spray, Fire Safety Journal, 43, pp. 512-528.

[60] Dlugogorski, B. Z., Mawhinney, J. R. and Duc, V. H., 1994. The measurement of heat release rates by oxygen consumption calorimetry in fires under suppression, Proceedings of the Fourth International Symposium, pp. 877-888.

[61] Bing1, Y., Guangxun1, L., Weicheng1, F. and Yaping, H., 2002. Heat release rate study of a pool fire interacting with water mists using a cone calorimeter, Chinese Journal of Quantum Electronics, 19, pp. 149-54.

[62] National Fire protection Association, 2003, "Section 11 Fire Suppression without Water", in Fire Protection Handbook.

[63] Kim, A. K., 2002. Overview of recent progress in fire suppression technology, Proceddings of the 2nd NRIFD Symposium, Tokyo, Japan, pp. 1-13.

[64] National Fire Protection Association, 2008. NFPA 750 "Standard on Water Mist Fire Protection Systems".

[65] Heskestad, G., 2003. Extinction of gas and liquid pool fires with water sprays, Fire Safety Journal, 38, pp. 301-317. 
[66] Rasbash, D. J., 1962. The extinction of fires by water sprays, Fire Research Abstracts and Reviews, 4, pp. 24-53.

[67] Rasbash, D. J., Rogowski, Z. W. and Stark, G. W. V., 1960. Mechanisms of extinction of liquid fires with water sprays, Combustion and Flame, 4, pp. 223-234.

[68] Downie, B., Polymeropoulos, C. and Gogos, G., 1995. Interaction of a water mist with a buoyant methane diffusion flame, Fire Safety Journal, 24, pp. 359-381.

[69] Yang, W., Parker, T., Ladouceur, H. D. and Kee, R. J., 2004. The interaction of thermal radiation and water mist in fire suppression, Fire Safety Journal, 39, pp. 4166 .

[70] Mawhinney, J. R., DiNenno and Williams, 1999.Water Mist Flashover Suppression and Boundary Cooling System for Integration with DC-ARM Volume II: Summary of Testing, Navy Technology Center for Safety and Survivability, A31 1963.

[71] Haerter, A., 1994. Fire tests in the Ofenegg tunnel in 1965, Proceedings of the International Conference on Fires in Tunnels, pp. 195-214.

[72] UPTUN, 2008.Evaluation of Current Mitigation Technologies in Existing Tunnels, Workpackage 2 D231.

[73] Hejny, H., 2007. The European project UpTun: Results of four years of research to improve the level of fire safety in existing tunnels, WIT Transactions on the Built Environment, pp. 191-204.

[74] UPTUN, 2008.Development of New Innovative Technologies, Workpackage 2 D241.

[75] Chen, L., Zhu, W., Cai, X., Pan, L. and Liao, G., 2009. Experimental study of water mist fire suppression in tunnels under longitudinal ventilation, Building and Environment, 44, pp. 446-455.

[76] Mawhinney, J. R. and Trelles, J., 2008, "CFD Modeling of the Interaction of Water Mist and Smoke Control System in Tunnels", in Smoke Control in Buildings and Tunnels, GIDAI-Fire safety-Research and Technology, pp. 281-304.

[77] Guigas, X., Weatherill, A. and Bouteloup, C., 2006. Water mist tests for the A86 east tunnel, 2nd International Symposium on Tunnel Safety \& Security, Madrid, Spain.

[78] Ingason, H., 2006.Model Scale Tunnel Fire Tests-Sprinkler, SP Technical Research Institute of Sweden, 2006:56. 
[79] Ko, Y., Michels, R. and Hadjisophocleous, G. V., 2009. Instrumentation Design for HRR Measurements in a Large-Scale Fire Facility, Fire Technology, pp. 1-15.

[80] Janssens, M. L., 1991. Measuring rate of heat release by oxygen consumption, Fire Technology, 27, pp. 234-249.

[81] Janssens, M. and Parker, W. J., 1992, "Oxygen Consumption Calorimetry", in Heat Release in Fires, pp. 31-59.

[82] Schlichting, H., 1979. "Turbulent Flow through pipes-experimental Results for Smooth Pipes", in Boundary-Layer Theory, 7th ed., New York, McGraw-Hill.

[83] Schlichting, H., 1987. Turbulent flow through pipes - Experimental results for smooth pipes, Boundary-Layer Theory, pp. 596-600.

[84] Brenden and Chamberlain, 2005.Heat Release Rates from Wall Assemblies Oxygen Consumption and Other Methods Compared, United States Department of Agriculture Forest Service Forest Products Laboratory Research, FPL-RP-476.

[85] Yeager, R. W., 1986. Uncertainty Analysis of Energy Release Rate Measurement for Room Fires, Journal of Fire Sciences, 4, pp. 276-296.

[86] Axelsson, J., Andersson, P., Lönnermark, A., Van Hees, P. and Wetterlund, I., 2001. Uncertainties in measuring heat and smoke release rates in the room/corner test and the SBI, SP REPORT, 2001.

[87] Barker, M., 1922. On the Use of Very Small Pitot-Tubes for Measuring Wind Velocity, 101, pp. 435-445.

[88] McCaffrey, B. J. and Heskestad, G., 1976. A robust bidirectional low-velocity probe for flame and fire application, Combustion and Flame, 26, pp. 125-127.

[89] Sette, B. J. G., 2005. Critical considerations on the use of a bi-directional probe in heat release measurements, Fire and Materials, 29, pp. 335-- 349.

[90] McGrattan, K., Hostikka, S. and Floyd, J., 2009.Fire Dynamics Simulator (Version 5): User Guide, National Institute of Technology and Standards, NIST SP 1019-5, NIST Special Publication 1019-5.

[91] Ko, Y., Kashef, A. and Hadjisophocleous, G., 2008. Modeling of smoke movement during the early stage of tunnel fires under different ventilation conditions, The International Congress of Smoke Control in Buildings and Tunnels, Santander, Spain., pp. 305-321. 
[92] Michels, R., 2009. Development and calibration of a heat release rate measurement system for an experimental atrium, M.Sc., Carleton University, Canada.

[93] American Society of Heating, Refrigerating, Air-Conditioning Engineers, 2005, "Chapter 2 - Fluid Flow", in ASHRAE Handbook Fundamentals, Inch-pound ed., Atlanta, Ga.

[94] Messerschmidt, B. and Van Hees, P., 2000. Influence of delay times and response times on heat release measurements, Fire and Materials, 24, pp. 121-130.

[95] Lyon, R. E. and Abramowitz, A., 1995. Effect of instrument response time on heat release rate measurements, Fire and Materials, 19, pp. 11-17.

[96] Anonymous, "Shielded/Unshielded Cables," [Online]. Available: Http://www.Connectworld.net/shielded-Cables.Html. [Accessed Dec, 2008].

[97] Babrauskas, V., 1983. Estimating large pool fire burning rates, Fire Technology, 19, pp. 251-261.

[98] Ang, A. and Tang, W., 1975, "Function of Radom Variables", in Probability Concepts in Engineering Planning and Design, pp. 170-218.

[99] Brohez, S., 2005. Uncertainty analysis of heat release rate measurement from oxygen consumption calorimetry, Fire and Materials, 29, pp. 383-394.

[100] Kragten, J., 1994. Tutorial review. Calculating standard deviations and confidence intervals with a universally applicable spreadsheet technique, The Analyst, 119, pp. 2161-2165.

[101] Bryant, R. A. and Mulholland, G. W., 2008. A guide to characterizing heat release rate measurement uncertainty for full-scale fire tests, Fire and Materials, 32, pp. 121-139.

[102] National Fire Protection Association, 2007. NFPA 13 "Standard for Installation of Sprinkler Systems", Quincy, Massachusetts.

[103] Ko, Y. and Hadjisophocleous, G., 2010. An experimental study on the impact of tunnel suppression on tunnel ventilation, Proceedings from the Fourth International Symposium on Tunnel Safety and Security, Frankfurt an Main, Germany, pp. 232240.

[104] Milke, J. A., Hugue, D. E., Hoskins, B. L. and Carroll, J. P., 2005. Tenability Analyses in Performance-Based Design Methods for Appraising the Effects of Exposure to Smoke or Heat from a Fire, Fire Protection Engineering, pp. 50-57. 
[105] Ko, Y. and Hadjisophocleous, G., 2010. Modelling the interaction between suppression and ventilation systems in tunnel fires, Proceedings of the Twelfth International Conference INTERFLAM 2010, Nottingham, UK, pp. 1103-1113.

[106] Chan, T., 1994. Measurements of water density and drop size distributions of selected ESFR sprinklers, Journal of Fire Protection Engineering, 6, pp. 79-87.

[107] Sheppard, D. T., 2002. Spray characteristics of fire sprinklers, Ph.D., Northwestern University.

[108] Turner, J. S., 1979. Buoyancy Effects in Fluids.

[109] Thomas, P. H., 1968. The movement of smoke in horizontal passages against an air flow, Fire Research Note, 723.

[110] Kurioka, H., Oka, Y., Satoh, H. and Sugawa, O., 2003. Fire properties in near field of square fire source with longitudinal ventilation in tunnels, Fire Safety Journal, 38, pp. 319-340.

[111] Ko, Y. and Hadjisophocleous, G., 2007. A numerical study of balcony spill plumes, Proceedings of the Seventh Asia-Oceania Symposium on Fire Science and Technology, Hong-kong.

[112] Beyler, C., 2002, "Fire Hazard Calculations for Large, Open Hydrocarbon Fires", in SFPE Handbook of Fire Protection Engineering, 3rd., National Fire Protection Association, pp. 3.268-3.314.

[113] Wickström, U., 2004. Heat transfer by radiation and convection in fire testing, Fire and Materials, 28, pp. 411-415.

[114] Hostikka, S. and McGrattan, K., 2006. Numerical modeling of radiative heat transfer in water sprays, Fire Safety Journal, 41, pp. 76-86.

[115] Ravigururajan, T. S. and Beltran, M. R., 1989. A model for attenuation of fire radiation through water droplets, Fire Safety Journal, 15, pp. 171-181.

[116] Dembele, S., Wen, J. X. and Sacadura, J. F., 2001. Experimental study of water sprays for the attenuation of fire thermal radiation, Journal of Heat Transfer, 123, pp. 534-543.

[117] Qiang, X., 2004. Experiment study of radiant heat blocking function of fine water mist suppressing small scale pool fire, Proceedings of SPIE - the International Society for Optical Engineering , pp. 524-531. 
[118] Parent, G., Boulet, P., Gauthier, S., Blaise, J. and Collin, A., 2006. Experimental investigation of radiation transmission through a water spray, Journal of Quantitative Spectroscopy and Radiative Transfer, 97, pp. 126-141.

[119] Ingason, H. and Wickström, U., 2007. Measuring incident radiant heat flux using the plate thermometer, Fire Safety Journal, 42, pp. 161-166.

[120] Holman, J. P., 1990., Heat Transfer, Mcgraw-hill, Inc.

[121] Mitsuishi, A., Sakai, A., Kitamura, K. and Misumi, T., 2009. Fluid flow and heat transfer of mixed convection adjacent to vertical heated plates placed in uniform horizontal flow of air, Heat Transfer - Asian Research, 38, pp. 347-360.

[122] Lam, C. S. and Weckman, E. J., 2009. Steady-state heat flux measurements in radiative and mixed radiative-convective environments, Fire and Materials, 33, pp. 303-321.

[123] Newman, J. S. and Tewarson, A., 1983. Flame propagation in ducts, Combustion and Flame, 51, pp. 347-355. 


\section{APPENDIX A: Velocity probe combinations}

Velocity probe location combinations in a $0.25 \mathrm{~m}$ grid across the fan chamber crosssection

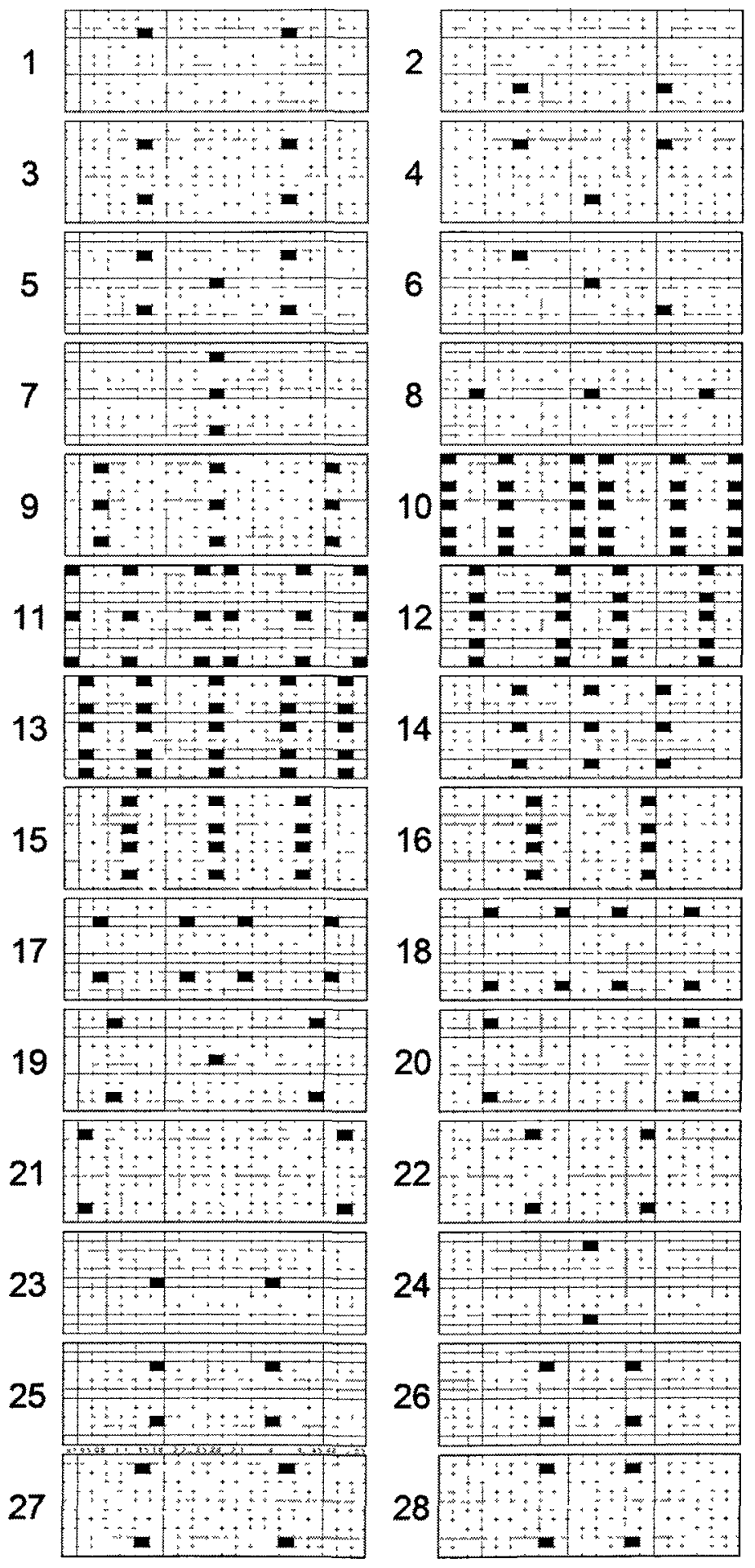




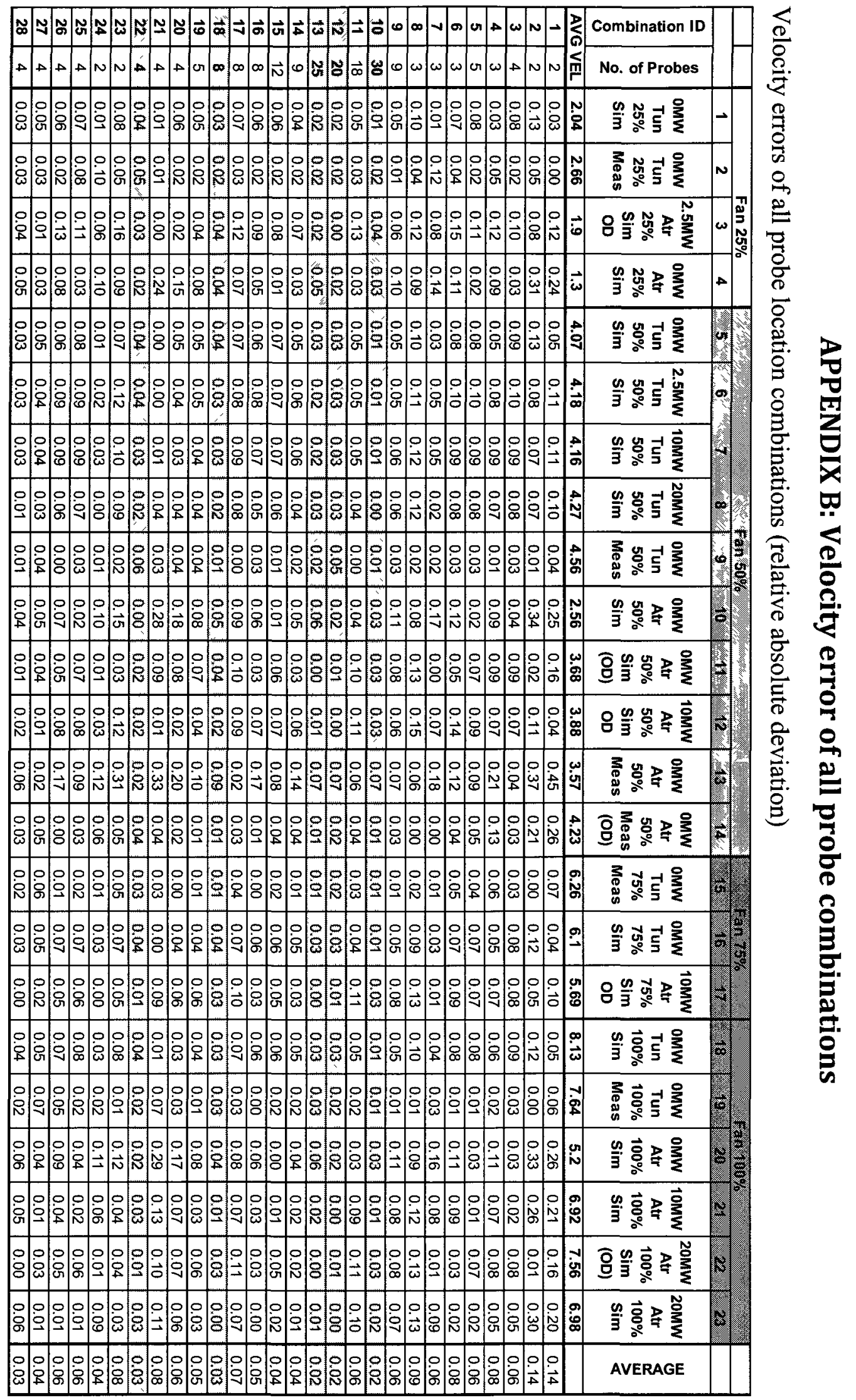




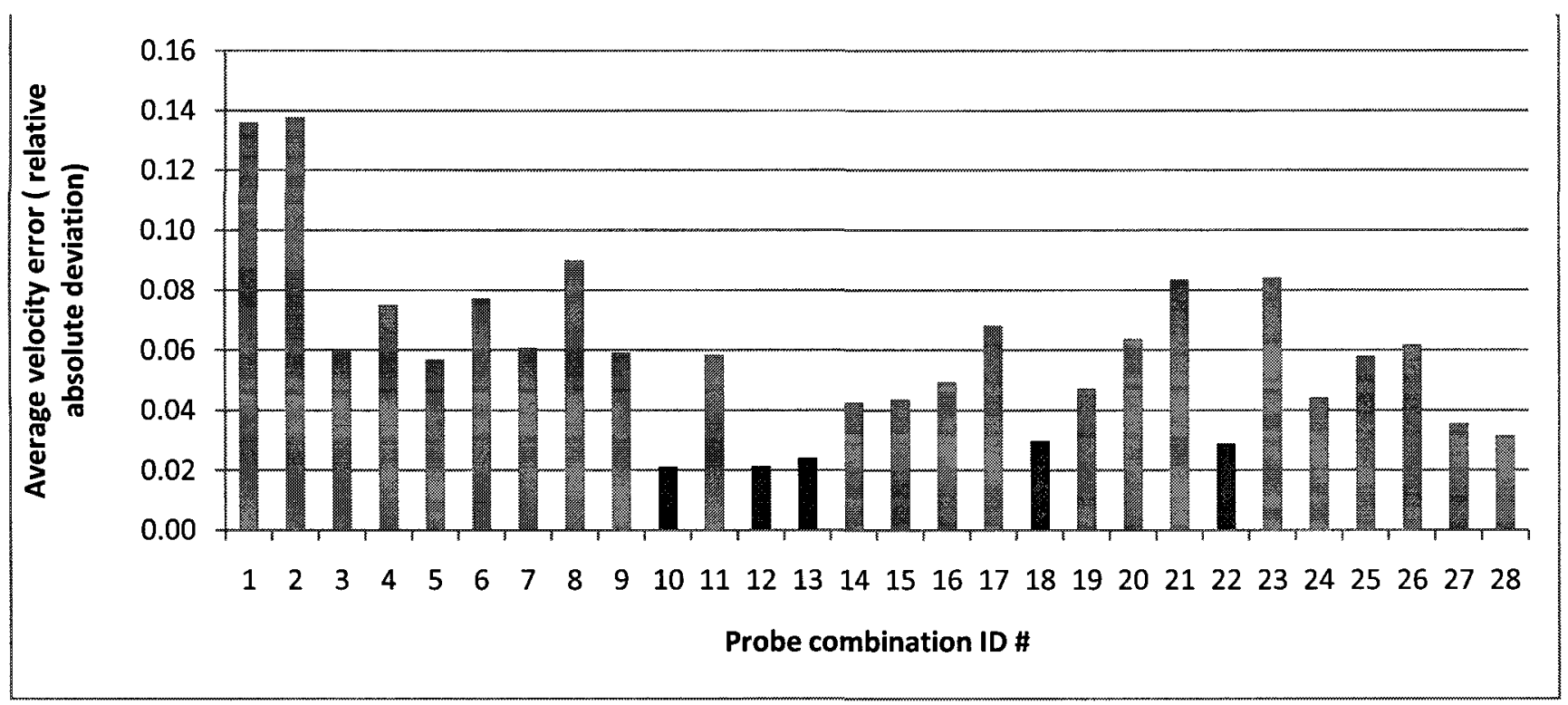




\section{APPENDIX C : A sample Kragten worksheet}

A sample Kragten worksheet for the test of $10 \mathrm{MW}$ with $50 \%$ fan speed

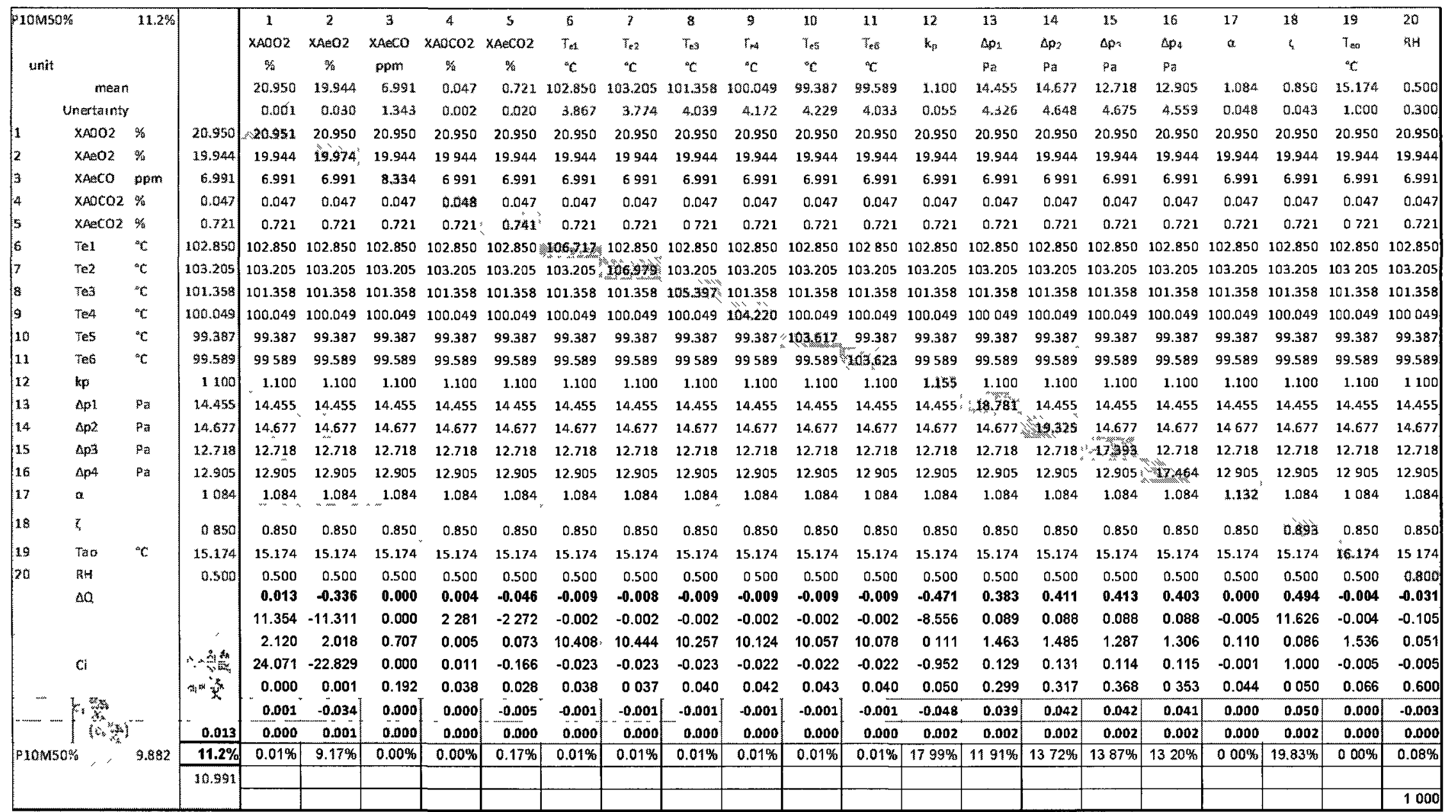




\section{APPENDIX D: Instrumentation and devices}

1) Propane burner

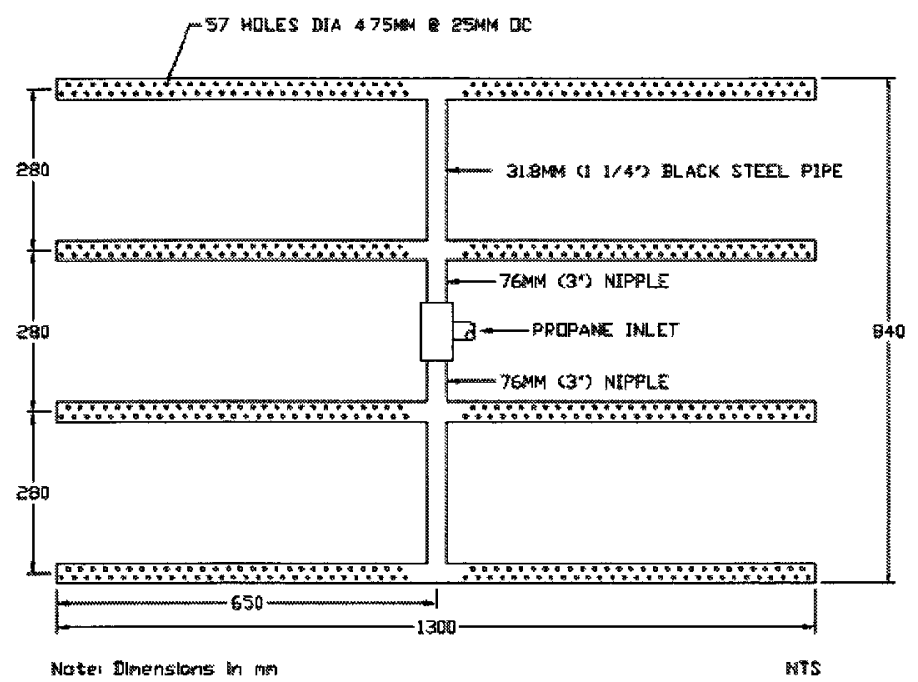

2) Gas grid

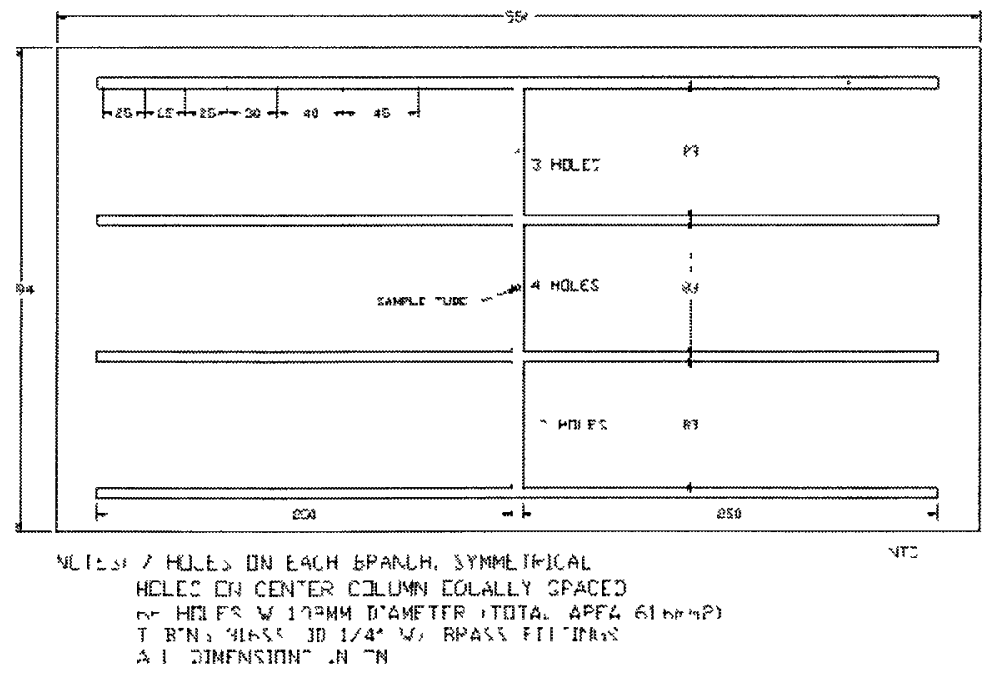


3) Bidirectional probe locations

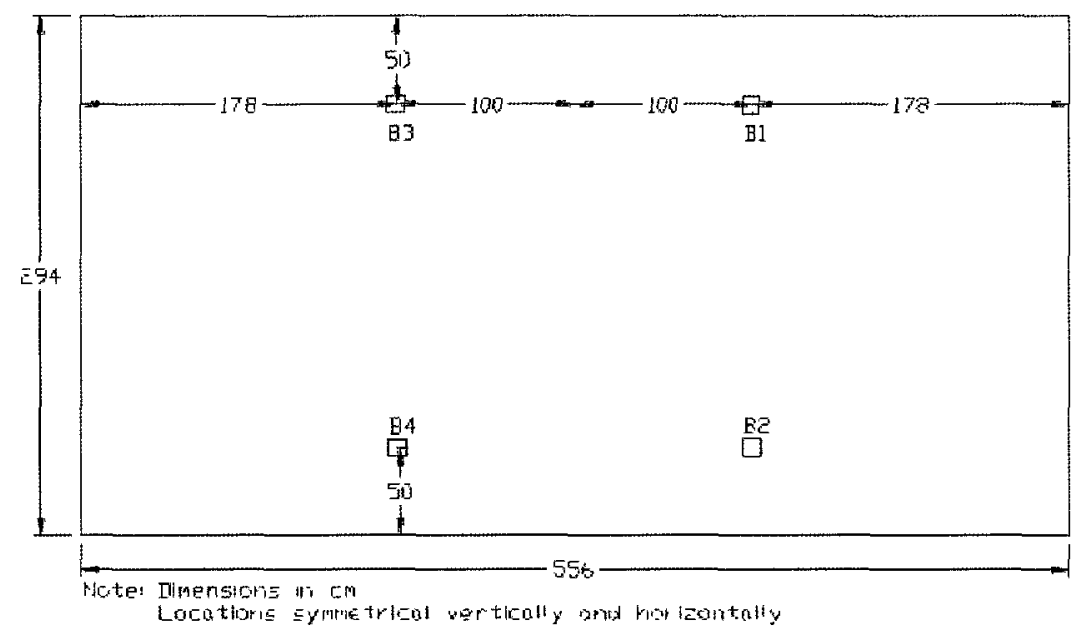

4) Bidirectional probes
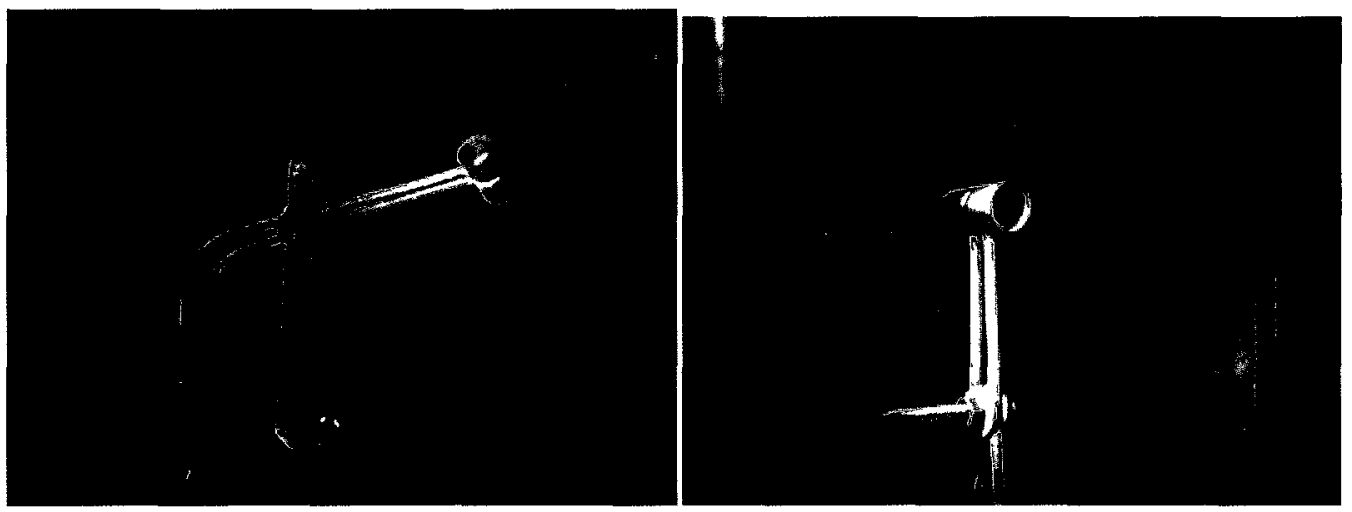

5) Gas Analyzer

EasyLine Continuous Gas Analyzers

ABB Models EL3020

$\mathrm{O} 2, \mathrm{CO}, \mathrm{CO} 2$ Concentrations

Accuracy $0.01 \% \mathrm{O} 2,0.1 \% \mathrm{CO} 2,0.02 \% \mathrm{CO}(\mathrm{Vol})$

6) Pressure Transducer

Omega PX-274

Accuracy $1 \%$ 
7) Data Acquisition system for the HRR measurement system

National Instruments (cDAQ-9172)

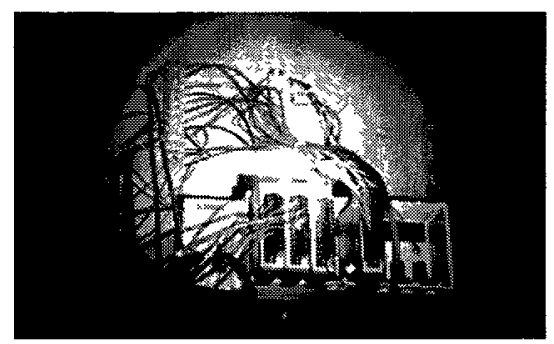

8) Propane Flow Meter

Precision Digital (PD 684-OK1)

9) Gas Sampling Pump

Dual Head Air Cadet Pump (Model 420-2901)

10) NRC Water pump

BBC, 50 HP, 1773 RPM, 49.5 A, 575 V.

When using a 1.5" Hose, the pump can provide about $700 \mathrm{l} / \mathrm{min}$ at a pressure of $80 \mathrm{PSI}$. The rain water reservoir at the lab contains at least 50.000 Gallon

11) Extra-Large Orifice Upright Sprinklers

Maximum Working Pressure: 175 psi (12 bar).

Factory tested hydrostatically to $500 \mathrm{psi}$ (34.5 bar).

Thread size: 3/4" NPT or $20 \mathrm{~mm}$ BSP

Nominal K-Factor: 11.2 U.S. (161.3 metric*)

Overall Length: 2-5/16" (58.7 mm)

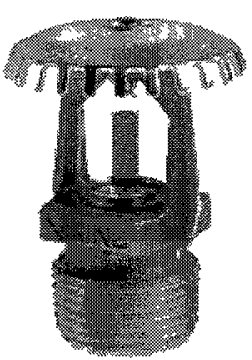


12) Water flow meter

The Badger Meter Series 200 flow sensor (Model 220SS)

Recommended Design Flow Range 0.5 to $30 \mathrm{ft} / \mathrm{sec}$

Initial detection below $0.3 \mathrm{ft} / \mathrm{sec}$

Accuracy $\pm 1.0 \%$ of full scale over recommended

Calibrated 0-600 gpm for a 4 sch. 10" pipe

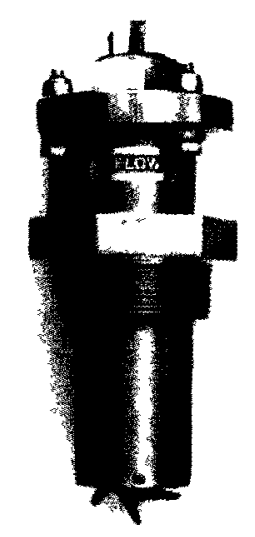

13) Gardon Gauge

Water-cooled sensor

Model number 64-20-18, Medtherm Corporation

Sensing surface emissivity was 0.92

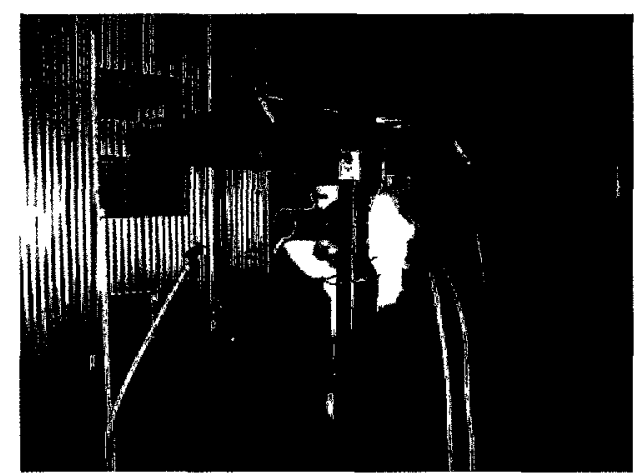

14) Plate Thermometer

According to ISO 834 EN 1363 Part 1

Material Special treated heat resistant Plate

Dimensions $100 \times 100 \times 10 \mathrm{~mm}$

Center part specially treated for optimal cosine sensitivity

Mineral insulated (Insulation MgO)

Inconel 600 sheathed

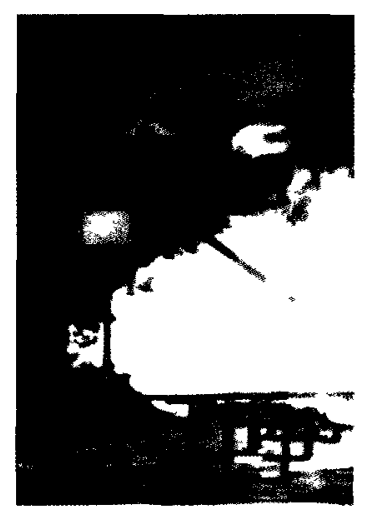


APPENDIX E: Photo log

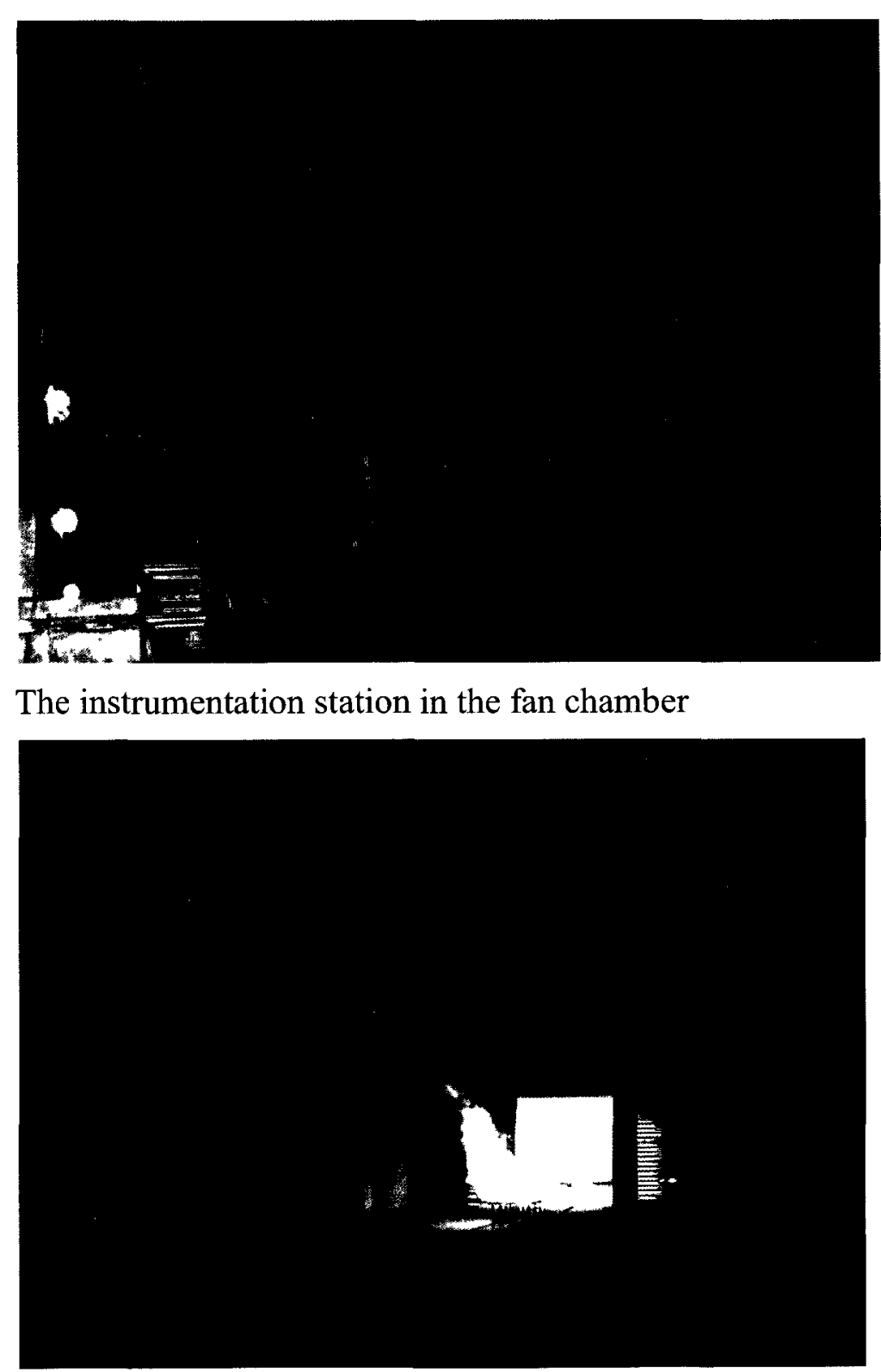

Calibration test 


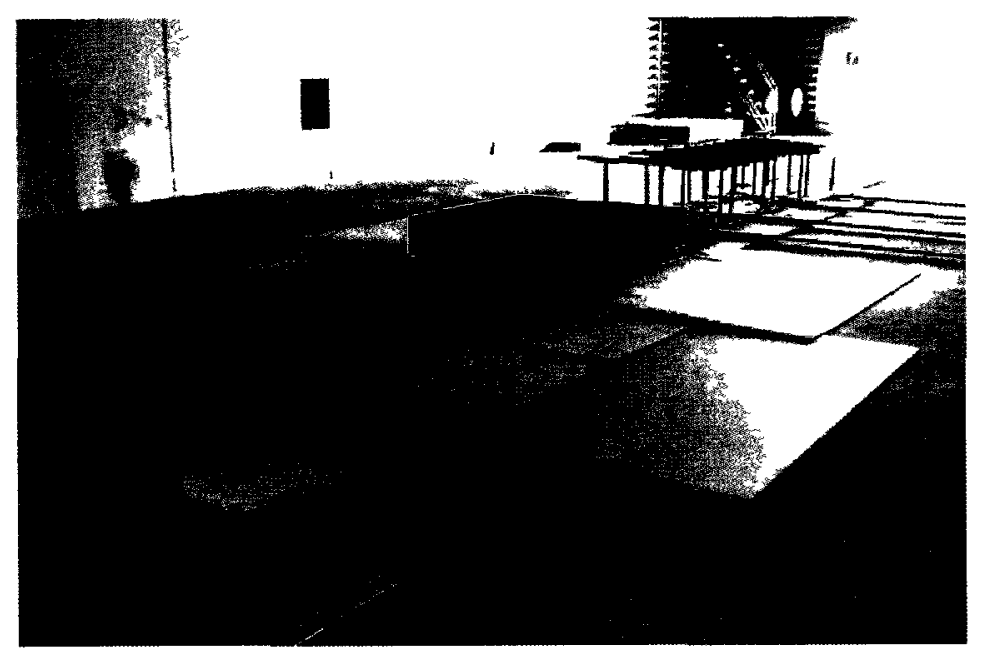

Heptane pool and propane burner

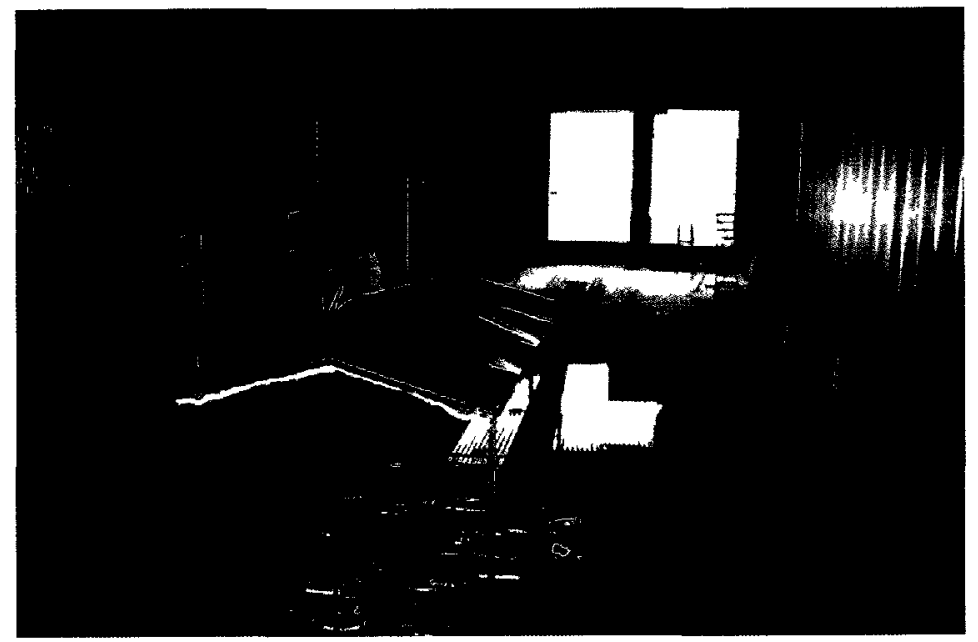

Fire set-up for suppression tests

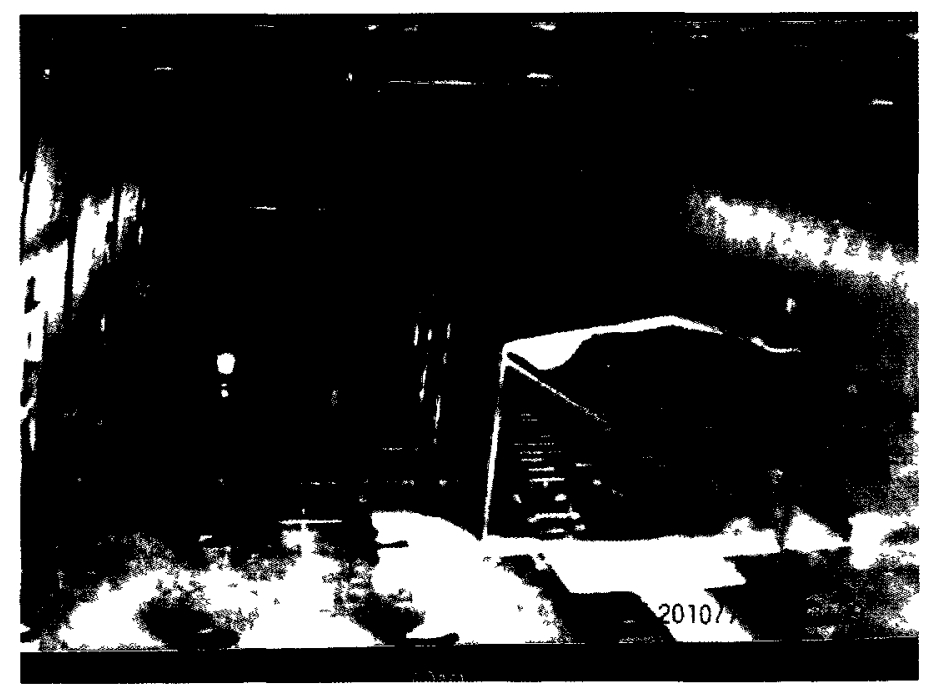

Bucket test 


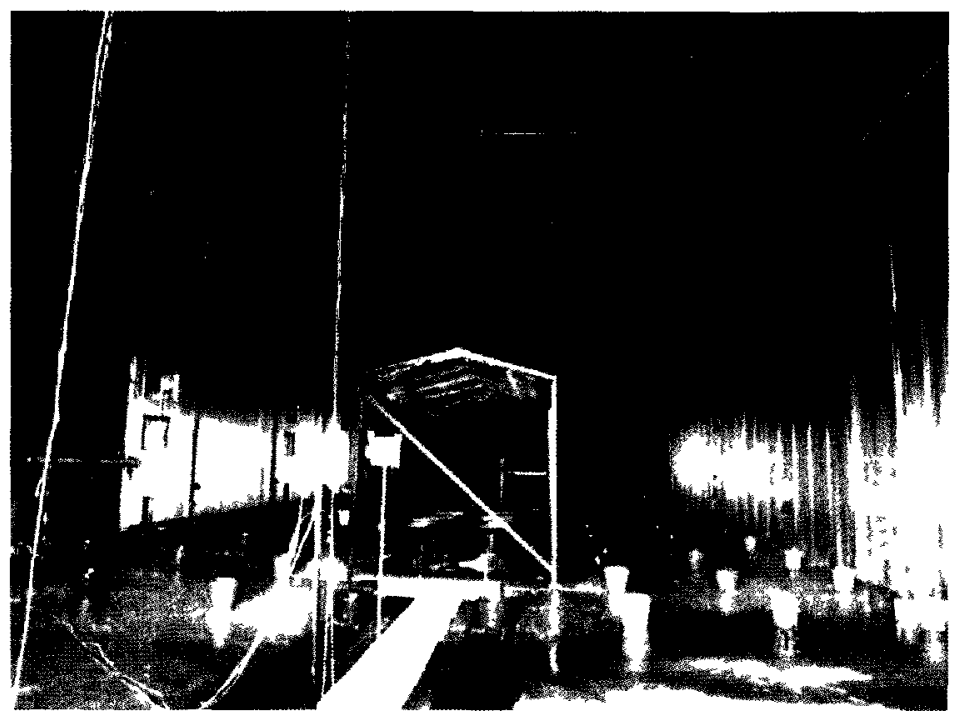

Bucket test

1

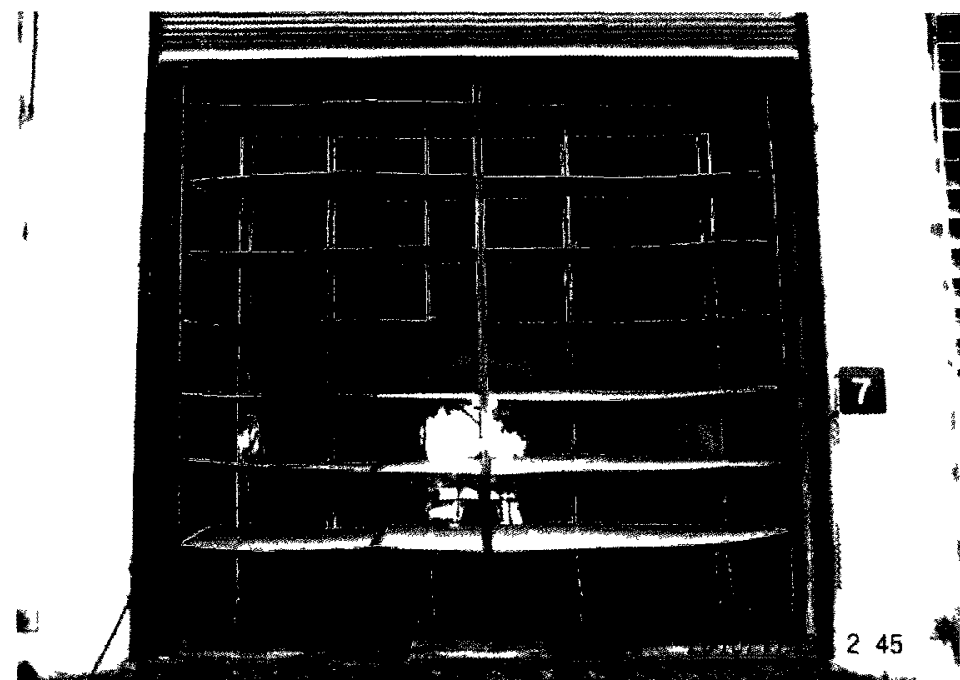

Vanes

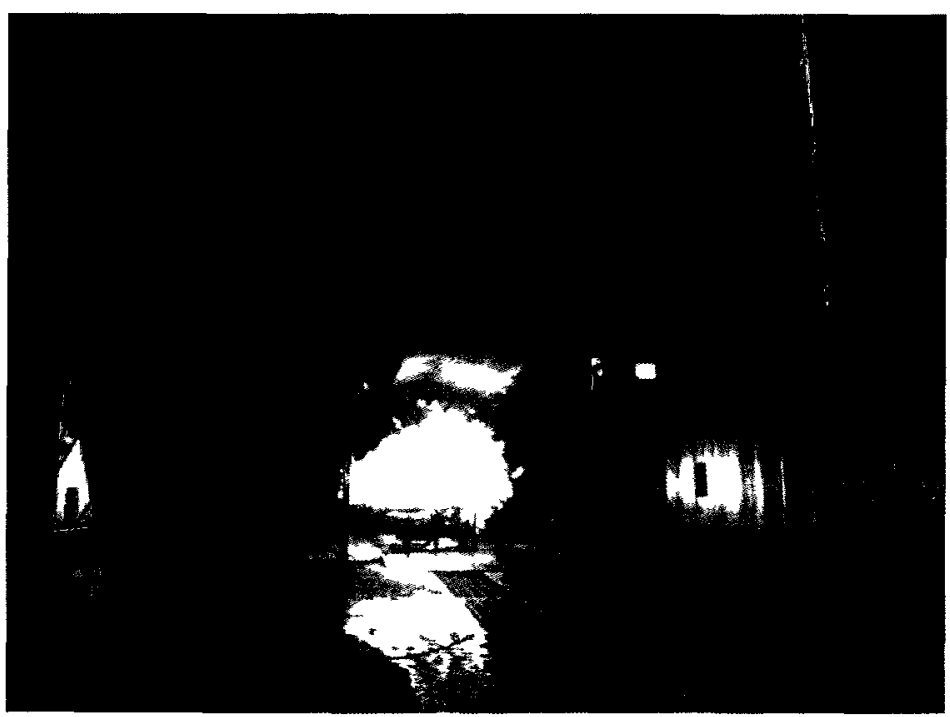

Suppression test 


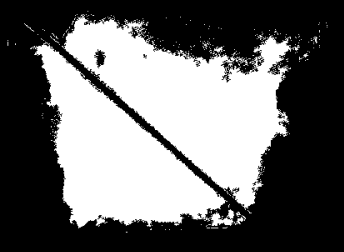

Suppression test

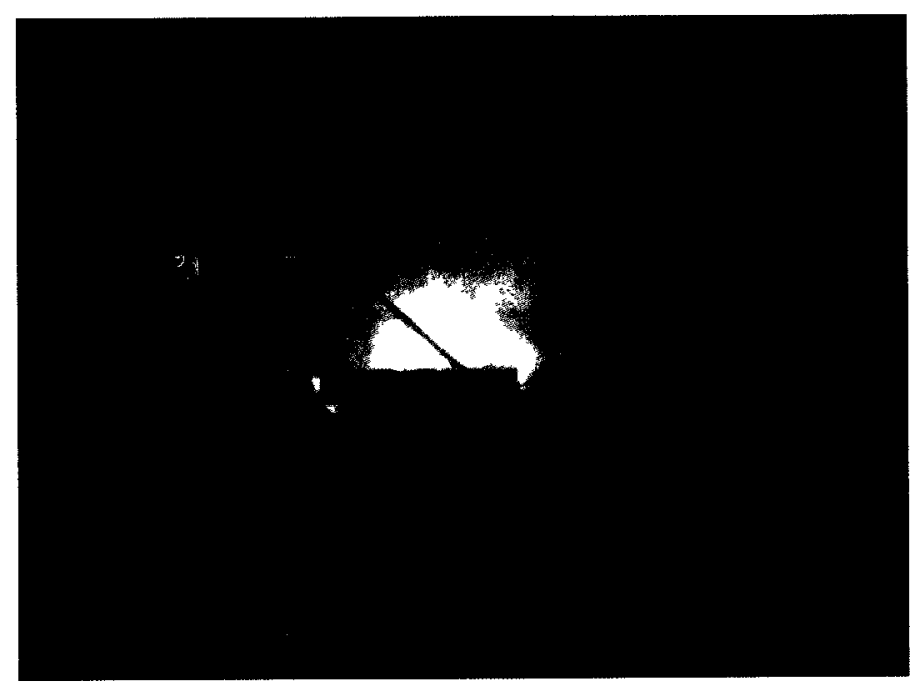

Suppression test

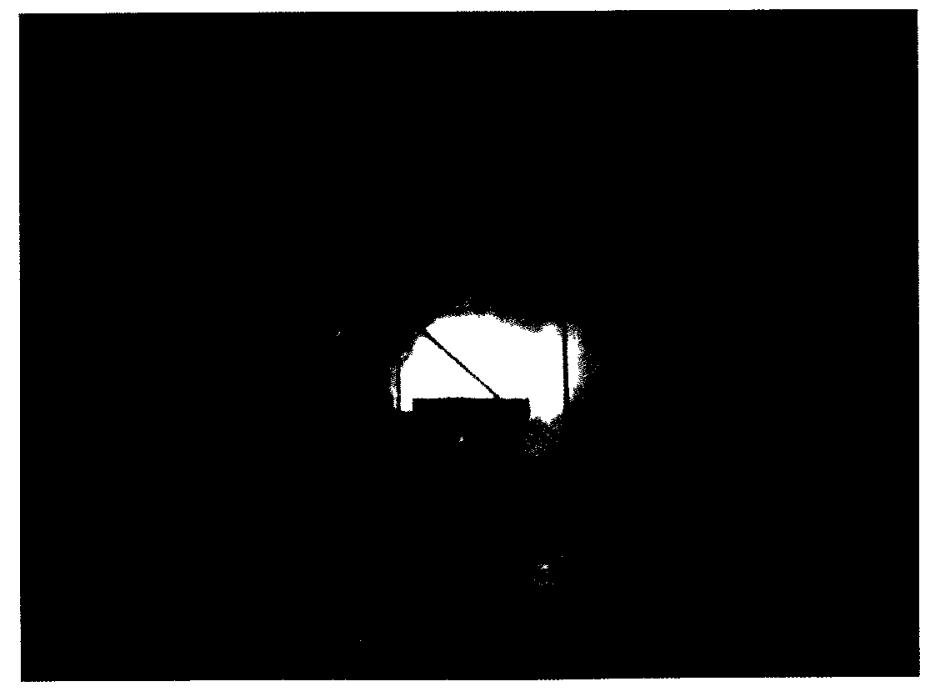

Suppression test 


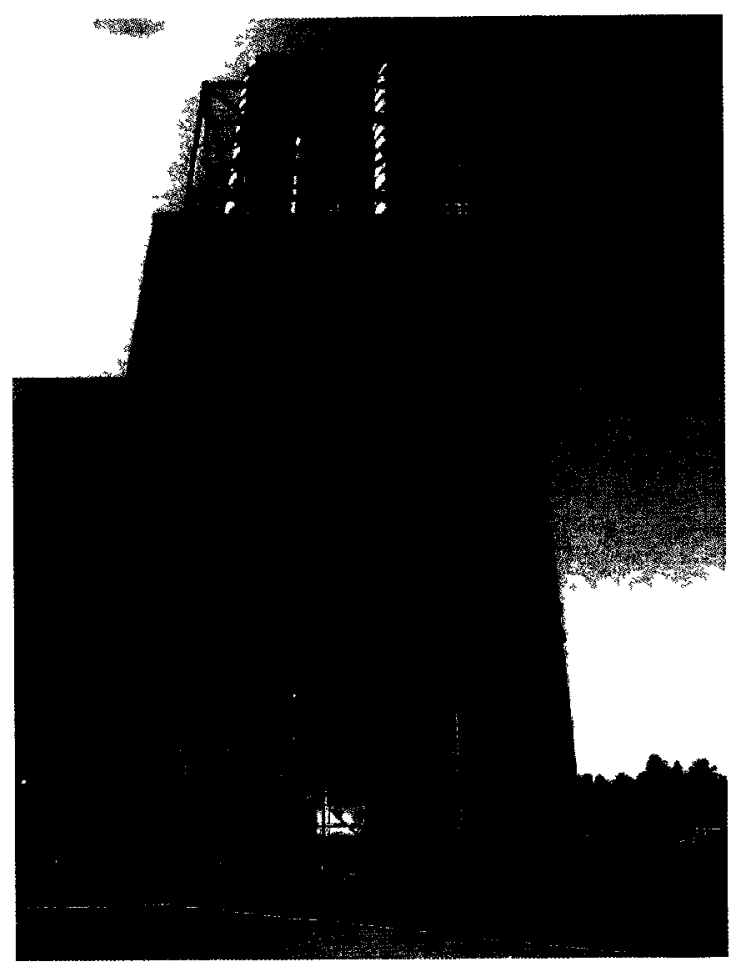

